\title{
Funktionelle Charakterisierung potentieller Pathogenitätsfaktoren aus Pseudomonas aeruginosa mittels biochemischer und evolutiver Methoden
}

\author{
Dissertation \\ zur Erlangung des Doktorgrades \\ der Mathematisch-Naturwissenschaftlichen Fakultäten \\ der Georg-August-Universität zu Göttingen
}

\author{
vorgelegt von \\ Thorsten Adams \\ aus Göttingen
}

2004 
D7

Referent:

PD Dr. Harald Kolmar

Korreferent:

PD Dr. Wilfried Kramer

Tag der mündlichen Prüfung: 27.Januar 2005 
Surface is an illusion, but so is depth.

(David Hockney) 


\section{Inhaltsverzeichnis}

1. Einleitung und Zielsetzung 9

1.1 Pseudomonas aeruginosa __ 9

1.2 Quorum Sensing _ 12

1.3 Oxidativer Streß in Bakterien durch reaktive Sauerstoffspezies ___ 16

1.4 Identifikation neuer potentieller Pathogenitätsfaktoren aus P. aeruginosa___ 18

2. Materialien__ 22

2.1 Bakterienstämme _ 22

2.1.1 Escherichia coli _ 22

2.1.2 Pseudomonas sp. 22

2.2 Plasmide _ 23

2.2.1 Vektoren zur Oberflächenpräsentation heterologer Proteine _ 23

2.2.2 Vektoren zur Herstellung löslicher Proteine __ 23

2.2.2.1 pASK75 23

2.2.2.2 pBBR22b/pBBR22bII _ 24

2.3 DNA-Längenstandards und Protein-Molekulargewichtsmarker _ 25

2.3.1 DNA-Längenstandards_ 25

2.3.2 Molekulargewichtsmarker für Proteine__ 26

2.4 Oligodesoxyribonukleotide___ 26

2.5 Enzyme und Proteine _ 26

2.6 Chemikalien _ 27

2.7 Sonstige Materialien und Geräte __ 29

2.8 Nährmedien zur Anzucht von Escherichia coli __ 33

2.9 Lösungen und Puffer _ 34

3. Methoden 41

3.1 Handhabung von Bakterien __ 41

3.1.1 Lagerung von Escherichia coli und Pseudomonas putida Stämmen __ 41

3.1.2 Anzucht und Vermehrung von Bakterienstämmen__ 41

3.1.3 Präparation und Transformation kompetenter E. coli Zellen mittels Hitzeschock ___ 41

3.1.4 Transformation von Escherichia coli durch Elektroporation __ 42

3.2 Molekularbiologische Arbeitsmethoden _ 42

3.2.1 Reinigung und Präzipitation von DNA _ 42

3.2.1.1 Präzipitation von DNA __ 42

3.2.1.2 Präparation einer Phenol-Lösung nach Grinsted und Bennett __ 43 
3.2.1.3 Reinigung von DNA in wäßrigen Lösungen durch Extraktion mit Phenol,

Phenol/Chloroform oder Chloroform 43

3.2.2 Agarosegelelektrophorese von DNA

3.2.3 Isolierung von DNA aus Agarosegelen 44

3.2.4 Abtrennung von Oligonukleotiden und kurzen DNA-Fragmenten mit Hilfe des NucleotraPCR-Kits (Macherey \& Nagel) 44

3.2.5 Isolierung von Plasmid-DNA aus Bakterienzellen__ 45

3.2.6 Isolierung genomischer DNA aus Pseudomonas aeruginosa __ 45

3.2.7 Bestimmung der Konzentration von DNA in wäßrigen Lösungen _ 45

3.3 Enzymatische Manipulation von DNA 46

3.3.1 Verdau von DNA mit Restriktionsendonukleasen _ 46

3.3.2 Auffüllen überhängender DNA-Enden __ 46

3.3.3 Ligation von DNA-Fragmenten___ 46

3.3.4 Polymerase-Kettenreaktion (PCR) _ 47

3.3.5 Klonierung von PCR Produkten in mittels TOPO TA Cloning Kit__ 48

3.4 Proteinchemische und präparative Arbeitsmethoden

3.4.1 Bestimmung der Konzentration von Proteinen in einer wäßrigen Lösung __ 48

3.4.2 Präparation von Proteinen der Membranen von Escherichia coli Zellen _ 49

3.4.3 Isolierung von periplasmatischen Proteinen aus Escherichia coli___ 49

3.4.4 Gewinnung von Gesamtzellextrakt von E. coli Zellen $\quad 50$

3.4.5 Gewinnung von Gesamtzellextrakt von P. aeruginosa Zellen _ 50

3.4.6 Denaturierende Polyacrylamidgelelektrophorese (SDS-PAGE) _ 50

3.4.6.1 Herstellung der Polyacrylamidgele__ 50

3.4.6.2 Durchführung der SDS-Polyacrylamidgelelektrophorese___ 51

3.4.7 Nachweis von Proteinen auf Nitrozellulose-Membranen (Westernblot) _ 51

3.4.8 Aufreinigung von Proteinen über immobilisierte Metallionen-Affinitätschromatographie 52

3.4.9 Aufreinigung von Proteinen über Anionenaustauscher-Chromatographie _ 52

3.4.10 Dialyse und Konzentration von Proteinlösungen __ 53

3.4.11 Dauerhafte Lagerung von Proteinen _ 53

3.5 Zellbiologische Arbeitsmethoden__ 53

3.5.1 Induktion der Expression in Bakterienkulturen _ 53

3.5.2 Behandlung von Zellen mit Trypsin und Permeabilisierung___ 54

3.5.3 Fluoreszenzmarkierung von Escherichia coli Zellen und Mikroskopie __ 54

3.5.4 Durchflusszytometrie und fluoreszenzaktivierte Zellsortierung von E. coli Zellen__ 55

3.5.5 Verwendung eines Acyl-Homoserinlacton-Monitorstammes zur Wahrnehmung von AHLs im Medium 55

3.5.6 Erstellung eines Repertoires von $\beta$-Laktamase Varianten durch Zufallsmutagenese und Anreichung von solchen Varianten, die auf der Zelloberfläche exponiert werden __ 56

3.5.7 Inkubation von Zellen in Alginatmikrosphären

3.6 Biochemische Methoden _ 58

3.6.1 Nachweis von Katalase__ 58

3.6.2 Nachweis von Peroxidase _ 58

3.6.3 Erzeugung von Superoxidradikalen und deren Nachweis mit Luminol _ 58 
3.6.4 Messung der NAD-Kinase Aktivität von Pa1572

3.6.5 Messung der NADPH-Oxidation durch Pa1572 _ 59

3.6.5.1 Messung der Aktivität von Zellysaten von Pa1572-exprimierenden Zellen __ 59

3.6.5.2 Messung der Aktivität von gereinigtem Protein __ 59

3.6.6 Reversed-Phase-High-Performance-Liquid-Chromatographie (RP-HPLC) von AcylHomoserinlactonen $\quad 60$

3.6.7 Kinetische Charakterisierung sowie biochemischer Nachweis von $\beta$-Laktamase ___ 60

4. Ergebnisse und Diskussion___ 62

4.1 Biochemische Charakterisierung der Proteine aus den $P$. aeruginosa Transposonmutanten__ 62

4.1.1 Untersuchungen der Mutante 41D3 _ 62

4.1.1.1 Phänotypen der Mutante __ 62

4.1.1.2 Genomischer Kontext der Mutation 41D3 und generelle Charakteristika von Rubredoxin

$\begin{array}{ll}\text { Reduktase } & 64\end{array}$

4.1.1.3 Klonierung der Rubredoxin Reduktase Pa5349 __ 65

4.1.1.3.1 Erstellung von pASK75Pa5349__ 66

4.1.1.3.2 Modifikation von pBBR22b _ 67

4.1.1.3.3 Klonierung von Pa5349 in pBBR22bII___ 67

4.1.1.4 Klonierung des Rubredoxins Pa5350 __ 69

4.1.1.5 Proteinreinigung der Rubredoxin Reduktase Pa5349___ 69

4.1.1.6 Proteinreinigung Pa5350__ 70

4.1.1.7 Spektroskopische Analyse von Pa5349 und Pa5350___ 71

4.1.1.7.1 Analyse von Rubredoxin Reduktase (Pa5349) ___ 71

4.1.1.7.2 Analyse von Rubredoxin (Pa5350)__ 72

4.1.1.8 Untersuchungen zum Abbau reaktiver Sauerstoffspezies __ 73

4.1.1.8.1 Test von Pa5349 und Pa5350 auf Katalaseaktivität und Peroxidaseaktivität __ 74

4.1.1.8.2 In vitro Untersuchungen zum Superoxidabbau durch Rubredoxin Reduktase und

Rubredoxin__ 76

4.1.1.8.3 Untersuchung einer möglichen Komplementation einer Escherichia coli Superoxid-

Dismutase Mutante durch Pa5349 79

4.1.1.8.4 Untersuchung einer indirekten Wirkung von Rubredoxin Reduktase und Rubredoxin bei dem Abbau von Superoxidradikalen __ 82

4.1.1.9 Kinetische Charakterisierung von Pa5349__ 86

4.1.1.10 Zusammenfassung und Diskussion der über Rubredoxin Reduktase gewonnenen Erkenntnisse

4.1.2 Untersuchungen der Mutante B7D3 __ 93

4.1.2.1 Phäntoypen der Mutante und genomische Organisation des betroffenen Gens Pa0740 93

4.1.2.2 Klonierung und Reinigung von Pa0740 __ 95

4.1.2.3 Klonierung und Reinigung von Pa0740 ohne Sendai-Epitop ___ 97

4.1.2.4 Test von Pa0740 auf mögliche $\beta$-Laktamase Aktivität ___ 99

4.1.2.5 Voruntersuchungen zum Einfluß von Pa0740 auf das Quorum Sensing _ _ 100

4.1.2.6 Untersuchung einer AHL-abbauenden Aktivität von Pa0740 mittles AHLMonitorstämmen 
4.1.2.7 Untersuchungen zum AHL-Abbau unter semiphysiologischen Bedingungen 106

4.1.2.8 Untersuchungen zum AHL-Abbau mittels HPLC Analytik und Massenspektrometrie

4.1.2.9 Zusammenfassung und Diskussion der über Pa0740 gewonnenen Erkenntnisse___ 112

4.1.3 Untersuchungen der Mutante 19C2 _ 114

4.1.3.1 Phäntoypen der Mutante und genomische Organisation von Pa1572 _ـ 114

4.1.3.2 Klonierung und Reinigung von Pa1572 __ 115

4.1.3.3 Untersuchungen der Enzymaktivität von Pa1572___ 116

4.1.3.3.1 NAD-Kinase-Aktivität___ 116

4.1.3.3.2 NADPH-Oxidoreduktase-Aktivität _ـ 117

4.1.3.4 Zusammenfassung und Diskussion der über Pa1572 gewonnenen Erkenntnisse __ 120

4.2 Funktionsaufklärung durch Analyse von Protein-Protein-Wechselwirkungen _ 122

4.2.1 Verfahren zur Analyse von Protein-Protein-Interaktionen__ 122

4.2.1.1 Der Hefe Two-Hybrid-Assay ___ 124

4.2.1.2 Analyse von Protein-Protein-Wechselwirkungen durch FRET _ 125

4.2.1.3 Analyse von Protein-Protein-Wechselwirkungen mit Protein-Microarrays___ 126

4.2.1.4 Analyse von Protein-Protein-Wechselwirkungen durch massenspektrometrische Methoden

4.2.2 Analyse von Protein-Protein-Interaktionen durch bakterielle Zelloberflächenpräsentation_

\begin{tabular}{lll}
\cline { 2 - 3 } 4.2.2.1 & Verfahren zur Zelloberflächenpräsentation von Proteinen__ & 127
\end{tabular}

4.2.2.2 Evaluation der bakteriellen Oberflächenpräsentation von Proteinen mit Hilfe des Intimin' Systems zur Analyse von Protein-Protein-Wechselwirkungen___ 131

4.2.2.2.1 Beschreibung des Intimin' Oberflächenpräsentationssystems _ 132

4.2.2.2.2 Untersuchung des Intimin' Systems in Hinblick auf die Präsentation verschiedener Passagierdomänen 133

4.2.2.2.3 Produktion von Intimin'-Passagierprotein-Fusionen in Escherichia coli __ 135

4.2.2.2.4 Untersuchung der Zelloberflächenpräsentation von Passagierdomänen ___ 136

4.2.2.2.5 Untersuchung der Oberflächenexposition von BLIP __ 139

4.2.2.2.6 Untersuchungen des Exports von Calmodulin ___ 141

4.2.2.2.7 Untersuchung der Oberflächenpräsentation von Bla___ 143

4.2.2.2.8 Untersuchung der Faltungsstabilität von Bla ___ 145

4.2.2.2.9 Interpretation und Diskussion der Beobachtungen der Faltungsstudie ___ 146

4.2.2.3 Konsequenzen dieser Ergebnisse für den Einsatz des Intimin'-Systems zum Zwecke der $\begin{array}{ll}\text { Protein-Protein-Interaktionsanalyse } & 148\end{array}$

4.2.3 ALD, ein neues System zur Oberflächenpräsentation ___ 149

4.2.3.1 Erläuterung der einzelnen Komponenten des Systems___ 150

4.2.3.1.1 Fixierung des löslichen Proteins auf der Zelloberfläche durch einen Heterodimer aus E-Coil und K-Coil _ 150

4.2.3.1.2 Lyse der Zellen, Wachstum in Mikrokompartimenten __ 154

4.2.3.2 Untersuchung der Bindung von PcrG an PcrV als Modellexperiment___ 158

4.2.3.2.1 Klonierung von pPREY-pcrG__ 159

4.2.3.2.2 Verpackung von Zellen, die pPREY-pcrG und pBAIT enthalten, in Alginatmikrokompartimente 
4.2.3.2.3 Untersuchung der Bindung von oberflächenständigem PcrG und löslichem PcrV 161 4.2.3.3 Konklusion_ 162

5. Zusammenfassung__ 164

6. Literatur__ 165

7. Anhang_ 189

7.1 Danksagung _ 189

7.2 Lebenslauf___ 190 


\section{Einleitung und Zielsetzung}

Vor der Entdeckung des Penicillins durch Alexander Fleming (FLEMING, 1929) war die Infektion mit pathogenen Mikroorganismen eine der hauptsächlichen Todesursachen (LEDERBERG, 2000). Auch heute sind in den weniger entwickelten Ländern pathogene Mikroorganismen in $46 \%$ der Todesfälle das kausative Agens, während in Industrieländern der Anteil der durch Infektionskrankheiten bedingten Sterblichkeit bei nur einem Prozent liegt (Madigan et al., 2000). Das opportunistische Pathogen Pseudomonas aeruginosa ist in der entwickelten Welt einer der Haupterreger nosokomialer Infektionen und eine Infektion mit diesem Mikroorganismus führt vor allem bei Mukoviszidosepatienten über einen längeren Zeitraum zu der Zerstörung des Lungengewebes und zum Tod. Eine antimikrobielle Therapie mit konventionellen Chemotherapeutika schlägt bei diesem Keim oftmals fehl, da er gegen viele in der Klinik verwendete Präparate resistent ist (NAKAE, 1997; SOFIANOU et al., 1997). Um eine gezielte Intervention mit neuartigen Therapeutika durchführen zu können ist es wichtig, möglichst viele Kandidatenproteine, die eine Rolle in der Ausprägung der Pathogenität spielen, zu identifizieren und zu charakterisieren.

Ziel dieser Arbeit ist die Charakterisierung ausgewählter Pathogenitätsfaktoren von Pseudomonas aeruginosa. Darüber hinaus werden Verfahren aufgezeigt, die es ermöglichen sollen, durch proteomweite Untersuchung der Wechselwirkungen der Proteine des Erregers miteinander, ausgewählte Pathogenitätsfaktoren in das komplexe Geschehen der Infektion funktionell einzuordnen.

In den folgenden Abschnitten wird auf Prozesse eingegangen, die im Zuge einer Infektion mit Pseudomonas aeruginosa eine Rolle spielen. Eine besondere Berücksichtigung finden die zelldichtenabhängige Regulation der Genexpression, die als Quorum Sensing bezeichnet wird, und die Antwort auf oxidativen Streß, dem der Mikroorganismus ausgesetzt ist.

\subsection{Pseudomonas aeruginosa}

Pseudomonas aeruginosa ist ein polar begeißeltes, stäbchenförmiges, Gram-negatives Bakterium (BOTZENHARDT und DöRING, 1993). Diese Gattung erhielt ihren Namen (aerugo, lat. = Grünspan) durch ihre charakteristische Farbe, die durch die Bildung der Farbstoffe Pyocyanin, Pyoverdin, Pyrorubin und Pyomelanin zustande kommt (BravenY und KrumPSCHMIDT, 1985). Das Bakterium stellt nur sehr geringe Anforderungen an seinen Lebensraum und ist durch selektive Regulation der Genexpression (GOVAN und DERETIC, 1996) in der Lage, sich an ein großes Spektrum vielfältiger Lebensbedingungen anzupassen. So können die Zellen in einem Temperaturbereich von $4{ }^{\circ} \mathrm{C}$ bis $43^{\circ} \mathrm{C}$ wachsen und zahlreiche Verbindungen, so auch verschiedene Kohlenwasserstoffe oder halogenierte Aromaten (HiCKeY und Focht, 1990) als Kohlenstoffquelle nutzen (PAlleroni, 1985). Der Keim wurde sogar in fast reinem Wasser (FAVERO et al., 1971) und auch in einigen Desinfektionsmitteln nachgewiesen (ADAIR et al., 1969). Diese hohe Anpassungsfähigkeit macht $P$. aeruginosa zu einem ubiquitärem Bakterium, das nur gegen Austrocknung empfindlich ist (BOTZENHARDT 
und DöRING, 1993; GREen et al., 1974; HofTe et al., 1990; PELLETT et al., 1983; ZIELINSKI et al., 1992).

Pseudomonas aeruginosa kann je nach Anforderungen des Habitates in einer mukösen und in einer nicht-mukösen Form persistieren (GOVAN und DereTIC, 1996; WoODS et al., 1991). In der nicht-mukösen Form ist das Bakterium begeißelt, so daß es neue Lebensräume erschließen kann. Allerdings ist es in dieser Form auch sensitiver gegenüber Antibiotika und immunologischen Abwehreaktionen. Muköse $P$. aeruginosa sind unbegeißelt und unterscheiden sich phänotypisch in vielen Merkmalen von der motilen Form (COSTERTON, 1980). So kommt es zu einer starken Produktion von Alginat, einem linearen anionischen Polymer aus 1,4-verknüpfter $\beta$-D-Mannuronsäure und $\alpha$-L-Guluronsäure, das eine hohe Viskosität aufweist (GILL et al., 1987). Das Exopolysaccharid bildet eine Glykokalyx, die die Bakterien vollständig umgibt. Bakterienzellen, die von der mukösen Alginatschicht umgeben sind, bezeichnet man als Biofilm (DuNNE, 2002), der den Zellen eine Resistenz gegenüber Antibiotika verleiht (NICKEL et al., 1985). Weiterhin wird durch die Bildung des Biofilms eine Anheftung der Zellen an den Untergrund vermittelt (COSTERTON, 1980) und der Halt der Kolonien gegen mechanische Beanspruchungen, wie etwa Gewässerströmungen oder der Cilienschlag eines besiedelten Epitels, gesichert (COSTERTON, et al., 1987).

P. aeruginosa kann nicht nur saprophytisch leben, sondern besitzt auch ein pathogenes Potential, wobei es vor allem immunsupprimierte oder anderweitig geschwächte Wirte befällt. Hierunter fallen insbesondere Mukoviszidosepatienten, Tumorkranke oder Verbrennungsopfer (GOVAN und DERETIC, 1996). Aufgrund seiner Anpassungsfähigkeit, seiner geringen Nährstoffanforderung und seiner Antibiotikaresistenz ist der Keim auch in Krankenhäusern $\mathrm{zu}$ finden, wo er mit ca. $10 \%$ einen großen Anteil nosokomialer Infektionen verursacht (BRAVENY und KRUMP-SCHMIDT, 1985; FrIDKIN und GAYNES, 1999; HORAN et al., 1986). Während der Infektion produziert $P$. aeruginosa eine Vielzahl von Pathogenitätsfaktoren (DÖRING et al., 1987; LORY und TAI, 1985). Zu diesen gehören unter anderem zwei toxische Proteine, Exotoxin A und Exoenzym S, die nach der Aufnahme in eukaryotische Zellen deren Zelltod bewirken. Verschiedene Proteasen (Elastase, alkalische Protease, LasA-Fragment) zerstören lokal die Gewebestruktur des Wirtsorganismus und hydrolysieren Immunglobuline, Komponenten des Komplementsystems und Rezeptoren der Immunzellen. Weiterhin sezerniert das Bakterium sogennante Rhamnolipide, Rhamnose enthaltenden Glykolipide (MAIER und SOBERON-CHAVEZ, 2000), welche detergenzähnliche, hitzestabile Zytotoxine sind, die aufgrund ihrer chemischen Struktur weder von Proteasen des Wirts zerstört werden noch eine Immunantwort induzieren können (DöRING et al., 1987). Die Expression eines großen Teils der Pathogenitätsfaktoren aus $P$. aeruginosa wird zelldichtenabhängig über das Quorum Sensing System, das nachfolgend detaillierter beschrieben wird, reguliert. Weiterhin können die Zellen auch über ein TypIII-Sekretionssystem gezielt Toxine in eukaryotische Zellen durch deren Zellmembran einschleusen. Die Effektormoleküle des TypIII-Sekretionssystems, ExoS (Goehring et al., 1999), ExoT (KRAll et al., 2000) und ExoU (SATO et al., 2003) zerstören in den Zielzellen das Zytoskelett und die Prozesse der Rho-Signaltransduktion.

Bei Mukoviszidosepatienten bleibt die Infektion mit Pseudomonas aeruginosa auf die Lunge beschränkt, ist dort aber ein entscheidender Faktor für den Krankheitsverlauf (HOIBY 
et al., 1986; PIER, 1985). Die Mukoviszidose oder Zystische Fibrose (engl. CF) ist durch die Ausbildung eines dichten, zähen Mucus in der Lunge klinisch charakterisiert (ROBINSON, 2001). Die erste Besiedelung der Patientenlunge mit $P$. aeruginosa erfolgt im Schnitt in einem Alter von fünf bis zehn Jahren (TÜMMLER und KIEWITZ, 1999), wobei die Patienten die Keime nicht selten in Kliniken oder Kureinrichtungen für Mukoviszidosekranke erwerben (TÜMMLER et al., 1991). Anfangs erfolgt eine Infektion mit der nicht-mukösen Form des Erregers aus einem geschützten Bereich des Nasen-Rachenraumes heraus. Die dabei von den Bakterien sezernierten Toxine (z.B. Exotoxin A) und Enzyme (z.B. Elastase, Hämolysine und proliferationshemmende Proteinasen) (WINKLER et al., 1985) führen zu einer Schädigung des Gewebes und einer Verzögerung der Immunantwort. Diese Pathogenitätsfaktoren werden zum Teil über das TypIII-Sekretionssystem direkt in die Wirtszelle eingeschleust, teilweise stehen sie unter der Kontrolle des Quorum Sensing und werden in die Umgebung sekretiert. Während der Infektion kommt es zu einer Umstellung der Pathogenitätsmechanismen und einer Anpassung an die Bedingungen, die in der Lunge von chronisch infizierten Mukoviszidosepatienten herrschen. (DACHEUx et al., 2000; GALLANT et al., 2000). Eine Wandlung zu der bei den meisten Patienten gefundenen mukoiden Form erleichtert den Bakterien die chronische Infektion der Lunge und führt zu einer höheren Mortalität im Vergleich mit Patienten, die mit dem nicht-mukösen Phänotyp infiziert sind (HENRY et al., 1992). Die bei CF-Patienten typische Hypergammaglobinämie und Leukozytose wird durch Toxine und stark antigen wirkende Zellwandbestandteile von $P$. aeruginosa ausgelöst. Viele der gebildeten Antikörper sind jedoch nicht opsonisierend, da sie z.B. durch bakterielle Proteasen gespalten werden, so daß die Phagozytose der Bakterien erschwert ist (FICK et al., 1985). Werden Immunkomplexe von Leukozyten phagozytiert, können sie nicht abgebaut werden, so daß die Zellen lysieren und die in ihnen enthaltenen Enzyme freigesetzt werden. Dies führt aufgrund von Entzündungsreaktionen und Nekrosen zu weiteren Schädigungen und $\mathrm{zu}$ einem fibrotischen Umbau des Lungengewebes (HOIBY et al., 1986). Zusätzlich können durch die von den Bakterien gebildeten Exopolysaccharide Bereiche der Lunge verschlossen werden, wodurch es in den so entstandenen Atelektasen zu einem Kollabieren des Lungengewebes kommt. Die für die Respiration zur Verfügung stehende Fläche wird zunehmend kleiner und die Patienten sterben an pulmonaler Insuffizienz. Eine vollständige Eliminierung der Bakterienzellen ist nach dem Auftreten von mukösen Mikrokolonien nur noch im Einzelfall und nach Gabe extrem hoher Antibiotikadosen möglich, da die Diffusion der Antibiotika in das Zentrum des Biofilms nur ungenügend stattfinden und $P$. aeruginosa aufgrund seines vielseitigen Stoffwechsels eine große Anzahl der Antibiotika eliminieren kann (Iyobe et al., 1991; Mulgrave, 1991; Olson et al., 1985). Im Verlauf der chronischen Besiedelung mit Pseudomonas aeruginosa kommt es bei den Bakterien teilweise zu einer genetisch fixierten Konversion des Phänotyps. Die entstehenden Varianten zeichnen sich durch eine mukoide Kolonieform, Verkürzung der Lipidpolysaccharidketten der äußeren Membran, den Verlust von Pili und Flagellen sowie eine verringerte systemische Virulenz aus (DERETiC et al., 1995; Goldberg und Pler, 1996). 


\subsection{Quorum Sensing}

Lange Zeit galt die weit verbreitete Meinung, daß Bakterien als individuelle Zellen existieren. Die Entdeckung einer interzellulären Kommunikation bei vielen Arten von Bakterien zeigte, daß diese Organismen zu einer koordinierten Aktivität befähigt sind, die zuvor nur mehrzelligen Lebewesen zugesprochen wurde. Diese Fähigkeit eines kollektiven Verhaltens birgt mehrere Vorteile, beispielsweise die Möglichkeit, zu einem neuen Ort zu migrieren, an dem ein besseres Nährstoffvorkommen oder günstigere Lebensbedingungen herrschen und sich an andere Wachstumsformen wie Sporulation oder die Persistenz in einem Biofilm anzupassen. Die Sprache dieser interzellulären Kommunikation basiert auf kleinen, von den Bakterien selber synthetisierten Molekülen, die als Autoinducer bezeichnet werden. Durch die Verwendung dieser Moleküle können die Bakterien ihr Verhalten in Abhängigkeit von der Zelldichte anpassen. Dieses Phänomen wurde von Fuqua und Kollegen als Quorum Sensing bezeichnet (FUQUA et al., 1994), wobei das Word Quorum (lat.) außerhalb dieser wissenschaftlichen Terminologie für die minimale Anzahl von Personen, die innerhalb einer Versammlung für das Erreichen einer Beschlußfähigkeit notwendig ist, verwendet wird. Das Prinzip dieser Zell-Zell-Kommunikation beruht darauf, daß die Exkretion von Autoinducern in das Medium durch nur wenige Zellen eine solche Konzentration bewirkt, die zu schwach für die Wahrnehmung der Moleküle ist. Mit steigender Zelldichte nimmt auch die Anzahl der sezernierten Autoinducer zu, bis bei einer kritischen Zelldichte ein Schwellenwert erreicht wird, der die Expression bestimmter, durch das Quorum Sensing regulierter Gene bewirkt (DE KIEVIT und IGLEWSKI, 2000).

Die meisten Autoinducermoleküle gehören zwei verschiedenen chemischen Kategorien an, zum einen Aminosäuren und kurze Peptide, die von Gram-positiven Organismen verwendet werden (KLEEREBEZEM et al., 1997), zum anderen Fettsäurederivate, wie sie von Gram-negativen Bakterien eingesetzt werden (RAVN et al., 2001). Diese Fettsäurederivate sind N-Acyl-Homoserinlactone (AHL), deren Acylseitenkette eine Länge zwischen vier und vierzehn Kohlenstoffatomen hat und an der dritten Position ein Sauerstoff oder eine Hydroxylgruppe als Modifikation tragen kann (DE KIEVIT und IGLEWSKI, 2000). Wenn diese Moleküle in einer ausreichend hohen Konzentration vorhanden sind, können sie sich an einen Transkriptionsaktivator, das sogenannte R-Protein, anlagern welches die Expression des Zielgens bewirkt (Abb. 1.1). Eines dieser Gene kodiert für das I-Protein, eine AHL-Synthase, das für die Synthese des entsprechenden AHL aus den Vorläufern S-Adenosylmetheonin und Acyl-Carrierprotein zuständig ist (WHITEHEAD et al., 2001). Die Bildung der Autoinducer beruht somit auf einer positiven Rückkopplung, da die Anwesenheit einer ausreichenden Menge der Moleküle eine weitere Synthese der Autoinducer bewirkt. 


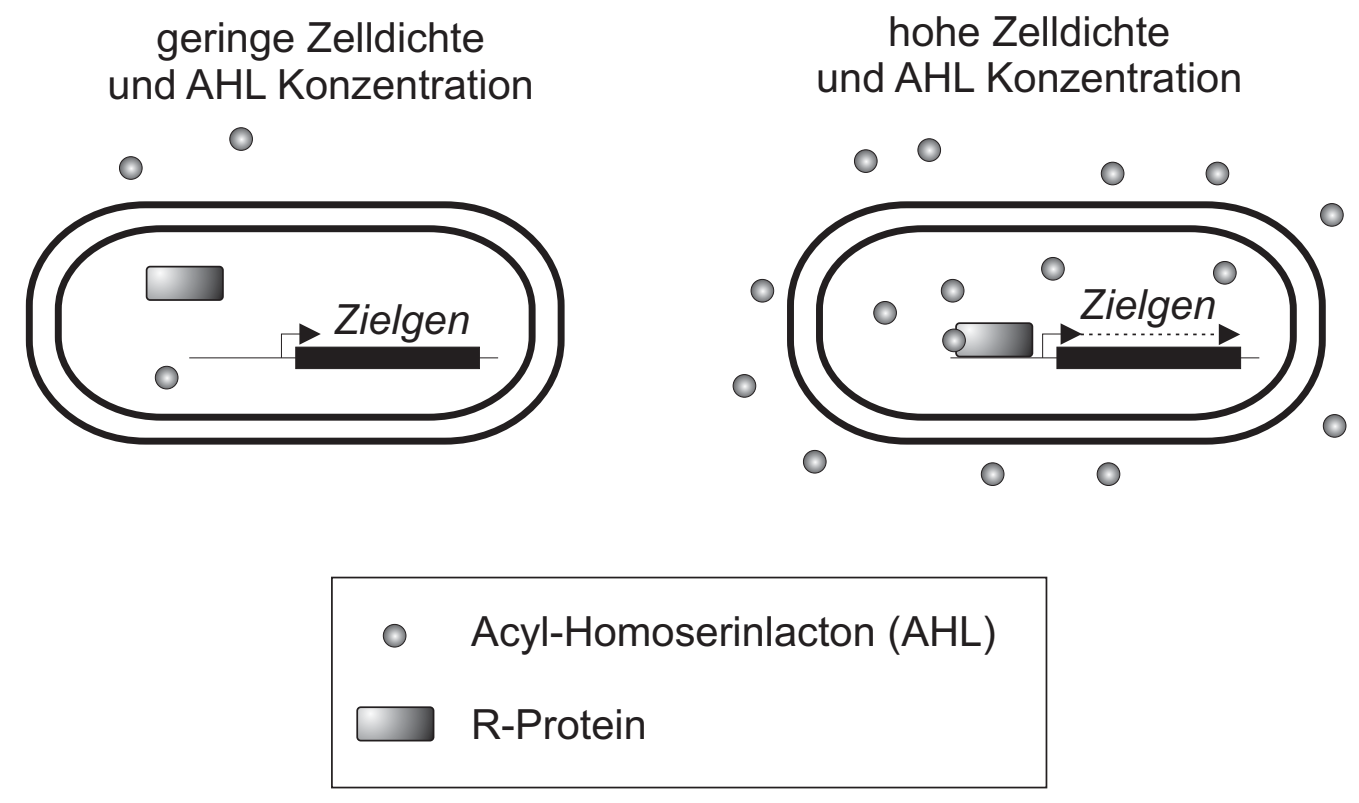

Abb. 1.1: Generelles Schema des Quorum Sensing. Bei einer geringen Zelldichte und Konzentration von AHL findet keine Transkription des Zielgens statt. Steigt die Dichte an Zellen und damit auch an Autoinducermolekülen an, kann das aktivierte R-Protein die Transkription der Zielgene bewirken.

Das Paradigma des Quorum Sensing ist die Regulation der Biolumineszenz in dem marinen, fakultativ symbiotischen Bakterium Vibrio fischeri. Freilebend im Seewasser, d.h. in geringen Zelldichten, zeigt $V$. fischeri keine Lumineszenz. Im Labor, im Kulturmedium, ist bei höheren Zelldichten eine blau-grüne Lumineszenz zu beobachten. Der Organismus bildet Symbiosen mit einigen Fisch- und Molluskenarten aus, wobei die Symbiose mit dem Cephalopoden Euprymna scolopes am besten untersucht ist. Dieser Mollusk besitzt ein Lichtorgan, in dem $V$. fischeri in hoher Zelldichte von $10^{10}-10^{11}$ Zellen/ml vorkommt und dem Tier die Fähigkeit zur indirekten Biolumineszenz verleiht (RUBY, 1999; VISICK und MCFALLNGAI, 2000). Diese dient zur Tarnung vor Freßfeinden bei Nacht, da der Umriß des in geringer Tiefe schwimmenden Mollusken gegen das von oben scheinendene Mondlicht schlecht wahrnehmbar ist (WHITEHEAD et al., 2001). Das Biolumineszenz-Gencluster von Vibrio fischeri besteht aus acht Genen, die in zwei biderektional transkribierten Operons (luxABCDEGI und luxR) angeordnet sind (ENGEBRECHT und SilvERMAn, 1984; SWARTZMAN et al., 1990). Die luxI und luxR Genprodukte wirken als Regulatoren der Biolumineszenz (ENGEBRECHT und SiLVERMAN, 1984), während die übrigen sechs Gene für das Enzym Luziferase und für Enzyme, die für die Synthese des Lumineszenz-Substrates notwendig sind, kodieren (HASTINGS und NEALSON, 1977). Beim Wachstum in Flüssigkultur zeigt $V$. fischeri erst nach einer Weile den Biolumineszenz-Phänotyp. Diese Verzögerung beruht darauf, daß es zuerst einer Anreicherung eines von $V$. fischeri selber produzierten Signalmoleküls über eine Schwellenkonzentration bedarf, bevor es zur Ausprägung der Biolumineszenz kommen kann (Hastings und Greenberg, 1999). Dieser Prozeß wird als Autoinduktion bezeichnet, also die Induktion von Genen durch die Anreicherung des Wachstumsmedium mit Molekülen, die durch den Organismus selber produziert worden sind (NEALSON et al., 1970). Bei dem chemischen Signal handelt es sich um ein N-(3-Oxohexanoyl)-Homoserinlacton (3Oxo-C8-HSL) (EBERHARD et al., 1981), das frei diffundieren kann, eine geringe effektive Konzentration zur Aktivierung der Biolumineszenz benötigt und von dem LuxI Protein in 
V. fischeri synthetisiert wird (KAPLAN und GREENBERG, 1985). Das Bakterium exprimiert eine basale Menge luxI bei geringer Populationsdichte, so daß die Konzentration an 3-Oxo-C8HSL im Medium gering bleibt. Wenn die Populationsdichte innerhalb eines abgeschlossenen Raumes wie dem Lichtorgan von Euprymna scolopes oder einem Erlenmeyerkolben zunimmt, steigt auch die Konzentration von 3-Oxo-C8-HSL im Medium. Sobald ein Schwellenwert überschritten wird, bindet das 3-Oxo-C8-HSL an LuxR und bewirkt, wahrscheinlich durch eine konformationelle Strukturänderung, die Aktivierung des Transkriptionsfaktors. Dieser bindet eine als Lux-Box bezeichnete DNA-Region, die ca. 40 bp stromaufwärts von dem Transkriptionsstart von luxABCDEGI liegt. Somit kommt es zu einer Synthese der mRNA für die Biolumineszenzproteine und die 3-Oxo-C8-HSL-Synthase LuxI, was in der Ausprägung der Biolumineszenz und der Synthese von neuem diffusiblem Autoinducer resultiert. Letzteres führt wiederum zur Aktivierung von weiterem LuxR Protein. Diese Autoinduktion stellt sicher, daß die Synthese von Biolumineszenzproteinen und Signalmolekülen nicht abbricht. Die effektive Konzentration von Autoinducern in den dicht besiedelten Lichtorganen von Euprymna scolopes beträgt mindestens 100 nM (BOETTCHER und RubY, 1995). Die Autoinduktion der Biolumineszenz erst bei einer bestimmten Zelldichte ermöglicht dem Bakterium einen rationellen Umgang mit Resourcen, da keine Energie für die Produktion der Biolumineszenzkomponenten verschwendet wird, wenn die Zellen nicht mit einem Wirt assoziiert sind.

Das opportunistische Pathogen Pseudomonas aeruginosa verwendet Quorum Sensing für seine pathogene Lebensweise. Ein großer Teil der zellassozierten und extrazellulären Virulenzfaktoren wird nicht konstitutiv, sondern in Abhängigkeit von der Zelldichte exprimiert (BRINT und OHMAN, 1995; CAO et al., 2001; HASSETT et al., 1999; LATIFI et al., 1995; OCHSNER und REISER, 1995; PEARSON, et al., 1997; WinSON et al., 1995). Die Regulation dieser Gene ist von einem Signalsystem abhängig, das zwei luxRI Homologe beinhaltet. Das erste dieser Quorum Sensing Systeme umfaßt LasI, daß für die Synthese des Signalmoleküls N-(3Oxododecanoyl)-Homoserinlacton (3-Oxo-C12-HSL) verantwortlich ist und den Transkriptionsaktivator LasR (GAMBello und IGLEWSKI, 1991; PEARSON et al., 1994). Es konnte gezeigt werden, daß das lasRI-System für die Regulation von LasA Elastase, LasB Elastase, ExotoxinA und Alkalischer Protease verantwortlich ist (GAMBELLO et al., 1993; JONES et al., 1993; PASSADOR et al., 1993; TODER et al., 1991). Analog zu V. fischeri ist die Expression von lasI von der Konzentration an LasR mit gebundenem 3-Oxo-C12-HSL abhängig, wodurch die Expression von lasI den Modus einer autoregulatorischen Rückkopplung besitzt (SEED et al., 1995). Ein weiteres Gen, rsaL, steht unter der Kontrolle von aktiviertem LasR. Das Genprodukt von rsaL wirkt durch die Inhibition der lasI Expression als negativer Regulator des $P$. aeruginosa Quorum Sensing (DE KIEVIT et al., 1999). Das System in $P$. aeruginosa ist komplexer als bei vielen anderen Bakterien, da dieser Organismus über zwei Signalsysteme verfügt (BRINT und OHMAN, 1995; OCHSNER und REISER, 1995; WINSON et al., 1995). Das rhl Quorum Sensing System beinhaltet den Transkriptionsaktivator RhlR und die Autoinducer Synthase RhlI, die für die Bildung des zweiten Signalmoleküls N-Butyryl-Homoserinlacton (C4-HSL) verantwortlich ist (PEARSON et al., 1995). Während C4-HSL frei aus den Zellen heraus und in diese hinein diffundieren kann, wird C12-HSL durch die MexAB-OprM Pumpe aktiv hinaus- und hinein befördert. (PEARSON et al., 1999). Der RhlR-C4-HSL Komplex 
kontrolliert die Expression von $\operatorname{rhlAB}$, welches für die Rhamnolipidsynthese verantwortlich ist (LATIFI et al., 1995; OCHSNER et al., 1994), lasB (PEARSON et al., 1995), und des SigmaFaktors rpoS (LATIFI et al., 1996). Weiterhin steht die Pyocyanin- und Cyanid-Synthese unter der Kontrolle des rhIRI-Systems (BRINT und OHMAN, 1995). Mit der Entdeckung zweier verschiedener Quorum Sensing Systeme kam die Frage einer möglichen Interaktion dieser beiden System auf. Trotz der strukturellen Ähnlichkeiten zwischen LasR und RhlR und den Ähnlichkeiten der beiden Autoinducer gibt es wenige Kreuzinteraktionen zwischen den beiden Systemen. LasR wird durch C4-HSL nicht aktiviert, und 3-Oxo-C12-HSL kann RhlR nur zu einem geringen Maß binden (PEARSON et al., 1997), wobei diese Bindung nicht zu einer Aktivierung des R-Proteins führt (DE KIEVIT und IGLEWSKI, 2000). Dies deutet darauf hin, daß die R-Proteine eine hohe Spezifität in Bezug auf die AHL, die zu ihrer Aktivierung befähigt sind, besitzen. Genauso werden die Gene, die unter der Kontrolle des einen Quorum Sensing Systems stehen, von dem Transkriptionsaktivator des anderen Systems nur minimal aktiviert (PEARSON et al., 1997). Der Grund dafür liegt in der Gegenwart von für den jeweiligen Transkriptionsaktivator spezifischen Erkennungssequenzen in den Promotorregionen der entsprechenden Gene (DE KIEVIT und IGLEWSKI, 2000). Dennoch gibt es eine Verbindung zwischen den beiden Systemen: da das lasRI-System die Expression von rhlI und rhlR reguliert, und 3-Oxo-C12-HSL in der Lage ist, mit C4-HSL um die Bindung an RhlR zu konkurrieren, offenbart sich eine hierarchische Anordnung der beiden Quorum Sensing Systeme in Pseudomonas aeruginosa, wobei lasRI das dominante System darstellt (LATIFI et al., 1996; PeSCI et al., 1997). Ein Schema des Quorum Sensing in P. aeruginosa ist in Abb. 1.2 dargestellt.

Zusätzlich zu den 3-Oxo-C12-HSL und C4-HSL findet man bei der Kultivierung von $P$. aeruginosa im Labor in geringeren Konzentrationen AHL mit anderen Kettenlängen vor. Alle bisher in der Literatur beschriebenen AHL-Synthasen verwenden ein S-AdenosylMetheonin und ein acyliertes Acyl Carrier Protein (ACP) als Substrate für die AHL-Synthese. In $P$. aeruginosa werden alle im Medium befindlichen 3-Oxo-C12-HSL durch LasI synthetisiert (DE KIEVIT und IGLEWSKI, 2000). Wenn einer der enzymatischen Schritte der Fettsäuresynthese, aus der das ACP stammt, nicht mehr im ausreichenden Maß stattfinden kann, wenn also nicht mehr genug ACP mit einer C-12 Kette zu Verfügung steht, kann kein 3-Oxo-C12-HSL mehr gebildet werden (HOANG et al., 2002). Die Kettenlänge der AHL wird somit zumindest teilweise durch Verfügbarkeit von 3-Oxo-Acyl-ACP Substraten reguliert. Die biologische Funktion dieser AHL anderer Kettenlänge ist nicht bekannt. Möglicherweise spielen sie eine Rolle als negative Regulatoren, in dem sie mit den prädominanten AHL um die Bindung an deren R-Proteine konkurrieren, so wie z.B. 3-Oxo-C12-HSL mit C4-HSL um die Bindung an RhlR konkurriert (PESCI et al., 1997). Mittlerweile ist ein drittes Signalmolekül aus P. aeruginosa bekannt, das keine strukturelle Ähnlichkeit mit den beiden anderen Autoinducern aufweist. Dieses Molekül ist ein 2-Heptyl-3-Hydroxy-4-Quinolon, das als Pseudomonas Quinolone Signal (PQS) bezeichnet wird und dessen Synthese von LasR gesteuert wird (PESCI et al., 1999). Exogen hinzugefügtes PQS besitzt die Fähigkeit, die Expression von las $B$ und $r h l I$, und in einem geringeren Maß auch die von las $R$ und $r h l R$ zu induzieren und stellt damit eine weitere Verbindung zwischen den beiden Quorum Sensing Systemen her (MCKNIGHT et al., 2000). 


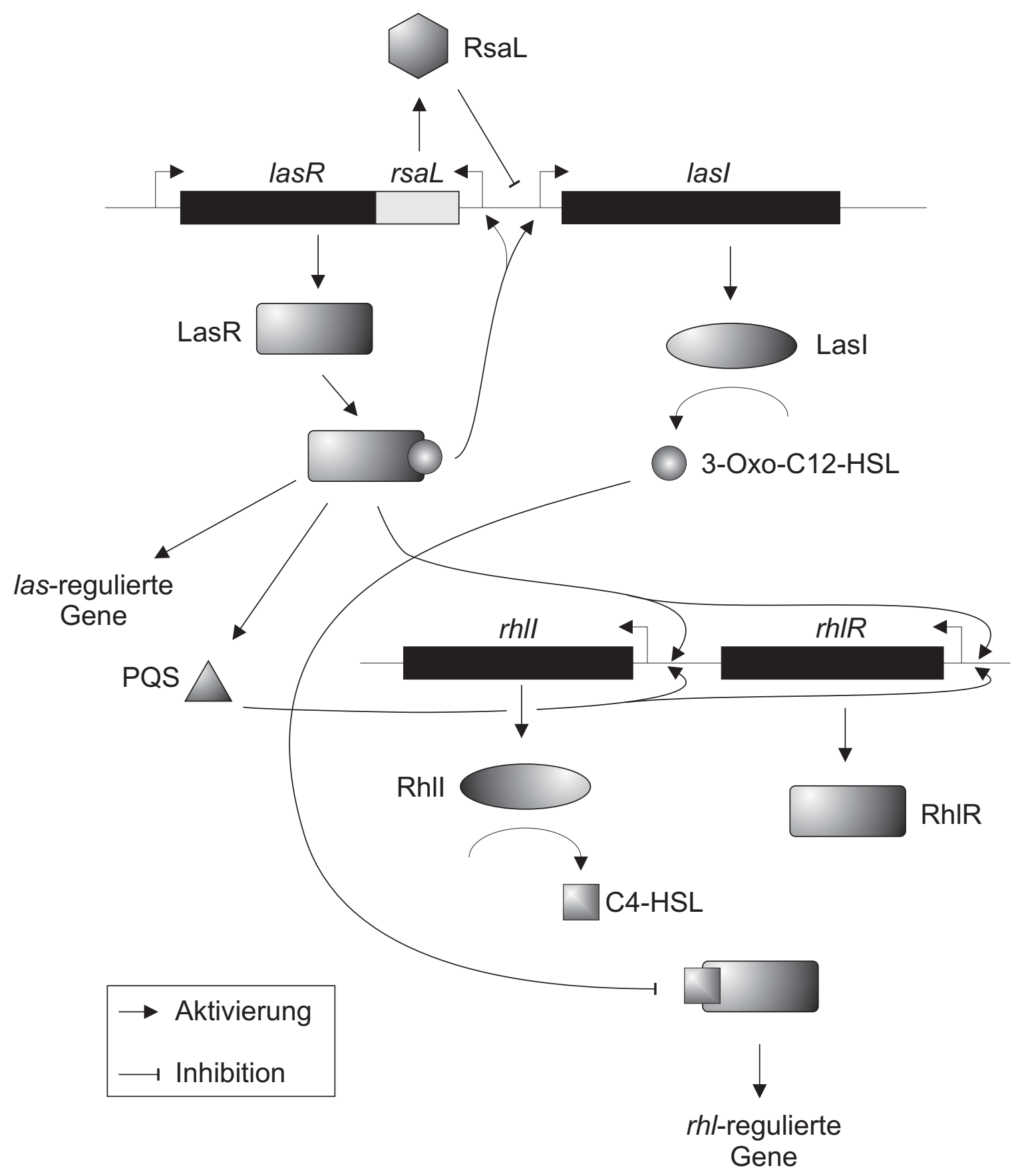

Abb. 1.2: Schema des hierarchischen Quorum Sensing in Pseudomonas aeruginosa. Schema modifiziert aus de Kievit et al. (DE KIEVIT und IGLEWSKI, 2000).

\subsection{Oxidativer Streß in Bakterien durch reaktive Sauerstoffspezies}

Molekularer Sauerstoff $\left(\mathrm{O}_{2}\right)$ ist ein Oxidationsmittel und ein Elektronenakzeptor in der Atmungskette (MADIGAN et al., 2000). In seiner häufigsten Form, dem Triplet-Sauerstoff, enthält er zwei ungepaarte Elektronen mit parallelem Spin in seinen $\pi$-antibindenden Orbitalen. Die meisten organischen Moleküle besitzen Elektronenpaare mit antiparallelem 
Spin und können daher nur ein Elektron auf einmal auf den Triplet-Sauerstoff übertragen. Andere toxische Formen des Sauerstoffs sind das Superoxid Anion $\left(\mathrm{O}_{2}^{--}\right)$, Wasserstoffperoxid $\left(\mathrm{H}_{2} \mathrm{O}_{2}\right)$ und das Hydroxylradikal (HO). $\mathrm{O}_{2}-\mathrm{H}_{2} \mathrm{O}_{2}$ entstehen in der Zelle selbst durch eine Autooxidation von respiratorischen Dehydrogenasen. Normalerweise verwenden diese Enzyme Flavinkofaktoren, um Hydridanionen von organischen Substraten zu akzeptieren. Die reduzierten Flavine übertragen dann die Elektronen auf Redoxcluster in dem Enzym. Wenn Sauerstoff jedoch mit dem reduzierten Flavin in Kontakt gerät, bevor jenes die Elektronen auf den nächsten Partner übertragen hat, kann ein Elektron auf den Sauerstoff überspringen und diesen reduzieren (MESSNER und IMLAY, 2002). Das Hydroxalradikal kann gebildet werden, wenn in der Fentonreaktion (Gleichung 1.1) ein Elektron von $\mathrm{Fe}^{2+}$ auf Wasserstoffperoxid übertragen wird. Das Eisen, daß diese Reaktion katalysieren kann, ist freies, in der Zelle vorliegendes Eisen, welches nicht an Enzyme oder Speicherproteine gebunden ist (IMLAY, 2003). Escherichia coli und Saccharomyces cerevisiae Zellen enthalten ca. $20 \mu \mathrm{M}$ freies Eisen (SRINIVASAN et al., 2000; WoODMANSEE und IMLAY, 2002). Eine weitere Quelle für reaktive Sauerstoffspezies (ROS), der vor allem pathogene Mikroorganismen ausgesetzt sind, sind Zellen des Immunsystems des Wirtes. Polymorphkernige Leukozyten (PMN) und neutrophile Granulozyten verwenden Wasserstoffperoxid zum Abtöten von Bakterienzellen. Nach der Internalisierung der Bakterien durch PMN wird Wasserstoffperoxid durch den sogenannten Respiratory Burst gebildet, wobei $\mathrm{O}_{2}$ verbraucht und $\mathrm{H}_{2} \mathrm{O}_{2}$ aus $\mathrm{O}_{2}^{--}$erzeugt wird. Das Wasserstoffperoxid wird intrazellulär in Vakuolen neben den Bakterien deponiert und als bakteriotoxisches Agens eingesetzt. Die PMN selber besitzen Katalase und Glutathionperoxidase, um sich vor der schädlichen Wirkung des Wasserstoffperoxids zu schützen (CLIFFORD und REPINE, 1982).

$$
\mathrm{H}_{2} \mathrm{O}_{2}+\mathrm{Fe}^{2+} \rightarrow \mathrm{Fe}^{3+}+\mathrm{HO}+\mathrm{OH}^{-}
$$

Superoxid oxidiert kleine Moleküle wie Polyphenole, Katecholamine, Ascorbat und Thiole (FARR und KogOMA, 1991; Fridovich, 1989). Proteine, die Eisen-Schwefel-Cluster $(\mathrm{Fe}-\mathrm{S})_{4}$ enthalten, werden von Superoxid ebenfalls geschädigt, da das $\mathrm{O}_{2}-$ ein Eisenatom von dem Cluster abstrahieren kann (FLINT et al., 1993). Die wichtigste Reaktion des Superoxids ist wahrscheinlich seine spontane Dismutation in Wasserstoffperoxid und $\mathrm{O}_{2}$ und seine Fähigkeit zur Reduktion von Übergangsmetallen und komplexierten Metallen (FARR und KOGOMA, 1991). So kann Superoxid in Proteinen komplexiertes Eisen und Kupfer reduzieren. Zum Beispiel kann das Eisen in Cytochrom $c$ von $\mathrm{Fe}^{(\mathrm{III})} \mathrm{zu}^{\mathrm{Fe}}{ }^{(\mathrm{II})}$ reduziert werden (FARR und Kogoma, 1991). Die Reaktionen von Wasserstoffperoxid in der Zelle sind bis heute nicht hinreichend aufgeklärt, da mikromolares $\mathrm{H}_{2} \mathrm{O}_{2}$ in den Zellen mit einer sehr hohen Geschwindigkeit abgebaut wird, so daß Experimentatoren gezwungen sind, unphysiologisch hohe Wasserstoffperoxid-Konzentrationen einzusetzen, die zur Ausbildung von Schäden führen, die unter physiologischen Bedingungen wahrscheinlich nicht auftreten (IMLAY, 2003). Wasserstoffperoxid wirkt als schwaches oxidierendes Agens und greift Thiolgruppen von Proteinen oder reduziertes Glutathion an (FARR und KOGOMA, 1991). Weiterhin reagiert Wasserstoffperoxid mit reduziertem Eisen oder Kupfer in der Fentonreaktion (1.1) unter Bildung des Hydroxlradikals, wobei die Reaktion mit Kupfer in vivo keine Rolle spielt, da die Konzentration an notwendigem, freien $\mathrm{Cu}^{(\mathrm{I})}$ in den Zellen zu gering ist (GUNTHER et al., 1995). Die potenteste reaktive Sauerstoffspezies ist das Hydroxylradikal, da dieses so reaktiv 
ist, daß es mit nahezu allen in der Zelle befindlichen Biomolekülen in sehr hoher Geschwindigkeit reagiert, diese oxidiert und damit schädigt (FARR und KOGOMA, 1991). Auch in der DNA kann das Hydroxylradikal eine Reihe von Schäden hervorrufen, beispielsweise die Bildung einer 8-Hydroxyguanin-Läsion (GIESE, 2002).

In der Natur sind vier verschiedene enzymatische Wege für die Entgiftung reaktiver Sauerstoffspezies bekannt. Wasserstoffperoxid wird von den beiden Enzymen Katalase und Peroxidase abgebaut, wobei letztere ein Reduktionsmittel, für gewöhnlich NADH, für die Elektronenübertragung auf das Peroxid benötigt. Die durch Katalase vermittelte Reaktion ist in Gleichung 1.2, die von Peroxidase katalysierte Reaktion in Gleichung 1.3 dargestellt.

$$
\begin{aligned}
& \mathrm{H}_{2} \mathrm{O}_{2}+\mathrm{H}_{2} \mathrm{O}_{2} \rightarrow 2 \mathrm{H}_{2} \mathrm{O}+\mathrm{O}_{2} \\
& \mathrm{H}_{2} \mathrm{O}_{2}+\mathrm{NADH}+\mathrm{H}^{+} \rightarrow 2 \mathrm{H}_{2} \mathrm{O}+\mathrm{NAD}^{+}
\end{aligned}
$$

Superoxid wird durch das Enzym Superoxid-Dismutase (SOD) entgiftet, welches zwei Moleküle Superoxid in ein Molekül Sauerstoff und ein Molekül Wasserstoffperoxid umwandelt (1.4).

$$
\mathrm{O}_{2 \cdot-}^{-\cdot} \mathrm{O}_{2 \cdot+}^{-\cdot} \mathrm{H}^{+} \rightarrow \mathrm{H}_{2} \mathrm{O}_{2}+\mathrm{O}_{2}
$$

Aerobe und fakultativ aerobe Mikroorganismen enthalten normalerweise sowohl Superoxid-Dismutase als auch Katalase (MADIGAN et al., 2000). Anaerobe Mikroorganismen, denen oft die Katalase, die Peroxidase und SOD fehlen, zeigen verschiedene Grade der Sauerstofftoleranz, von extrem sensitiv (z.B. methanogene Bakterien) bis aerotolerant (z.B. Sulfat-reduzierende Spezies) (AUCHERE und RUSNAK, 2002). In diesen Gruppen der Bakterien wurde eine weitere Klasse sauerstoffentgiftender Enzyme, die Superoxid-Reduktasen (SOR) (LOMBARD et al., 2000b) gefunden. Diese eisenhaltigen Proteine wirken als Oxidoreduktasen und erhalten die Reduktionsäquivalente von reduzierten Pyridinnukleotiden über intermediäre Elektronentransportproteine (AUCHERE und RUSNAK, 2002) (1.5). Mindestens drei verschiedene SOR sind aus der Literatur bekannt, die das Protein Rubredoxin als Elektronenüberträger verwenden (AUCHERE et al., 2004; EMERSON et al., 2002; JENNEY et al., 1999).

$$
\mathrm{NAD}(\mathrm{P}) \mathrm{H}+\mathrm{O}_{2 \cdot}^{-\cdot}+2 \mathrm{H}^{+} \rightarrow \mathrm{H}_{2} \mathrm{O}_{2}+\mathrm{NAD}(\mathrm{P})^{+}
$$

\subsection{Identifikation neuer potentieller Pathogenitätsfaktoren aus $\mathrm{P}$. aeruginosa}

Um neue Pathogenitätsfaktoren in Pseudomonas aeruginosa zu identifizieren, wurden in der Arbeitsgruppe von Professor Tümmler an der Medizinischen Hochschule Hannover Transposonmutanten des $P$. aeruginosa Stammes TBCF10839 erzeugt, die im Hinblick auf zwei verschiedene Phänotypen untersucht wurden. Zum einen wurde die Fähigkeit der Zellen, in Granulozyten zu persistieren nachgeprüft, zum anderen wurde untersucht, ob die Mutanten weiterhin in der Lage waren, Quorum Sensing zu betreiben (WIEHLMANN et al., 2002). Beides sind Eigenschaften, die mit der Pathogenität der Zellen in Verbindung stehen. 
Die in den Mutanten durch Transposonintegration betroffenen Gene sind somit wahrscheinlich Pathogenitätsfaktoren.

Der $P$. aeruginosa Stamm TBCF10839 wurde 1983 aus einem Mukoviszidosepatienten mit akuter und chronischer Hypoxämie isoliert und unterscheidet sich phänotypisch von anderen Isolaten durch eine erhöhte Virulenz (TÜMMLER, 1987; TÜMMLER et al., 1991). Er ließ sich durch Antibiotikagabe nicht aus der Lunge eliminieren. Nur durch eine hochdosierte intravenöse Kombinationstherapie mit Ceftazidim und Tobramycin konnte eine Verbesserung des klinischen Zustandes erreicht werden. Dieser Stamm zeigt, wie die meisten aus Mukoviszidosepatienten isolierten Stämme einen mukösen Phänotyp. Die schwere Eliminierbarkeit von $P$. aeruginosa TB und das geringe Ansprechen auf eine antibiotische Therapie deuten darauf hin, daß dieses Bakterium entweder eine ungewöhnlich hohe Resistenz oder einen atypischen Pathogenitätsmechanismus aufweist (TÜMMLER, 1987). Bei Untersuchungen im Labor zeigte sich, daß dieser Stamm in der Lage ist, in Granulozyten zu überleben, während andere Isolate dazu nicht in der Lage sind (WIEHLMANN, 2001).

Die Erzeugung der Mutanten erfolgte über ein Verfahren, das als Signature Tagged Mutagenesis (STM) bezeichnet wird (HENSEL et al., 1995; Hensel, 1998). Mit diesem ist die simultane Untersuchung von bis $\mathrm{zu} 100$ quasi-isogenen Transposonmutanten, die sich lediglich durch die Anwesenheit einzigartiger DNA-Sequenzen innerhalb des Transposons unterscheiden, möglich. Gene, die für das Überleben in einem bestimmten Habitat von Interesse notwendig sind, können identifiziert werden, in dem die Gesamtheit von Mutanten nach solchen Individuen durchmustert wird, die nicht mehr in diesem Habitat überleben können. Die Transposonplasmide werden in vitro durch PCR Amplifikation einer variablen Sequenz und Ligation in einen Vektor erzeugt. Anschließend werden die Plasmide in einen Escherichia coli Stamm eingebracht, der als Donor in einer triparentalen Konjugation fungiert, bei der das Plasmid in den Stamm P. aeruginosa TBCF10839 eingebracht wird (WieHLMANn et al., 2002). Bei der triparentalen Konjugation wird ein mobilisierbares Plasmid mit Hilfe eines Helferstammes, der über die für die Konjugation notwendigen Gene verfügt, von einem selbst nicht zur Konjugation fähigen Donorstamm auf einen Akzeptorstamm übertragen. Für die Erzeugung der Mutanten wurden Gruppen von 48 Donoren eingesetzt, da es bei der gleichzeitigen Verwendung von mehr Donorstämmen zu starken statistischen Signalschwankungen bei der späteren Detektion kommen kann (DARWIN und MILLER, 1999). Die so erzeugten Mutanten wurden in Mikrotiterplatten angeordnet und inkubiert. Durch die Anordnung der Mikrotiterplatten in Reihen von A-H und Spalten von 1-12 ergibt sich die Bezeichnung einer individuellen Mutante, die aus der Bezeichnung der entsprechenden Mikrotiterplatte und den Koordinaten auf der Platte besteht, beispielsweise 41D3. Die Kulturen wurden in zwei Ansätze aufgeteilt und der eine ohne und der andere mit Selektionsdruck inkubiert. Aus den beiden Gruppen wurde nach Beendigung der Selektion die genomische DNA der Bakterien isoliert, die spezifischen Signalsequenzen mittels PCR amplifiziert und die PCR Produkte mit einem geeigneten Verfahren markiert. Diese so gewonnenen Sonden wurden dann mit einem DNA-Blot hybridisiert, auf dem die Signalsequenzen der Donorplasmide fixiert waren. In diesem Blot werden die Signalsequenzen derjenigen Bakterien, die die Selektion nicht überlebt haben, nicht markiert. Durch Nukleotidsequenzanalyse konnten anschließend die Gensequenzen, in denen das 
Transposon integriert ist, identifiziert werden (WIEHLMANN, 2001). In Abb. 1.3 ist das Verfahren der STM graphisch dargestellt.
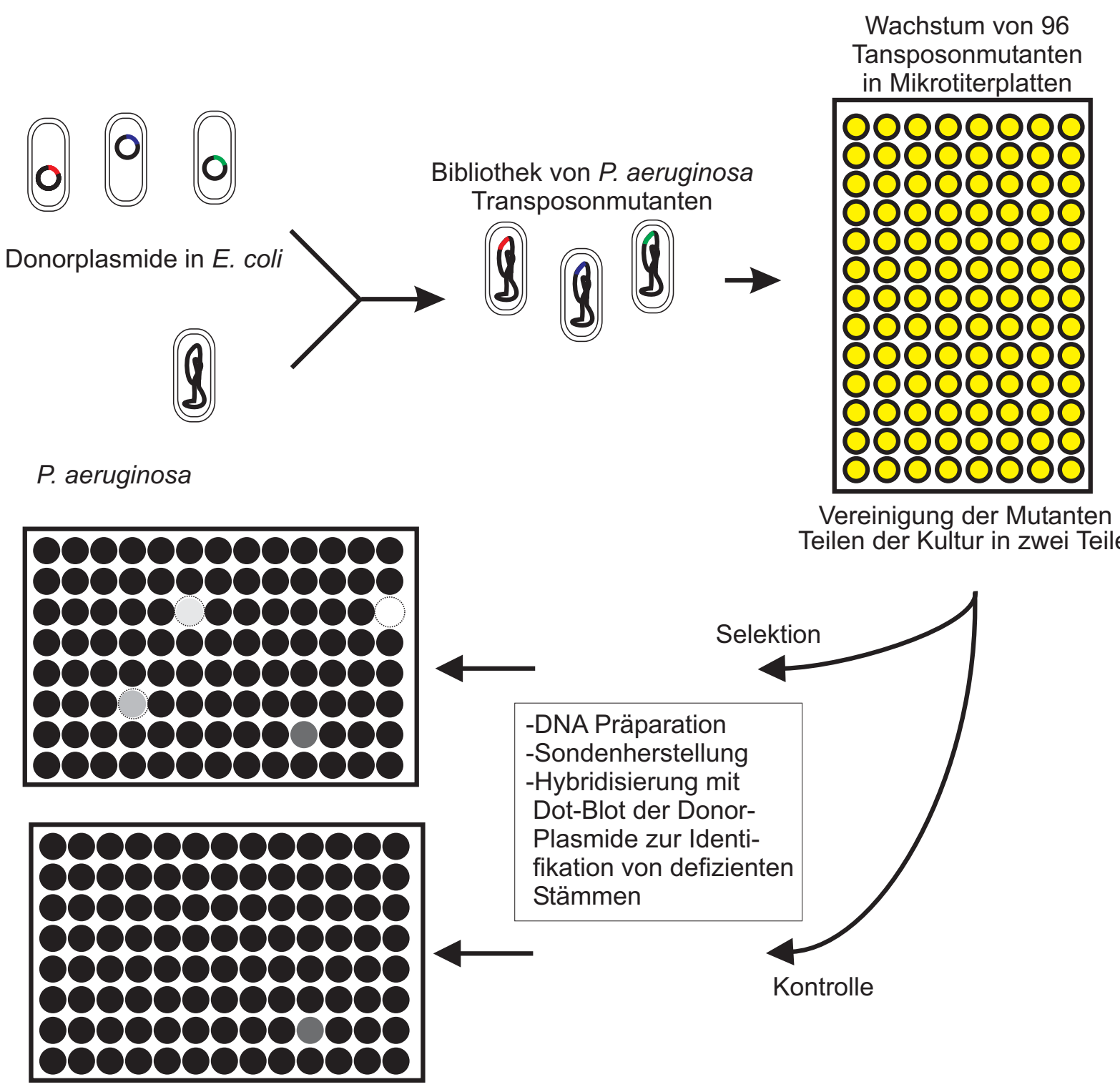

Kontrolle

Abb. 1.3: Identifikation von essentiellen Genen durch Signature Tagged Mutagenesis (STM). Eine Bibliothek von $P$. aeruginosa Transposonmutanten wird durch triparentale Konjugation erzeugt und in Mikrotiterplatten inkubiert. Nach der Inkubation werden die Zellen vereinigt und eine Hälfte der Selektion zugeführt während die andere Hälfte als Kontrolle dient. Die DNA aus beiden Ansätzen wird präpariert und separat mit einem DotBlot, auf dem die Donorplasmide arrangiert sind, hybridisiert. Somit können Individuen identifiziert werden, die die Selektion nicht überlebt haben.

Wiehlmann und Kollegen verwendeten die STM-Mutanten, um Gene zu identifizieren, die eine Rolle bei dem Wachstum in Granulozyten und beim Quorum Sensing spielen. Zur Bestimmung der intragranulozytären Überlebensfähigkeit wurden $P$. aeruginosa Mutanten mit frisch präparierten Granulozyten inkubiert. Zu diesem Ansatz wurde humanes AB-Serum gegeben, da die Granulozyten zur Erkennung der Bakterien ein funktionsfähiges Komplementsystem benötigen, weil ohne eine Opsonisierung der Bakterien keine Phagozytose stattfinden kann. Die Verwendung des Serums der Blutgruppe AB ermöglichte es, Granulozyten verschiedener Spender ohne Rücksicht auf die jeweilige Blutgruppe zu 
verwenden. Die Granulozyten wurden mit einer zehn bis zwanzigfachen Anzahl von Bakterien vermischt und nach einer Inkubationsphase durch Filtration von den freien Bakterien getrennt. Die Granulozyten wurden lysiert und das Lysat auf Agarplatten inkubiert, um die aus den Immunzellen freigesetzten Bakterien $\mathrm{zu}$ vermehren. Die weitere Untersuchung erfolgte wie weiter oben dargestellt.

Um einen Einfluß der generierten Mutationen auf das Quorum Sensing zu untersuchen, wurden die Bakterien zusammen mit einem E. coli Detektorstamm, der ein episomales Luziferasegen unter der Kontrolle eines AHL-Promotors besitzt, in Mikrotiterplatten inkubiert. Die erzeugte Lumineszenz wurde quantifiziert, und diejenigen Mutanten, die in diesen Versuchen auffällig waren, wurden ein zweites Mal analysiert, in dem sie orthogonal zu dem Detektorstamm auf eine Agarplatte ausgebracht wurden. Der bei diesen Experimenten beobachtete Parameter ist die Fähigkeit der Mutante zu Synthese von AHL. Bei diesen Untersuchungen handelt es sich um eine klassische Durchmusterung, bei der jede Mutante einzeln untersucht wird. Die Anwesenheit der einzigartigen Signalsequenzen war in diesem Fall nicht notwendig.

Bei diesen Untersuchungen wurden 13 Mutanten identifiziert, die eine verringerte Fähigkeit zum Überleben in Granulozyten besaßen, und zwei, deren Überlebensfähigkeit verbessert war (WIEHLMANN, 2001). 18 Mutanten, die eine verringerte oder keine Produktion von Acyl-Homoserinlactonen zeigten, konnten isoliert werden. Eine Mutante zeigte eine erhöhte Produktion der Autoinducer (WiehlmanN, 2001). Drei dieser Mutanten, bei denen der Phänotyp eine starke Ausprägung zeigte, wurden für eine weitere Charakterisierung im Rahmen dieser Arbeit ausgewählt. Die Mutante 41D3 zeigte eine zwanzigfach geringere Überlebensfähigkeit in Granulozyten im Vergleich zu dem Wildtyp-Stamm TBCF10839 (WieHLMANN, 2001). Weiterhin konnte bei dieser Mutante eine deutlich erhöhte Sensitivität gegenüber Wasserstoffperoxid nachgewiesen werden (WIEHLMANN et al., 2002). Die Transposonintegration fand in dem Gen Pa5349 statt, welches als putative Rubredoxin Reduktase annotiert ist. Rubredoxin Reduktasen sind Proteine, die ein Eisen-Schwefel-Cluster enthalten und die Übertragung von Elektronen von Kofaktoren, meistens NADH oder NADPH, auf das Protein Rubredoxin katalysieren. Die Mutante 19C2 zeigt im Vergleich zum Wildtyp eine um das sechzehnfache reduzierte Überlebensfähigkeit in Granulozyten. Bei der Untersuchung des Quorum Sensing zeigte sich, daß die Produktion von AcylHomoserinlactonen deutlich niedriger als bei dem Wildtyp liegt. Das in diesem Stamm von der Transposonintegration betroffene Gen ist Pa1572, das als konserviertes Protein mit unbekannter Funktion annotiert ist und über eine konservierte Domäne mit hoher Ähnlichkeit zu Proteinen der Familie der ATP-NAD-Kinasen verfügt. Enzyme dieser Klasse katalysieren die Phosphorylierung von NAD zu NADP und verwenden ATP als Phosphorquelle. Die weiterhin ausgewählte Mutante B7D3 zeigte einen ungewöhnlichen Phänotyp, da in dieser die Sekretion von Acyl-Homoserinlactonen verstärkt war. Das in diesem Stamm von der Transposonintegration betroffene Gen $\mathrm{Pa} 0740$ ist als putative $\beta$ Laktamase annotiert und sein Genprodukt sollte im Hinblick auf eine AHL-abbauende Aktivität zu untersucht werden. 


\section{Materialien}

\subsection{Bakterienstämme}

\subsubsection{Escherichia coli}

BMH71-18 (Quelle: B. Müller-Hill)

$\left[\Delta(\right.$ lac-proAB $)$ sup E, thi, $\mathrm{F}^{\prime}$ lac ${ }^{\mathrm{q}}$ lacZ $\Delta \mathrm{M} 15$, pro $\left.^{+} B^{+}\right]$

BMH71-18 dsbA (Quelle: H. Kolmar)

[ $\Delta$ (lac-proAB) supE, thi, dsbA::kan1; $\mathrm{F}^{\prime}$ lac ${ }^{\mathrm{q}}$ lacZ $\Delta \mathrm{M} 15$, pro $A^{+} B^{+}$;] Dieser Stamm wurde durch P1-Transduktion des $d s b A:: k a n 1$ Locus aus JCB609 (BARDWELL et al., 1991) nach BMH 71-18 hergestellt.

BMH71-18 mutS (KRAMER et al., 1984)

[ $\Delta$ (lac-proAB)supE, thi, mutS215:: Tn10 (tetR); F' lac1 ${ }^{\mathrm{q}}$ lacZ $\Delta \mathrm{M} 15$, pro $\left.A^{+} B^{+}\right]$

BL21(DE3) (Quelle : Fa. Novagen)

$\left[\mathrm{F}^{-}\right.$omp ThsdSB( $\left(\mathrm{rB}^{-} \mathrm{mB}^{-}\right)$gal dcm (DE3)]

MT102 (pSB403), Biosensorstamm zur Wahrnehmung von Acyl-Homoserinlactonen (RAVN et al., 2001)

[thi, araD139, (araleu) $\Delta 7697$, lac $\Delta \mathrm{X} 74$, ga1U, rpsL, $h s d R(\mathrm{pSB} 403)]$

\subsubsection{Pseudomonas sp.}

Pseudomonas putida (pKR-C12), Biosensorstamm zur Wahrnehmung von AcylHomoserinlactonen (RIEDEL et al., 2001).

Stamm F117, AHL-negatives Derivat von P. putida: [IsoF, ppuI]

\section{Pseudomonas aeruginosa PAO1 (DSM 1707)}

Pseudomonas aeruginosa TBCF10839 (TÜMMLER, 1987; TÜMMLER et al., 1991; WIEHLMANN et al., 2002)

Virulentes Klinikisolat aus der Medizinischen Hochschule Hannover, im folgenden auch als TB bezeichnet. 


\subsection{Plasmide}

\subsubsection{Vektoren zur Oberflächenpräsentation heterologer Proteine}

Die zur Oberflächenpräsentation von Fusionsproteinen auf der Oberfläche von E. coli verwendeten Plasmide basieren alle auf dem Vektor pASKInt100 (Abb. 2.1, WENTZEL et al., 2001). In diesem kann ein Gen unter der Kontrolle des Tetrazyklin-Promotor/Operators eingebracht werden. Durch das Vorhandensein zweier Ribosomenbindungsstellen wird eine effiziente Initiation der Translation gewährleistet.

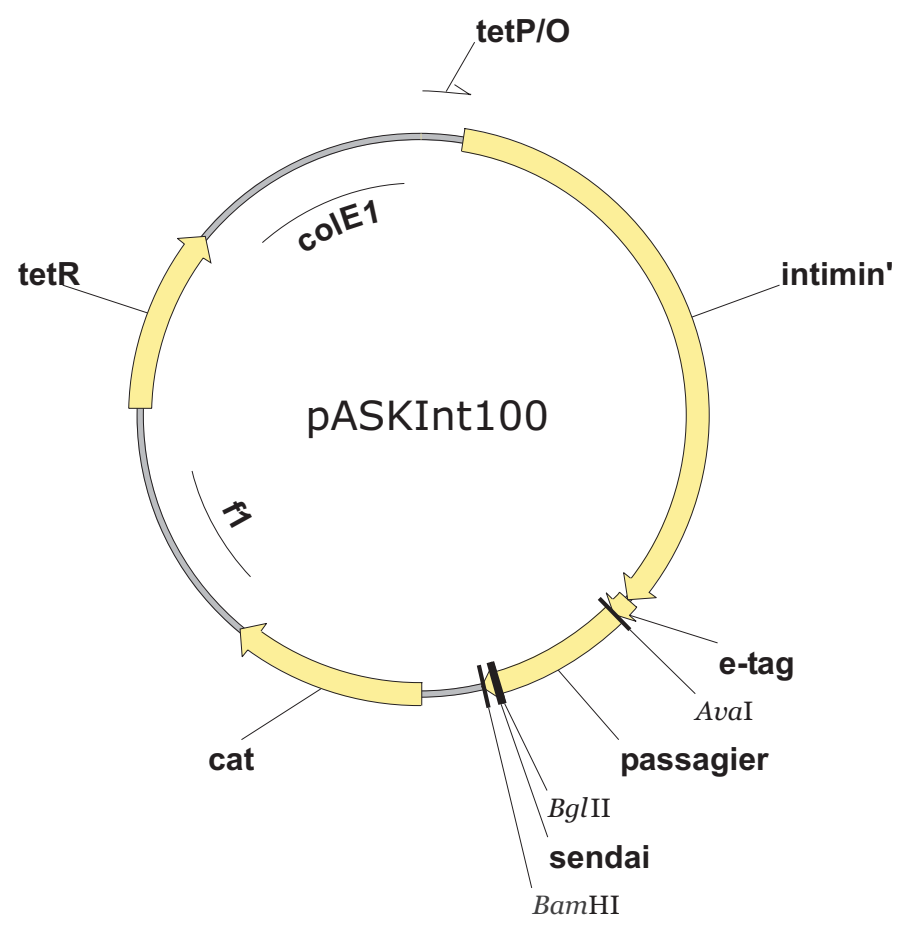

Abb. 2.1: Schematische Darstellung des Vektors pASKInt100, der das Strukturgen von Intimin trägt. f1, f1 Replikationsursprung; cat, Chloramphenicol Acetyl-Transferase-Gen; tetR, Gen, das für den Tetrazyklin Repressor kodiert; colE1, ColE1 Replikationsursprung; tetP/O. Tetrazyklin-Promotor/Operator Sequenz; intimin', verkürztes Intimin aus EHEC O157:H7 von Codon 1 bis 659; e-tag, E-tag-Epitop (GAPVPYPDPLEPR) kodierende Sequenz; sendai, 13-Aminosäuren langes Epitop (DGSLGDIEPYDSS) des Sendai-Virus-L-Proteins. Der Vektor besitzt singuläre AvaI und BglII Restriktionserkennungsstellen für die Fusion diverser Passagierdomänen.

\subsubsection{Vektoren zur Herstellung löslicher Proteine}

\subsubsection{1 pASK75}

Der in dieser Arbeit eingesetzte Vektor (Abb. 2.2) basiert auf dem originalen pASK75 Plasmid von Arne Skerra (SKERRA, 1994). Zusätzlich wird dem heterolog zu exprimierenden Protein C-terminal noch ein 13 Aminosäure langes Epitop Sequenz (DGSLGDIEPYDSS) für die Erkennung durch den monoklonalen Anti-Sendai Antikörper (EINBERGER et al., 1990) sowie ein Hexahistidinanhängsel, welches zur Reinigung des löslichen Proteins über immobilisierte Metallionenaustauschchromatographie dient, anfusioniert. 


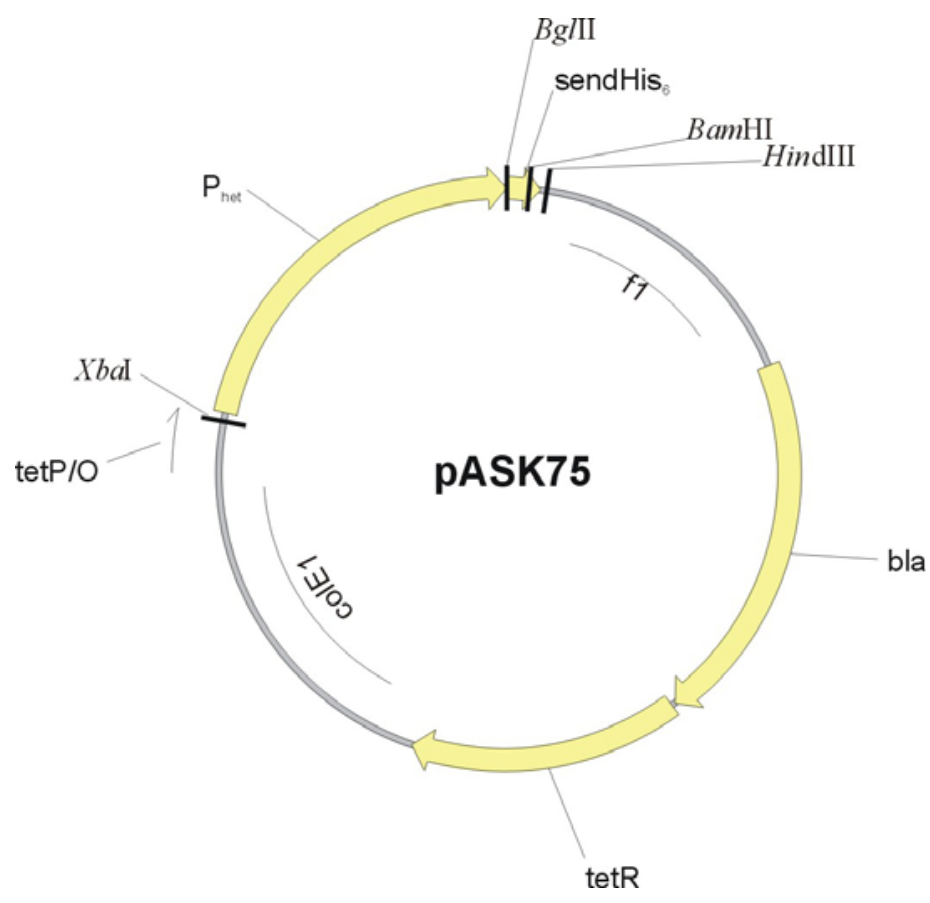

Abb. 2.2: Genetische Karte des Plasmids pASK75. Pfeilrichtungen geben die funktionellen Orientierungen der genetischen Elemente an. tetP/O: tet-Promotor/Operator-Region, colE1: Replikationsursprung, bla: das codierende Gen für die $\beta$-Laktamase, tetR: das codierende Gen für den Tetrazyklin-Repressor, fl: Replikationsursprung des filamentösen Phagen f1, sendHis 6 : kodierende Region des Epitops für die Erkennung durch Anti-Sendai Antikörper mit anfusionierter Sequenz für das Hexahistidinanhängsel, $P_{\text {het }}$ heterolog zu exprimierendes Gen aus Pseudomonas aeruginosa. Die Erkennungssequenzen der für die Klonierung relevanten Restriktionsenzyme sind angegeben.

\subsubsection{2 $\quad \mathrm{pBBR} 22 \mathrm{~b} / \mathrm{pBBR} 22 \mathrm{bII}$}

Das Plasmid pBBR22b (Abb. 2.3) (Rosenau und JAEGeR, 2004) stammt aus dem Labor von Professor Jäger aus Jülich und dient ebenfalls der heterologen Expression löslicher Proteine. Dieses Plasmid ist eine Fusion aus dem kommerziell erhältlichen pET22b Plasmid (Fa. Novagen), von dem Promotor/Operator Region, Replikationsursprung, Antibiotikaresistenzgen und das lacI-Gen stammen, sowie dem Plasmid pBBR1 aus Bordetella bronchisepta (SzPIRER et al., 2001), von dem die Mobilisierungsregion stammt. Letztere dient dem konjugativen Transfer des Plasmids in Pseudomonas putida Stämme, die zur heterologen Expression herangezogen werden können. Somit besteht die Möglichkeit auf einen anderen Expressionsstamm auszuweichen, falls die Expression des entsprechenden Gens in Escherichia coli keine zufriedenstellenden Ausbeuten ermöglicht. Der Promotor ist ein synthetisches Konstrukt aus dem Promotor der RNA-Polymerase aus dem T7Bakteriophagen und dem Bindungsort für den lac-Repressor, der ebenfalls plasmidkodiert vorliegt. Für die Expression eines heterologen Proteins ist die Verwendung eines Expressionsstammes notwendig, der eine im Genom integrierte, induzierbare T7-RNA Polymerase trägt. Im Rahmen dieser Arbeit wurde hierfür der Escherichia coli Stamm BL21(DE3) verwendet. Ein Derivat dieses Plasmids, bei dem die BglII Erkennungsstelle entfernt wurde, trägt die Bezeichnung pBR22bII. 


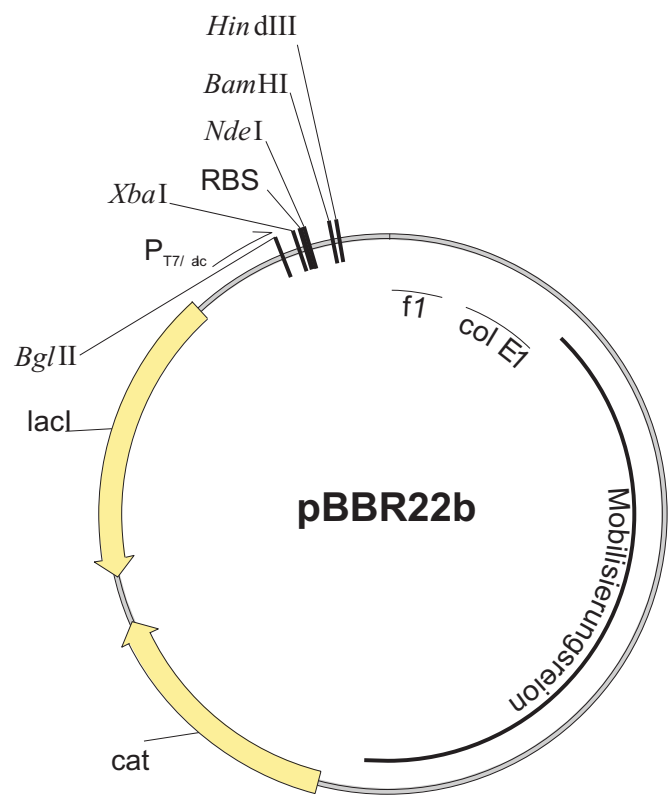

Abb. 2.3: Genetische Karte des Plasmids pBBR22b. Pfeilrichtungen geben die funktionellen Orientierungen der genetischen Elemente an. $\mathrm{P}_{\mathrm{T} 7 / \mathrm{lac}}$ T7-Promotor/ lac-Operator, colE1: Replikationsursprung, cat: das codierende Gen für die Chloramphenicol-Acetyltransferase, lacI: das codierende Gen für den Lac-Repressor, f1: Replikationsursprung des filamentösen Phagen f1, Mobilisierungsregion: Mobilisierungsgene aus Bordetella bronchisepta für den konjugativen Transfer des Plasmids. Die Erkennungssequenzen der für die Klonierung relevanten Restriktionsenzyme sind angegeben.

\subsection{DNA-Längenstandards und Protein-Molekulargewichtsmarker}

\subsubsection{DNA-Längenstandards}

Lösungen von DNA-Längenstandards (MBI-Fermentas) wurden mit TE-Puffer und Sucrosefarbmarker auf eine DNA-Konzentration von $0,1 \mu \mathrm{g} / \mu \mathrm{l}$ eingestellt und bei $4{ }^{\circ} \mathrm{C}$ gelagert.

\section{$\lambda$-DNA, Eco47I geschnitten}

Fragmentlängen in bp:

$8126,6555,6442,3676,2605,2555,2134,2005,1951,1612,1420,1284,985,974,894,597$, $590,513,511,433,345,398,310,308,272,242,215,151,88,72,67,45,42,32,28,23$

\section{0 bp GeneRuler}

Fragmentlängen in bp:

$1031,900,800,700,600,500,400,300,200,100,80$ 


\subsubsection{Molekulargewichtsmarker für Proteine}

ProteinLadder (MBI Fermentas) zur Molekulargewichtsbestimmung von Proteinen mittels Polyacrylamidgelelektrophorese. Beeinhaltet 7 Banden der relativen Molekulargewichte $14400,18400,25000,35000,45000,66200,116000$

\subsection{Oligodesoxyribonukleotide}

AC656: 5'-GACCGAGATAGGGTTGAGTG-3'

BlaSigNdeup: 5'-GAACATATGCACCCAGAAACGCTGG-3'

BlaBgl12dwn: 5'-GCCCAGATCTCCAATGCTTAATCAGTGAG-3'

Pa0740Ndeup: 5'-GACGGCCATATGAGCCGTCTGCTTGCACTCCTG-3'

Pa0740lo: 5'-GCGCAGATCTGCCTTCGGACTTCGCCGCCGGCGT-3'

Pa1572Ndeup: 5'-GACGGCCATATGGACATGTTTCGCCTGGGGTTG-3'

Pa1572Ndelo: 5'-GCGCAGATCTAGCGCCCGCGGGCGCGTCCTGGTC-3'

Pa5349up: 5'-GCGCTCTAGATAACGAGGGCAAAAAATGAGCGAGCGT

GCGCCCCTGGTA-3’

Pa5349Ndeup: 5'-GACGGCCATATGAGCGAGCGTGCGCCCCTGGTA-3'

Pa5349lo: 5'-GCGCAGATCTAGCCATGAGGCCGGGTAACTCTTTG-3'

Pa5350Ndeup: 5'-GACGGCCATATGCGCAAGTGGCAATGCGTGGTC-3'

Pa5350lo: 5'-GCGCAGATCTGGCGATCTCGATCATCTCGAA-3'

pPREY-PcrG-up: 5'-GCGCCCCGGGATGGGCGACATGAACGAA-3'

pPREY-PcrG-lo: 5'-GCGCGGATCCTCAGATCAACAAGCCACGCAT-3'

\subsection{Enzyme und Proteine}

Amersham Pharmacia Biotech, Freiburg

Anti-E-Tag Antikörper

MBI Fermentas, Vilnius, Litauen

Restriktionsendonukleasen, Rinderserumalbumin (BSA), T4-DNA-Ligase, T4 DNA Polymerase, Molekulargewichtsmarker für Proteine

Molecular Probes, Eugene, USA

Streptavidin, R-Phycoerythrin-Konjugat $(1 \mathrm{mg} / \mathrm{ml})$ 
New England Biolabs, Bad Schwalbach

Restriktionsendonukleasen, Rinderserumalbumin (BSA)

Promega, Madison, USA

Tfl-Polymerase $(5 \mathrm{u} / \mu \mathrm{l})$

Sigma, Deisenhofen

Anti-Maus IgG (whole molecule), Biotin-Konjugat (polyklonaler Anti-Maus Antikörper aus der Ziege), Anti-Kaninchen IgG (whole molecule), Biotin-Konjugat (polyklonaler Anti-Maus Antikörper aus der Ziege), Isocitrat-Dehydrogenase (NADP-abhängig), aus dem Schweineherzen präpariert, Xanthinoxidase aus der Buttermilch, ca. 33 Units/ml, Bovine Superoxid-Dimutase, ca. 10000 Units/ml

TaKaRa, Otsu, Japan

LaTaq DNA Polymerase zur Amplifikation GC-reicher DNA

Sonstiges:

Anti-Sendai Antikörper: von H. Einberger und H.P. Hofschneider (EINBERGER et al., 1990) (Max-Planck-Institut für Biochemie, Martinsried) zur Verfügung gestellter monoklonaler Maus Antiköper gegen ein 13 Aminosäuren langes Epitop aus dem L-Protein des Sendai Virus

\subsection{Chemikalien}

ACROS, Geel, Belgien

Anhydrotetracyclin (ATC)

Applichem, Darmstadt

Imidazol, Isopropyl- $\beta$-D-Thiogalactopyranosid (IPTG)

Baker, Deventer, Holland

$\mathrm{N}^{\prime}, \mathrm{N}^{`}$-Dimethylformamid

Biozym, Hess. Oldendorf

Biozym DNA Agarose

Boehringer Mannheim, Mannheim

Ampicillin, 2'-Desoxyribonukleosid-5'-Triphosphate (dATP, dCTP, dGTP, dTTP) 
Calbiochem, San Diego, USA

7-(Thienyl-2-Acetamido)-3-(2-(N,N-Dimethyl-Aminophenylazo) Pyridiniummethyl)-3Cephem-4-Carboxylsäure (Handelsname PADAC)

Difco, Dreieich

Bacto-Agar

Fluka, Neu-Ulm

$\mathrm{N}$-(Dodecanoyl)-Homoserinlacton (C12-HSL), Dimethylsulfoxid (DMSO), Bromphenolblau, Glycerin, $\beta$-Mercaptoethanol, Saccharose, Natriumchlorid, $\mathrm{D}(+)$ Glukose Monohydrat, Hydroxy-Ethylzellulose (HEC)

FMC Biopolymer, Drammen, Norwegen

Protanal LF20/40

Gibco BRL, Eggenstein

Yeast Extract

ICN Biochemicals, Aurora, USA

Borsäure, Ethylendiamintetraessigsäure Dinatriumsalz (EDTA), Tris(Hydroxymethyl)Aminomethan (Tris)

Merck, Darmstadt

Alle nicht explizit aufgeführten Chemikalien, die zur Anwendung kamen.

Metabion, Martinsried

Oligodesoxyribonukleotide

MJ Research, Watertown, USA

Chill out 14 (Flüssigwachs)

MWG, Ebersberg

Oligodesoxyribonukleotide

National Diagnostics, Simerville, USA

Protogel 
Oxoid, Wesel

Agar Bacteriological, Trypton, Yeast Extract

Riedel-De Haen, Seelze

Ammoniumacetat, Chloroform, Ethanol, Formamid, Methanol, Natriumchlorid, Salzsäure, Ammoniumsulfat

Serva, Heidelberg

Ammoniumperoxidisulfat, Ethylendiamintetraessigsäure Dinatriumsalz (EDTA), D(+)Glukose Monohydrat, Dithiotreitol (DTT), 25\%-ige Glutaraldehydlösung, Natriumdodecylsulfat (SDS), N,N,N',N'-Tetramethyl-Ethylendiamin (TEMED)

Sigma, Deisenhofen

Borsäure, Bromphenolblau, Chloramphenicol, Ethidiumbromid, Isooktan, KaliumHexacyanoferrat(II)-Hydrat, Kalium-Hexacyanoferrat(III)-Hydrat, Natriumperiodat, NLauroylsarcosin, Triethanolamin, Tris(Hydroxymethyl)-Aminomethan (Tris), Triton X100, TWEEN 20 , TWEEN 85 (Polyoxyethylen-20-Sorbitan-Trioleat), SPAN 85 (SorbitanTrioleat), Xanthin, Oligodesoxyribonukleotide, alle anderen nicht explizit aufgeführten Chemikalien

\subsection{Sonstige Materialien und Geräte}

American National Can., Chicago, USA

Parafilm "M" Laboratory Film

Bender \& Hobein, Zürich, Schweiz

Vortex Genie 2

BioRad, München

Gene Pulser und Pulse Controller, Elektroporationsküvetten (Innendurchmesser $=2 \mathrm{~mm}$ )

Biozym, Hessisch Oldendorf

PCR-Tube ultradünn, $0,2 \mathrm{ml}$

Braun, Melsungen

Injektions-Kanülen 
CEAG Schirp Reinraumtechnik, Essen

Envirco Sterilbank

Constant Systems, Low March, Daventry, Großbritannien

CellDisruptor BasicZ

Coulter Corporation (Epics Division), Hialeah, USA

EPICS Alignment Fluorespheres for optical alignment of flow cytometers, fluoreszierende MicroBeads

Cybertech, Berlin

Cybertech CS-1 Elektronische Sofortbildkamera

Cytomation Inc., Fort Collins, USA

MoFlo Cytometer mit Cyclone Sortiereinheit, Fluorescence Activated CellSorter (FACS) mit Coherent Enterprise II Laser, Cyclops Software-Paket

Eigenbau Rührgerät zur Erstellung von Emulsionen

Antrieb: Heidolph Laborrührer Typ RZR, stufenlos regelbar von 170 - 1700 UPM. Als Rührkopf dient ein Carbon-Hydropropeller, Durchmesser $31 \mathrm{~mm}$, Steigung 1,6 (Graupner Nr. 2327.21), der durch eine gekapselt laufende Edelstahlwelle von $26 \mathrm{~cm}$ Länge und $4 \mathrm{~mm}$ Durchmesser (Graupner Nr. 412) mit dem Antrieb verbunden ist.

Eppendorf, Hamburg

Reaktionsgefäße 2,0 ml Safe-Lock, Reaktionsgefäße 1,5 ml, Multipipette, Combitips für die Multipipette 0,5 ml, 1,25 ml, 2,5 $\mathrm{ml}$ und 12,5 ml

Genomed, Bad Oeyenhausen

JetStar Plasmid Midiprep Kit 2.0

Gilson, USA

Mikroliter-Pipetten, $1000 \mu \mathrm{l}, 200 \mu \mathrm{l}$ und $20 \mu \mathrm{l}$

C. A. Greiner \& Söhne, Nürtingen

Röhrchen $12 \mathrm{ml}$

Heinemann, Schwäbisch Gmünd

Ultraschallgerät Branson Sonifier W-250, SLM Aminco French Press 
Heinzinger, Rosenheim

Stromversorger LNGs 350-06

Hellma, Müllheim/Baden

Quarzküvetten (0,5 $\mathrm{ml}$ und $2 \mathrm{ml}, 1 \mathrm{~cm}$ Schichtdicke)

Herolab, Wiesloch

UVT2035 302 nm UV-Leuchttisch, Plastikröhrchen für die Ultrazentrifugation

Hettich Zentrifugen, Tuttlingen

Kühlzentrifuge Mikro Rapid/K, Kühlzentrifuge Rotanta/RPC, Kühlzentrifuge Roto Silenta/RP, Kühlzentrifuge Rotixa/RP, Mikroliter-Tischzentrifuge

Hitachi, Tokyo, Japan

F-4500 Fluoreszenz-Spektralphotometer

Hoefer Scientific, San Francisco, USA

Platten für SDS-Gele, Midget-Apparatur

InforMax Inc., Bethesda, USA

VectorNTI 5 Bioinformatik-Software, Demoversion

Ingold, Steinbach

pH-Elektrode U402-M5

IKA-Labortechnik, Staufen

beheizbarer Magnetrührer IKAMAG RCT

Kimberley-Clark, USA

Kimwipes Papiertücher, fusselfrei; SafeSkin Einmalhandschuhe

Knick, Berlin

pH-Meter 761 Calimatic

Kontron, Eching

Zweistrahl-Spektralphotometer Uvikon 933, Centrikon T-1055 Ultrazentrifuge + TST4114 Schwenkbecherrotor 
Köttermann Labortechnik, Uetze/Hänigsen

Wasserbad, Schüttelwasserbad

Macherey-Nagel, Düren

Nucleotrap- und NucleotrapCR-Kit

Menzel-Gläser, Braunschweig

Objektträger (76 x 26 mm), Deckgläser (18 x 18 mm)

Millipore, Eschborn

Filtereinheiten Millex FG13, Ultrafree-20 Nanopore-Wasser-Anlage, Centiprep Proteinkonzentratoren

Minolta, Japan

Spiegelreflexkamera X-700

MJ Research, Watertown, USA

DNA Thermal Mini-Cycler PTC-150

Perseptive Biosystems, Foster City, USA

BioCad Vision Workstation, automatisierte Chromatographieanlage

Pharmacia/LKB, Freiburg

Elektrophorese Stromversorger ECPS 3000/150, 2117-250 Novoblot elektrophoretische Transferapparatur NOVABLOT 2117-2250, Chelating Sepharose

Roth, Karlsruhe

VISKING Dialysierschlauch mit Ausschlußgrenze 14000 relatives Molekulargewicht

SafeSkin, Neufarn

Satin Plus, puderfreie Latex-Einmalhandschuhe

Sarstedt, Nümbrecht

Reaktionsgefäße 1,5 ml, Röhrchen $5 \mathrm{ml}$, Röhrchen $50 \mathrm{ml}$, Petrischalen $(92 \times 16 \mathrm{~mm}$ und $150 \times 20 \mathrm{~mm}$ ) 


\section{Sartorius, Göttingen}

Minisart NML Sterilfilter, Sartorius Universal U 4800P Feinwaage, Vivaspin Proteinkonzentratoren

Savant Instruments, Vaterstetten

SpeedVac Concentrator SVC $200 \mathrm{H}$

Schleicher und Schuell, Dassel

Nitrozellulose-Membran, 3 MM-Filterpapier (Whatman)

Schott, Mainz

Glaswaren

Sorvall, Bad Nauheim

Zentrifuge RC-5C, Rotortypen SS34 und GSA

SPSS Inc., Chicago, USA

SigmaPlot 2000, Software für wissenschaftliche EDV Demoversion

Wissenschaftlich-Technische Werkstätten, Weilheim

pH-Meter-522

\section{Zeiss, Göttingen}

Mikroskop Axioskop mit Durchlicht und Auflichtfluoreszenz (Filtersätze: 487902 und 487909) und Kameraaufsatz, Okulare: Vergrößerung 10 x, Sehfeldzahl 20, Objektive: Plan Neofluar 63 x/1,25 Oil, 440480, Plan Neofluar 100 x/1,25 Oil, 440460, Acroplan 20 x, 440845, Immersionsöl

Ziegra, Isernhagen

Eismaschine

\subsection{Nährmedien zur Anzucht von Escherichia coli}

dYT-Medium

$1 \%(w / v)$ Hefe-Extrakt, 1,6 \% (w/v) Trypton, 0,5 \% (w/v) $\mathrm{NaCl}$ 


\section{M9-Minimalmedium}

$7 \mathrm{~g} \mathrm{Na}_{2} \mathrm{HPO}_{4}$ x $2 \mathrm{H}_{2} \mathrm{O}, 3 \mathrm{~g} \mathrm{KH}_{2} \mathrm{PO}_{4}, 1 \mathrm{~g} \mathrm{NH}_{4} \mathrm{Cl}, \mathrm{H}_{2} \mathrm{O}$ ad $1000 \mathrm{ml}$. Komplettiert mit $25 \mathrm{ml}$

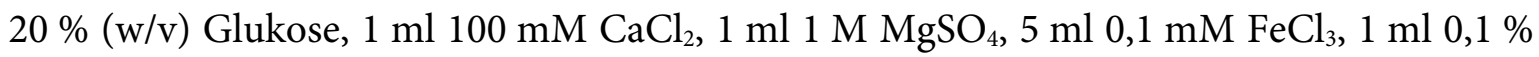
$(w / v)$ Thiamin, jeweils aus sterilen Lösungen zugesetzt.

\section{SOC-Medium}

0,5\% (w/v) Hefe-Extrakt, $2 \%$ (w/v) Trypton, 2,5 mM KCl, $10 \mathrm{mM} \mathrm{NaCl}$. Nach dem Autoklavieren Zugabe von sterilfiltrierter Glukose auf eine Endkonzentration von $20 \mathrm{mM}$, sowie von sterilfiltriertem $\mathrm{MgCl}_{2}$ und $\mathrm{MgSO}_{4}$, jeweils auf eine Endkonzentration von $10 \mathrm{mM}$.

Die Nährmedien wurden zur Sterilisation $20 \min$ bei $121^{\circ} \mathrm{C}$ autoklaviert.

Für feste Medien wurden vor dem Autoklavieren 1,5 \% (w/v) Bacteriological Agar (Oxoid) zugegeben.

Antibiotika wurden aus den entsprechenden 1000-fach konzentrierten Stammlösungen bis zu einer Endkonzentration von 25 mg/l Chloramphenicol, 37,5 mg/l Kanamycin bzw. 100 mg/l Ampicillin zugegeben.

\subsection{Lösungen und Puffer}

\section{Alginat-Stammlösung}

1,2 \% Protanal LF20/40 (w/v), gelöst in sterilem bidest. $\mathrm{H}_{2} \mathrm{O}$

Alkalische Phosphatase Reaktions-Puffer

100 mM Tris- $\mathrm{HCl}, \mathrm{pH}$ 9, $100 \mathrm{mM} \mathrm{NaCl}, 50 \mathrm{mM} \mathrm{MgCl} 2$

\section{Ampicillin-Stammlösung}

$100 \mathrm{mg} / \mathrm{ml}$ Ampicillin (Na-Salz) in Wasser, sterilfiltriert

\section{Anhydrotetracyclin-Stammlösung}

$2 \mathrm{mg} / \mathrm{ml}$ Anhydrotetracyclin in $\mathrm{N}^{`}, \mathrm{~N}^{`}$-Dimethylformamid

\section{APS-Stammlösung}

$10 \%$ APS (Ammoniumperoxydisulfat) in Wasser

\section{AT P-Stammlösung}

$100 \mathrm{mM}$ Adenosin-Triphosphat in Wasser 
BCIP

$50 \mathrm{mg} / \mathrm{ml}$ BCIP (5-Brom-4-Chlor-3-Indolyl-Phosphat-p-Toluidinsalz) in $70 \%$ Dimethylformamid

Chloramphenicol-Stammlösung

$25 \mathrm{mg} / \mathrm{ml}$ Chloramphenicol in $96 \%$ Ethanol

dNTP-Stammlösung

je $100 \mathrm{mM}$ dNTP $(\mathrm{N}=\mathrm{A}, \mathrm{C}, \mathrm{G}, \mathrm{T})$, mit $1 \mathrm{M}$ Tris-Base auf $\mathrm{pH} 7$ eingestellt

dNTP-Stammlösung für die PCR

je $10 \mathrm{mM}$ dNTP $(\mathrm{N}=\mathrm{A}, \mathrm{C}, \mathrm{G}, \mathrm{T})$, aus dNTP-Stammlösungen mit Wasser verdünnt

E1 (Jetstar 2.0 Plasmid Kit (Genomed))

50 mM Tris-HCl, pH 8, 10 mM EDTA, $100 \mu \mathrm{g} / \mathrm{ml}$ RNaseA

E2 (Jetstar 2.0 Plasmid Kit (Genomed))

$200 \mathrm{mM} \mathrm{NaOH}, 1 \%(\mathrm{w} / \mathrm{v})$ SDS

E3 (Jetstar 2.0 Plasmid Kit (Genomed))

3,2 M Kaliumacetat-Essigsäure, $\mathrm{pH}$ 5,5

E4 (Jetstar 2.0 Plasmid Kit (Genomed))

600 mM NaCl, 100 mM Natriumacetat-Essigsäure, pH 5

E5 (Jetstar 2.0 Plasmid Kit (Genomed))

800 mM NaCl, 100 mM Natriumacetat-Essigsäure, pH 5

E6 (Jetstar 2.0 Plasmid Kit (Genomed))

1,25 M NaCl, 100 mM Tris-HCl, pH 8,5

Ethidiumbromid-Stammlösung (10x)

$10 \mathrm{mg} / \mathrm{ml}$ Ethidiumbromid

Formamid-Farbmarker

91,2 \% Formamid, 20 mM EDTA, pH 8,3, 0,15 mM Bromphenolblau 
Hoechst-Puffer (nicht reduzierend)

8 M Harnstoff, 200 mM Tris-Base, $2 \%$ (w/v) SDS, 0,15 mM Bromphenolblau

\section{Hoechst-Puffer (reduzierend)}

8 M Harnstoff, $200 \mathrm{mM}$ Tris-Base, $2 \%$ (w/v) SDS, 0,15 mM Bromphenolblau, $200 \mathrm{mM}$ Dithiothreitol

Glukose-6-Phosphat-Stammlösung

$68 \mathrm{mg} / \mathrm{ml}$ in Wasser, entspricht einer Konzentration von $200 \mathrm{mM}$

\section{IMAC-Puffer I}

$100 \mathrm{mM} \mathrm{NaH}_{2} \mathrm{PO}_{4} / \mathrm{Na}_{2} \mathrm{HPO}_{4}, \mathrm{pH} 8,100 \mathrm{mM} \mathrm{NaCl}$

IMAC-Puffer II

$100 \mathrm{mM} \mathrm{NaH} \mathrm{PO}_{4} / \mathrm{Na}_{2} \mathrm{HPO}_{4}, \mathrm{pH}$ 8, $100 \mathrm{mM} \mathrm{NaCl}, 1 \mathrm{M}$ Imidazol

IPTG-Stammlösung

1 M IPTG in Wasser, sterilfiltriert

Isocitrat-Stammlösung

$51,5 \mathrm{mg} / \mathrm{ml}$ in Wasser, entspricht einer Konzentration von $200 \mathrm{mM}$

Isooktan/Span85 Lösung

19,8 ml Span85 (Fluka), ad $500 \mathrm{ml}$ Isooktan

Kalium-Hexacyanoferrat(II)-Stammlösung

0,01 g Kalium-Hexacyanoferrat(II) in $2 \mathrm{ml}$ demineralsiertem Wasser

Kalium-Hexacyanoferrat(III)-Stammlösung

0,01 g Kalium-Hexacyanoferrat(III) in $2 \mathrm{ml}$ demineralsiertem Wasser

Kanamycin-Stammlösung

$75 \mathrm{mg} / \mathrm{ml}$ Kanamycin in Wasser, sterilfiltriert

Laemmli Puffer (SDS PAGE Laufpuffer)

25 mM Tris- $\mathrm{HCl}, 200$ mM Glycin, 0,1 \% (w/v) SDS 


\section{Luminol-Lösung}

30 mM Luminol (Geschenk von Dr. L. Wiehlmann, MHH) gelöst in $1 \mathrm{M} \mathrm{NaOH}$

\section{Luminol-Reagenz}

1:1 (v/v) 20 mM Luminol-Lösung / 200 mM Wasserstoffperoxid-Lösung

\section{NAD-Stammlösung}

$13 \mathrm{mg} / \mathrm{ml}$ Nikotinamid-Adenin-Dinukleotid Dinatriumsalz (NAD) in Wasser, entspricht einer Konzentration von $20 \mathrm{mM}$

\section{NADP-Stammlösung}

$15 \mathrm{mg} / \mathrm{ml}$ Nikotinamid-Adenin-Dinukleotid-Phosphat Dinatriumsalz (NADP) in Wasser, entspricht einer Konzentration von $20 \mathrm{mM}$

\section{NBT-Stammlösung}

$75 \mathrm{mg} / \mathrm{ml} \mathrm{NBT}$ (Nitroblautetrazoliumchlorid) in 70 \% Dimethylformamid,

\section{PAG Färbelösung}

$1000 \mathrm{ml}$ Methanol, $15 \mathrm{~g}$ Coomassie Briliant Blue $R$

\section{PBS-Puffer}

$140 \mathrm{mM} \mathrm{NaCl}, 10 \mathrm{mM} \mathrm{KCl}, 6,4 \mathrm{mM} \mathrm{Na}_{2} \mathrm{HPO}_{4}, 2 \mathrm{mM} \mathrm{KH}_{2} \mathrm{PO}_{4}$

\section{PBST-Puffer}

$140 \mathrm{mM} \mathrm{NaCl}, 10 \mathrm{mM} \mathrm{KCl}, 6,4 \mathrm{mM} \mathrm{Na}_{2} \mathrm{HPO}_{4}, 2 \mathrm{mM} \mathrm{KH}_{2} \mathrm{PO}_{4}, 0,05$ \% (v/v) TWEEN 20

\section{Periprep-Puffer I}

200 mM Tris-HCl, pH 9, 100 mM EDTA, 20 \% (w/v) Saccharose

\section{Periprep-Puffer II}

10 mM Tris-HCl, $\mathrm{pH} 9$

Phenol/Chloroform

1 Vol Phenol/TE, 1 Vol Chloroform

\section{Ponceau S-Färbelösung}


$0,3 \%$ (w/v) Ponceau S (3-Hydroxy-4-(2-Sulfo-4-(4-Sulfophenylazo)-Phenylazo)-2,7Naphthalendisulfonsäure), 3 \% (w/v) Trichloressigsäure, 3 \% (w/v) Sulfosalicylsäure

\section{Qiagen P1}

50 mM Tris-HCl, pH 8, 10 mM EDTA, $100 \mu \mathrm{g} / \mathrm{ml}$ RNAseA

\section{Qiagen P2}

$200 \mathrm{mM} \mathrm{NaOH}, 1 \%(\mathrm{w} / \mathrm{v}) \mathrm{SDS}$

\section{Qiagen Buffer P3}

3,0 M Natriumacetat, $\mathrm{pH}$ 5,5

\section{Qiagen Buffer QBT}

$750 \mathrm{mM} \mathrm{NaCl}, 50 \mathrm{mM}$ MOPS (3-Morpholino-Propan-Sulfonsäure), pH 7, 15\% Isopropanol, $0,15 \%$ Triton X-100

\section{Qiagen Buffer QC}

1,0 M NaCl, 50 mM MOPS (3-Morpholino-Propan-Sulfonsäure), pH 7, 15 \% Isopropanol

\section{Buffer QF}

1,25 M NaCl, 50 mM Tris- $\mathrm{HCl}, \mathrm{pH}$ 8,5, 15 \% Isopropanol

Reaktionspuffer für Restriktionsendonukleasen (MBI Fermentas, 10x)

Blau: $\quad 10 \mathrm{mM}$ Tris- $\mathrm{HCl}, \mathrm{pH} 7,5,10 \mathrm{mM} \mathrm{MgCl}_{2}$

Grün: $\quad 10 \mathrm{mM}$ Tris- $\mathrm{HCl}, \mathrm{pH} 7,5,10 \mathrm{mM} \mathrm{MgCl} 2,50 \mathrm{mM} \mathrm{NaCl}$

Orange: $50 \mathrm{mM}$ Tris- $\mathrm{HCl}, \mathrm{pH}$ 7,5, $10 \mathrm{mM} \mathrm{MgCl}_{2}, 100 \mathrm{mM} \mathrm{NaCl}$

Rot: $\quad 10 \mathrm{mM}$ Tris- $\mathrm{HCl}, \mathrm{pH} 8,5,10 \mathrm{mM} \mathrm{MgCl}_{2}, 100 \mathrm{mM} \mathrm{KCl}$

Gelb: $\quad 33$ mM Tris-Essigsäure, pH 7,9, 10 mM Magnesiumacetat, 66 mM Kaliumacetat

\section{Reaktionspuffer für Restriktionsendonukleasen (NEB, 10x)}

NEB1: $\quad 10 \mathrm{mM}$ Bis-Tris Propan-HCl, pH 7, $10 \mathrm{mM} \mathrm{MgCl} 2,1 \mathrm{mM}$ DTT

NEB2: $\quad 10 \mathrm{mM}$ Tris-HCl, $\mathrm{pH}$ 7,9, $10 \mathrm{mM} \mathrm{MgCl}_{2}, 50 \mathrm{mM} \mathrm{NaCl}, 1 \mathrm{mM}$ DTT

NEB3: $\quad 50$ mM Tris-HCl, pH 7,9, 10 mM MgCl 2,100 mM NaCl, 1 mM DTT

NEB4: 20 mM Tris-Essigsäure, pH 7,9, 10 mM Magnesiumacetat, 50 mM Kaliumacetat, $1 \mathrm{mM}$ DTT 


\section{RNaseA-Stammlösung}

$10 \mathrm{mg} / \mathrm{ml}$ RNaseA, $10 \mathrm{mM}$ Tris- $\mathrm{HCl}, \mathrm{pH} 7,5,15 \mathrm{mM} \mathrm{NaCl}, 20 \mathrm{~min}$ auf $100^{\circ} \mathrm{C}$ erhitzt, langsam auf RT abgekühlt und bei $4{ }^{\circ} \mathrm{C}$ gelagert

\section{Sammelgel-Puffer für SDS Gele}

1,25 M Tris-HCl, $\mathrm{pH}$ 6,8

\section{Sucrosefarbmarker}

$60 \%(w / v)$ Sucrose, 0,1 \% (w/v) Bromphenolblau, 0,1 \% (w/v) Xylencyanol FF in 1x TAE

\section{Sucrosegradientenpuffer}

100 mM Tris-HCl, pH 8, 10 mM EDTA, 100 mM NaCl, 18,5 \% (w/v) Saccharose

\section{T4-DNA-Ligase-Puffer (10x)}

400 mM Tris- $\mathrm{HCl}, \mathrm{pH}$ 7,8, 100 mM MgCl 2,100 mM DTT, 5 mM ATP

Taq-Polymerase-Puffer / Taq-Puffer (10x)

$500 \mathrm{mM}$ KCl, 100 mM Tris-HCl, pH 9, 15 mM MgCl 2,1 \% (w/v) Triton X 100

\section{TAE-Puffer}

$40 \mathrm{mM}$ Tris-Acetat, $5 \mathrm{mM}$ Natriumacetat, $1 \mathrm{mM}$ EDTA, pH 7,4

\section{TBE-Puffer}

89 mM Tris-Base, 89 mM Borsäure, 2,5 mM EDTA

\section{TE-Puffer}

$10 \mathrm{mM}$ Tris- $\mathrm{HCl}, 0,5 \mathrm{mM}$ EDTA, $\mathrm{pH} 8$

\section{TFB-1 Puffer}

$100 \mathrm{mM} \mathrm{RbCl}, 50 \mathrm{mM}, \mathrm{MnCl}, 30 \mathrm{mM} \mathrm{KOAc}, 10 \mathrm{mM} \mathrm{CaCl} 2,15$ \% Glycerin, pH 5,8- 6,2 mit Essigsäure eingestellt. Lagerung bei $4{ }^{\circ} \mathrm{C}$.

\section{TFB-2 Puffer}

$10 \mathrm{mM}$ MOPS (3-Morpholino-Propan-Sulfonsäure), $10 \mathrm{mM} \mathrm{RbCl}, 75 \mathrm{mM} \mathrm{CaCl} 2,15 \%$ Glycerin, $\mathrm{pH}$ 7. Lagerung bei $4{ }^{\circ} \mathrm{C}$. 
1,875 M Tris- $\mathrm{HCl}, \mathrm{pH} 8,8$

Tris-Puffer

Tris(Hydroxymethyl)-Aminomethan in Wasser auflösen und den pH-Wert mit Säure einstellen. Für Tris-HCl wird Salzsäure, für Tris-Acetat wird Essigsäure verwendet. Der $\mathrm{pH}$-Wert von Tris-Puffer kann mit normalen $\mathrm{pH}$-Elektroden nicht genau bestimmt werden, weswegen $\mathrm{pH}$-Indikatorpapier verwendet werden muß.

\section{Tween85-Stammlösung}

4,2 $\mathrm{ml}$ Tween 85 ad $50 \mathrm{ml}$ bidest. $\mathrm{H}_{2} \mathrm{O}$

\section{Wasserstoffperoxid-Lösung}

$200 \mathrm{mM}$ Wasserstoffperoxid in destilliertem Wasser

\section{Westernblot-Transferpuffer}

25 mM Tris-HCl, 192 mM Glycin, $20 \%$ (v/v) Methanol

\section{Xanthin-Stammlösung}

$1 \mathrm{mM}$ Xanthin in $50 \mathrm{mM}$ Natriumphosphat, Zugabe von $\mathrm{NaOH}$ bis sich das Xanthin löst. Kurz vor der Verwendung mittels Durchströmen mit Druckluft mit Sauerstoff angereichert.

Alle Puffer und Lösungen wurden, soweit nicht anders angegeben, mit demineralisiertem Wasser (Millipore, Nanopore-Wasser-Anlage) angesetzt. 


\section{Methoden}

\subsection{Handhabung von Bakterien}

\subsubsection{Lagerung von Escherichia coli und Pseudomonas putida Stämmen}

Die in dieser Arbeit verwendeten Stämme der Gram-negativen Proteobakterien Escherichia coli oder Pseudomonas putida wurden dauerhaft entweder als Glyzerinkultur oder als Stichkultur gelagert. Für erstere wurden $1 \mathrm{ml}$ einer in der stationären Phase befindlichen Kultur des entsprechenden Stammes mit $3 \mathrm{ml}$ sterilem Glyzerin vermischt und bei $-70{ }^{\circ} \mathrm{C}$ in einem Schraubdeckelgefäß eingelagert. Für die Herstellung einer Stichkultur wurde eine mit $1 \mathrm{ml} \mathrm{LB}$-Agar befüllte Glasphiole mit dem entsprechenden Stamm mittels einer Impfnadel beimpft und über Nacht bei $37{ }^{\circ} \mathrm{C}$ inkubiert. Die Glasphiole wurde mit Parafilm luftdicht verschlossen und bei Raumtemperatur aufbewahrt.

Für eine kurzfristige Lagerung bis zu 8 Wochen Dauer wurden die entsprechenden Bakterienstämme auf M9-Minimalplatten oder, falls auf diesen Platten kein Wachstum möglich war, auf LB-Platten ausgestrichen und über Nacht bei $37^{\circ} \mathrm{C}$ inkubiert. Anschließend wurden die Platten bei $4{ }^{\circ} \mathrm{C}$ gelagert.

\subsubsection{Anzucht und Vermehrung von Bakterienstämmen}

Die verwendeten Escherichia coli-Stämme wurden, falls nicht anders aufgeführt, bei $37^{\circ} \mathrm{C}$ in dYT-Medium vermehrt, während für die Propagation von Pseudomonas putida im allgemeinen LB-Medium verwendet wurde. Im Falle von Plasmid- oder Genom-kodierter Resistenz wurden entsprechende Antibiotika aus sterilen Stammlösungen den Medien zugesetzt. Bei einem Volumen von bis zu $5 \mathrm{ml}$ wurden die Kulturen in Reagenzgläsern kultiviert, welche zur Belüftung in einem temperierbaren Roller rotierten. Bei einem Volumen von $10 \mathrm{ml}$ oder mehr wurden die Kulturen in Erlenmeyerkolben unter einer Thermohaube oder in einem Wasserbad unter Schütteln bei $150 \mathrm{Upm}$ inkubiert.

Die optische Dichte der bewachsenen Kultur wurde photometrisch bei $600 \mathrm{~nm}\left(\mathrm{OD}_{600}\right)$ gegen das unbeimpfte Medium bestimmt. Die Zellen wurden davor so verdünnt, daß die $\mathrm{OD}_{600}$ kleiner als 0,8 war. Die tatsächliche Zelldichte wurde dann aus dem gemessenen Wert errechnet.

Bei der Erstellung von Wachstumskurven wurde ein Aliquot aus der Kultur entnommen, wenn nötig in frischem Medium verdünnt und die $\mathrm{OD}_{600}$ bestimmt. Der Rest der Kultur wurde bis zum nächsten Meßpunkt weiter inkubiert.

\subsubsection{Präparation und Transformation kompetenter Escherichia coli Zellen mittels Hitzeschock (INOUE et al., 1990)}

$300 \mathrm{ml}$ SOC-Medium wurden in einem 11 Kolben mit Zellen des entsprechenden Stammes inokuliert und bei $37^{\circ} \mathrm{C}$ und $150 \mathrm{Upm}$ bis zu einer $\mathrm{OD}_{600}$ von $0,4-0,5$ vermehrt. Die Kultur wurde auf Eis abgekühlt und in $50 \mathrm{ml}$ Falcon Röhrchen überführt und durch Zentrifugation (Hettich Rotanta/RPC, $4000 \mathrm{Upm}, 10 \mathrm{~min}, 4^{\circ} \mathrm{C}$ ) pelletiert. Die sedimentierten 
Zellen wurden in $90 \mathrm{ml}$ eiskaltem TFB I-Puffer vorsichtig resuspendiert. Die Bakteriensuspension wurde 10 min auf Eis inkubiert und wie oben beschrieben zentrifugiert. Danach wurde das Pellet in $12 \mathrm{ml}$ eiskaltem TFB II-Puffer resuspendiert und Aliquots zu $200 \mu \mathrm{l}$ in vorgekühlte Eppendorf-Reaktionsgefäße pipettiert. Diese wurden dann bei $-70{ }^{\circ} \mathrm{C}$ gelagert.

Zur Transformation wurden die Zellen auf Eis aufgetaut. Die zu transformierende DNA wurde in einem Volumen von maximal $10 \mu \mathrm{l}$ zugegeben. Nach fünfminütiger Inkubation auf Eis wurde der Transformationsansatz für $45 \mathrm{~s}$ einem Hitzeschock bei $42{ }^{\circ} \mathrm{C}$ ausgesetzt. Anschließend wurde der Transformationsansatz auf Eis abgekühlt und $800 \mu 37^{\circ} \mathrm{C}$ warmes dYT-Medium zugegeben. Zur Ausprägung der Antibiotikaresistenz wurden die Proben $60 \mathrm{~min}$ bei $37^{\circ} \mathrm{C}$ inkubiert und anschließend Aliquots auf Selektivagar ausplattiert.

\subsubsection{Transformation von Escherichia coli durch Elektroporation}

Zur Transformation von E. coli Zellen mit Plasmiden wurde nach der Methode von Dower et al. (DOWER et al., 1988) verfahren. Hierzu wurden die Zellen des entsprechenden Bakterienstammes von einer Agar-Platte in dYT angeimpft und bis zu einer $\mathrm{OD}_{600}$ von 0,4 bis maximal 0,6 vermehrt. Anschießend wurden die Zellen in einem $50 \mathrm{ml}$ Schraubdeckelgefäß pelletiert (Hettich-Kühlzentrifuge Rotanta/RPC, $4000 \mathrm{Upm}, 10 \mathrm{~min}, 4^{\circ} \mathrm{C}$ ). Die Zellen wurden in $30 \mathrm{ml}$ eiskaltem, autoklaviertem, demineralisiertem Wasser resuspendiert und erneut unter denselben Bedingungen pelletiert. Die Waschschritte wurden zweimal wiederholt, wobei beim zweiten Schritt $20 \mathrm{ml}$ und bei dritten Schritt $10 \mathrm{ml}$ Wasser verwendet wurden. Nach dem letzten Zentrifugationsschritt wurden die Zellen in $200 \mu \mathrm{l}-400 \mu \mathrm{l}$ eiskaltem Wasser resuspendiert. Während der gesamten Prozedur wurden die Zellen auf Eis gelagert.

Zur Transformation wurden $100 \mu \mathrm{l}$ der vorbereiteten Zellsuspension mit maximal $10 \mu \mathrm{l}$ DNA-Lösung in auf Eis vorkühlten Elektroporationsküvetten mit $0,2 \mathrm{~cm}$ Plattenabstand gemischt. Die Zellen wurden durch Anlegen eines Spannungspulses (2500 V, 25 $\mu$ F, $200 \Omega$ ) im Gene-Pulser ${ }^{\circledR}$ (BioRad) transformiert. Gleich nach Auslösen des Pulses wurden die Küvetten mit $1 \mathrm{ml}$ sterilem dYT Medium gespült und die Zellen $1 \mathrm{~h}$ bei $37^{\circ} \mathrm{C}$ in sterilen $1,5 \mathrm{ml}$ Reaktionsgefäßen inkubiert. Anschließend wurde zur Bestimmung der Transformantenzahl die Zellsuspension in Verdünnung auf selektive VollmediumsAgarplatten ausgestrichen und über Nacht bei $37^{\circ} \mathrm{C}$ inkubiert.

\subsection{Molekularbiologische Arbeitsmethoden}

Molekularbiologische Arbeitstechniken, die im Folgenden nicht explizit aufgeführt und beschrieben sind, wurden nach SAMBROOK et al., 1989 durchgeführt.

\subsubsection{Reinigung und Präzipitation von DNA}

\subsubsection{Präzipitation von DNA}

DNA wurde aus einer wäßrigen Lösung durch Zugabe von 1/10 Vol. 7 M Ammoniumacetatlösung sowie $3 \mathrm{Vol}$. $96 \%$ Ethanol, Inkubation für $2 \mathrm{~h}$ bei $4{ }^{\circ} \mathrm{C}$ und Zentrifugation 
(13 $000 \mathrm{Upm}, 30 \mathrm{~min}, 4^{\circ} \mathrm{C}$ ) gefällt. Das DNA-haltige Pellet wurde mit $70 \%(\mathrm{v} / \mathrm{v})$ Ethanol gewaschen und erneut unter denselben Bedingungen abzentrifugiert. Die Lösung wurde abgezogen und das Pellet bei $37^{\circ} \mathrm{C}$ oder in der SpeedVac getrocknet.

Eine weitere Möglichkeit war die Präzipitation von DNA mit Isopropanol, wobei hier weniger Salz präzipitiert, was später für empfindliche Anwendungen wie enzymatische Manipulationen von Vorteil sein kann. Hierzu wurde die DNA Lösung mit 0,7 Vol. Isopropanol versetzt und sogleich bei $13000 \mathrm{Upm}$ und $4{ }^{\circ} \mathrm{C}$ für $30 \mathrm{~min}$ abzentrifugiert. Da Isopropanol weniger flüchtig ist als Ethanol, wurde das Pellet stets mit $70{ }^{\circ} \mathrm{C}(\mathrm{v} / \mathrm{v})$ Ethanol gewaschen, die Lösung abgezogen und das Pellet bei $37^{\circ} \mathrm{C}$ oder in der SpeedVac getrocknet.

\subsubsection{Präparation einer Phenol-Lösung nach Grinsted und Bennett (GRINSTED und} BENNETT, 1988)

$500 \mathrm{~g}$ festes Phenol wurden in $130 \mathrm{ml}$ Wasser, 7,5 $\mathrm{ml} 2 \mathrm{~N} \mathrm{NaOH}$ und $6 \mathrm{ml} 1 \mathrm{M}$ Tris-Cl, pH 7,5 gelöst. Nach dem Lösen wurde zum Schutz vor Oxidation 0,1\% (w/v) 8Hydroxychinolin zugegeben. Die Lösung wurde lichtgeschützt gelagert. Die so präparierte Lösung wird als Phenol, und die Mischung aus je $50 \%$ (v/v) Phenol und Chloroform als Phenol/Chloroform bezeichnet.

\subsubsection{Reinigung von DNA in wäßrigen Lösungen durch Extraktion mit Phenol, Phenol/Chloroform oder Chloroform}

Um Proteine oder hydrophobe Bestandteile aus einer DNA-haltigen Lösung zu entfernen, wurde die Lösung mit Phenol und Chloroform extrahiert. Hierzu wurde die Lösung zuerst mit 1 Vol. Phenol versetzt und gründlich mit Hilfe eines Vortex-Mischers gemischt. Um die wäßrige und die organische Phase zu trennen, wurde der Ansatz zentrifugiert (13000 Upm, 5 min, Raumtemperatur). Die obere, wäßrige Phase wurde in ein neues Gefäß überführt und mit 1 Vol. Phenol/Chloroform versetzt. Nach dem Mischen mit dem Vortex-Mischer wurde wie zuvor zentrifugiert und die wäßrige Phase in ein neues Gefäß überführt und einer Chloroform Extraktion, die analog den zuvor beschriebenen Extraktionen durchgeführt wurde, unterzogen. Die letzte Chloroform Extraktion diente der Entfernung von restlichem Phenol.

\subsubsection{Agarosegelelektrophorese von DNA}

Normalerweise erfolgte die Auftrennung von DNA in Agarosegelen unterschiedlicher Konzentrationen (0,8-2 \% Agarose in TBE Puffer). Höher konzentrierte Gele eignen sich besser zur Auftrennung kleinerer Fragmente und umgekehrt. Falls nicht anders spezifiziert wurden $1 \%$ ige Gele benutzt. Die Agarose wurde fest eingewogen, mit TBE auf das gewünschte Volumen aufgefüllt und auf einer Heizplatte aufgekocht. Nach Abkühlen der Lösung auf ca. $50^{\circ} \mathrm{C}$ wurden $0,5 \mu \mathrm{g} / \mathrm{ml}$ Ethidiumbromid zugesetzt. Das Gel wurde in eine Gelschale $(125 \times 80$ x 7,5 mm) gegossen und ein Taschenkamm gesetzt. Nach dem Erstarren des Gels wurde der Taschenkamm entfernt und das Gel in eine mit TBE-Puffer gefüllte 
Elektrophoresekammer gegeben. Es wurde so viel Puffer hinzugefügt, bis das Gel komplett bedeckt war. Alternativ wurden Flachbett-Gelkammern $(100 \times 70 \times 0,5 \mathrm{~mm})$ verwendet, bei denen das Gel direkt in einen abgegrenzten Bereich der Elektrophoresekammer gegossen wurde. Die DNA-Proben wurden mit mindestens 1/5 Vol Sucrosefarbmarker versetzt und in die Geltaschen gefüllt. Die Elektrophorese wurde bei einer Feldstärke zwischen 5 bis $10 \mathrm{~V} / \mathrm{cm}$ durchgeführt. Die aufgetrennten DNA-Fragmente wurden im UV-Durchlicht (302 nm) durch Fluoreszenz des eingelagerten Ethidiumbromids sichtbar gemacht und fotografiert. Zur Längen- und Konzentrationsbestimmung der resultierenden DNA-Banden wurden DNAFragmentlängenstandards (DNA-Konzentration: $100 \mathrm{ng} / \mu \mathrm{l}$ ) verwendet.

Für sehr kleine DNA Fragmente kamen Gele mit 2 \% Agarose und zusätzlich 1 \% HEC (Hydroxy-Ethylzellulose) (PERLMAN et al., 1987) zum Einsatz. Diente die Agarosegelelektrophorese nicht alleine der Analytik, sondern sollten die DNA-Fragmente aus dem Gel aufgereinigt werden, so wurde TAE statt TBE als Puffer verwendet, da sich in TAE Puffer weniger Substanzen befinden, die eine enzymatische Manipulation der DNA unterbinden können (DOWNEY, 2003). Außerdem wurde kein Ethidiumbromid, sondern statt dessen SYBR Green (Molecular Probes) als Fluoreszenzfarbstoff verwendet. Dies hatte vor allem den Grund, das SYBR Green im Vergleich zu Ethidiumbromid ein wesentlich geringeres karzinogenes Potential besitzt (SINGER et al., 1999) und somit die Handhabung der Proben für den Experimentator sicherer macht.

\subsubsection{Isolierung von DNA aus Agarosegelen}

Zur Reinigung von DNA-Fragmenten aus Agarosegelen kamen diverse kommerziell erhältliche Kits zum Einsatz. Ausdrücklich waren dies: das Invisorb Spin DNA Extraction Kit der Firma Invitek, das Nucleotrap-Kit der Firma Macherey \& Nagel, das QIAquick Gel Extraction Kit der Firma Qiagen und das Wizard SV Gel and PCR Cleanup System der Firma Promega. Die DNA wurde mit einem unbenutzten Skalpell aus der Gelmatrix ausgeschnitten, wobei darauf geachtet wurde, die DNA so wenig wie möglich dem UV-Licht auszusetzen. Es wurde anschließend stets nach dem Protokoll der Herstellerfirma verfahren. Schließlich wurde die DNA in $50 \mu \mathrm{l}$ autoklaviertem, demineralisiertem Wasser aufgenommen und für weitere Manipulationen eingesetzt.

\subsubsection{Abtrennung von Oligonukleotiden und kurzen DNA-Fragmenten mit Hilfe des NucleotraPCR-Kits (Macherey \& Nagel)}

Um aus einer komplexen DNA-Lösung Salze, Mono- und Oligonukleotide sowie kurze DNA-Fragmente zu entfernen, kam das NucleotraPCR-Kit der Firma Macherey \& Nagel zum Einsatz. Die NucleotraPCR-Suspension bindet dabei nur DNA-Fragmente mit einer Größe von mehr als $150 \mathrm{bp}$. Es wurde nach dem "direct purification"-Protokoll des Herstellers verfahren und im letzten Schritt des Protokolls die gereinigte DNA mit $50 \mu$ l Wasser eluiert. 


\subsubsection{Isolierung von Plasmid-DNA aus Bakterienzellen}

Zur Präparation von Plasmid-DNA im präparativen Maßstab wurden das JetStar Plasmidpräparations-Kit der Firma Genomed sowie das Qiagen Plasmid Midi Kit verwendet, welche beide auf dem Prinzip der alkalischen Lyse beruhen. Es wurden Zellpellets aus $50 \mathrm{ml}$ Übernachtkulur nach Herstellervorschrift aufgearbeitet.

Die Präparation von Plasmid-DNA im analytischen Maßstab wurde mit Hilfe des Invisorb Spin Plasmid Mini Kit der Firma Invitek oder dem Qiagen QIAprep Spin Miniprep durchgeführt. Hier wurde in der Regel von $2 \mathrm{ml}$ einer stationären Übernachtkultur ausgegangen. Es wurde nach der Vorschrift des Herstellers verfahren.

\subsubsection{Isolierung genomischer DNA aus Pseudomonas aeruginosa}

P. aeruginosa Zellen wurden im S2-Labor der Medizinischen Hochschule Hannover in LB-Medium bis zur stationären Phase vermehrt. Anschließend wurden die Zellen durch Zentrifugation ( $4000 \mathrm{Upm}, 10 \mathrm{~min}, 4^{\circ} \mathrm{C}$ ) pelletiert. Pellets aus jeweils $200 \mathrm{ml}$ Kultur wurden in $50 \mathrm{ml} \mathrm{Schraubdeckelgefäßen} \mathrm{bis} \mathrm{zur} \mathrm{weiteren} \mathrm{Verwendung} \mathrm{bei}-20^{\circ} \mathrm{C}$ eingelagert.

Zur Präparation der genomischen DNA wurden ein Zellpellet aufgetaut und in $19 \mathrm{ml}$ TEPuffer resuspendiert, dem $1 \mathrm{ml} 10 \%$ SDS zugesetzt wurden. Anschließend wurden $100 \mu \mathrm{l}$ $20 \mathrm{mg} / \mathrm{ml}$ Proteinase $\mathrm{K}$ Lösung zu dem Ansatz gegeben und bei $37^{\circ} \mathrm{C}$ im Wasserbad für eine Stunde inkubiert. Hierbei lysierten die Zellen und die Proteinbestandteile wurden enzymatisch abgebaut. Danach wurden dem Ansatz 3,6 $\mathrm{ml} 5 \mathrm{M} \mathrm{NaCl}$ zugeben und gründlich gemischt, wobei die Proteine und Membranbestandteile ausfallen sollten. Diese wurden durch Zentrifugation präzipitiert (Hettich-Kühlzentrifuge Rotanta/RPC, $4000 \mathrm{Upm}, 30 \mathrm{~min}, 4^{\circ} \mathrm{C}$ ). Der wäßrige Überstand wurde in ein neues Gefäß überführt und mit $3 \mathrm{ml} \mathrm{CTAB/NaCl}$ Lösung $(10 \%[\mathrm{w} / \mathrm{v}] \mathrm{CTAB}$ in $0,7 \mathrm{M} \mathrm{NaCl})$ versetzt. Nach einer Inkubation bei $65^{\circ} \mathrm{C}$ im Wasserbad für 20 min wurde 1 Vol. Chloroform zugegeben und gründlich mit dem VortexMischer gemischt. Es folgte ein Zentrifugationsschritt wie oben angegeben. Die wäßrige Phase wurde in ein neues Gefäß überführt und einer Phenol/Chloroform Extraktion unterzogen (3.2.1.3). Schließlich wurde die DNA aus der wäßrigen Lösung mit Isopropanol (3.2.1.1) präzipitiert und mit Hilfe eines Glasstabes aufgewickelt. Nach dem Waschen mit 70 \% Ethanol wurde die DNA getrocknet und in $2 \mathrm{ml}$ TE Puffer aufgenommen. Um hochreine DNA zu erhalten, wurde die genomische DNA schließlich noch mit dem Qiagen Genomic Tip 500/G Kit aufgereinigt.

\subsubsection{Bestimmung der Konzentration von DNA in wäßrigen Lösungen}

Die DNA-Konzentration wurde in einem Kontron Zweistrahl-Spektralphotometer (Uvicon ${ }^{\circledR}$ 960) ermittelt. Für doppelsträngige DNA wurde die Absorption einer verdünnten DNA Lösung bei einer Wellenlänge von $260 \mathrm{~nm}$ in einer Mikroküvette (Hellma, QS 1,000) gegen Wasser gemessen. Eine Absorption von 1,0 entspricht dabei einer Konzentration von $50 \mu \mathrm{g} / \mathrm{ml}$. Durch zusätzliche Messung der Lösung bei $280 \mathrm{~nm}$ konnte eine Aussage über die Reinheit der Lösung gemacht werden. Für eine proteinfreie Desoxysribonukleinsäurelösung sollte das Verhältnis von $\mathrm{OD}_{260} / \mathrm{OD}_{280}$ ungefähr 2:1 sein. Obwohl die photometrische 
Bestimmung der DNA Konzentration allgemeine Anerkennung im Laboralltag erfährt, weiß man mittlerweile, daß die damit gewonnenen Werte relativ starken Schwankungen unterworfen sind. Wilfinger und Kollegen (WILFINGER et al., 1997) konnten zeigen, daß in Abhängigkeit von $\mathrm{pH}-$ Wert und Salzgehalt des verwendeten Wassers ein und derselben DNAPräparation die $\mathrm{OD}_{260} / \mathrm{OD}_{280}$-Verhältnisse und die berechnete Konzentration um bis zu 25\% schwanken.

\subsection{Enzymatische Manipulation von DNA}

\subsubsection{Verdau von DNA mit Restriktionsendonukleasen}

Der enzymatische Verdau von DNA wurde mit Restriktionsendonukleasen unter den vom jeweiligen Hersteller des Enzyms empfohlenen Temperatur- und Pufferbedingungen durchgeführt. Simultane Spaltungen mit mehreren Enzymen wurden unter denjenigen Pufferbedingungen durchgeführt, bei dem jedes eingesetzte Enzym eine Aktivität von mindestens $50 \%$ besaß. War ein Mehrfachverdau aufgrund abweichender Pufferanforderungen nicht möglich, wurden die Verdaus nacheinander unter den vom Hersteller empfohlenen Bedingungen durchgeführt. Die DNA wurde in der Regel in einer Endkonzentration des Spaltungsansatzes von $100 \mathrm{ng} / \mu \mathrm{l}$ mit 1 - 2 Einheiten Enzym pro Mikrogramm DNA für $1 \mathrm{~h}$ inkubiert.

\subsubsection{Auffüllen überhängender DNA-Enden}

Zum Auffüllen von beispielsweise nach Spaltung mit Restriktionsendonukleasen entstehenden überhängenden DNA-Enden wurde T4 DNA-Polymerase verwendet. Hierzu wurde die DNA zusammen mit $100 \mu \mathrm{M}$ dNTPs im vom Hersteller gelieferten Reaktionspuffer für 20 min bei $11^{\circ} \mathrm{C}$ inkubiert. Pro Mikrogramm DNA wurden 5 Units Enzym eingesetzt. Unmittelbar nach Ablauf der Inkubationszeit wurde eine Phenol/Chloroform Extraktion (3.2.1.3) durchgeführt.

\subsubsection{Ligation von DNA-Fragmenten}

Für die Ligation von DNA-Fragmenten wurde ein bis zu fünffacher molarer Überschuß an DNA-Insert-Fragment gegenüber dem DNA-Vektor-Fragment eingestellt. Es wurde ausschließlich T4-DNA Ligase und der von MBI Fermentas mitgelieferte T4-DNA Ligasepuffer verwendet. Im allgemeinen wurden pro Ligation 2-4 Einheiten Ligase in einem Endvolumen von 20 - $40 \mu$ verwendet. Der Ansatz wurde über Nacht bei $15^{\circ} \mathrm{C}$ im Wasserbad inkubiert. Nach der Ligation wurde die T4-Ligase durch eine Phenol/Chloroform-Extraktion (3.2.1.3) inaktiviert. Die DNA wurde vor der Transformation mit Ethanol (3.2.1.1) gefällt und in $10 \mu \mathrm{l}$ sterilem demineralisiertem Wasser aufgenommen. 


\subsubsection{Polymerase-Kettenreaktion (PCR)}

Die Polymerase-Chain-Reaction (PCR) (Mullis und FAlOONA, 1987; SAIKI et al., 1988; SAIKI et al., 1985) ist eine in vitro Methode zur enzymatischen Amplifikation spezifischer DNA-Fragmente. Sie ermöglicht, aus einem komplexen DNA-Gemisch selektiv eine DNAMatrize zu vervielfachen. Im ersten Schritt wird die doppelsträngige DNA durch Erhitzen denaturiert. Im zweiten Schritt, dem Absenken der Temperatur, hybridisieren zwei komplementäre Oligonukleotid-Primer mit der Matrizen-DNA und flankieren die zu amplifizierende Zielregion. Diesen Vorgang bezeichnet man als Annealing. Im dritten Schritt werden die beiden Primer mit Hilfe einer thermostabilen Polymerase bei deren Temperaturoptimum, welches in den meisten Fällen bei $72{ }^{\circ} \mathrm{C}$ liegt, verlängert. Dieser Vorgang wird als Primer-Extension bezeichnet. Es wird eine bestimmte Anzahl an Amplifikationszyklen durchgeführt, wodurch die von den beiden Primern flankierte DNARegion exponentiell vermehrt wird.

Die PCR-Bedingungen mußten je nach Länge der zu amplifizierenden Sequenz, sowie der Länge und des G/C-Gehaltes der verwendeten spezifischen Primer angepaßt werden. Die Reaktionen wurden stets in einem Gesamtvolumen von $50 \mu$ d durchgeführt. Als Matrize wurden ca. 5-10 ng DNA eingesetzt. In die Reaktionsgefäße wurden zuerst $25 \mu$ des Reaktionspuffers und die DNA Matrize gegeben. Die Gefäße wurden mit Mineralöl überschichtet, um die Evaporation der Flüssigkeit während der Amplifikationszyklen zu verhindern. Nachdem der Reaktionsansatz im PCR-Gerät für 2 min auf $98{ }^{\circ} \mathrm{C}$ erhitzt wurde, wurden dem Ansatz noch 2,5 $\mu \mathrm{l}$ des zehnfach konzentrieren Reaktionspuffers, $1 \mu \mathrm{l} 10 \mathrm{mM}$ dNTPs, jeweils $1 \mu \mathrm{l}$ der Primer $(10 \mu \mathrm{M})$ und eine Einheit der thermostabilen Polymerase zugegeben. Das Gesamtvolumen des Ansatzes wurde mit Wasser auf $50 \mu$ l gebracht.

Diese Abwandlung der PCR, bei der die Matrize zuerst denaturiert wird, wird als Hot Start-PCR bezeichnet und ermöglich eine höhere Spezifität durch Vermeidung von PrimerFehlpaarungen (TAYLOR et al., 1997). Im allgemeinen wurde dieser der Vorzug gegenüber der konventionellen PCR gegeben.

Die Länge und die Temperatur der einzelnen Reaktionsschritte der PCR-Zyklen, sowie deren Anzahl wurde durch die Wahl der Matrize, die Basenzusammensetzung, Länge der Primer und durch die Länge der $\mathrm{zu}$ amplifizierenden Sequenz bestimmt. Die Elongationsreaktion (Primer-Extension) wurde bei $72^{\circ} \mathrm{C}$ für $60 \mathrm{~s}$ pro $1000 \mathrm{bp}$ durchgeführt. Die Anzahl der Zyklen betrug zwischen 20 und 30. Die Schmelztemperatur $T_{M}$ eines Oligonukleotids wurde nach folgender empirischer Formel (3.1) berechnet, welche sowohl den relativen G/C-Gehalt (\% G/C) als auch die Länge der Oligonukleotide ( $n$ ) berücksichtigt:

$$
T_{M}\left[{ }^{\circ} \mathrm{C}\right]=69,3+0,41 \cdot(\% \mathrm{G} / \mathrm{C})-\frac{650}{n}
$$

Die errechnete Temperatur lag in der Regel zwischen $45^{\circ} \mathrm{C}$ und $60^{\circ} \mathrm{C}$. Die optimale Annealing-Temperatur $T_{A}$ für eine Polymerasekettenreaktion wurde nach (3.2) bestimmt: 


$$
T_{A}=\frac{\left(\mathrm{T}_{\mathrm{M} 1}+\mathrm{T}_{\mathrm{M} 2}\right)}{2}-3^{\circ} \mathrm{C}
$$

$T_{M 1}$ und $T_{M 2}$ stehen dabei für die Schmelztemperaturen der beiden verwendeten Primer. Die PCR wurde in einem Minicycler (MJ Research) oder einem Primus 96 Thermocycler (MWG Biotech) durchgeführt.

\subsubsection{Klonierung von PCR Produkten in mittels TOPO TA Cloning Kit}

Das TOPO TA Cloning Kit der Firma Invitrogen kann für die direkte Klonierung von PCR-Produkten, die mit Taq DNA Polymerase erzeugt worden sind, eingesetzt werden. Diese Polymerase besitzt eine matritzenunabhängige terminale Transferase-Aktivität, die einzelne Desoxyadenosine an die 3' Termini der PCR-Produkte anfügt. Der linearisierte Vektor pCR4TOPO, der in dieser Arbeit zum Einsatz kam, verfügt über einzelne DesoxythimidinÜberhänge an seinen 3' Termini. Somit kann das PCR Produkt mit dem linearisierten Vektor hybridisieren. Der Kern dieser Technologie ist der Einsatz der Topoisomerase I des Vaccinia Virus, die an Duplex DNA an spezifischen Stellen bindet und das Phosphodiestherrückrat der DNA nach der Sequenz 5'-CCCTT in einem Strang spaltet (SHUMAN, 1991). Die Energie des gespaltenes Phosphodiestherrückrads wird durch die Bildung einer kovalenten Bindung zwischen dem 3' Phosphat des gespaltenen Stranges und einem Tyrosyl Restes des Enzyms konserviert. Diese Phospho-Tyrosyl Bindung kann von dem 5'-Hydroxyl des originalen gespaltenen DNA Stranges oder des hybridisierten PCR Produktes angegriffen werden, was zu einer Reversion der Reaktion und dem Ablösen der Topoisomerase führt (SHUMAN, 1994). Weiterhin macht das Plasmid pCR4-TOPO von einem positiven Selektionsmechanismus Gebrauch, der auf der Disruption des letalen Escherichia coli Gens $c c d B$, welches an lacZ fusioniert ist, basiert (BERNARD und COUTURIER, 1992; BERNARD et al., 1994; BERNARD et al., 1993). Durch die Ligation des PCR-Produktes wird die Expression dieses Fusionsgens unterbunden und eine positive Selektion von Transformanten ermöglicht.

In der Praxis ist diese Methode eine sehr schnelle, einfache und effiziente Möglichkeit der Ligation von PCR Produkten. Nach der enzymatischen Synthese des PCR Produktes wurde dieses durch Phenol/Chloroform Extraktion (3.2.1.3) und Ethanolpräzipitation (3.2.1.1) gereinigt. Anschließend wurde ein Ansatz bestehend aus 0,5 $\mu \mathrm{l}$ des pCR4-Plasmides, 0,5 $\mu \mathrm{l}$ des 1:4 (v/v) in Wasser verdünntem Reaktionspuffers und $2 \mu \mathrm{l}$ des PCR Produktes für 5 min bei Raumtemperatur inkubiert. Es erfolgte eine unmittelbar anschließende Transformation von elektrokompetenten Zellen (3.1.4).

\subsection{Proteinchemische und präparative Arbeitsmethoden}

\subsubsection{Bestimmung der Konzentration von Proteinen in einer wäßrigen Lösung}

Die Proteinkonzentration einer wäßrigen Proteinlösung wurde photometrisch bei einer Wellenlänge von $280 \mathrm{~nm}$ gegen das Lösungsmittel bestimmt. Die aromatischen Aminosäureseitenketten des Proteins sowie die vorhandenen Disulfidbrücken sind an der 
Absorption des Lichtes wesentlich beteiligt. Tryptophanreste haben hierbei den höchsten molaren Extinktionskoeffizienten von $5500 \mathrm{M}^{-1} \mathrm{~cm}^{-1}$, gefolgt von Tyrosinresten mit $1490 \mathrm{M}^{-1} \mathrm{~cm}^{-1}$ und Disulfidbrücken mit $125 \mathrm{M}^{-1} \mathrm{~cm}^{-1}$.

Ist die Zusammensetzung des Proteins bekannt, so kann der molare Extinktionskoeffizient durch folgende Gleichung (PACE et al., 1995) (3.3) berechnet werden:

$$
\varepsilon(\operatorname{Protein})=5500 *\left[\sum \operatorname{Trp}\right]+1490 *\left[\sum \text { Tyr }\right]+125 *\left[\sum \text { Disulfid }\right]
$$

Mit Hilfe des so berechneten molaren Extinktionskoeffizienten konnte die Konzentration der Proteine aus der gemessenen Absorption bei $280 \mathrm{~nm}$ berechnet werden.

\subsubsection{Präparation von Proteinen der Membranen von Escherichia coli Zellen (verändert nach KLAUSER et al., 1992)}

Zur Gewinnung der Proteinfraktion der Membranen von Escherichia coli wurden die in der logarithmischen Wachstumsphase befindlichen Bakterienzellen einer $50 \mathrm{ml}$ Kultur bei einer O.D. 600 von 0,8 mit Induktor versetzt, weitere drei Stunden bei $37^{\circ} \mathrm{C}$ kultiviert und schließlich durch Zentrifugation geerntet (Hettich-Kühlzentrifuge Rotanta/RPC, $4000 \mathrm{Upm}$, $10 \mathrm{~min}, 4^{\circ} \mathrm{C}$ ). Die Zellen wurden in $10 \mathrm{ml}$ PBS resuspendiert und mit dem CellDisruptor (Constant Systems Ltd.) bei einem Druck von 1,5 kbar aufgeschlossen. Das so erhaltene Lysat wurde in einem $50 \mathrm{ml}$ Schraubdeckelgefäß für $10 \mathrm{~min}$ bei $4000 \mathrm{Upm}$ und $4{ }^{\circ} \mathrm{C}$ zentrifugiert, um noch intakte Zellen zu entfernen. Der Überstand wurde mit $100 \mathrm{mM}$ Tris-Cl pH 8, $10 \mathrm{mM}$ EDTA, $1 \%(\mathrm{v} / \mathrm{v})$ Triton-X 100 (Endkonzentrationen) versetzt und der Ansatz für 30 min auf Eis inkubiert. Anschließend wurde die Lösung in ein $13 \mathrm{ml}$ Ultrazentrifugenröhrchen überführt, das Röhrchen gegebenenfalls mit PBS aufgefüllt und der Ansatz mit Paraffin überschichtet. Das Röhrchen wurde tariert, in den TST41-14 Schwenkbecherrotor geladen und in der Kontron Centrikon T-1055 Ultrazentrifuge im Vakuum zentrifugiert (100.000 x $g$, $\left.2 \mathrm{~h}, 15^{\circ} \mathrm{C}\right)$. Die im Pellet vorliegenden Proteine der Membran wurden mit $200 \mu \mathrm{l}$ ProteinProbenpuffer oder Hoechst-Puffer versetzt und durch Ultraschallbehandlung (Branson Sonifier W-250, 10-15 mal, $40 \%$, Stufe 2) gelöst und anschließend für $10 \mathrm{~min}$ auf $98^{\circ} \mathrm{C}$ erhitzt. Unlösliche Bestandteile wurden durch Zentrifugation (13.000 Upm, $5 \mathrm{~min}, 4^{\circ} \mathrm{C}$ ) pelletiert und der Überstand durch Polyacrylamidgelelektrophorese analysiert.

\subsubsection{Isolierung von periplasmatischen Proteinen aus Escherichia coli}

Zur Präparation periplasmatischer Proteine wurden $50 \mathrm{ml}$ dYT-Medium mit dem entsprechenden Stamm inokuliert und bei Erreichen einer $\mathrm{OD}_{600}$ von 0,2-0,4 die Proteinexpression induziert. Nach ca. 15 Stunden Wachstum bei $37{ }^{\circ} \mathrm{C}$ wurden die Zellen durch Zentrifugation geerntet (Hettich-Kühlzentrifuge Rotanta/RPC, $4000 \mathrm{Upm}, 10 \mathrm{~min}$, $4{ }^{\circ} \mathrm{C}$ ) und in $2 \mathrm{ml}$ eiskaltem Periprep-Puffer I auf Eis resuspendiert. Es folgte eine Inkubation

auf Eis für $30 \mathrm{~min}$, bevor die Zellen abermals abzentrifugiert (Hettich-Kühlzentrifuge Rotanta/RPC, $4000 \mathrm{Upm}, 10 \mathrm{~min}, 4^{\circ} \mathrm{C}$ ) wurden. Das Pellet wurde in $2 \mathrm{ml}$ Periprep-Puffer II 
aufgenommen und für 30 min auf Eis inkubiert. Durch den osmotischen Schock platzt die äußere Membran und entläßt den Inhalt des Periplasmas ins Medium. Die Zelltrümmer wurden abzentrifugiert (14000 Upm, $1 \mathrm{~min}, 4^{\circ} \mathrm{C}$ ) und der proteinhaltige Überstand wurde in ein frisches Reaktionsgefäß überführt, worin er bis zur Analyse bei $-20^{\circ} \mathrm{C}$ eingefroren wurde.

\subsubsection{Gewinnung von Gesamtzellextrakt von E. coli Zellen}

Zur Gewinnung von Gesamtzellextrakt von E. coli wurden die Bakterien einer für $3 \mathrm{~h}$ induzierten $50 \mathrm{ml}$ Kultur durch Zentrifugation geerntet (Hettich-Kühlzentrifuge Rotanta/RPC, $4000 \mathrm{Upm}, 10 \mathrm{~min}, \mathrm{RT}$ ). Das Zellpellet wurde in $2 \mathrm{ml}$ PBS resuspendiert und bei $-70{ }^{\circ} \mathrm{C}$ eingefroren. Nach dem Wiederauftauen wurden die Zellen mit Ultraschall (Branson Sonifier W-250, 10-15 mal, $40 \%$, Stufe 2) auf Eis aufgeschlossen. Zur Entfernung von Zelltrümmern wurde der Extrakt abschließend zentrifugiert (14000 Upm, $5 \mathrm{~min}, 4^{\circ} \mathrm{C}$ ). Der Überstand wurde in ein neues Reaktionsgefäß überführt.

\subsubsection{Gewinnung von Gesamtzellextrakt von $P$. aeruginosa Zellen}

Zur Gewinnung von Gesamtzellextrakt von Pseudomonas aeruginosa wurden die Bakterien einer $500 \mathrm{ml}$ Kultur in LB-Medium durch Zentrifugation geerntet (HettichKühlzentrifuge Rotanta/RPC, $4000 \mathrm{Upm}, 10 \mathrm{~min}, \mathrm{RT}$ ). Das Zellpellet wurde in $10 \mathrm{ml}$ sterilem Wasser resuspendiert und bei $-70{ }^{\circ} \mathrm{C}$ eingefroren. Nach dem Wiederauftauen wurden die Zellen mit Ultraschall (Branson Sonifier W-250, 10-15 mal, $40 \%$, Stufe 2) auf Eis aufgeschlossen. Zur Entfernung von Zelltrümmern wurde der Extrakt abschließend zentrifugiert (14000 Upm, $5 \mathrm{~min}, 4^{\circ} \mathrm{C}$ ). Der Überstand wurde in ein neues Reaktionsgefäß überführt. Die Lysate wurden in verschlossenen Gefäßen unter Luftausschluß bis zur weiteren Verwendung auf Eis gelagert.

\subsubsection{Denaturierende Polyacrylamidgelelektrophorese (SDS-PAGE)}

Proteine lassen sich unter denaturierenden Bedingungen über SDS-haltige Polyacrylamidgele der Größe nach auftrennen (LAEMMLI, 1970). Die hergestellten Gele hatten eine Größe von 100 x 60 × 0,75 mm. Es wurden sowohl 12,5\%ige als auch $15 \%$ ige (w/v) SDSPolyacrylamidgele verwendet.

\subsubsection{Herstellung der Polyacrylamidgele}

In dem verwendeten Gelgießstand wurden in der Regel 10 Polyacrylamidgele gleichzeitig hergestellt. Die Gele wurden zwischen eine Aluminiumoxid- und eine Glasplatte gegossen. Für das 12,5\%ige Trenngel wurden 27,6 ml $30 \%(w / v)$ Acrylamid/Bisacrylamid (29:1, Protogel), 14,4 ml Trenngelpuffer, $720 \mu \mathrm{l} 10 \%$ (w/v) SDS, 27,2 ml Wasser, $40 \mu \mathrm{l}$ TEMED und zuletzt $240 \mu \mathrm{l}$ APS-Stammlösung vermischt und bis zu einer Höhe von ca. $5 \mathrm{~cm}$ in den Gelgießstand gegossen. Für das 15 \%ige Trenngel wurden $45 \mathrm{ml} 30 \%(\mathrm{w} / \mathrm{v})$ Acrylamid/Bisacrylamid (29:1, Protogel), $18 \mathrm{ml}$ Trenngelpuffer, $900 \mu \mathrm{l} 10 \%$ (w/v) SDS, 
25,8 ml Wasser, $45 \mu \mathrm{l}$ TEMED und zuletzt $300 \mu \mathrm{l}$ APS-Stammlösung eingesetzt. Jedes Gel wurde mit $500 \mu \mathrm{l}$ Isopropanol überschichtet, damit sich eine ebene Oberfläche ergab. Nach vollständiger Polymerisation des Acrylamids wurde das Isopropanol abgegossen. Für das verwendete Sammelgel wurden 4,48 ml 30 \% (w/v) Acrylamid/Bisacrylamid (29:1, Protogel), 2,8 ml Sammelgelpuffer, 0,56 $\mu \mathrm{l} 10 \%$ (w/v) SDS, 20,4 $\mathrm{ml}$ Wasser, $30 \mu \mathrm{l}$ TEMED und zuletzt $100 \mu \mathrm{l}$ APS-Stammlösung zusammengegeben. Jedes Gel wurde bis zur Oberkante des Gelgießstands befüllt, zuletzt wurden die Taschenkämme eingebracht. Nach vollständiger Polymerisation wurden die Gele aus dem Gelgießstand entfernt, einzeln in mit demineralisiertem Wasser befeuchtete Papiertücher eingeschlagen und gemeinsam in Plastiktüten verpackt. In dieser Form wurden die Gele für einige Wochen bei $4{ }^{\circ} \mathrm{C}$ gelagert.

\subsubsection{Durchführung der SDS-Polyacrylamidgelelektrophorese}

Das Polyacrylamidgel wurde in die Laufkammer eingesetzt und die Kammer mit Laemmli-Puffer befüllt. Der Taschenkamm wurde entfernt und die Proben wurden, mit 1/2 bis $1 \mathrm{Vol}$ Hoechstpuffer versetzt, in die Geltaschen gefüllt. Als Protein-Molekulargewichtsstandard kam die Protein Ladder der Firma MBI Fermentas zum Einsatz. Die Elektroden wurden mit der Stromversorgung verbunden. Die Elektrophorese wurde bis zum Durchlauf der Farbmarkerbande konstant bei $6 \mathrm{~W}$ Leistung pro Gel durchgeführt. Nach dem Lauf wurde das Gel zwischen den Platten herausgeholt und die Proteine durch Färbung mit einer Lösung aus $10 \mathrm{ml}$ PAG Färbelösung und $10 \mathrm{ml} 10 \%$ iger (v/v) Essigsäure sichtbar gemacht. Hierzu wurde das Gel für $10 \mathrm{~min}$ in der Färbelösung geschwenkt und diese anschließend durch Kochen in einem Mikrowellenherd wieder aus dem Gelmaterial entfernt, wobei die Proteinbanden sichtbar wurden. Optional konnte das Gel auch durch Schwenken in einer Entfärbelösung, bestehend aus $30 \%(\mathrm{v} / \mathrm{v})$ Ethanol und $10 \%$ (v/v) Essigsäure entfärbt werden.

\subsubsection{Nachweis von Proteinen auf Nitrozellulose-Membranen (Westernblot)}

Zum Nachweis von mit SDS-Gelen aufgetrennten Proteinen wurden diese mittels Elektrotransfer auf eine Nitrozellulose-Membran übertragen (Fa. Schleicher \& Schuell). Hierzu wurde ein Filterpapier (Fa. Schleicher \& Schuell) in der Größe des Polyacrylamidgels zugeschnitten, mit Westernblot-Transferpuffer getränkt und auf die Graphitanode einer Novoblot-Apparatur (LKB Bromma) gelegt. Auf das Filterpapier wurde die auf Gelgröße zugeschnittene Nitrozellulose-Membran gelegt, welche zuvor ebenfalls in WesternblotTransferpuffer getränkt worden war. Das die Proteine enthaltende Polyacrylamidgel wurde in Westernblot-Transferpuffer geschwenkt und in nassem Zustand auf die Nitrozellulose gelegt. Ein weiteres Filterpapier, auf Gelgröße zugeschnitten, wurde, ebenfalls getränkt, darauf gelegt. Es folgte das Aufsetzen der Kathode und der Elektrotransfer der Proteine auf die Membran. Die Proteine wurden für ca. $1 \mathrm{~h}$ bei einer konstanten Spannung von $10 \mathrm{~V}$ aus dem Gel auf die Nitrozellulose transferiert. Nach dem Transfer wurde die Apparatur auseinandergebaut und die Membran für 3 min mit Ponceau S-Färbelösung inkubiert, wodurch die gebundenen Proteine sichtbar wurden. Mit einem Bleistift wurden die Markerbanden angezeichnet, bevor die Membran zweimal für je $10 \mathrm{~min}$ mit $20 \mathrm{ml}$ PBS-Puffer gewaschen wurde. Anschließend 
wurde für $1 \mathrm{~h}$ in $20 \mathrm{ml}$ PBS mit $2 \%$ BSA unter leichtem Schwenken inkubiert, bevor dreimal $10 \mathrm{~min}$ mit je $20 \mathrm{ml}$ PBST gewaschen wurde. Es folgte eine einstündige Inkubation der Membran mit dem ersten Antikörper, welcher 1/10000 mit PBS in einem Endvolumen von $20 \mathrm{ml}$ verdünnt worden war. Nach dreimaligem Waschen mit PBST folgte eine einstündige Inkubation der Membran mit dem zweiten, an Alkalische Phosphatase gekoppelten Antikörper, welcher 1/10000 mit PBS-Puffer in einem Endvolumen von $20 \mathrm{ml}$ verdünnt worden war. Nach erneut dreimaligem Waschen mit PBST wurde der Westernblot entwickelt. Dazu wurde die Membran mit einer Lösung aus 12,5 $\mu$ l NBT und $75 \mu \mathrm{l}$ BCIP in $20 \mathrm{ml}$ APPuffer solange inkubiert, bis Banden zu sehen waren. Die Farbreaktion wurde durch mehrmaliges Waschen mit demineralisiertem Wasser abgestoppt. Zur Dokumentation des Ergebnisses wurde die Membran gescannt oder fotografiert.

\subsubsection{Aufreinigung von Proteinen über immobilisierte Metallionen- Affinitätschromatographie (IMAC)}

Proteine, welche ein terminales Oligohistidinanhängsel aufwiesen, konnten über immobilisierte Metallionen-Affinitätschromatographie (IMAC) aufgereinigt werden. Dazu wurden $4 \mathrm{ml}$ Chelating Sepaharose (Pharmacia) in eine $15 \mathrm{ml}$ Säule (Durchmesser $12 \mathrm{~mm}$ ) mit vorgelegter Fritte gegeben und nach Sedimentation der Sepharose die Säulenmatrix mit ca. $100 \mathrm{ml}$ Wasser gewaschen. $10 \mathrm{ml} 100 \mathrm{mM} \mathrm{NiCl}_{2}$-Lösung wurden auf die Säule gebracht, welche anschließend mit $2 \times 10 \mathrm{ml}$ Wasser und $10 \mathrm{ml}$ IMAC I Puffer gewaschen und äquilibriert wurde.

Die Zellen aus einer induzierten $1000 \mathrm{ml}$ Übernachtkultur wurden durch Zentrifugation (Hettich-Kühlzentrifuge Roto/Silenta, $4000 \mathrm{Upm}, 10 \mathrm{~min}, 4^{\circ} \mathrm{C}$ ) geerntet. Das Pellet wurde in $25 \mathrm{ml}$ IMAC I Puffer resuspendiert und die Zellen wurden mit dem CellDisruptor (Constant Systems Ltd.) bei 1500 bar aufgeschlossen. Die Zelltrümmer wurden anschließend durch Zentrifugation in einem SS34 Zentrifugenröhrchen bei 13000 UPM und $4{ }^{\circ} \mathrm{C}$ für 15 min pelletiert. Der proteinhaltige Überstand wurde auf die Säule aufgetragen. Die Säule wurde mit $2 \times 10$ ml IMAC I-Puffer gewaschen und anschließend die schrittweise Elution gebundener Proteine vollzogen. Eluiert wurde mit steigender Konzentration von Imidazol in IMACPuffer. Es wurde mit je $10 \mathrm{ml} 20 \mathrm{mM}, 40 \mathrm{mM}, 60 \mathrm{mM}, 100 \mathrm{mM}, 200 \mathrm{mM}$ und $500 \mathrm{mM}$ Imidazol eluiert. Aliquots der Fraktionen wurden mit SDS-PAGE analysiert. Die Säulenmatrix wurde mit $2 \times 10 \mathrm{ml}$ 0,5 M EDTA, pH 9,0 regeneriert und mit reichlich Wasser gewaschen, bevor sie wiederverwendet werden konnte.

\subsubsection{Aufreinigung von Proteinen über Anionenaustauscher-Chromatographie}

Die Aufreinigung von Proteinen über Anionenaustauscher-Chromatographie wurde auf der BioCad Vision Workstation durchgeführt, die eine automatisierte Reinigung erlaubt. Das gelöste Protein, das zuvor durch eine immobilisierte Metallionen-Affinitätschromatographie (IMAC) (siehe 3.4.8) gewonnen worden war, wurde zuerst durch Dialyse in einen geeigneten Puffer überführt. Dies war in diesem Fall $50 \mathrm{mM}$ Tris-Cl, pH 8,0, der auch als Laufpuffer in der Chromatographie eingesetzt wurde. Das Protein wurde auf eine Anionenaustauschersäule 
gepumpt (MonoQ, Amersham-Pharmacia). Es erfolgte ein Waschschritt mit 5 Säulenvolumen Laufpuffer. Anschließend wurde das Protein mit einem zweiphasigen Salzgradienten von der Säule eluiert. In der ersten Phase wurde die NaCl-Konzentration innerhalb von 24 Minuten von $0 \mathrm{M}$ auf $0,75 \mathrm{M}$ erhöht. In der zweiten Phase wurde die Salzkonzentration innerhalb von 12 Minuten von $0,75 \mathrm{M}$ auf 1,5 M erhöht. Der Gradient wurde erzeugt, indem Puffer A (50 mM Tris-Cl, pH 8,0) mit Puffer B (50 mM Tris-Cl, pH 8,0, $3 \mathrm{M} \mathrm{NaCl}$ ) gemischt wurde. Die Elutionsfraktionen wurde mit Hilfe eines automatisierten Fraktionssammlers aufgefangen. Anhand des Chromatogramms konnte bestimmt werden, in welchen Fraktionen sich Protein befand, diese Fraktionen wurden dann durch SDS-PAGE analysiert.

\subsubsection{Dialyse und Konzentration von Proteinlösungen}

Nach der SDS-PAGE Analyse wurden diejenigen Fraktionen, welche das gereinigte Protein enthielten, in einen Dialyseschlauch (Visking, Fa. Roth) transferiert und über Nacht im Kühlraum gegen ein mindestens hundertfaches Volumen des gewünschten Puffers dialysiert. Nach der Dialyse wurden die Proteine mit den kommerziell erhältlichen Proteinkonzentratoren VivaSpin (Fa. Sartorius) oder Centriprep (Fa. Millipore) in einer Hettich-Kühlzentrifuge Rotanta/RPC bei $4{ }^{\circ} \mathrm{C}$ und einer relativen Zentrifugalbeschleunigung von $3000 \mathrm{x} g$ so lange zentrifugiert, bis das gewünschte Endvolumen erreicht worden war.

\subsubsection{Dauerhafte Lagerung von Proteinen}

Zur dauerhaften Lagerung der gereinigten Proteine wurde die wäßrige Lösung in flüssigen Stickstoff getropft. Die so entstanden Kugeln wurden in einem fest verschlossenen Plastikgefäß bei $-70^{\circ} \mathrm{C}$ gelagert und bei Bedarf in der benötigten Menge entnommen.

\subsection{Zellbiologische Arbeitsmethoden}

\subsubsection{Induktion der Expression in Bakterienkulturen}

Im Rahmen dieser Arbeit kamen Plasmide zum Einsatz, welche die regulierte Expression kodierter Gene erlauben. Verwendet wurde die lac-Promotor/Operatorregion, die tet $A$ Promotor/Operatorregion sowie ein T7-Promotor kombiniert mit einem lac-Operator.

Die Induktion der Transkription vom lac-Promotor aus wurde durch Zugabe von IPTG in einer Endkonzentration von $1 \mathrm{mM}$ zu einer in der logarithmischen Wachstumsphase befindlichen Kultur von E. coli erreicht. Es folgte in der Regel das weitere Wachstum bis in die stationäre Wachstumsphase.

Die Expression ausgehend vom tetA-Promotor/Operator wurde in der Regel durch Zugabe von Anhydrotetrazyklin, welches auf E.coli im Gegensatz zu Tetrazyklin nicht antibiotisch wirkt, induziert. Für die Expression von Intimin-Fusionsprotein von pASK75Derivaten (SKERRA, 1994) aus wurde dYT-Medium mit dem das entsprechende Expressionsplasmid enthaltenden Stamm inokuliert und bei $37^{\circ} \mathrm{C}$ bis zu einer $\mathrm{OD}_{600}$ von 0,2 bis 0,3 inkubiert und mit $0,2 \mu \mathrm{g} / \mathrm{ml}$ Anhydrotetrazyklin für $60 \mathrm{~min}$ induziert. Für die 
Expression von Fusionsproteinen, welche später aus den Zellen aufgereinigt werden sollten, wurden die Zellen bis in die stationäre Phase vermehrt.

Die Expression in 71-18mutS (KRAMER et al., 1984) wurde in der Regel durch Zugabe von Tetrazyklin mit einer Endkonzentration von $12,5 \mu \mathrm{g} / \mathrm{ml}$ induziert. Das in diesem Stamm integrierte Transposon Tn10 vermittelt den Zellen eine Resistenz gegen dieses Antibiotikum. Besonders bei gewünschter längerer Induktionszeit von bis zu 48 h Dauer kam dieser Stamm zu Anwendung. Die höhere Stabilität von Tetrazyklin gegenüber Anhydrotetrazyklin bei $37^{\circ} \mathrm{C}$ erlaubt längere Induktionszeiten.

Die Expression von Genen mit dem T7-Promotor erfolgte in dem Stamm BL21(DE3) (GrodBerg und DunN, 1988), welcher eine im Genom integrierte T7 RNA Polymerase besitzt, die wiederum unter der Kontrolle des lac-Promotors steht. Durch Zugabe von $1 \mathrm{mM}$ IPTG zu einer Bakterienzellkultur bei einer $\mathrm{OD}_{600}$ von 0,8-0,9 wurde die Expression des T7RNA-Polymerasegens induziert, was die Transkription des Gens, welches unter der Kontrolle des T7-Promotors stand, bewirkte. Im Regelfall erfolgte weiteres Wachstum bis in die stationäre Phase.

\subsubsection{Behandlung von Zellen mit Trypsin und Permeabilisierung}

Die Zellen wurden nach der Induktion bei einer $\mathrm{OD}_{600}$ von 0,8 (3.5.1) noch weitere $3 \mathrm{~h}$ vermehrt. Anschließend wurden die Zellen durch Zentrifugation (Hettich-Kühlzentrifuge Rotanta/RPC, $4000 \mathrm{Upm}, 10 \mathrm{~min}, 4^{\circ} \mathrm{C}$ ) pelletiert und in PBS resuspendiert. Die Suspension wurde auf eine $\mathrm{OD}_{600}$ von 10 eingestellt und für $10 \mathrm{~min}$ bei $37^{\circ} \mathrm{C}$ mit $50 \mu \mathrm{g} / \mathrm{ml}$ Trypsin inkubiert. Um das Trypsin nach der Reaktion zu entfernen, wurden die Zellen mehrfach mit PBS gewaschen und wie oben zentrifugiert. Die äußere Membran der Zellen konnte vor der Behandlung mit Trypsin permeabilisiert werden, indem die Zellen für eine Stunde in $200 \mathrm{mM}$ Tris-HCl, pH 9,0, 100 mM EDTA, 20 \% (w/v) Saccharose auf Eis inkubiert wurden.

\subsubsection{Fluoreszenzmarkierung von Escherichia coli Zellen und Mikroskopie}

Je nach Zelldichte wurden bis zu $800 \mu \mathrm{l}$ einer induzierten Bakterienkultur in einem 1,5 ml Reaktionsgefäß abzentrifugiert (13000 Upm, 1 min, RT). Das Pellet wurde mit $500 \mu \mathrm{l}$ sterilem PBS gewaschen, in $10 \mu \mathrm{l}$ PBS aufgenommen, mit $1 \mu \mathrm{l}$ primärem Antikörper aus der Maus (Anti-Sendai Antikörper (EInBERger et al., 1990) oder Anti-E-Tag Antikörper (Amersham Pharmacia)) oder dem Kaninchen versetzt und für 10 min bei RT inkubiert. Nach Zugabe von $500 \mu \mathrm{l}$ PBS wurden die Zellen zentrifugiert, in $10 \mu \mathrm{l}$ eines Anti-Maus oder Anti-Kaninchen IgG (whole molecule)-Biotin-Konjugates (Sigma), das 1:10 in PBS verdünnt war, aufgenommen und für 10 min bei RT inkubiert. Die Zellen wurden durch Zugabe von $500 \mu \mathrm{l}$ PBS gewaschen, in $10 \mu \mathrm{l}$ mit 1:10 in PBS verdünntem Streptavidin, R-Phycoerythrin-Konjugat aufgenommen und für 10 min bei Raumtemperatur inkubiert. Die Inkubation erfolgte im Dunkeln um ein Ausbleichen des R-Phycoerythrins zu vermeiden. Die Zellen wurden im Anschluß erneut mit $500 \mu \mathrm{l}$ PBS gewaschen, bevor sie nach der letzten Zentrifugation (13000 Upm, $1 \mathrm{~min}, \mathrm{RT}$ ) in $20 \mu \mathrm{l}$ sterilem PBS-Puffer aufgenommen wurden. $10 \mu \mathrm{l} \mathrm{der}$ 
fluoreszenzmarkierten Zellen wurden in ca. $3 \mathrm{ml}$ sterilem PBS-Puffer in einem $5 \mathrm{ml}$-Röhrchen für die FACS-Sortierung bzw. FACS-Analyse verdünnt und der Rest als Rücklage auf Eis im Dunkeln gelagert. Sollten die Zellen im Fluoreszenzmikroskop betrachtet werden, so wurde $1 \mu \mathrm{l}$ auf einen Objektträger gegeben, mit einem Deckglas bedeckt und unter dem Zeiss Axioscope Fluoreszenzmikroskop unter Verwendung des Zeiss-Filtersatzes 487715 untersucht.

\subsubsection{Durchflusszytometrie und fluoreszenzaktivierte Zellsortierung von Escherichia coli Zellen}

Für durchflusszytometrische Untersuchungen und fluoreszenzaktivierte Zellsortierungen wurde der MoFlo der Firma Cytomation verwendet. Es wurden nach 3.5.3 präparierte Zellen herangezogen. Der Strahlengang des FACS wurde unter Verwendung fluoreszierender MicroBeads (Fa. Coulter) justiert und fokussiert und die Photomultiplier wurden auf die Werte 730 (side scatter), 600 (FITC-Fluoreszenz), 600 (Phycoerythrin-Fluoreszenz) eingestellt. Die Anzahl der Ereignisse wurde bei einer Tropfenzahl zwischen 95.000 und 100.000 pro Sekunde auf maximal 30.000 pro Sekunde begrenzt. Der Hintergrundwert betrug in keinem Fall mehr als 100 Ereignisse pro Sekunde (0,3 \%). Es wurden in der Regel 300.000 Ereignisse vermessen. Die Datenverwaltung erfolgte mit dem Softwarepaket CyClops. Die weitere Aufbereitung der gewonnen Daten wurde mit dem Programm SigmaPlot (SPSS Inc.) durchgeführt.

Sollte eine Sortierung durchgeführt werden, wurde zusätzlich zur Justierung des Strahlengangs und des Flüssigkeitsstrahls auch noch der Tropfenabrißpunkt eingestellt und die Tropfenverzögerung bestimmt und kalibriert. Je nach Anreicherungsgrad wurde im single-sort- oder enrich-Modus sortiert, um nach Bedarf negative von positiven Ereignissen scharf oder weniger scharf voneinander abzutrennen. Die positiven Zellen konnten entweder in $5 \mathrm{ml}$ Röhrchen sortiert werden oder mit Hilfe des CyClone-Einzelablagearms auf Agarplatten abgelegt werden. Die Frequenz der Ereignisse betrug zwischen 5.000 und 25.000 pro Sekunde bei einem Druck im Probenröhrchen zwischen 59 und 61 psi.

\subsubsection{Verwendung eines Acyl-Homoserinlacton-Monitorstammes zur Wahrnehmung von AHLs im Medium}

Der Stamm Pseudomonas putida (pKR-C12) (RIEDEL et al., 2001) wurde in $50 \mathrm{ml}$ LBMedium, das mit $20 \mu \mathrm{g} / \mathrm{ml}$ Gentamycin komplettiert war, bei $30^{\circ} \mathrm{C}$ inokuliert. Nach 3 Stunden wurde die Zellkultur in Aliquots von jeweils $3 \mathrm{ml}$ aufgeteilt. $\mathrm{Zu}$ diesen Kulturen wurden dann die Ansätze, deren AHL-Gehalt untersucht werden sollte, zugegeben. Die Messung der Fluoreszenz der Stämme erfolgte nach einer Übernachtinkubation bei $30^{\circ} \mathrm{C}$. Hierzu wurden die Kulturen 1:50 in sterilem Wasser verdünnt und im Fluoreszenzspektrophotometer vermessen. Die Anregungswellenlänge betrug $488 \mathrm{~nm}$, die Emissionswellenlänge $518 \mathrm{~nm}$. Die gemessene Fluoreszenz wurde in ein Verhältnis zu der Zellzahl gesetzt. Hierzu wurde die optische Dichte bei $600 \mathrm{~nm}\left(\mathrm{OD}_{600}\right)$ gemessen. Der 
Quotient aus der relativen Fluoreszenz und der $\mathrm{OD}_{600}$ wurde ermittelt. Dieser stellte ein Maß für die durch im Medium befindliche AHL vermittelte $g f p$-Expression dar.

Die AHL-enthaltenden Ansätze wurden wie folgt vorbereitet: 3 oder $5 \mathrm{mM}$ des entsprechenden AHL wurden mit der gewünschten Menge Protein versetzt und mit PBS auf ein Volumen von $100 \mu \mathrm{l}$ gebracht. Als Kontrolle wurde ein Ansatz ohne Protein verwendet. Anschließend erfolgte eine Inkubation des Ansatzes bei $30{ }^{\circ} \mathrm{C}$ über Nacht. Am nächstem Morgen wurden die Ansätze gevortext um sicherzustellen, daß eventuell ausgefallene AHL wieder in Lösung geraten. Danach wurden verschiedene Volumina Ansätze zu den vorbereiteten Kulturen mit dem Monitorstamm gegeben.

\subsubsection{Erstellung eines Repertoires von $\beta$-Laktamase Varianten durch Zufalls- mutagenese und Anreichung von solchen Varianten, die auf der Zelloberfläche exponiert werden}

Der Escherichia coli Stamm 71-18mutS wurde nacheinander mit den Plasmiden pASKInt100-Bla und pZA22-mutD5*, einen Derivat von pZA22-MCS1 (LUTZ und BUJARD, 1997), transformiert. Das zweite Plasmid trägt das dnaQ Gen mit der mutD5 Mutation, welches eine dominant-negative $\varepsilon$-Untereinheit der Korrekturlese-Exonuklease der DNA Polymerase III kodiert und unter lac-Promotor Kontrolle steht (SELIFONOVA et al., 2001; WU et al., 1990). Die Zellen wurden über Nacht in $50 \mathrm{ml} \mathrm{dYT} \mathrm{Medium,} \mathrm{das} \mathrm{mit} 25 \mu \mathrm{g} / \mathrm{ml}$ Chloramphenicol, 37,5 $\mu \mathrm{g} / \mathrm{ml}$ Kanamycin und $1 \mathrm{mM}$ IPTG komplettiert war, bei $37^{\circ} \mathrm{C}$ in einem vierfachen Ansatz vermehrt. An nächsten Tag wurden $50 \mu \mathrm{l}$ der Übernachtkultur verwendet, um $50 \mathrm{ml}$ frisches Medium mit denselben Antibiotika und dem Induktor zu inokulieren. Die Zellen wurden erneut über Nacht bei $37^{\circ} \mathrm{C}$ vermehrt. Diese Prozedur wurde noch zweimal wiederholt. Durch diesen Prozeß der Zufallsmutagenese wurde ein Repertoire von Varianten generiert. Durch Zufall wurde bekannt, daß die Zugabe von 0,6 \% SDS (w/v) und $1 \mathrm{mM}$ EDTA zu dem Medium die Lyse von Zellen, die eine Fusion aus Intimin' und dem Wildtyp-bla exprimieren, bewirkt. Um die Anzahl der Zellen, die ein Wildtyp bla-Gen auf dem Plasmid besaßen, zu reduzieren, wurden $250 \mu \mathrm{l}$ des Medium nach dem letzten Mutageneseschritt zur Inokulation von $50 \mathrm{ml}$ dYT mit $25 \mu \mathrm{g} / \mathrm{ml}$ Chloramphenicol, $37,5 \mu \mathrm{g} / \mathrm{ml}$ Kanamycin, 0,6\% SDS (w/v), $1 \mathrm{mM}$ EDTA und $15 \mathrm{mM} \beta$-Mercaptoethanol verwendet. Die Zellen wurden bis zu einer $\mathrm{OD}_{600}$ von 0,2 vermehrt und anschließend wurde die Expression des Fusionsproteins durch Zugabe von $0,2 \mu \mathrm{g} / \mathrm{ml}$ Anhydrotetrazyklin zu einem $10 \mathrm{ml}$ Aliquot dieser Kultur für weitere $2 \mathrm{~h}$ induziert. $5 \mathrm{ml}$ dieser Kultur wurden verwendet, um $50 \mathrm{ml}$ dYT mit $25 \mu \mathrm{g} / \mathrm{ml}$ Chloramphenicol, 37,5 $\mu \mathrm{g} / \mathrm{ml}$ Kanamycin, 0,6 \% SDS (w/v), $1 \mathrm{mM}$ EDTA und $15 \mathrm{mM} \beta$-Mercaptoethanol zu inokulieren. Die Vermehrung der Zellen erfolgte über Nacht bei $30^{\circ} \mathrm{C}$. Am nächsten Morgen wurde $1 \mathrm{ml}$ der Übernachtkultur zur Inokulation von $50 \mathrm{ml}$ dYT mit $25 \mu \mathrm{g} / \mathrm{ml}$ Chloramphenicol, 37,5 $\mu \mathrm{g} / \mathrm{ml} \mathrm{Kanamycin,} \mathrm{0,6} \mathrm{\%} \mathrm{SDS} \mathrm{(w/v),} 1 \mathrm{mM}$ EDTA und $15 \mathrm{mM} \beta$-Mercaptoethanol verwendet. Bei Erreichen einer $\mathrm{OD}_{600}$ von 0,2 wurde die Genexpression durch Zugabe von $0,2 \mu \mathrm{g} / \mathrm{ml}$ Anhydrotetrazyklin induziert und die Zellen nach $1 \mathrm{~h}$ durch sukzessive Inkubation mit dem Anti-Sendai Antikörper, einem biotinylierten AntiMaus Antikörper und Streptavidin, R-Phycoerythrin-Konjugat markiert. 150000 
Fluoreszenzereignisse wurden durch FACS (3.5.4) aussortiert. Dabei wurden nur solche Ereignisse berücksichtigt, die in ein Fenster von 15 bis 1333 relative Fluoreszenz (von insgesamt 10000 Einheiten), fielen. Die Zellen wurden über Nacht auf Agarplatten mit $10 \mu \mathrm{g} / \mathrm{ml}$ Tetrazyklin und $20 \mu \mathrm{g} / \mathrm{ml}$ Ampicillin inkubiert. Am nächsten Tag wurden die Zellen mit einem Drigalskispatel von den Platten gekratzt und für zwei weitere Runden identischer Markierung und Sortierung verwendet. Nach der letzten Markierungsrunde wurden die Zellen einzeln mit der Cyclone-Einheit des MoFlo Zellsortiergerätes auf Agarplatten deponiert. Die so gewonnenen Klone wurden vermehrt und die Sequenz der bla-Varianten wurde durch Nukleotidsequenzanalyse bestimmt.

\subsubsection{Inkubation von Zellen in Alginatmikrosphären}

Vor der Verwendung als Matrix mußte die 1,2 \%ige (w/v) Alginat-Stammlösung (siehe 2.9) durch eine Reihe von Filtrierschritten gereinigt und sterilisiert werden. Die Alginatlösung wurde hierfür schrittweise durch Filter mit den Porengrößen $1,2 \mu \mathrm{m}, 0,8 \mu \mathrm{m}, 0,45 \mu \mathrm{m}$ und $0,22 \mu \mathrm{m}$ gegeben. Diese Filtration diente auch der Entfernung einiger Kontaminanten wie Proteinen und Polyphenolen (SMIDSRøD und SKJAK-BRAEK, 1990).

Die zu verpackenden Zellen wurden in dYT bei einer Temperatur von $30^{\circ} \mathrm{C}$ angezogen. Nach ca. $4 \mathrm{~h}$ wurden die Zellen durch Zentrifugation geerntet, in sterilem Wasser resupendiert und die $\mathrm{OD}_{600}$ auf einen Wert von 2,0 eingestellt. Zwei Milliliter dieser Zellsupension wurden mit $8 \mathrm{ml}$ der Alginat-Stammlösung in ein $100 \mathrm{ml}$ Becherglas gegeben und in die Rührapparatur (2.7) eingespannt. Es erfolgte die Zugabe von 21,6 ml einer Lösung von $4 \%$ (v/v) Span85 in Isooktan (Heng et al., 2003). Das Becherglas wurde mit Aluminiumfolie abgedeckt und der Rührvorgang auf Stufe 7 (ca. 1200 UPM) für 15 min

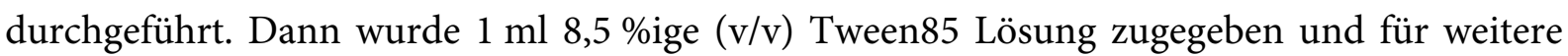
15 min gerührt. Schließlich erfolgte die Zugabe einer $6 \%$ igen (w/v) $\mathrm{CaCl}_{2}$-Lösung und weiteres Rühren für $15 \mathrm{~min}$. Um die Alginatmikrosphären von dem organischen

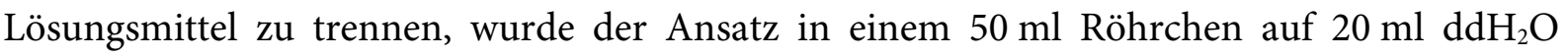
geschichtet und für $10 \mathrm{~min}$ bei $3000 \mathrm{UPM}$ und $20^{\circ} \mathrm{C}$ zentrifugiert (Hettich-Kühlzentrifuge Rotanta/RPC). Das Pellet, das die Alginatmikrokompartimente enthielt, wurde in einen Kolben mit $50 \mathrm{ml}$ dYT mit $20 \mathrm{mM} \mathrm{CaCl}_{2}$ überführt und für $2 \mathrm{~h}$ bei $30^{\circ} \mathrm{C}$ inkubiert. Anschließend erfolgte die Zugabe von $0,2 \mu \mathrm{g} / \mathrm{ml}$ Anhydrotetrazyklin, um die Induktion der Genexpression vom Tetrazyklinpromotor $\mathrm{zu}$ induzieren. Nach $24 \mathrm{~h}$ Inkubation bei Raumtemperatur wurde IPTG in einer Endkonzentration von $1 \mathrm{mM}$ zugegeben und die Inkubation über Nacht weiter geführt.

Nach der Inkubation erfolgte eine Zentrifugation (Hettich-Kühlzentrifuge Rotanta/RPC, $750 \mathrm{Upm}, 15 \mathrm{~min}, 20^{\circ} \mathrm{C}$ ), nach der das Pellet in $30 \mathrm{ml}$ sterilem $\mathrm{ddH}_{2} \mathrm{O}$ resuspendiert und erneut zentrifugiert (Hettich-Kühlzentrifuge Rotanta/RPC, $750 \mathrm{Upm}, 15 \mathrm{~min}, 20^{\circ} \mathrm{C}$ ) wurde. Das Pellet wurde in $2 \mathrm{ml}$ sterilem $\mathrm{ddH}_{2} \mathrm{O}$ resuspendiert. Jeweils $1 \mathrm{ml}$ der Suspension wurde auf ein Kissen von $20 \mathrm{ml} 20 \%$ igen (w/v) Ficoll400 (Pharmacia Fine Chemicals) geschichtet und zentrifugiert (Hettich-Kühlzentrifuge Rotanta/RPC, $750 \mathrm{Upm}, 15 \mathrm{~min}, 20^{\circ} \mathrm{C}$ ). Dieser letzte Zentrifugationsschritt diente zur Trennung der Alginatmikrosphären von den freien 
Bakterien. Das Pellet wurde in $20 \mathrm{ml}$ PBS mit $20 \mathrm{mM}$ EDTA resuspendiert und für $20 \mathrm{~min}$ unter Schütteln inkubiert, um danach zentrifugiert $\mathrm{zu}$ werden (Hettich-Kühlzentrifuge Rotanta/RPC, $4000 \mathrm{Upm}, 12 \mathrm{~min}, 20^{\circ} \mathrm{C}$ ). Dieser Schritt wurde einmal wiederholt. Die Zellen standen sodann für weitere Arbeitsschritte zu Verfügung.

\subsection{Biochemische Methoden}

\subsubsection{Nachweis von Katalase}

Wäßrige Lösung mit $3 \%$ Wasserstoffperoxid wurde auf einen Objektträger getropft und die zu untersuchenden Lösungen zugegeben. Bei einer Bildung von Sauerstoff aus Wasserstoffperoxid entstanden Luftblasen. Die Ergebnisse wurden photographisch dokumentiert.

\subsubsection{Nachweis von Peroxidase}

Eine Peroxidaseaktivität wurde durch Oxidation des Substrats ABTS [2,2' Azino-di-(3Ethyl-Benzthiaziolin-Sulfonsäure] kolorimetrisch untersucht. In Gegenwart von Wasserstoffperoxid wird das ABTS durch die Peroxidase zu einem in wäßriger Lösung stabilen Radikal oxidiert (CHILDS und BARDSLEY, 1975), welches ein Absorptionsmaximum bei $411 \mathrm{~nm}$ besitzt und daher der Substratlösung eine blau-grüne Farbe verleiht (CANO et al., 2000). Zuerst wurde die Substratlösung hergestellt. Aus 0,1 M Citratpuffer und 0,1 M diNatriumhydrogenphosphatpuffer wurden $0,1 \mathrm{M}$ Citrat-Phosphatpuffer, $\mathrm{pH}$ 8,0 angesetzt. Dann wurden $22 \mathrm{mg}$ ABTS / $100 \mathrm{ml}$ Puffer gelöst. Vor Verwendung des Substrates werden $10 \mathrm{ml}$ dieser Lösung mit 1,5 $\mu \mathrm{l} 30 \% \mathrm{H}_{2} \mathrm{O}_{2}$ versetzt, was einer Endkonzentration von $0,0045 \%$ oder 1,5 mM Wasserstoffperoxid entspricht. Nach der Zugabe der zu untersuchenden Lösungen wurde der Farbumschlag qualitativ beobachtet.

\subsubsection{Erzeugung von Superoxidradikalen und deren Nachweis mit Luminol}

Superoxid-Dimutase katalysiert die Dismutation von Superoxid in molekularen Sauerstoff und Wasserstoffperoxid. Zur Erzeugung der Superoxidradikale wurde das Xanthin/XanthinOxidase System eingesetzt (HuU et al., 1984). Xanthin-Oxidase katalysiert die Reaktion von Xanthin, molekularem Sauerstoff und Wasser zu Harnsäure, Wasserstoffperoxid und Superoxid (3.3).

$$
\text { Xanthin }+\mathrm{O}_{2}+\mathrm{H}_{2} \mathrm{O} \rightarrow \text { Harnsäure }+\mathrm{H}_{2} \mathrm{O}_{2}+\mathrm{O}_{2} \cdot
$$

Zum Nachweis der so erzeugten Superoxidradikale dient die Luminolreaktion. Diese beruht auf der Oxidation von teilweise deprotoniertem Luminol durch $\mathrm{Fe}^{(\mathrm{III})} \mathrm{zu}$ einem Radikalanion und der Reaktion des Superoxids mit dem Radikalanion unter der Bildung eines angeregten Zwischenproduktes, welches bei der Rückkehr in den normalen Zustand 
Lichtquanten emittiert (Merenyi und Lind, 1980). Die Anwesenheit einer SuperoxidDismutase in dieser Reaktion bewirkt die Verringerung der Menge des zur Verfügung stehenden Superoxids und damit auch der entstehenden Lumineszenz.

Um Proteine auf eine Superoxid-Dismutase oder Superoxid-Reduktase-Aktivität zu untersuchen, wurden Reaktionen in PBS in einem Gesamtvolumen von $1 \mathrm{ml}$ angesetzt, welche $10 \mu \mathrm{l}$ einer Kalium-Hexacyanoferrat(III)-Stammlösung (siehe 2.9), $1 \mu \mathrm{l}$ Xanthin-Oxidase (33 Einheiten/ml) (siehe 2.5), die $\mathrm{zu}$ untersuchenden Proteine und eventuell notwendige Kofaktoren enthielten. Separat wurden $100 \mu \mathrm{l}$ einer $30 \mathrm{mM}$ Luminollösung in $1 \mathrm{M} \mathrm{NaOH}$ sowie $10 \mu \mathrm{l}$ einer $1 \mathrm{mM}$ Xanthin-Stammlösung (siehe 2.9) gemischt und diese Lösung dem Reaktionsansatz zum Starten der Lumineszenzreaktion zugegeben. Unmittelbar nach Zugabe wurde die Lumineszenz in einem Fluoreszenz-Spektralphotometer bei $415 \mathrm{~nm}$ gemessen, wobei die Lichtquelle für die Anregung deaktiviert war.

\subsubsection{Messung der NAD-Kinase Aktivität von Pa1572}

$50 \mu \mathrm{l}$ einer $200 \mathrm{mM}$ ATP-Stammlösung, $65 \mu \mathrm{l}$ der Isocitrat-Dehydrogenase Präparation (Sigma), $25 \mu \mathrm{l}$ einer $200 \mathrm{mM}$ Isocitrat-Stammlösung und $50 \mu \mathrm{l}$ einer $20 \mathrm{mM}$ NADStammlösung wurden mit $100 \mathrm{mM}$ Phosphatpuffer, $\mathrm{pH}$ 8,0, $100 \mathrm{mM} \mathrm{NaCl}$ auf ein Volumen von $900 \mu \mathrm{l}$ gebracht und die Absorption wurde bei $340 \mathrm{~nm}$ gemessen. Nach ca. 1,5 min wurden $100 \mu$ leiner ca. $5 \mathrm{mg} / \mathrm{ml}$ Proteinlösung von Pa1572 dazugegeben und die Absorption für weitere 2,5 min verfolgt.

\subsubsection{Messung der NADPH-Oxidation durch Pa1572}

\subsubsection{Messung der Aktivität von Zellysaten von Pa1572-exprimierenden Zellen}

Es wurden $450 \mu \mathrm{l} E$. coli Zellysat und $25 \mu \mathrm{l}$ einer $200 \mathrm{mM}$ Isocitrat-Stammlösung mit $100 \mathrm{mM}$ Phosphatpuffer, $\mathrm{pH} 8,0,100 \mathrm{mM} \mathrm{NaCl}$ auf ein Volumen von $850 \mu$ gebracht. Die Reaktion wurde durch Zugabe von $150 \mu \mathrm{l}$ einer $20 \mathrm{mM}$ NADP-Stammlösung gestartet und Absorption bei $340 \mathrm{~nm}$ gemessen.

\subsubsection{Messung der Aktivität von gereinigtem Protein}

Im Zweistrahlphotometer wurden zwei Ansätze parallel bei $340 \mathrm{~nm}$ vermessen. Die Zusammensetzungen der Reaktionsansätze sind in Tabelle 3.1 dargestellt. 


\begin{tabular}{|l|l|r|l|}
\hline Küvette $A$ & & Küvette $B$ & \\
\hline $\begin{array}{l}\text { Volumen } \\
(\mu l)\end{array}$ & Reagenz & Volumen $(\mu \mathrm{l})$ & Reagenz \\
\hline 450 & Bl21(DE3) Lysat & 450 & Bl21(DE3) Lysat \\
\hline 25 & Isocitrat Stammlösung & 25 & Isocitrat Stammlösung \\
\hline 175 & Puffer & 375 & Puffer \\
\hline 200 & Protein & 150 & NADP- Stammlösung \\
\hline 150 & NADP-Stammlösung & 1000 & Summe \\
\hline 1000 & Summe & & \\
\hline
\end{tabular}

Tab. 3.1: Zusammensetzung der Reaktionsansätze bei der Messung der NADPH-Oxidation durch gereinigtes Pa1572 Protein.

Die Reaktion wurde durch die Zugabe der NADP Stammlösung gestartet.

\subsubsection{Reversed-Phase-High-Performance-Liquid-Chromatographie (RP-HPLC) von Acyl-Homoserinlactonen}

Um Acyl-Homoserinlactone chromatographisch aufzutrennen, wurde die ReversedPhase-HPLC mit einer Kingsorb ${ }^{\text {Tw }} \mathrm{C}_{18}$-Säule (Phenomenex) eingesetzt. Die Trennung erfolgte isokratisch mit einem Methanol-Wasser Lösungsmittelgemisch über einen Zeitraum von 30 Minuten. Die einzusetzende Methanolkonzentration war für das jeweilige AHL spezifisch und wurde zuvor durch Trennung der AHL auf einem Methanolgradienten von 20-100\% Methanol in Wasser ermittelt. Die isokratische Chromatographie erfolgte dann bei einer Methanolkonzentration, die um $10 \%$ unter derjenigen Methanolkonzetration lag, bei der das jeweilige AHL im Gradienten eluiert wurde (SCHAEFER et al., 2000). Die Detektion der AHL erfolgte bei einer Wellenlänge von $207 \mathrm{~nm}$.

Vor der Trennung auf der $\mathrm{C}_{18}$-Säule mußten die Proben aufgearbeitet werden. Hierzu wurde der Ansatz, der die Acyl-Homoserinlactone enthielt, mit einem Volumen Essigsäureethylester versetzt und gevortext. Der Ansatz wurde kurz anzentrifugiert, damit sich die Phasen trennen konnten. Die obere, organische Phase wurde in ein neues Gefäß überführt. Da die AHLs nicht quantitativ in die organische Phase übergehen, wurde die Extraktion zwei weitere Male durchgeführt und die organischen Phasen jeweils vereinigt. Das Lösungsmittel Essigsäureethylester wurde anschließend über Nacht in der SpeedVac oder im Lyophilisator abgezogen. Die im Pellet verbliebenen AHL wurden einem MethanolWassergemisch, dessen Methanol-Konzentration gleich der in der Chromatographie eingesetzten Konzentration war, gelöst und der Chromatographie zugeführt.

\subsubsection{Kinetische Charakterisierung sowie biochemischer Nachweis von $\beta$-Laktamase}

Zum Nachweis von $\beta$-Laktamase in einem Proteinpräparationsansatz wurde das $\beta$-Laktamase-Substrat 7-(Thienyl-2-Acetamido)-3-(2-(N,N-Dimethyl-Aminophenylazo) Pyridiniummethyl)-3-Cephem-4-Carboxylsäure (Handelsname PADAC, Fa. Calbiochem) 
verwendet. Dieses Substrat besitzt ein Absorptionsmaximum bei $570 \mathrm{~nm}$, welches sich nach Hydrolyse des Laktamringes durch $\beta$-Laktamase nach $450 \mathrm{~nm}$ verschiebt. Der molare Absorptionskoeffizient von PADAC beträgt $45000 \mathrm{M}^{-1} \mathrm{~cm}^{-1}$ bei $570 \mathrm{~nm}$ in Wasser. Die Reaktion ist in Abbildung 3.1 schematisch dargestellt. Zum Nachweis von $\beta$-Laktamase in einem Präparationsansatz wurden $50 \mu$ l Proteinlösung mit $1 \mu \mathrm{l}$ einer PADAC Stammlösung $(10 \mathrm{mg} / \mathrm{ml})$ versetzt. Nach wenigen Sekunden konnte bei Anwesenheit von $\beta$-Laktamase ein Farbumschlag beobachtet werden. Zur Bestimmung der kinetischen Parameter verschiedener $\beta$-Laktamase-Varianten wurde die Hydrolyse des Substrates photometrisch bei $450 \mathrm{~nm}$ über die Zeit verfolgt.

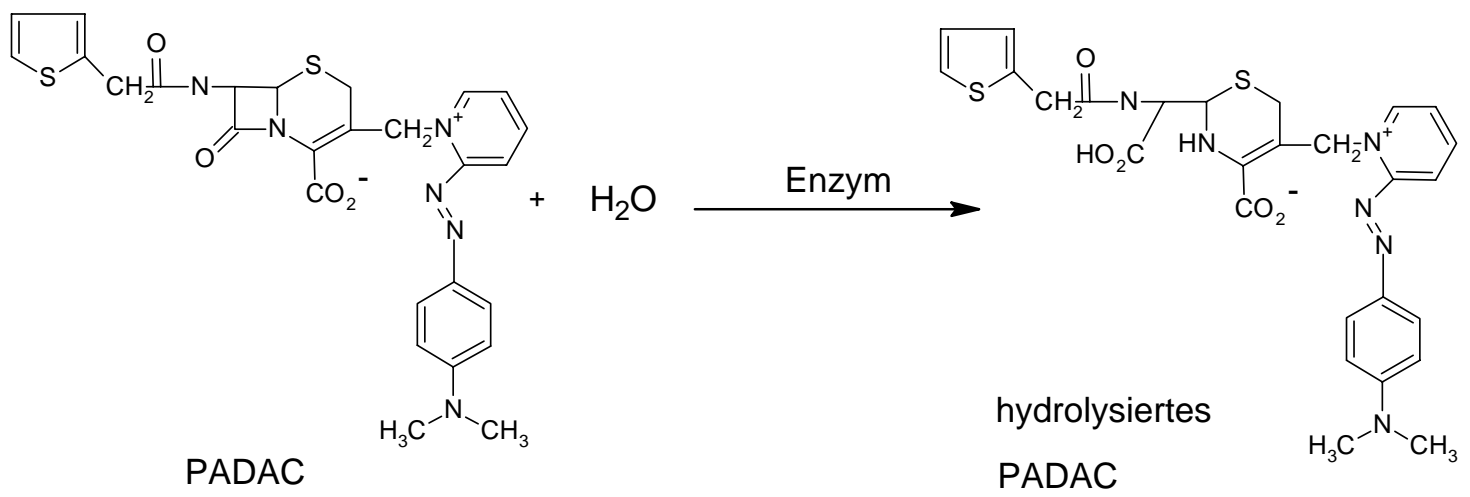

Abb. 3.1: Schematische Darstellung der enzymatischen Hydrolyse von PADAC.

Eine weitere Möglichkeit der Bestimmung der $\beta$-Laktamase-Aktivität ist die Messung der Hydrolyse von Penicillin G. Das Hydrolyseprodukt besitzt einen geringeren molaren Extinktionskoeffizienten bei einer Wellenlänge von $232 \mathrm{~nm}$ (WALEY, 1974). Durch Messung mit einem Zweistrahlphotometer kann die Hydrolyse bestimmt werden. In eine Quarzglasküvette wurden 2,5 $\mu \mathrm{l} 100 \mathrm{mM}$ Penicillin G und 247,5 $\mu$ l IMAC I Puffer gegeben. In die zweite Küvette wurden 2,5 $\mu \mathrm{l} 100 \mathrm{mM}$ Penicillin G, $20 \mu \mathrm{l} \mathrm{Pa0740} \mathrm{(3,39} \mathrm{mg/ml)} \mathrm{und} \mathrm{227,5}$ $\mu$ IMAC I Puffer gegeben. Die Absorption wurde bei $232 \mathrm{~nm}$ für 35 Minuten verfolgt. Anschließend wurden $1 \mu \mathrm{l}$ eines RTEM-1 $\beta$-Laktamase Fusionsproteins $(\sim 0,1 \mathrm{mg} / \mathrm{ml})$, bestehend aus der $\beta$-Laktamase, dem Sendai-Epitop und einem Hexahistidinanhängsel, zu der zweiten Küvette gegeben und die Absorption für weitere 10 Minuten verfolgt. 


\section{Ergebnisse und Diskussion}

In dem nun folgenden Kapitel werden die Untersuchungen, die an den drei Transposonmutanten 41D3, B7D3 und 19C2 des Pseudomonas aeruginosa Stammes TBCF10839 (TÜMMLER, 1987; TÜMMLER et al., 1991) durchgeführt wurden, erläutert. Diese waren bei einer Suche nach potentiellen Pathogenitätsfaktoren aus $P$. aeruginosa an der Medizinischen Hochschule in Hannover identifiziert worden (WIEHLMANN, 2001). In der dort durchgeführten Durchmusterung einer Bibliothek von $P$. aeruginosa Transposonmutanten wurde nach solchen Stämmen Ausschau gehalten, deren Fähigkeit zum intrazellulären Wachstum in Granulozyten eingeschränkt war oder deren Produktion der Quorum Sensing Autoinducer attenuiert war. Im Vordergrund der Untersuchungen steht dabei die Gewinnung der in diesen Mutanten durch Transposonintegration ausgeschalteten Proteine und deren biochemische Charakterisierung, die in dem Abschnitt 4.1 beschrieben wird. Bei der Mutante 41D3 ist das Gen Pa5349, das für eine Rubredoxin Reduktase kodiert, durch die Transposonintegration inaktiviert. Das in der Mutante B7D3 betroffene Gen Pa0740 ist als putative $\beta$-Laktamase annotiert, während das Gen Pa1572, welches in der Mutante 19C2 durch die Transposonintegration betroffen ist, als konserviertes hypothetisches Protein annotiert ist und über eine konservierte Domäne mit hoher Ähnlichkeit zu Proteinen der Familie der ATP-NAD-Kinasen verfügt. Zum weiteren Verständnis der Funktionen der oben genannten potentiellen Virulenzfaktoren im zellulären Kontext des Pathogens $P$. aeruginosa ist es wünschenswert und notwendig, Interaktionspartner dieser Proteine zu identifizieren. Im Zuge einer experimentellen Annäherung wurde zum einen ein kürzlich eingeführtes Verfahren, das auf der Zelloberflächenpräsentation von Proteinen beruht (WENTZEL et al., 2001), auf seine Eignungsfähigkeit für die Analyse von Protein-Protein-Wechselwirkungen untersucht (Abschnitt 4.2.2). Zum anderen wurde ein neues allgemeines Verfahren zur Identifizierung von Protein-Protein-Wechselwirkungen entwickelt (Abschnitt 4.2.3).

\subsection{Biochemische Charakterisierung der Proteine aus den P. aeruginosa Transposonmutanten}

\subsubsection{Untersuchungen der Mutante 41D3}

\subsubsection{Phänotypen der Mutante}

Die bei der STM Durchmusterung in der Arbeitsgruppe von B. Tümmler an der Medizinischen Hochschule Hannover gefundene Mutante 41D3 zeigte eine zwanzigfach geringere Überlebensfähigkeit in Granulozyten im Vergleich zu dem Wildtyp-Stamm TBCF10839 (WieHLMANN, 2001). Die Durchführung des Selektionsexperimentes ist in der Einleitung (Abschnitt 1.4) beschrieben. Auch die Überlebensfähigkeit der Mutante in humanem AB-Serum war um das Zweieinhalbfache verringert. Eine Zugabe von humanem Serum zu dem Testsystem ist notwendig, da die Granulozyten nur in Gegenwart eines funktionsfähigen Komplementsystems in der Lage sind, die Bakterien zu phagozytieren. Der Einsatz von Serum der Blutgruppe AB ermöglicht die Verwendung von Granulozyten diverser Spender ohne Rücksichtnahme auf die entsprechende Blutgruppe des Spenders. Der Quotient 
aus der Überlebensfähigkeit in Granulozyten und der Überlebensfähigkeit in dem humanen $\mathrm{AB}$-Serum beträgt 8 . Dies ist ein Indikator dafür, daß tatsächlich die interzelluläre Persistenz bei dieser Mutante geringer ist, und daß der beobachtete Phänotyp nicht alleine auf eine erhöhte Sensitivität gegenüber dem Serum zurückzuführen ist.

Weiterhin zeigt diese Mutante eine deutlich erhöhte Sensitivität gegenüber Wasserstoffperoxid (WIEHLMANN et al., 2002). Um dies zu untersuchen, wurde in LB Agar Wasserstoffperoxid mit einer initialen Konzentration von $8 \mathrm{mM}$ gegeben. Unmittelbar nach dem Erkalten des Agars wurde eine Zellsuspension auf den Agar geträufelt und anschließend bei $37^{\circ} \mathrm{C}$ für 16 Stunden inkubiert. Eine genaue Angabe der Wasserstoffperoxidkonzentration ist unter den gegebenen Umständen nicht möglich, da die Halbwertszeit des Peroxids im Agar sehr kurz ist. Der auf die Zellen ausgeübte oxidative Streß dauerte somit nicht über die gesamte Zeit des Experimentes an, sondern nahm über die Zeit ab. Dennoch konnten auf dem Agar mit $\mathrm{H}_{2} \mathrm{O}_{2}$ nur Zellen wachsen (Abb. 4.1), die den initialen oxidativen Streß überstanden hatten. Im Gegensatz zu den Wildtyp-Zellen war die Mutante 41D3 nicht in der Lage, auf dem wasserstoffperoxidhaltigen Agar $\mathrm{zu}$ wachsen. Die Beobachtung der Defizienz des intrazellulären Wachstums in Granulozyten könnte ein direkter Effekt der beobachteten Sensitivität gegenüber Wasserstoffperoxid sein, da die phagozytierenden Granulozyten große Mengen von Wasserstoffperoxid als Mikrobiozid einsetzen (CLIFFORD und REPINE, 1982).
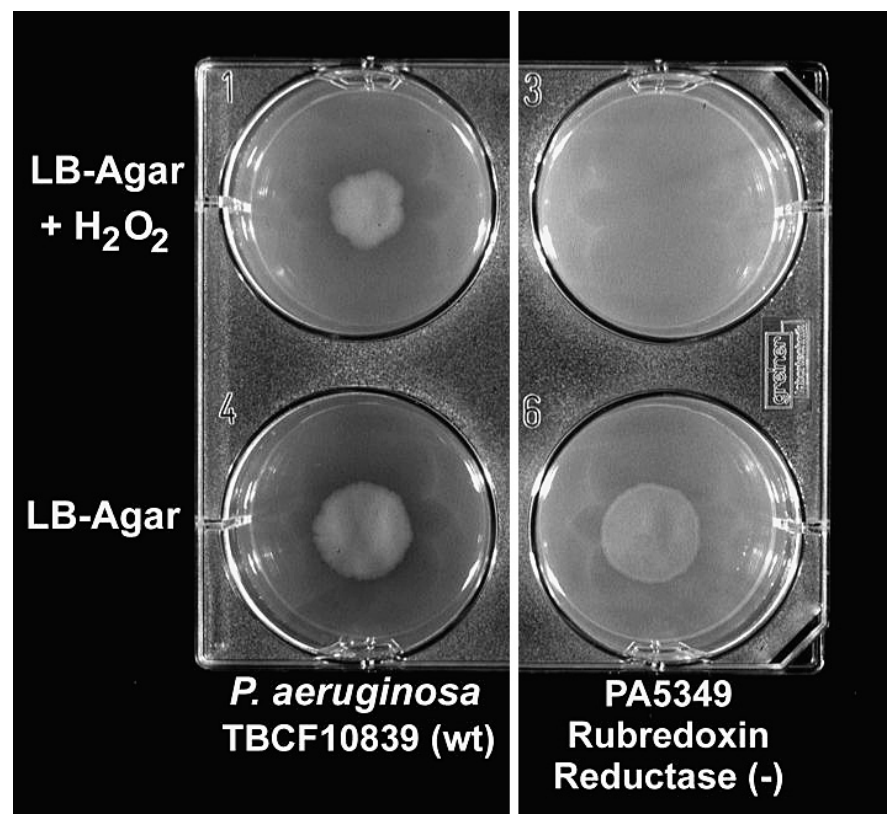

Abb. 4.1: Sensitivität der Mutante 41D3 (rechte Spalte) gegenüber einer initialen Konzentration von $8 \mathrm{mM}$ Wasserstoffperoxid. Während der Wildtyp (linke Spalte) resistent gegenüber den verwendeten Konzentrationen von Wasserstoffperoxid war, konnte die Rubredoxin Reduktase-Mutante nicht auf Agar mit Wasserstoffperoxid wachsen. In der unteren Reihe ist als Kontrolle Zellwachstum der beiden Stämme auf Agar ohne Wasserstoffperoxid zu sehen. Abbildung modifiziert aus WIEHLMANN et al., 2002.

Die Bildung von Acyl-Homoserinlactonen ist bei der Mutante 41D3 ebenfalls beeinträchtigt (WiehlmanN, 2001). So zeigte die Mutante in dem Bioassay, mit dem die Synthese der AHL untersucht wird, keinerlei Aktivität. Die Sekretion von Proteasen (BRINT und OHMAN, 1995) und Elastasen (LATIFI et al., 1995), die erst bei hohen Wachstumsdichten exprimiert werden, wird in Pseudomonas aeruginosa durch Quorum Sensing reguliert. Auf 
Minimalplatten, die 0,5 \% Casein als einzige Kohlenstoffquelle enthalten, können nur solche Zellen wachsen, die zur Exkretion von Proteasen befähigt sind. Das Wachstum der Mutante 41D3 im Vergleich zum Wildtyp wurde auf solchen Platten untersucht. Hierbei zeigte sich, daß die Mutante nicht in der Lage war, Casein als Kohlenstoffquelle zu verwenden und demnach wahrscheinlich einen Defekt in der Exkretion von Proteasen, deren Expression durch das Quorum Sensing kontrolliert wird, besitzt (WIEHLMANN, 2001). Die Exkretion von Elastase konnte durch Betrachtung des Wachstums der Zellen auf Minimalplatten mit 0,5 \% Gelatine untersucht werden, da das in der Gelatine hauptsächlich enthaltene Protein Kollagen durch eine exkretierte Elastase abgebaut wird. Auch auf diesen Platten konnte kein Wachstum von 41D3 beobachtet werden, so daß man davon ausgehen kann, daß dieser Stamm nicht zur Synthese der durch das Quorum Sensing System kontrollieren Elastase und Kollagenase befähigt ist.

\subsubsection{Genomischer Kontext der Mutation 41D3 und generelle Charakteristika von Rubredoxin Reduktase}

Die Mutante 41D3 trägt eine Transposonintegration in dem $P$. aeruginosa Gen Pa5349 an der Position 977. Dieses Gen ist in der Pseudomonas aeruginosa Genom Datenbank (PAGD, www.pseudomonas.com) als putative Rubredoxin Reduktase annotiert. Die besten Homologien hat es zu den Rubredoxin Reduktasen RubB aus Acinetobacter sp. ADP1 (GEISSDORFER et al., 1995) mit einer Sequenzidentität von 40,1 \% auf Proteinebene und zu der Rubredoxin Reduktase AlkT aus Pseudomonas putida (EGGINK et al., 1990) mit einer Sequenzidentiät von 37,1 \%. Durch Komplementation einer inaktiven Rubredoxin Reduktase aus Pseudomonas putida Gpo1 durch Pa5349 konnte gezeigt werden, daß Pa5349 tatsächlich eine Rubredoxin Reduktase-Aktivität in vivo besitzt (SMITS et al., 2003).

Bei der Betrachtung der genomischen Organisation fällt auf, daß das Gen Pa5349 zusammen mit dem Gen Pa5350 in einem Operon transkribiert wird (Abb. 4.2). Pa5350 kodiert für ein putatives Rubredoxin. Weiterhin befindet sich in unittelbarer Nachbarschaft das Gen Pa5351, welches ebenfalls für ein putatives Rubredoxin kodiert, allerdings von einem eigenen Promotor transkribiert wird. Diese beiden Rubredoxine sind homolog zu dem Rubredoxin RubA aus Acinetobactersp. ADP1 (GEISSDORFER et al., 1995), wobei 70 bzw. 72 \% der Proteinsequenz identisch sind. Die Gesamtheit der Gene Pa5349 bis Pa5351 bezeichnet man auch als RubA1A2B Gencluster, abgeleitet von denen in der Literatur auch verwendeten Bezeichnungen RubA1 (Pa5351), RubA2 (Pa5350) sowie RubB (Pa5349) (SMITs et al., 2003). Auch für die beiden Rubredoxine konnte funktionell der Nachweis erbracht werden, daß diese in der Lage sind, die Funktion der entsprechenden Rubredoxine aus Pseudomonas putida Gpo1 (SMITS et al., 2003) zu übernehmen.

Die beiden Rubredoxine Pa5350 und Pa5351 werden in Pseudomonas aeruginosa konstitutiv exprimiert, wobei die Expression von Pa5351 zu Beginn der exponentiellen Phase am höchsten ist, während die höchste Expression von Pa5350 zum Ende der exponentiellen Phase nachgewiesen wurde (MARIN et al., 2003). Beide Proteine sind zu 83,3\% (FASTA) auf Sequenzebene identisch. 


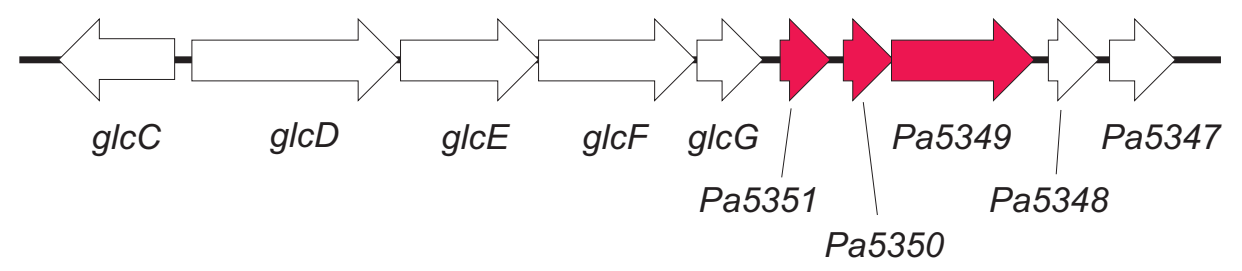

Abb. 4.2: Genomische Organisation des sogenannten RubA1A2B Genclusters in P. aeruginosa PAO1, modifiziert nach SMITS et al., 2003. Pa 5351: Rubredoxin2 (RubA2), Pa5350: Rubredoxin1 (RubA1), Pa5349: Rubredoxin Reduktase (RubB). glcCDEFG: zu E. coli glcRDEFG homologe Gene, welche eine Rolle in der Glykolatoxidation spielen. Pa5348, Pa5347: hypothetische Proteine.

\subsubsection{Klonierung der Rubredoxin Reduktase Pa5349}

Für die Klonierung der löslichen Proteine kamen zwei verschiedene Vektoren zum Einsatz. Zum einen wurde hier der Vektor pASK75 (2.2.2.1) verwendet, zum anderen das Expressionsplasmid pBBR22b (2.2.2.2) Das Plasmid pASK75 eignet sich für die zytoplasmatische Expression löslicher Proteine. Den entsprechenden Proteinen wird auf DNA-Ebene die kodierende Sequenz für das Sendai-Epitop (EINBERGER et al., 1990) sowie ein Hexahistidinanhängsel angefügt. Die Ausstattung der Proteine mit dem Sendai Epitop erlaubt einen immunhistochemischen oder immunhistologischen Nachweis dieser Proteine, was beispielsweise bei der Untersuchung von Protein-Protein-Wechselwirkungen von Vorteil ist. Der Vektor besitzt die Tetrazyklin-Promotor/Operator-Sequenz, wobei die ersten sieben Codone des tet $A$-Strukturgens beibehalten wurden, gefolgt von einem Stopcodon und einer weiteren ribosomalen Bindungsstelle. Durch die Verwendung von tandenrepitierten ribosomalen Bindungsstellen soll eine effiziente Initiation der Translation erreicht werden (SKERRA, 1994).

Bei dem Tetrazyklin-Promotor handelt es sich zwar um einen in Gegenwart des Repressors verhältnismäßig dichten, jedoch nicht um den stärksten bekannten Promotor. Gerade im Hinblick auf die mögliche Ausbeute an heterologem Protein erscheint es jedoch wünschenswert, einen möglichst starken Promotor zu verwenden. Weiterhin gibt es in der Literatur diverse Beispiele dafür, daß eine heterologe Expression von Genen aus Pseudomonas aeruginosa in Escherichia coli nicht zur Gewinnung aktiver Proteine führte (CRONIN und MCINTIRE, 2000; Lu et al., 2002; ROSENAU und JAEGER, 2000; ROSENAU und JAEGER, 2004).

Aufgrund dieser Überlegungen wurde eine Klonierung der Pseudomonas aeruginosa Gene in den Vektor pBBR22b (2.2.2.2) angestrebt. In diesem Vektor ist eine effiziente Transkription des Zielgens durch die Verwendung von T7-RNA Polymerase gewährleistet. Dieses Enzym besitzt eine sehr hohe Prozessivität und Spezifität für T7-Promotoren (STUDIER und Moffatt, 1986; TABOr und Richardson, 1985). Eine rigide Regulation des Promotors wird durch die Verwendung des lac-Operators erreicht. Auf dem Plasmid befindet sich das lacl ${ }^{g}-$ Gen, wodurch der Lac-Repressor in cis zur Verfügung gestellt und die Transkription des 
Zielgens effizient unterbunden wird. Durch Zugabe des Induktors IPTG wird gleichzeitig die Abdissoziation des Repressors von seiner Erkennungssequenz und die Expression einer im Genom des verwendeten Expressionsstammes kodierten T7-RNA-Polymerase, welche sich unter der Kontrolle des lac-Operators befindet, ausgelöst. Dennoch ist eine effiziente Produktion in E. coli auch mit der Verwendung dieses Vektors nicht garantiert. Beispielsweise können sich die heterolog exprimierten Proteine in Einschlußkörperchen einlagern, ein Prozeß, der bis heute nur ungenau verstanden ist, aber durch Anwesenheit von für das entsprechende Protein spezifische Chaperone unterbunden werden könnte (SCHLIEKER et al., 2002). Eine Expression der entsprechenden Proteine in Pseudomonas aeruginosa selber könnte daher theoretisch zu einer besseren Ausbeute führen. Aus diesem Grunde wurde das Plasmid mit der Mobilisierungsregion des Vektors pBBR1 aus Bordetella bronchisepta (SzPIRER et al., 2001) versehen, welche eine Replikation des Plasmids in einer Reihe von Gram-negativen Bakterien ermöglicht. Da die Expression von heterologen Proteinen in dem Pathogen Pseudomonas aeruginosa in Deutschland und anderen Ländern streng reguliert wird, konstruierten Jäger und Mitarbeiter einen Pseudomonas putida Stamm, in welchem sie erfolgreich diverse Pseudomonas aeruginosa-Gene unter Verwendung des pBBR22bPlasmides exprimieren konnten (RosenAU und JAEgER, 2004). Somit steht, sollte die Expression der heterologen Protein in E. coli nicht erfolgreich sein, ein weiterer Organismus als Ausweichmöglichkeit zu Verfügung.

\subsection{Erstellung von pASK75Pa5349}

Die kodierenden Sequenz des Pa5349 Genes wurde durch PCR unter der Verwendung der beiden Oligonukleotide Pa5349up und Pa5349 (2.4) amplifiziert. Als Matrize diente Pseudomonas aeruginosa DNA des Stammes PAO1 (2.1.1). DNA dieses Stammes wurde als Matrize eingesetzt, da seine Genomsequenz vollständig bestimmt ist und somit die ein Abgleich zwischen der Sequenz des klonierten Gens mit der Sollsequenz durchgeführt werden kann. LaTaq-Polymerase (Fa. TaKaRa) wurde unter Verwendung des GCI-Puffers eingesetzt. Die Zusammensetzung dieses Puffers wird von der Firma nicht angegeben, dennoch eignet sich dieses Produkt besonders gut zur Amplifikation von GC-reicher DNA. Das PCR-Produkt wurde gereinigt (3.2.4) und mit den Restriktionsendonukleasen XbaI und BglII verdaut (3.3.1). Nach dem Verdau erfolgte eine Phenol/Chloroform Extraktion (3.2.1.3) und eine Präzipitation der DNA mit Ethanol (3.2.1.1). Zur Kontrolle wurde das DNA Fragment mittels Agarosegelelektrophorese (3.2.2) analysiert.

Das Plasmid pASK75pcrV wurde freundlicherweise von Andreas Christmann zur Verfügung gestellt. Dieses Plasmid enthielt bereits ein Zielgen zur heterologen Expression, welches durch restriktionsenzymatischen Verdau mit den Enzymen XbaI und BglII entfernt wurde (3.3.1). Nach Reinigung des Vektorfragmentes über ein Agarosegel (3.2.3) wurde das zuvor präparierte, für Pa5349 kodierende DNA Fragment mit dem Vektorfragment enzymatisch ligiert (3.3.3). Es erfolgte eine Transformation des E. coli Stammes 71-18 (3.1.4). Die Transformanten wurden für eine Plasmidminipräpration (3.2.5) vermehrt und die so 
gewonnenen Plasmide durch enzymatischen Verdau mit XbaI und BglII (3.3.1) analysiert. Die Nukleotidsequenz der positiven Klone wurde durch Auftragssequenzierung ermittelt.

\subsection{Modifikation von pBBR22b}

In das Plasmid pBBR22b wurde ein tripartites Fusionsgen, bestehend aus Pa5349, der kodierenden Sequenz für das Sendai-Epitop sowie der genetischen Information für ein Hexahistidinanhängsel, eingeführt. In diesem Fusionsgen befindet sich eine NdeI Restriktionserkennungsstelle vor dem Pa5349-Gen und eine BglII Erkennungsstelle zwischen Pa5349 und der Sendai-Epitopsequenz, so daß durch restriktionsenzymatische Spaltung mit NdeI und BglII ein Austausch des Pa5349-Gens gegen ein beliebiges anderes Strukturgen möglich ist, welches dann ebenfalls als Fusion an das Sendai-Epitop mit einem Hexahistidinanhängsel produziert werden kann. Am 3'-Ende der Genkassette befindet sich eine Erkennungsstelle für HindIII, so daß die komplette Kassette durch Restriktionsspaltung mit NdeI und HindIII in die multiple Klonierungstelle des Plasmids, die ebenfalls Erkennungssequenzen für diese beiden Restriktionsenzyme enthält, eingesetzt werden kann. Das Plasmid pBBR22b besitzt allerdings eine Endogene BglII Erkennungsstelle, die vor dem Einsetzen der Genkassette entfernt werden mußte, da ansonsten ein späterer Austausch des Strukturgens nicht mehr möglich gewesen wäre. Hierzu wurde das Plasmid mit BglII verdaut (3.3.1). Es erfolgte eine Phenol/Chloroform Extraktion (3.2.1.3), anschließend wurde die DNA mit Ethanol gefällt (3.2.1.1). Die überhängenden DNA Enden wurden mit T4-DNA Polymerase aufgefüllt (3.3.2) und anschließend wurden die DNA Enden durch enzymatische Ligation wieder miteinander verbunden (3.3.3). Der Ansatz wurde für eine Transformation von 71-18 eingesetzt. Transformanten wurden einzeln vermehrt und die Plasmid DNA präpariert (3.2.5). Ein enzymatischer Verdau mit BglII und anschließende Gelelektrophorese (3.2.2) zeigte an, daß die Entfernung der BglII-Erkennungstelle erfolgreich war. Der resultierende Vektor wurde als pBBR22bII bezeichnet.

\subsection{Klonierung von Pa5349 in pBBR22bII}

Für die Konstruktion von pBBR22bIIPa5349 (Abb. 4.3) wurde die Genkassette bestehend aus dem Strukturgen Pa5349, der kodierenden Sequenzen des Sendai-Epitopes und des Hexahistidinanhängsels durch PCR mit den beiden Oligonukleotiden Pa5349Ndeup und AC656 (2.4) ausgehend von dem Vektor pASK75Pa5349 als Matrize amplifiziert. Dadurch wurde eine NdeI Restriktionserkennungsstelle am Beginn der Genkassette erzeugt. Nach einer Aufreinigung des PCR Produktes durch Phenol/Chloroform Extrakion (3.2.1.3) und Ethanolpräzipitation (3.2.1.1) erfolgte der restriktionsenzymatische Verdau mit den beiden Enzymen NdeI und HindIII sowie eine erneute Phenol/Chloroform Extrakion und Ethanolpräzipitation. Das Akzeptorplasmid pBBR22bII wurde nach demselben Schema ebenfalls mit den Enzymen NdeI und HindIII verdaut und anschließend wurde das Vektorfragment über Agarosegelelektrophorese gereinigt (3.2.3). Das gespaltene PCRProdukt wurde mit dem Vektorfragment ligiert (3.3.3) und elektrokompetente Zellen des 
Stammes 71-18 transformiert (3.1.4). Einzelne Transformanten wurden vermehrt und die Plasmide präpariert (3.2.5).

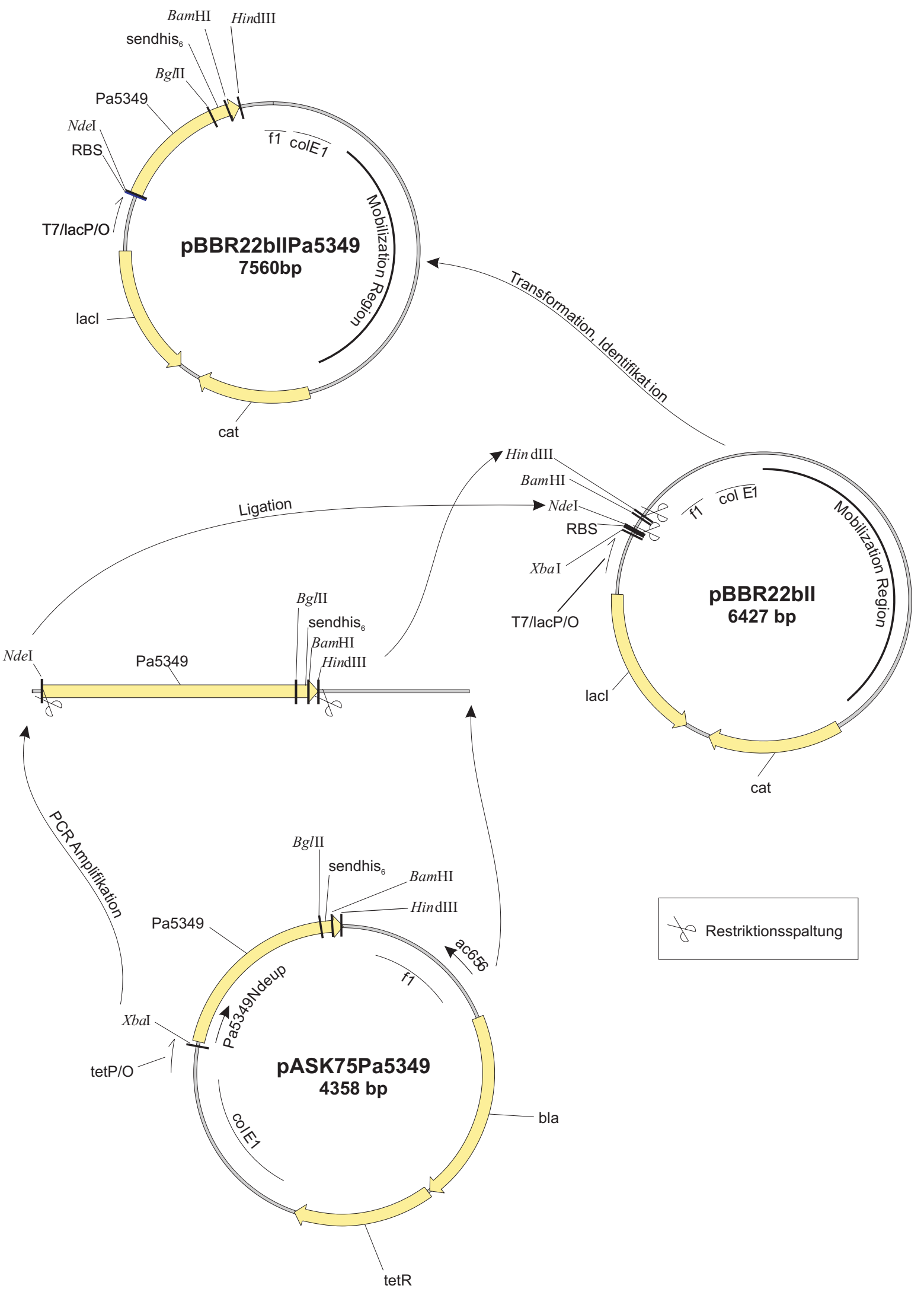


Abb. 4.3: Klonierungsschema von pBBR22bIIPa5349.

Die Identifikation von Klonen, welche die Genkassette trugen, erfolgte durch Verdau der Plasmide mit den Restriktionsenzymen NdeI und HindIII. Die Sequenz der positiven Klone wurde durch Nukleotidsequenzanalyse verifiziert.

\subsubsection{Klonierung des Rubredoxins Pa5350}

Die kodierende Sequenz von Pa5350 wurde durch PCR mit den beiden Oligonukleotiden Pa5350Ndeup und Pa5350lo unter Verwendung genomischer DNA von $P$. aeruginosa PAO1 amplifiziert. Auch in diesem Fall wurde wieder die LaTaq Polymerase der Firma TaKaRa eingesetzt. Die für die Klonierung notwendigen Erkennungsstellen für NdeI und BglII wurden durch die Oligonukleotide eingeführt. Das resultierende PCR-Produkt wurde durch Phenol/Chloroform Extraktion (3.2.1.3) und Ethanolpräzipitation gereinigt (3.2.1.1). Anschließend erfolgte die Klonierung in pCR4TOPO (Invitrogen, 3.3.5). Einzelne Transformanten wurden vermehrt und die Plasmide präpariert (3.2.5). Die Identifikation von positiven Klonen erfolgte durch Restriktionsspaltung mit NdeI und BglII (3.3.1) und anschließende Analyse der DNA Fragmente durch Agarosegelelektrophorese (3.2.2). Der resultierende Vektor wurde als pCR4-TOPOPa5350 bezeichnet. Eine Zwischenklonierung in pCR4-TOPO wurde in Betracht gezogen, da sich eine direkte Klonierung des PCR-Produktes in pBBR22bII in mehreren Versuchen als erfolglos erwies.

Für die Klonierung des Pa5350-Strukturgens in pBBR22bII wurde das Akzeptorplasmid pBBR22bIIPa5349 mit den Enzymen NdeI und BglII verdaut (3.3.1). Das Vektorfragment wurde aus einem Agarosegel gereinigt (3.2.3). Das Plasmid pCR4-TOPOPa5350 wurde nach demselben Muster prozessiert, nur das in diesem Fall nicht das Vektorfragment, sondern das Fragment, welches das Pa5350-Gen trug, aus dem Agarosegel gereinigt wurde. Es erfolgte eine Ligation der beiden Fragmente (3.3.3) sowie die Transformation von 71-18 Zellen (3.1.4). Einzelne Transformanten wurden vermehrt und die Plasmide präpariert (3.2.5). Die Identifikation von positiven Klonen erfolgte durch Verdau der Plasmide mit den Restriktionsenzymen NdeI und BglII. Die Sequenzen der positiven Klone wurden durch Nukleotidsequenzanalyse verifiziert.

\subsubsection{Proteinreinigung der Rubredoxin Reduktase Pa5349}

Mittels immobilisierter Metallionen-Affinitätschromatographie (IMAC) wurde das Fusionsprotein aus dem Pa5349 Strukturgen, dem Sendai-Epitop und dem Hexahistidinanhängsel aus einer $1000 \mathrm{ml}$ Kultur von induzierten 71-18 (pASK75Pa5349) wie in Methoden 3.4.8 beschrieben, gereinigt. Die Fraktionen wurden auf einem 12,5 \%igen SDS Gel analysiert (3.4.6), welches in Abbildung 4.4 gezeigt ist.

In den Elutionsfraktionen der Nickel-Chelatsäule, welche $60 \mathrm{mM}, 100 \mathrm{mM}$ und $200 \mathrm{mM}$ Imidazol enthielten, fand sich eine Proteinbande, die der erwarteten Größe des 
Fusionproteins von 43500 relativem Molekulargewicht entsprach. Diese Fraktionen wurden vereinigt und gegen $4000 \mathrm{ml} 100 \mathrm{mM}$ Phosphatpuffer, $\mathrm{pH} 8,0 ; 100 \mathrm{mM} \mathrm{NaCl}$ dialysiert (3.4.10). Nach der Dialyse wurde die Proteinlösung einkonzentriert (3.4.10) und durch Eintropfen in flüssigen Stickstoff schockgefroren (3.4.11). Somit stand das Protein für nachfolgende Analysen zur Verfügung. Die Konzentration wurde photometrisch ermittelt und betrug $196 \mu \mathrm{M}$. Die gesamte Ausbeute an Protein betrug 13 mg pro Liter Bakterienkultur.

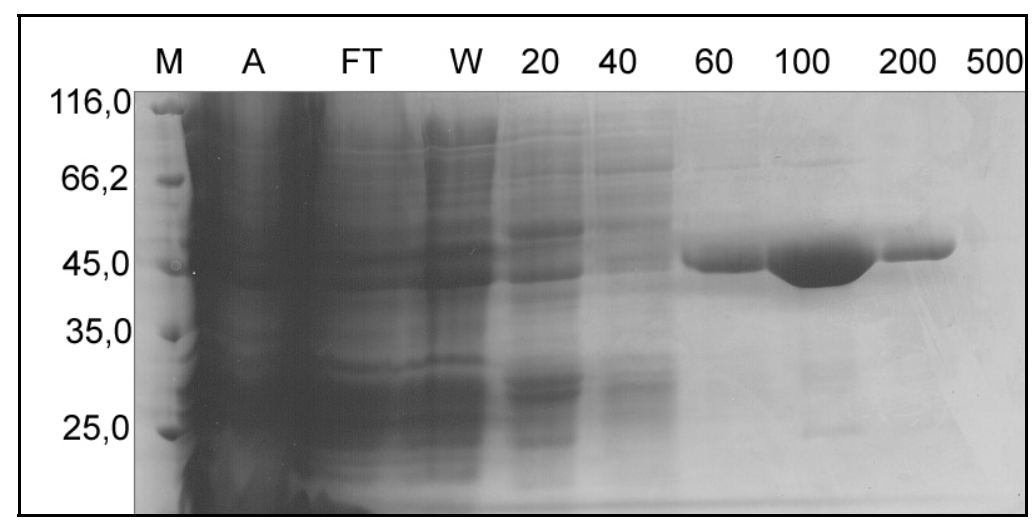

Abb. 4.4: IMAC Reinigung von Pa5349 und Analyse durch SDS-PAGE. M: Proteinlängenstandard, A: Auftrag, FT: Durchlauf, W: Waschfraktion, 20-500: Elution mit 20, 40, 60, 100, 200 und 500 mM Imidazol, respektive.

\subsubsection{Proteinreinigung Pa5350}

Die Proteinreinigung erfolgte analog wie für die Reinigung von Pa5349 beschrieben. Zur Proteinproduktion wurden Zellen des Stammes BL21(DE3) mit dem Plasmid pBBR22bIIPa5350 transformiert, da dieser Stamm eine induzierbare T7-RNA-Polymerase besitzt. Die Fraktionen wurde auf einem 15 \%igen Gel zur Analyse aufgetragen. Abbildung 4.5 zeigt das Proteingel. Die Konzentration wurde photometrisch ermittelt und betrug $735 \mu \mathrm{M}$. Die gesamte Ausbeute an Protein betrug $17 \mathrm{mg}$ pro Liter Bakterienkultur

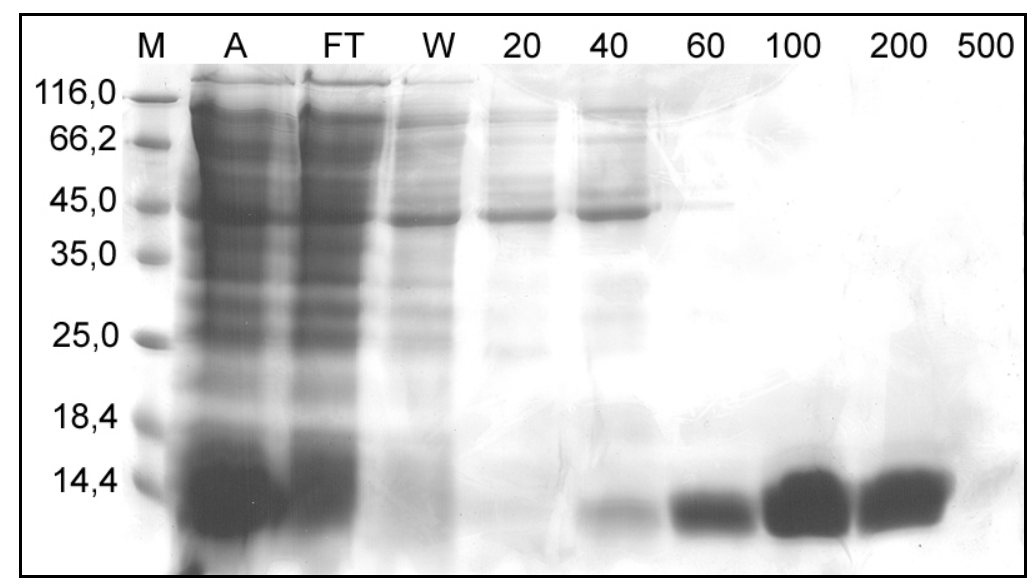

Abb. 4.5: IMAC Reinigung von Pa5350 und Analyse durch SDS-PAGE. M: Proteinlängenstandard, A: Auftrag, FT: Durchlauf, W: Waschfraktion, 20-500: Elution mit 20, 40, 60, 100, 200 und 500 mM Imidazol, respektive. 


\subsubsection{Spektroskopische Analyse von Pa5349 und Pa5350}

\subsection{Analyse von Rubredoxin Reduktase (Pa5349)}

Das Spektrum einer Proteinlösung mit einer Konzentration von $0,9 \mathrm{mg} / \mathrm{ml}$ bzw. $21 \mu \mathrm{M}$ in $16 \mathrm{mM}$ Phospatpuffer $\mathrm{pH} 8,16 \mathrm{mM} \mathrm{NaCl}$ wurde mit einem Spektralphotometer aufgenommen. Das Protein war unter aeroben Bedingungen gereinigt worden und lag daher im oxidierten Zustand vor. Um das Protein zu reduzieren, wurde reduziertes NikotinamidAdenin-Dinukleotid (NADH) in einem 30-fachen molaren Überschuß zu der Proteinlösung gegeben. Dieser hohe Überschuß wurde gewählt, um der Oxidation des Proteins durch ubiquitären molekularen Sauerstoff entgegen zu wirken und das Protein während der Meßdauer im reduzierten Zustand zu halten. Für das reduzierte Protein wurde ebenfalls ein Spektrum aufgenommen. Die Spektren sind in Abb. 4.6 dargestellt.

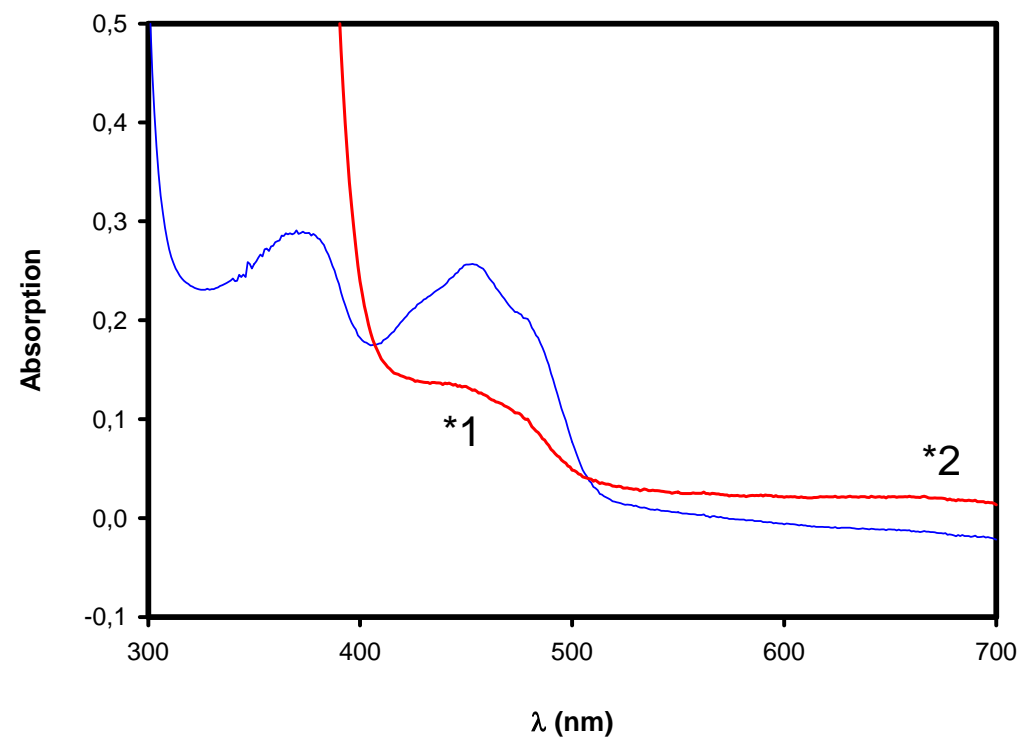

Abb. 4.6: UV-vis Spektrum von oxidierter (blau) und reduzierter (rot) Rubredoxin Reduktase. ${ }^{\star} 1$ bezeichnet den Bereich, in dem die Absorption in der reduzierten Form abnimmt. In Bereich ${ }^{\star} 2$ kommt es zu einer Erhöhung der Absorption durch Bildung eines Ladungs-Transfer-Komplexes aus reduziertem Dihydroflavin und NAD ${ }^{+}$ (LEE, H. J. et al., 1998).

Das Spektrum der oxidierten Rubredoxin Reduktase zeigt Maxima bei 371 und $454 \mathrm{~nm}$ sowie eine Schulter bei $477 \mathrm{~nm}$. Bei der reduzierten Form findet man eine deutliche Reduktion der Absorption bei $454 \mathrm{~nm}\left({ }^{*} 1\right.$ in Abb. 4.6) sowie eine Erhöhung der Absorption im Wellenlängenbereich von $510-700 \mathrm{~nm}\left({ }^{\star} 2\right.$ in Abb. 4.6) vor. Sowohl die beiden charakteristischen Maxima der oxidierten Form sowie das Ausbleichen bei $454 \mathrm{~nm}$ bei der reduzierten Form sind ein typischen Kennzeichen von Proteinen, die eine Flavin-AdeninMononukleotid (FAD)-Chromophore enthalten (Guedon und Petitdemange, 2001; MA und ADAMS, 1999). Die Erhöhung der Absorption bei 510-700 nm wird durch die Bildung eines Ladungs-Transfer-Komplexes im Protein aus reduziertem Dihydroflavin und $\mathrm{NAD}^{+}$ hervorgerufen (LEE, H. J. et al., 1998). Die starke Erhöhung der Absorption unterhalb von $400 \mathrm{~nm}$ bei der reduzierten Form ist durch die Zugabe des NADH bedingt und kein Effekt des 
Proteins selber. Aus dem Spektrum des oxidierten Proteins läßt sich auch das molare Verhältnis von Protein und FAD berechnen. Der molare Extinktionskoeffizient von FAD beträgt $11300 \mathrm{M}^{-1} \mathrm{~cm}^{-1}$ bei $450 \mathrm{~nm}$ (BEAUCAMP et al., 1974). Aus der gemessenen Absorption von 0,256 ergibt sich eine FAD-Konzentration von $22,7 \mu \mathrm{M}$ in der Küvette. Die Proteinkonzentration beträgt $21 \mu \mathrm{M}$, bestimmt durch Messung bei $280 \mathrm{~nm}$ (3.4.1). Somit ergibt sich ein Protein/FAD-Verhältnis von 1:1,09 oder beinahe 1:1.

Die aus den Spektren gewonnenen Daten sprechen dafür, daß ein Mol Rubredoxin Reduktase ein Mol Flavin-Adenin-Mononukleotid (FAD) als Ladungs-Transferzentrum enthält, welches durch NADH reduziert werden kann. Weiterhin findet man in der Primärsequenz von PA5349 die Aminosäureabfolge TSHANIYALDG, welche die Signatur einer FAD-Bindesequenz darstellt (EGGINK et al., 1990). In der Literatur gibt es zahlreiche Hinweise darauf, daß Rubredoxin Reduktasen FAD als prosthetische Gruppe verwenden (Guedon und Petitdemange, 2001; Ma und Adams, 2001; Ueda und Coon, 1972). Untersuchungen zu Pa5349 im Hinblick darauf sind aus der Literatur bisher nicht bekannt.

\subsection{Analyse von Rubredoxin $(\mathrm{Pa} 5350)$}

Die Spektren von oxidiertem und reduziertem Rubredoxin wurden aufgenommen. Hierzu wurde eine $50 \mu \mathrm{M}$ Proteinlösung in $100 \mathrm{mM}$ Phosphatpuffer, $\mathrm{pH} 8,0,100 \mathrm{mM} \mathrm{NaCl}$ eingesetzt. Zur Bestimmung des Spektrums der reduzierten Form wurde das Protein durch Zugabe eines 10-fachen molaren Überschusses NADPH, das ebenfalls als Elektronendonor geeignet ist, und 2,5 $\mathrm{M}$ Rubredoxin Reduktase reduziert. Da die Menge eingesetzter Rubredoxin Reduktase 20-fach geringer ist als die von Rubredoxin, ist ein großer Anteil ersterer an der gemessenen Absorption nicht zu erwarten. Die Spektren sind in Abb. $4.7 \mathrm{zu}$ sehen.

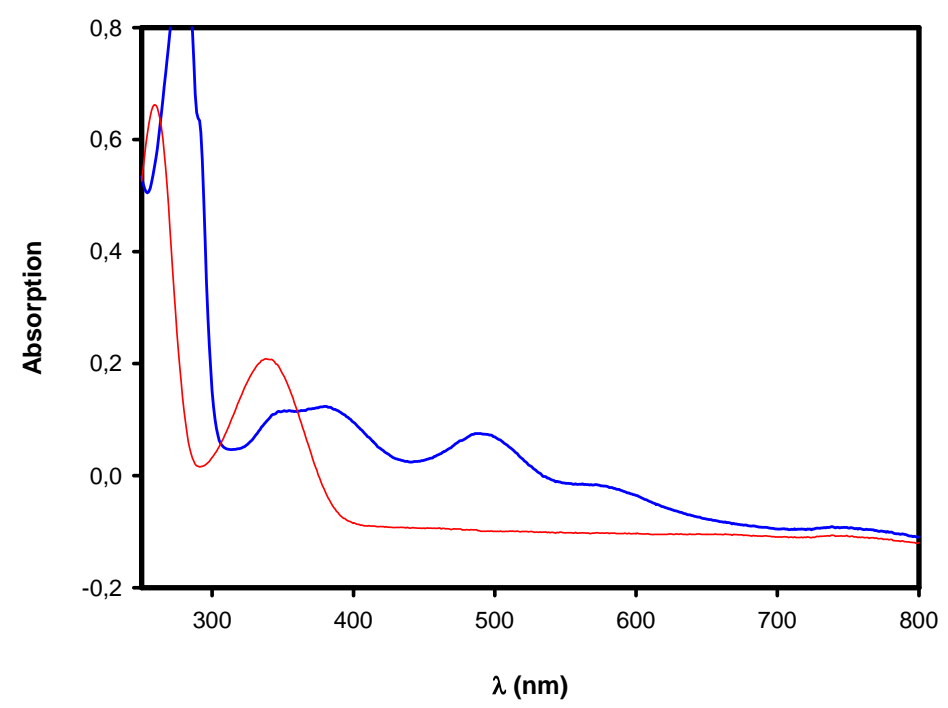

Abb. 4.7: UV-vis Spektrum von oxidiertem (blau) und reduziertem (rot) Rubredoxin. 
Das ermittelte Spektrum des oxidierten Rubredoxins entspricht mit seinen Maxima bei $495 \mathrm{~nm}$ und $378 \mathrm{~nm}$ einem typischen Spektrum eines Rubredoxins, welches ein Eisenatom enthält. Dieses Eisenatom wird von den Schwefelatomen der vier Cysteinreste in nahezu tetrahedraler Konfirmation koordiniert (LODE und COON, 1971). Das Spektrum des reduzierten Proteins zeigt den Verlust des Maximums bei $495 \mathrm{~nm}$ was ein Anzeichen der Reduktion des gebundenen Eisenatom von der $\mathrm{Fe}^{(\mathrm{III})}$ - zur Fe ${ }^{(\mathrm{II})}$-Form darstellt (RAGSDALE und LJUNGDAHL, 1984). Das diese Eigenschaften auf eine Reduktion des Eisens und nicht etwa auf dessen Verlust zurückzuführen sind, zeigt sich dadurch, daß es zu einer Reoxidation des reduzierten Rubredoxins durch molekularen Sauerstoff kommt, wenn der Ansatz für eine Weile an Luftsauerstoff stehen gelassen wird. Das neue Maximum bei $340 \mathrm{~nm}$ wird vermutlich durch die Absorption des NADPH bei dieser Wellenlänge hervorgerufen (ZIEGENHORN et al., 1976).

\subsubsection{Untersuchungen zum Abbau reaktiver Sauerstoffspezies}

Durch Wiehlmann und Kollegen konnte gezeigt werden, daß die Mutante 41D3 eine erhöhte Sensitivität gegenüber Wasserstoffperoxid aufweist (WIEHLMANN et al., 2002). Dieses ist selber ein zellschädigendes Agens (IMLAY, 2002). Durch den Zerfall des Wasserstoffperoxids kann jedoch auch Superoxid gebildet werden, welches ebenfalls eine reaktive Sauerstoffspezies ist, die Zellschäden bewirken kann (FARR und KOGOMA, 1991; FRIDOVICH, 1989). Hierfür sind zwei Reaktionen notwendig. Zum einen reagiert in der Fentonreaktion (4.1) Wasserstoffperoxid mit $\mathrm{Fe}^{2+} \mathrm{zu} \mathrm{Fe}^{3+}$, einem Hydroxid Anion und einem Hydroxylradikal. Das Eisen, welches die Fentonreaktion katalysiert, ist freies und nicht an Enzyme gebundenes Eisen (IMLAY, 2003). Es konnte gezeigt werden, daß Escherichia coli und Saccharomyces cerevisiae Zellen ca. 20-30 $\mu \mathrm{M}$ freies Eisen enthalten (SRINIVASAN et al., 2000; WOODMANSEE und IMLAY, 2002)

$$
\mathrm{H}_{2} \mathrm{O}_{2}+\mathrm{Fe}^{2+} \rightarrow \mathrm{Fe}^{3+}+\mathrm{HO}+\mathrm{OH}^{-}
$$

Das Hydroxylradikal kann selber wieder mit Wasserstoffperoxid reagieren, wobei es zu der Bildung von Superoxid-Radikalanionen kommt:

$$
\mathrm{HO}+\mathrm{H}_{2} \mathrm{O}_{2} \rightarrow \mathrm{H}_{3} \mathrm{O}^{+}+\mathrm{O}_{2}^{-\cdot}
$$

Die beobachtete gesteigerte Empfindlichkeit der Mutante 41D3 gegenüber Wasserstoffperoxid könnte demnach sowohl auf eine Sensitivität gegenüber Wasserstoffperoxid selber als auch auf eine erhöhte Sensibilität gegenüber den gebildeten Superoxidradikalen zurück zu führen sein. Das Protein Rubredoxin Reduktase könnte entweder eine direkte Wirkung in der Entgiftung der ROS spielen, in dem es analog zu einer Katalase oder Peroxidase Wasserstoffperoxid abbaut oder die Funktion einer Superoxidabbauenden Superoxid-Dismutase oder Superoxid-Reduktase übernimmt. Weiterhin könnte Rubredoxin Reduktase eine indirekte Rolle in dem Abbau von ROS spielen, indem es Reduktionsäquivalente für ein weiteres, unbekanntes Enzym zur Verfügung stellt, daß im Abbau der ROS involviert ist. Die verschiedenen Möglichkeiten der Rubredoxin Reduktase 
Aktivität sind in dem Schema in Abb. 4.8 dargestellt. In den nun folgenden Abschnitten soll systematisch untersucht werden, ob Rubredoxin Reduktase eine Rolle in einem dieser Abbauwege spielt.

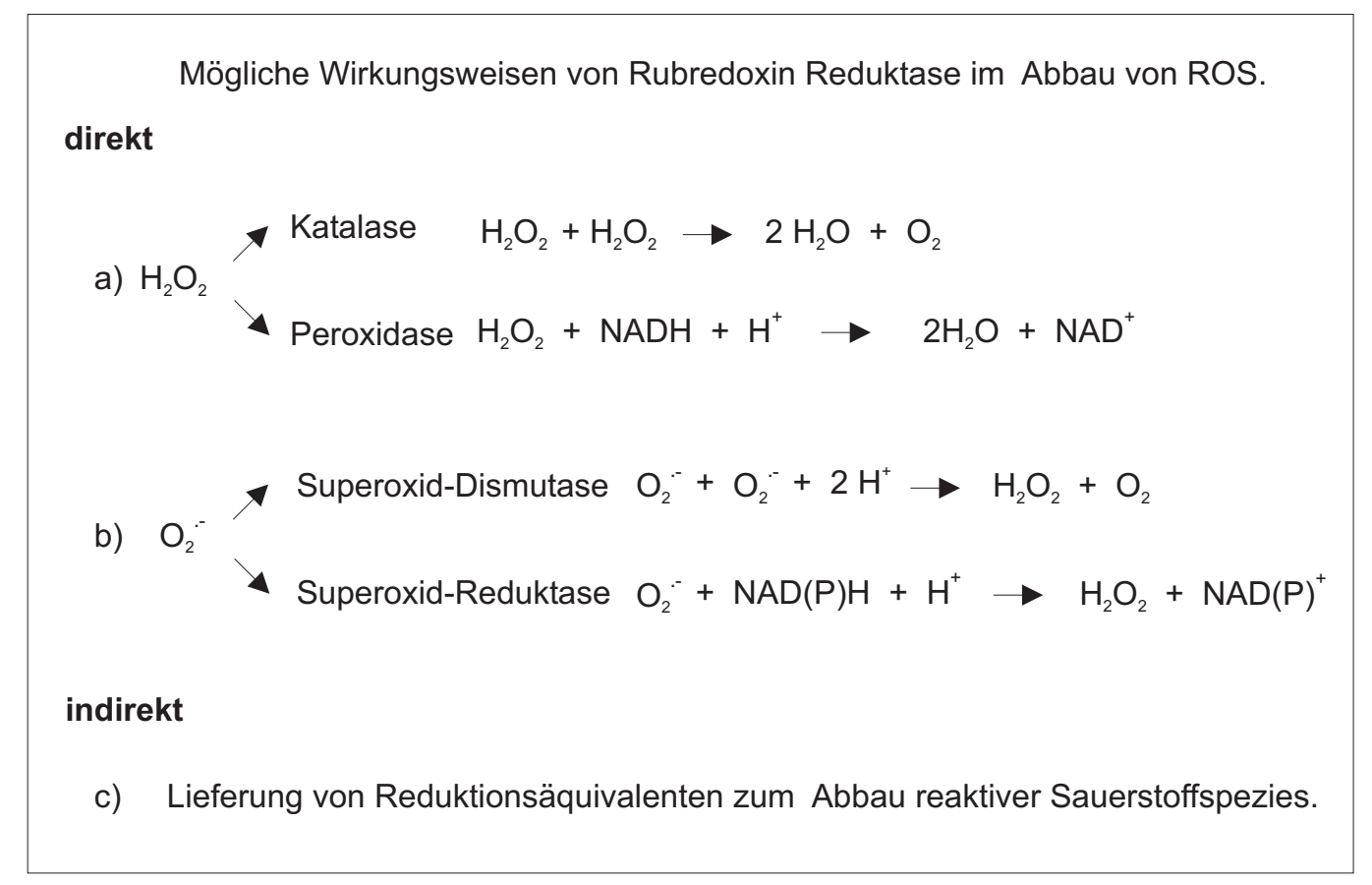

Abb. 4.8: Schema einer möglichen Rolle von Rubredoxin Reduktase in den verschiedenen Abbauwegen der reaktiven Sauerstoffspezies. Das Protein könnte direkt die Funktion einer Katalase, einer Peroxidase, einer Superoxid-Dismutase oder einer Superoxid-Reduktase übernehmen. Es könnte aber auch eine indirekte Rolle in der Entgiftung der ROS spielen, in dem es einem bisher unbekannten Enzym Reduktionsäquivalente zur Verfügung stellt.

\subsection{Test von $\mathrm{Pa} 5349$ und $\mathrm{Pa} 5350$ auf Katalaseaktivität und Peroxidaseaktivität}

Da bei der Mutante 41D3 eine erhöhte Sensitivität gegenüber Wasserstoffperoxid nachgewiesen werden konnte, wurde untersucht, ob Rubredoxin Reduktase und Rubredoxin selber in der Lage sind, Wasserstoffperoxid über eine Katalase- bzw. Peroxidaseaktivität abzubauen. Die Katalaseaktivität wurde getestet, indem jeweils ca. 1 nmol Rubredoxin Reduktase und Rubredoxin in $3 \%$ ige $\mathrm{H}_{2} \mathrm{O}_{2}$ Lösung gegeben wurden. Zusätzlich wurde noch $2 \mu$ mol NADH zu dem Ansatz gegeben. Als Kontrolle wurden jeweils $10 \mu$ l eines Lysates (3.4.5) der beiden Stämme TB und 41D3 eingesetzt. Beim Vorhandensein einer Katalase bilden sich Luftbläschen, die durch den produzieren Sauerstoff entstehen. Abb. 4.9 zeigt die vier Ansätze.

Wie man in der Abbildung erkennen kann, kam es bei der Zugabe der beiden Lysate zu einer Schaumbildung durch endogene Katalaseaktivität. Diese scheint in TB sogar schwächer zu sein als in 41D3, es wurden gleiche Mengen an Lysat, welches aus identischen Zellzahlen gewonnen wurde, eingesetzt. Bei der Zugabe der beiden Proteine und des Elektronendonors konnte hingegen keine Blasenbildung und somit Katalaseaktivität beobachtet werden. Dieses Ergebnis zeigt, daß die Mutante 41D3 über eine funktionelle Katalase verfügt und daß das Protein Pa5349 in Kombination mit Pa5350 und NADH keine Katalaseaktivität besitzt. 


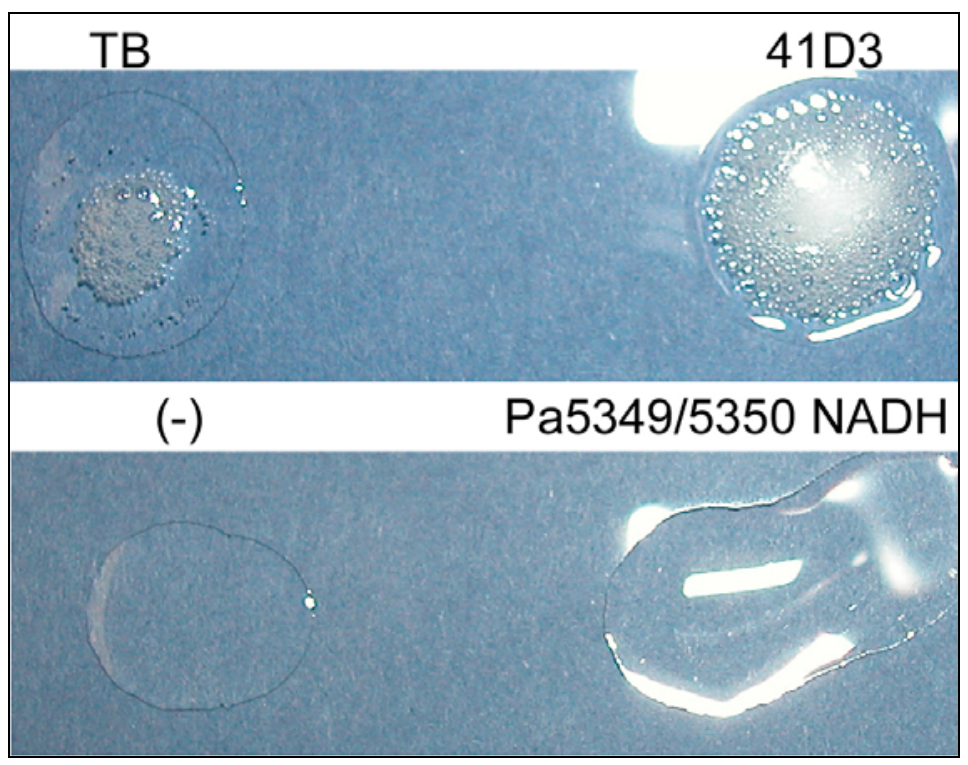

Abb. 4.9: Untersuchung der Katalaseaktivität: Obere Reihe. TB und 41D3 Lysate wurden mit der Wasserstoffperoxidlösung inkubiert. Untere Reihe: links (-) Negativkontrolle, keine Zugabe. Rechts Zugabe von $\mathrm{Pa} 5349 / 5350 / \mathrm{NADH}$ zu der Wasserstoffperoxidlösung.

Eine Peroxidaseaktivität der beiden Proteine wurde ebenfalls untersucht. Hierfür wurde die Oxidation des Substrates ABTS als Untersuchungsmethode gewählt (siehe 3.6.2). In Gegenwart von Wasserstoffperoxid wird das ABTS durch die Peroxidase zu einem in wäßriger Lösung stabilen Radikal oxidiert (CHILDS und BARDSLEY, 1975), welches ein Absorptionsmaximum bei $411 \mathrm{~nm}$ besitzt und daher der Substratlösung eine blau-grüne Farbe verleiht (CANO et al., 2000). Zu der Substratlösung wurden ca. jeweils $1 \mathrm{nmol}$ Rubredoxin Reduktase, Rubredoxin und $2 \mu \mathrm{mol}$ NADH gegeben und der Farbumschlag qualitativ beobachtet. Nach 10 Minuten wurde das Ergebnis photographisch dokumentiert (Abb. 4.10).

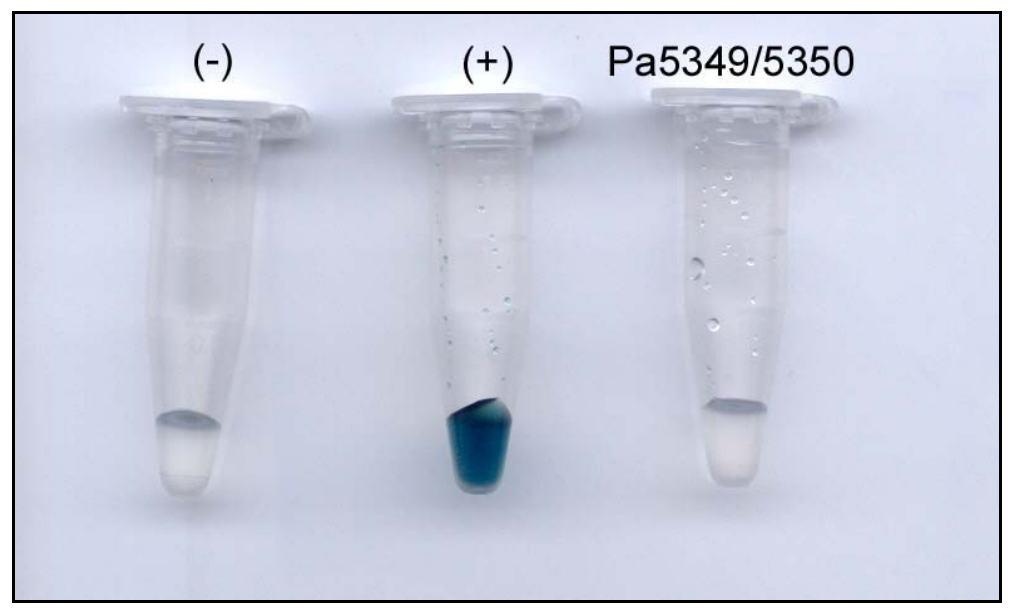

Abb 4.10: Qualitative Auswertung der Peroxidaseaktivität nach 10 Minuten Inkubation. (-): Negativkontrolle, nur Substrat. (+): Positivkontrolle, Zugabe von $1 \mu$ Horseradish Peroxidase (1 mg/ml). Pa5349/5350: Zugabe von jeweils 1 nmol Rubredoxin Reduktase, Rubredoxin und $200 \mu \mathrm{M}$ NADH. 
Wie man in der Abbildung erkennen kann, erfolgte bei der Zugabe von Pa5349, Pa5350 und dem Elektronendonor kein Farbumschlag, während bei der Positivkontrolle der Farbumschlag bereits unmittelbar erfolgte. Als Positivkontrolle wurde $1 \mu$ l einer $1 \mathrm{mg} / \mathrm{ml}$ Horseradish Peroxidase-Lösung (Fa. Sigma) eingesetzt.

Wie diese Untersuchungen zeigen, konnte dem Ensemble von Rubredoxin Reduktase, Rubredoxin und dem Elektronendonor $\mathrm{NADH}$ weder eine Katalaseaktivität noch eine Peroxidaseaktivität zugewiesen werden.

\subsection{In vitro Untersuchungen zum Superoxidabbau durch Rubredoxin Reduktase und Rubredoxin}

Zur Erzeugung der kurzlebigen Superoxidradikale wurde das Xanthin/Xanthin-Oxidase System (HuU et al., 1984) eingesetzt. Xanthin-Oxidase katalysiert die Reaktion von Xanthin, molekularem Sauerstoff und Wasser zu Harnsäure, Wasserstoffperoxid und Superoxid (4.3).

Xanthin $+\mathrm{O}_{2}+\mathrm{H}_{2} \mathrm{O} \rightarrow$ Harnsäure $+\mathrm{H}_{2} \mathrm{O}_{2}+\mathrm{O}_{2 \cdot-}$

Zum Nachweis der so erzeugten Superoxidradikale diente die Luminolreaktion. Diese beruht auf der Oxidation von Luminol durch $\mathrm{Fe}^{(\mathrm{III})}$ und der Reaktion des oxidierten Luminols mit Superoxid (MerenYI und LIND, 1980). Das Reaktionsschema ist in Abbildung 4.11 dargestellt. In wäßriger, basischer Lösung kommt es zu einer teilweisen Deprotonierung von Luminol ( $\left.\mathrm{HL}^{-}\right)$. Im nachfolgenden Schritt wird das Luminolanion von einem $\mathrm{Fe}^{(\mathrm{III})} \mathrm{zu}$ einem Radikalanion $\left(\mathrm{L}^{-}\right)$oxidiert. Dieses reagiert mit einem Superoxidradikal unter Bildung einer unstabilen Zwischenstufe $\mathrm{zu}$ einem angeregten Aminophthalat unter Elimination von molekularem Stickstoff. Unter Emission von Lichtquanten kehrt das Molekül von dem angeregten zu dem normalen Zustand zurück. Die so erzeugte Lumineszenz ist bei $415 \mathrm{~nm}$ meßbar. 


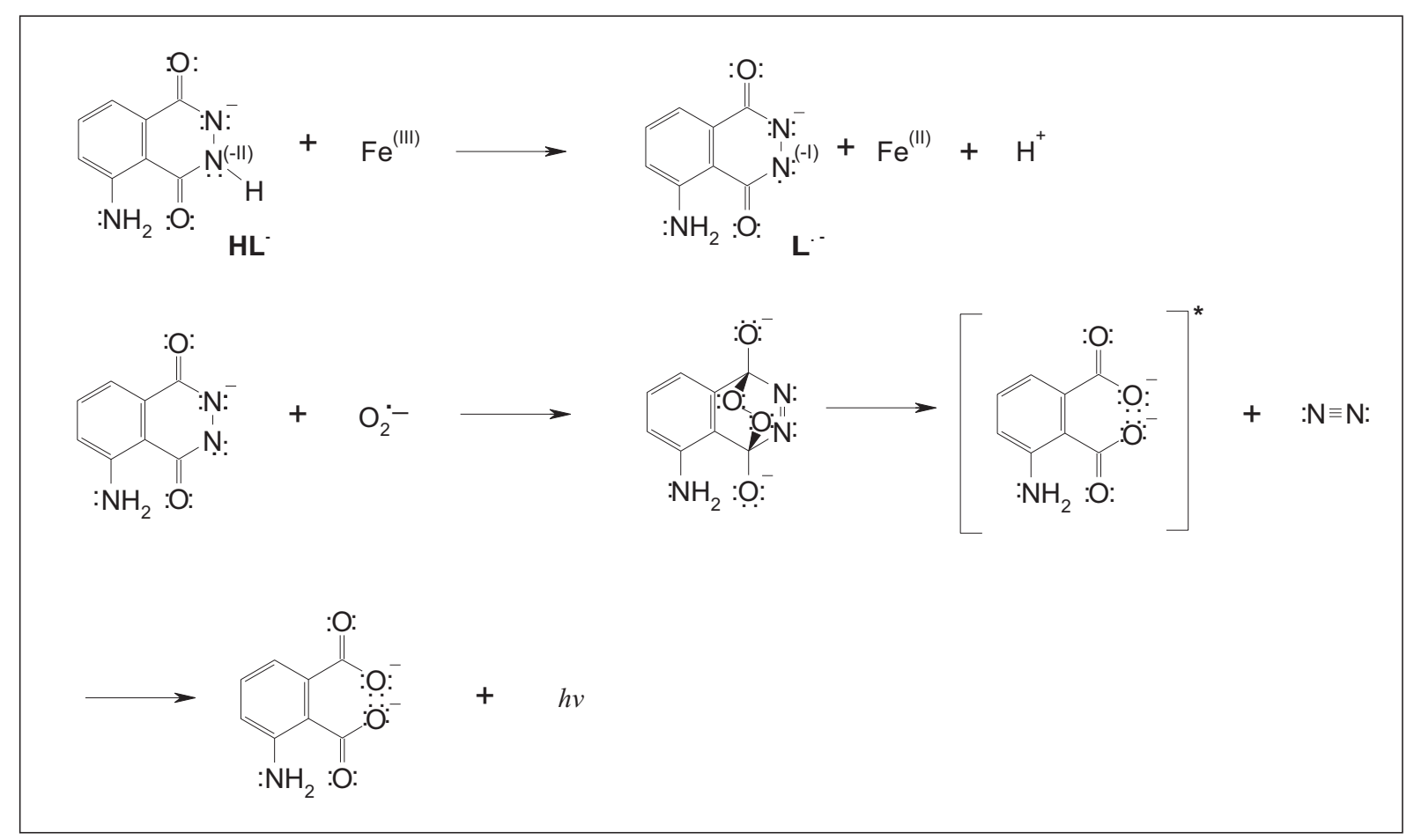

Abb. 4.11: Reaktionsschema von Luminol mit $\mathrm{Fe}^{(\mathrm{III})}$ und Superoxid.

Die Reaktionen mit Xanthin und Xanthin-Oxidase wurden wie in Abschnitt 3.6.3 beschrieben angesetzt. Die Negativkontrolle enthielt Xanthin, Xanthinoxidase, Luminol und Kalium-Hexacyanoferrat ${ }^{(\mathrm{III})}$, während der Positivkontrolle $1600 \mathrm{pmol}$ bovine SuperoxidDismutase (Fa. Sigma) zugesetzt wurden. Um einen Effekt der Rubredoxin Reduktase zu untersuchen, wurden dem Ansatz 640 pmol Rubredoxin Reduktase, 3150 pmol Rubredoxin und $0,5 \mu \mathrm{mol} \mathrm{NADH}$ zugegeben. Diese Menge an $\mathrm{NADH}$ wäre ausreichend, um Reduktionsäquivalente für die gesamte Reduktion des entstandenen Superoxids zu liefern, da die Menge an Xanthin in dem Ansatz 0,01 $\mu$ mol beträgt und somit maximal $0,01 \mu \mathrm{mol}$ Superoxid entstehen können. Die Ansätze wurden im Duplikat durchgeführt und die Lumineszenz bei $415 \mathrm{~nm}$ gemessen. In Abb. 4.12 A sind die registrierten Kurven dargestellt. Das Flächenintegral unter den jeweiligen Kurven stellt ein Maß für die Menge an umgesetzten Luminol und damit für Menge an Superoxidradikalen, die für die Luminolreaktion zur Verfügung stehen, dar. Der relative Luminolumsatz ist in dem Balkendiagramm in Abb. 4.12 B dargestellt. 
A

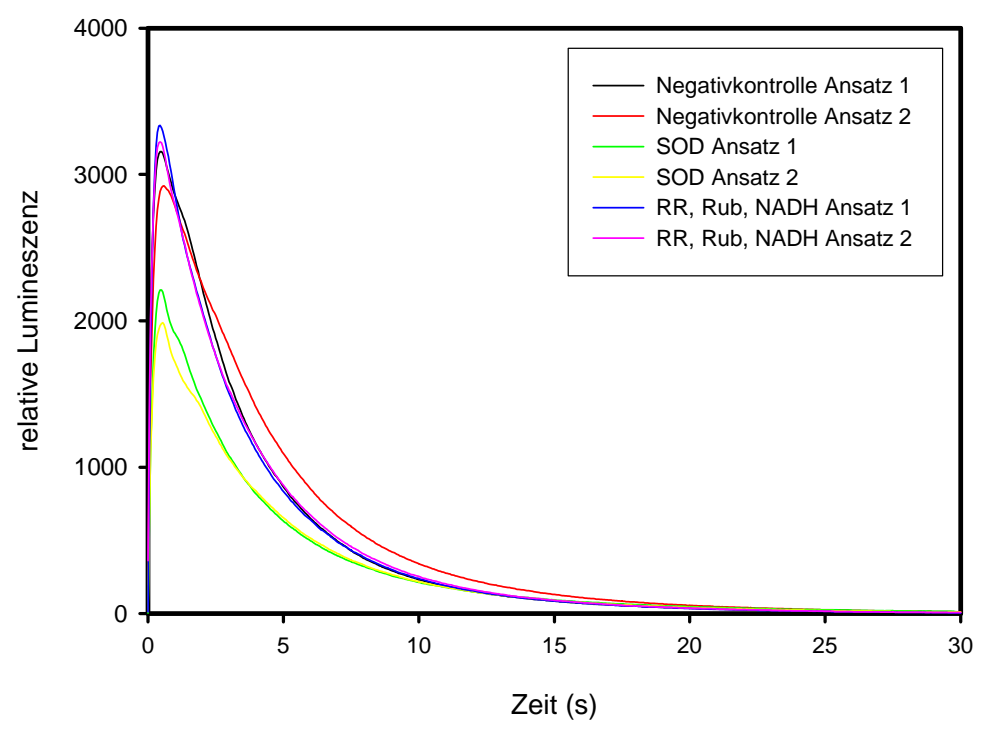

B

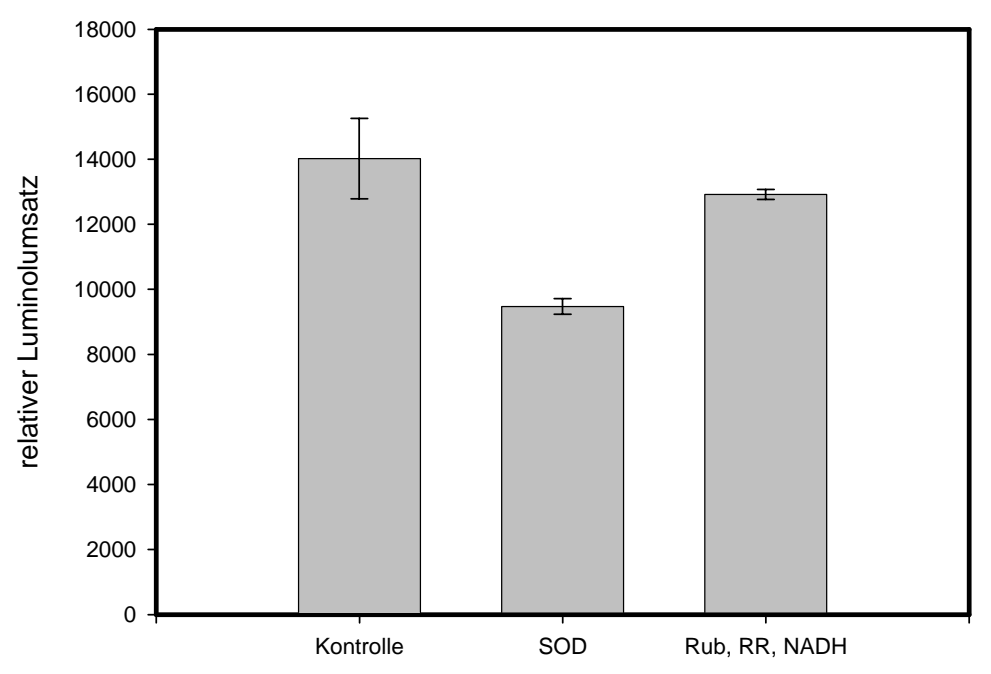

Abb. 4.12: (A) Luminolreaktion mit durch Xanthin/Xanthinoxidase erzeugtem Superoxid. Negativkontrolle ohne Zugabe von Proteinen. Bovine Superoxid-Dismutase (SOD) wurde als Positivkontrolle eingesetzt. In dem dritten Ansatz wurde ein möglicher Superoxidabbau durch Rubredoxin Reduktase (RR), Rubredoxin (Rub) und NADH untersucht. Die Lumineszenz wurde bei $415 \mathrm{~nm}$ gemessen. (B) Berechnung des Flächenintegrals unter den Kurven aus A als Maß für den relativen Luminolumsatz.

Während durch die Zugabe von SOD der relative Luminolumsatz deutlich geringer als bei der Kontrolle ist, erfolgt bei der Zugabe von Rubredoxin Reduktase, Rubredoxin und NADH keine Verringerung des relativen Luminolumsatzes. Dies deutet darauf hin, daß das Ensemble von Rubredoxin Reduktase und Rubredoxin nicht in der Lage ist, Superoxidradikale zu entfernen. Somit haben diese beiden Proteine weder eine direkte Superoxid-Dimutase- noch eine direkte Superoxid-Reduktase-Funktion. 


\subsection{Untersuchung einer möglichen Komplementation einer Escherichia coli Superoxid-Dismutase Mutante durch Pa5349}

In den im folgenden beschriebenen Experimenten wurde untersucht, ob das Genprodukt von Pa5349 in der Lage ist, eine Escherichia coli Mutante, der die beiden SuperoxidDismutasen SodA und SodB fehlen, zu komplementieren. E. coli enthält, so wie viele andere Gram-negative Bakterien, zwei Superoxid-Dismutasen (SOD), zum einen eine SOD (SodA), die Mangan in ihrem aktiven Zentrum enthält (KEELE et al., 1970) und zum anderen eine SOD (SodB), die Eisen als prosthetische Gruppe enthält (YosT und FridoviCH, 1973). Eine sodA $\operatorname{sod} B$ Doppelmutante ist nicht mehr in der Lage, auf Minimalmedium aerob zu wachsen und zeigte auch im Vollmedium eine erhöhte Sensitivität gegenüber Paraquat, einem Superoxidradikal-erzeugenden Agens (CARLIOZ und TouATI, 1986). Der Escherichia coli Stamm QC774, der ein Derivat des Stammes GC4468 ist, trägt Transposonintegrationen in den Genen $\operatorname{sod} A$ und $\operatorname{sod} B$, wodurch keine Expression von funktioneller SodA und SodB mehr möglich ist. Dieser Stamm zeigte eine erhöhte Sensitivität gegenüber Paraquat und Wasserstoffperoxid (CARLIOZ und TOUATI, 1986).

Durch die Zugabe des Agens Paraquat Dichlorid wird die Bildung von Superoxidradikalen bewirkt. Paraquat ist ein kationisches Bipyridyliumsalz, welches auch als Pflanzenschutzmittel Verwendung findet. Durch chemische Reduktion sowie durch Photolyse in Gegenwart von primären und sekundären Alkoholen entsteht aus dem divalenten Kation ein stabiles Kationradikal (Reaktionsgleichung 4.4). Als Elektronendonor für die chemische Reduktion dient beispielsweise zelluläres NADPH (LEDWITH, 1977).

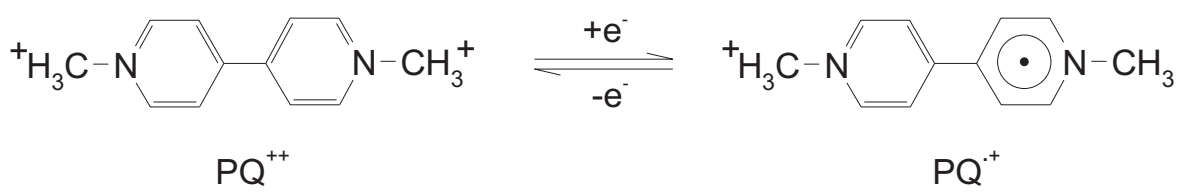

Dieses Kationradikal reagiert spontan mit molekularem Sauerstoff unter Bildung von Superoxid (Reaktionsgleichung 4.5).

$$
\mathrm{PQ}^{+}+\mathrm{O}_{2} \rightarrow \mathrm{PQ}^{++}+\mathrm{O}_{2}^{-\cdot}
$$

Die Superoxidradikale werden im E. coli Wildtyp sodann durch die Superoxid-Dismutase entgiftet, diese Reaktion kann in dem Stamm QC774 nicht stattfinden.

Um das Verhalten der beiden Stämme QC774 und GC4468 in An- und Abwesenheit von Paraquat zu untersuchen, wurden jeweils 2 Kolben mit $50 \mathrm{ml}$ dYT mit den beiden Stämmen inokuliert und bei $37^{\circ} \mathrm{C}$ inkubiert. Bei Erreichen einer $\mathrm{OD}_{600}$ von 0,1 bis 0,2 wurde zu den Stämmen $100 \mu \mathrm{M}$ Paraquat gegeben. Die $\mathrm{OD}_{600}$ wurde in regelmäßigen Zeitintervallen bestimmt. Die daraus abgeleiteten Wachstumskurven finden sich in Abb. 4.13. Wie man in 
der Abbildung erkennen kann, ist der Stamm QC774 sensitiv gegenüber Paraquat, da sein Wachstum ab dem Zeitpunkt der Zugabe von PQ langsamer fortschreitet. Der Stamm GC4468 hingegen zeigt keine Sensitivität gegenüber Paraquat, sein Wachstum verläuft mit oder ohne Zugabe des Agens gleich schnell. Weiterhin ist zu erkennen, daß der Stamm QC774 generell langsamer wächst als GC4468.

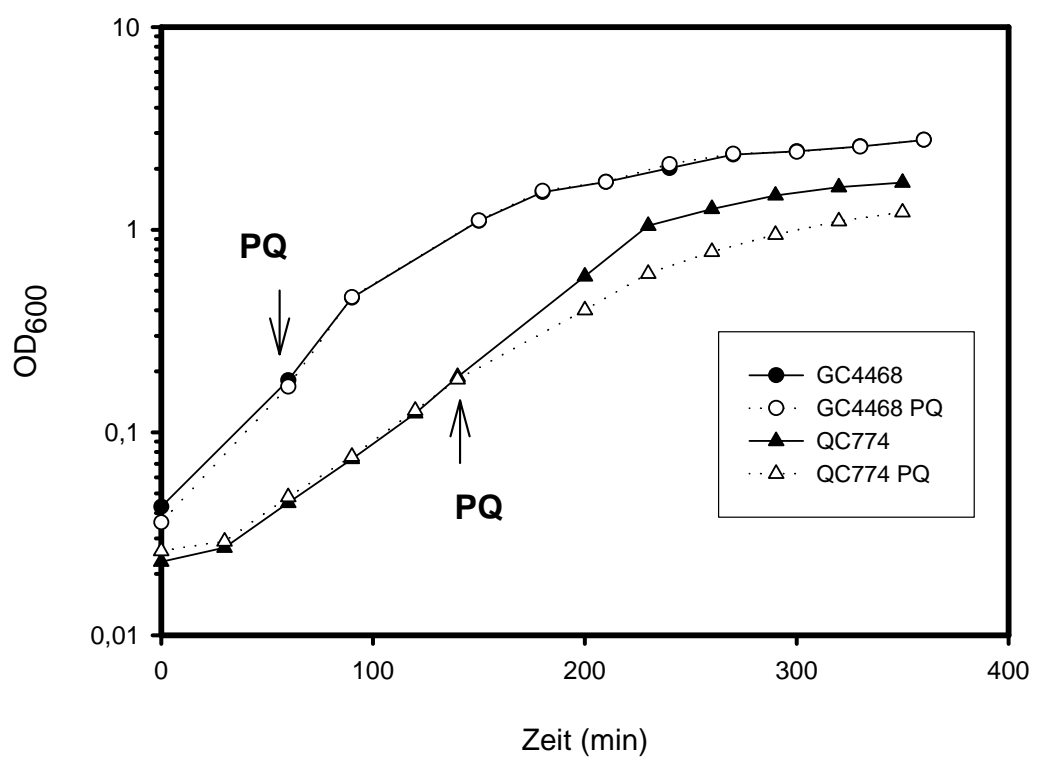

Abb. 4.13: Wachstumskurven der beiden Stämme GC4468 und QC774 in dYT, welches zum angegebenen Zeitpunkt mit $100 \mathrm{mM}$ Paraquat versetzt wurde.

Um einen möglichen Effekt der Expression von Pa5349 auf die Sensitivität gegenüber Paraquat zu untersuchen, wurde der Stamm QC774 mit dem Plasmid pASK75Pa5349 transformiert. Die Wachstumskurven wurden in $50 \mathrm{ml} \mathrm{LB-Medium,} \mathrm{welches} \mathrm{mit} \mathrm{dem}$ Antibiotikum Ampicillin komplettiert worden war, bei einer Temperatur von $37^{\circ} \mathrm{C}$ gemessen. Insgesamt wurden drei Ansätze jeweils im Triplikat aufgenommen. Bei zwei der drei Ansätze wurden nach 120 Minuten $200 \mu \mathrm{M}$ Paraquat zugegeben, bei einer dieser Ansätze war die Expression von Pa5349 durch Zugabe von Anhydrotetrazyklin induziert worden. Die Wachstumskurven sind in Abb. 4.14 dargestellt. Es wurde der Mittelwert berechnet und gegen die Zeit aufgetragen. Die Fehlerbalken bezeichnen die ermittelte Standardabweichung und erscheinen Aufgrund der gewählten logarithmischen Auftragung inhomogen. Wie aus der Abbildung $4.14 \mathrm{zu}$ erkennen ist, ist der Stamm QC774 sensitiv gegenüber Paraquat. Während die Kontrolle ohne Zugabe von Paraquat nach 530 Minuten bis zu einer $\mathrm{OD}_{600}$ von 2,64 gewachsen ist, ist der Stamm mit Zugabe von $200 \mu \mathrm{M}$ Paraquat nach derselben Zeitdauer nur bis $\mathrm{zu}$ einer $\mathrm{OD}_{600}$ von 0,97 gewachsen. Die Expression von Pa5349 hat keinen positiven Einfluß auf das Zellwachstum, im Gegenteil wachsen die Zellen nur bis zu einer OD $_{600}$ von 0,81 . 


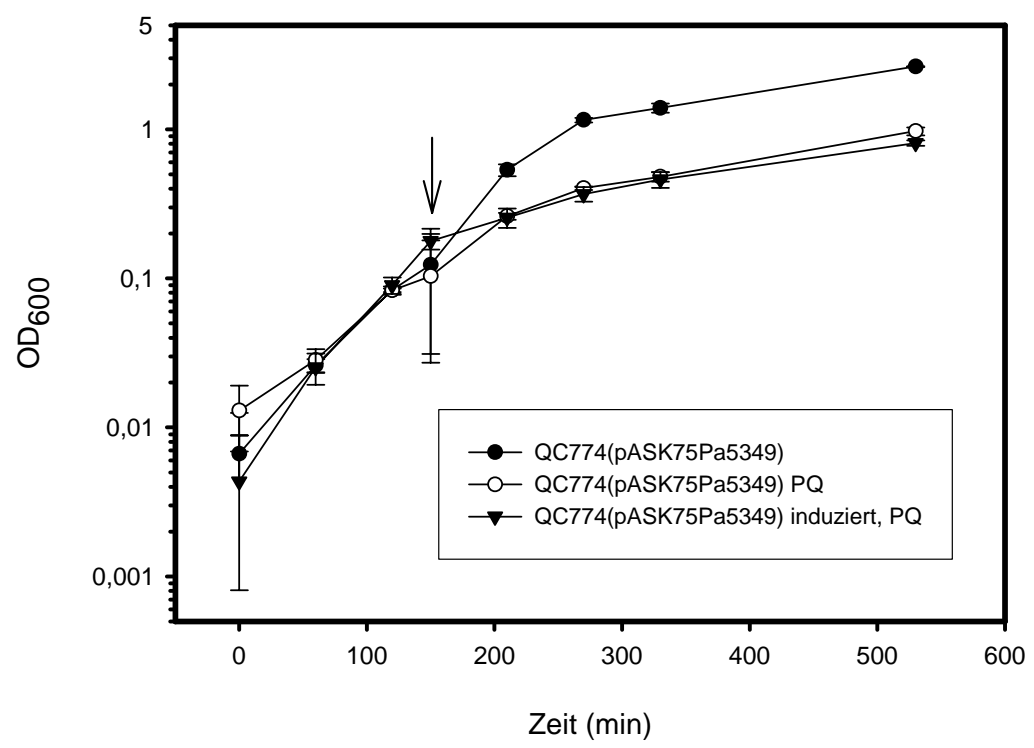

Abb. 4.14: Wachstumskurven des Stammes QC774 (pASK75Pa5349): ausgefüllte Kreise: ohne Zusätze; offene Kreise: Zugabe von $200 \mu \mathrm{M}$ Paraquat; Dreiecke: Induktion der Genexpression durch Zugabe von 0,2 $\mu \mathrm{g} / \mathrm{ml}$ ATC, Zugabe von $200 \mu \mathrm{M}$ Paraquat. Der Pfeil bezeichnet den Zeitpunkt der Zugabe von Paraquat.

Somit kann festgehalten werden, daß die Expression von Pa5349 in dem Stamm QC774 nicht zu der Komplementation des Phänotyps in Bezug auf die Empfindlichkeit gegenüber Paraquat geführt hat. In der Literatur sind zwei Fälle beschrieben, in denen die Fähigkeit eines als Rubredoxin Reduktase annotierten Proteins zur Komplementation des Stammes QC774 untersucht wurde. So wurde gezeigt, daß die heterologe Expression der putativen Rubredoxin Oxidoreduktase rbo aus Desulfovibrio vulgaris den sodA' sodB- Phänotyp aus Escherichia coli supprimieren kann (PIANZZOLA et al., 1996). Das rbo Genprodukt aus Desulfoarculus baarsii ist ebenfalls in der Lage, den Phänotyp dieser E. coli Mutante zu komplementieren (LIOCHEV und FrIDOVICH, 1997). Die Annotation der beiden putativen Rubredoxin Reduktasen beruht auf einer Homologie mit der Rubredoxin Reduktase aus Desulfovibrio gigas (BRUMLIK und VOORDOUW, 1989), für die ein funktioneller Nachweis einer Elektronenübertragung von $\mathrm{NADH}$ auf Rubredoxin erbracht werden konnte (VICTOR et al., 2003). Hingegen konnte weder für Rbo aus Desulfoarculus baarsii noch für Rbo aus Desulfovibrio vulgaris gezeigt werden, daß diese Proteine in der Lage sind, Elektronen auf Rubredoxin zu übertragen (LOMBARD et al., 2000a).

Die Primärsequenzen des Desulfovibrio Rbo und Pa5349 sind nur wenig homolog. So konnte mit dem Needleman-Wunsch Algorithmus (NEEDLEMAN und WUNSCH, 1970) unter Verwendung des Programms EMBOSS (RICE et al., 2000) ermittelt werden, daß nur 5,4 \% der Aminosäuren sequenzidentisch sind. Das rbo-Genprodukt aus Desulfoarculus baarsii hat mit 1,5 \% sequenzidentischen Aminosäuren eine noch geringere Homolgie zu Pa5349, wie mit demselben Verfahren ermittelt. Die Sequenzen der Rubredoxine aus D. vulgaris, D. baarsii und $P$. aeruginosa besitzen jedoch Sequenzhomologien, da diese Proteine über eine identische konservierte Rubredoxin-Domäne verfügen (Identifikationsnummer cd00730). Die Unterschiede zwischen den Primärsequenzen von Pa5349 und den beiden Rbo Proteinen aus 
D. vulgaris und $D$. baarsii deuten auch darauf hin, daß diese Proteine in der Zelle eine unterschiedliche Funktion ausüben.

Durch die vorangegangenen Experimente konnte keine direkte Rolle für Pa5349 im Abbau von Superoxid gezeigt werden.

\subsection{Untersuchung einer indirekten Wirkung von Rubredoxin Reduktase und Rubredoxin bei dem Abbau von Superoxidradikalen}

Da die beiden Proteine Rubredoxin und Rubredoxin Reduktase eine Funktion im Elektronentransport spielen, muß bei einer indirekten Wirkung von Rubredoxin Reduktase auf den Abbau von Superoxid die Anwesenheit eines Elektronenakzeptor in der P. aeruginosa Zelle angenommen werden, der durch die beiden Proteine beliefert wird und die Elektronen weiter auf Superoxidradikale überträgt und diese somit reduziert. In den im folgenden dargestellten Experimenten wurde untersucht, ob sich den $P$. aeruginosa Zellysaten eine Komponente befindet, die zum Abbau von Superoxid befähigt ist, und ob diese Komponente Elektronen durch Rubredoxin Reduktase und Rubredoxin erhalten kann. Hierzu wurden Superoxidradikale durch Verwendung des Xanthin/Xanthinoxidase Systems generiert (Reaktionsgleichung 4.3) und mit der Luminolreaktion (Abb. 4.11) nachgewiesen, wie schon in Abschnitt 4.1.1.8.2 beschrieben. Damit die Luminolreaktion ablaufen kann, ist die Präsenz von $\mathrm{Fe}^{\text {(III) }}$ notwendig, welches durch Zugabe von Kalium-Hexacyanoferrat ${ }^{\text {(III) }}$ bereitgestellt wurde.

Als Kontrolle der Lumineszenzreaktion wurde ein Reaktionsansatz mit 0,01 $\mu$ mol Xanthin-Stammlösung (siehe 2.9), $3 \mu \mathrm{mol}$ Luminol-Stammlösung (siehe 2.9) und $1 \mu \mathrm{l}$ Xanthinoxidase (siehe 2.5) in einem Gesamtvolumen von einem Milliliter PBS vorbereitet. Unmittelbar nach Zugabe der Xanthinoxidase wurde der Ansatz gemischt und genau $15 \mathrm{~s}$ später wurde die Luminolreaktion durch Zugabe von $0,01 \mu \mathrm{mol}$ Kalium-Hexacyanoferrat ${ }^{(I I I)}$ gestartet und die Lumineszenz bei $415 \mathrm{~nm}$ registriert. Es wurden Gesamtzellextrakte identischer Zellzahl der Rubredoxin Reduktase-Mutante 41D3 und des Wildtyps TB hergestellt (3.4.5). Diese Lysate der beiden Stämme wurden auf ihre Fähigkeit, die Luminolreaktion zu attenuieren, untersucht. Ein solche Attenuation müßte entweder auf der Entfernung der Superoxidradikale oder der Reduktion des $\mathrm{Fe}^{(\mathrm{III})}$ beruhen, da diese beiden Komponenten für den Ablauf der Luminolreaktion hinreichend und notwendig sind (MERENYI und LIND, 1980). Jeweils $200 \mu \mathrm{l}$ der Lysate des Stammes TB oder der Mutante 41D3 wurden zu den Reaktionen zugegeben, wobei das Reaktionsvolumen ebenfalls ein Milliliter, eingestellt mit PBS, betrug. Die Messungen wurden jeweils im Duplikat durchgeführt und sind in Abb. 4.15 gezeigt. Durch die Zugabe des Lysates der Mutante 41D3 war keine signifikante Änderung der Luminol-Lumineszenz zu beobachten. Eine Zugabe von Lysat des Stammes TB resultierte hingegen in einer drastischen Abnahme der Lumineszenz. 


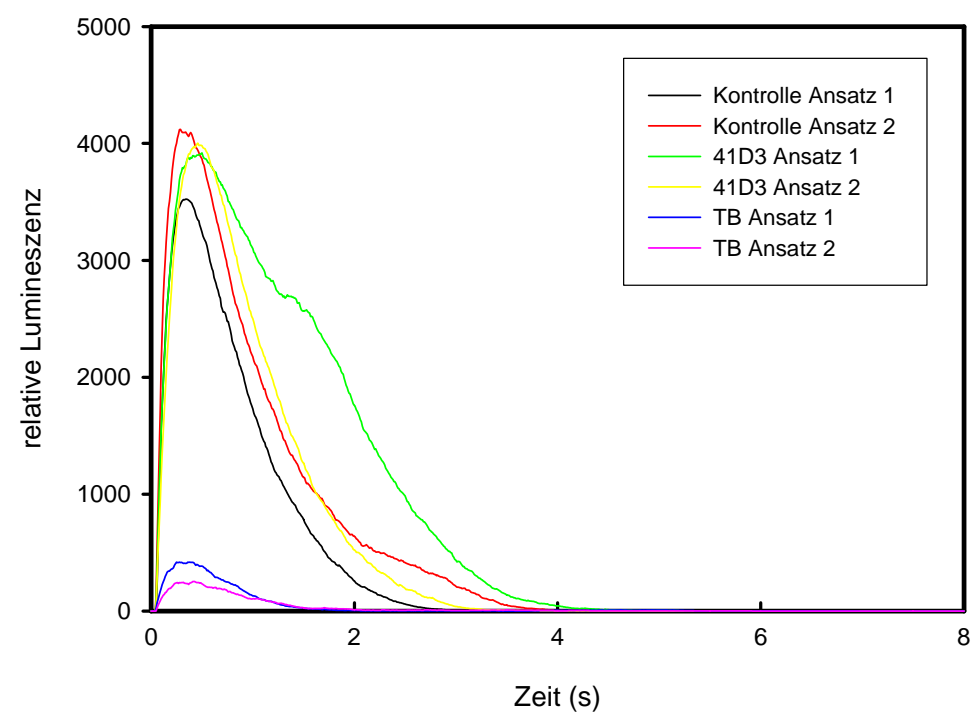

Abb. 4.15: Messung der relativen Lumineszenz der Luminolreaktion und Effekt der Zugabe von Lysaten der Stämme TB (Wildtyp) und der Mutante 41D3.

Anschließend wurde untersucht, ob die Proteine Rubredoxin Reduktase und Rubredoxin in der Lage sind, Elektronen auf einen Akzeptor in der $P$. aeruginosa Zelle zu übertragen. Als Hypothese wurde angenommen, daß sich dieser Akzeptor sowohl in dem Lysat des Wildtyps als auch in dem Lysat der Mutante befände, in dem letzteren aber nicht mit Reduktionsäquivalenten beliefert werden könne.

Es wurde ein Reaktionsansatz mit $200 \mu$ l 41D3-Lysat, 1200 pmol Rubredoxin Reduktase, 6000 pmol Rubredoxin, 2,5 $\mu \mathrm{mol} \mathrm{NADH}, 0,01 \mu \mathrm{mol}$ Xanthin, $3 \mu \mathrm{mol}$ Luminol-Stammlösung (siehe 2.9) und $1 \mu$ Xanthinoxidase (siehe 2.5) in einem Gesamtvolumen von einem Milliliter PBS vorbereitet. Unmittelbar nach Zugabe der Xanthinoxidase wurde der Ansatz gemischt und genau $15 \mathrm{~s}$ später wurde die Luminolreaktion durch Zugabe von 0,01 $\mu$ mol Kalium-

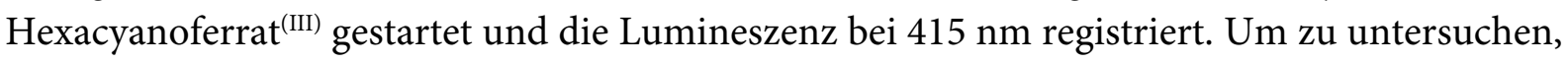
ob eine Attenuation der Lumineszenz durch eine Entfernung der Superoxidradikale bewirkt werden kann, wurde als Positivkontrolle ein Ansatz mit $200 \mu \mathrm{l}$ 41D3-Lysat, 0,01 $\mu \mathrm{mol}$ Xanthin, $3 \mu \mathrm{mol}$ Luminol-Stammlösung (siehe 2.9), $1 \mu$ Xanthinoxidase und $1600 \mathrm{pmol}$ boviner Superoxid-Dismutase (Fa. Sigma) vorbereitet. Die Messungen wurden jeweils im Duplikat durchgeführt und sind in der Abb. 4.16 dargestellt. Durch die Zugabe von Rubredoxin Reduktase, Rubredoxin und NADH wurde, im Vergleich zur Zugabe des 41D3Lysates, eine deutliche Abnahme der Lumineszenz registriert. Ebenso verhält es sich bei der Zugabe von Superoxid-Dimutase, die ebenfalls zu einer deutlichen Verringerung der Luminol-Lumineszenz führte.

Der relative Luminolumsatz aller Reaktionen wurde bestimmt, in dem das Flächenintegral aller Messungen aus den Abbildungen 4.15 und 4.16 berechnet wurde. Dieser Umsatz, der in dem Balkendiagramm in Abb. 4.17 dargstellt ist, ist ein Maß für die Menge an Superoxidradikalen, die für den Ablauf der Luminolreaktion zur Verfügung stehen. 


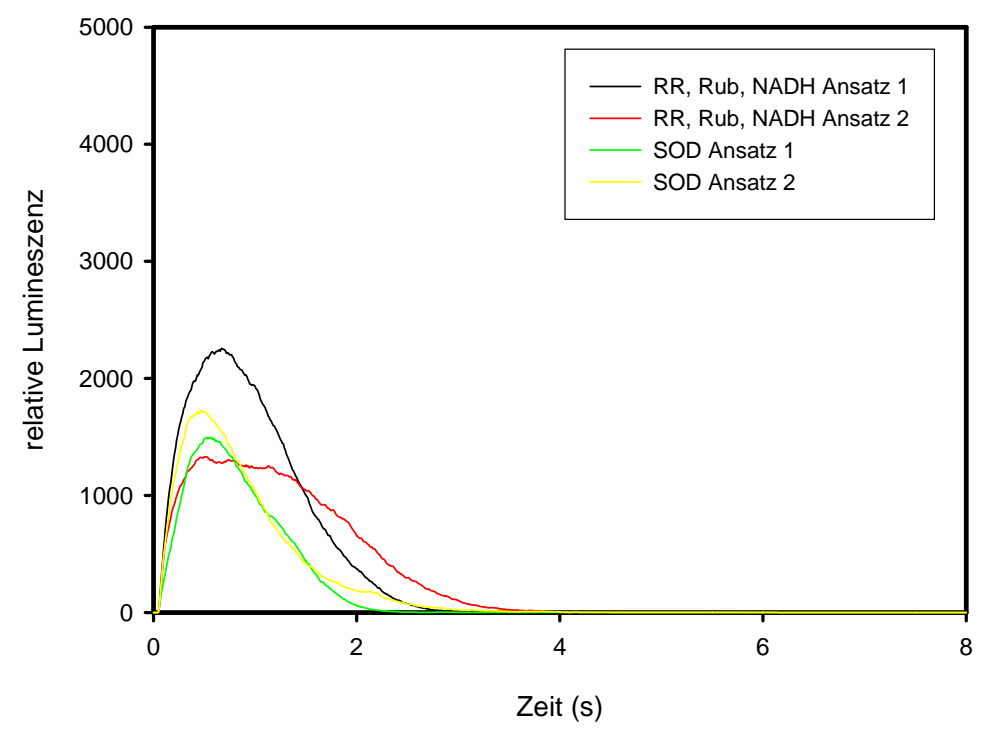

Abb. 4.16: Messung der relativen Lumineszenz der Luminolreaktion mit Zugabe von Lysat der Mutante 41D3, daß entweder mit Rubredoxin Reduktase (RR), Rubredoxin (Rub) und NADH oder mit boviner SuperoxidDismutase (SOD) supplementiert war.

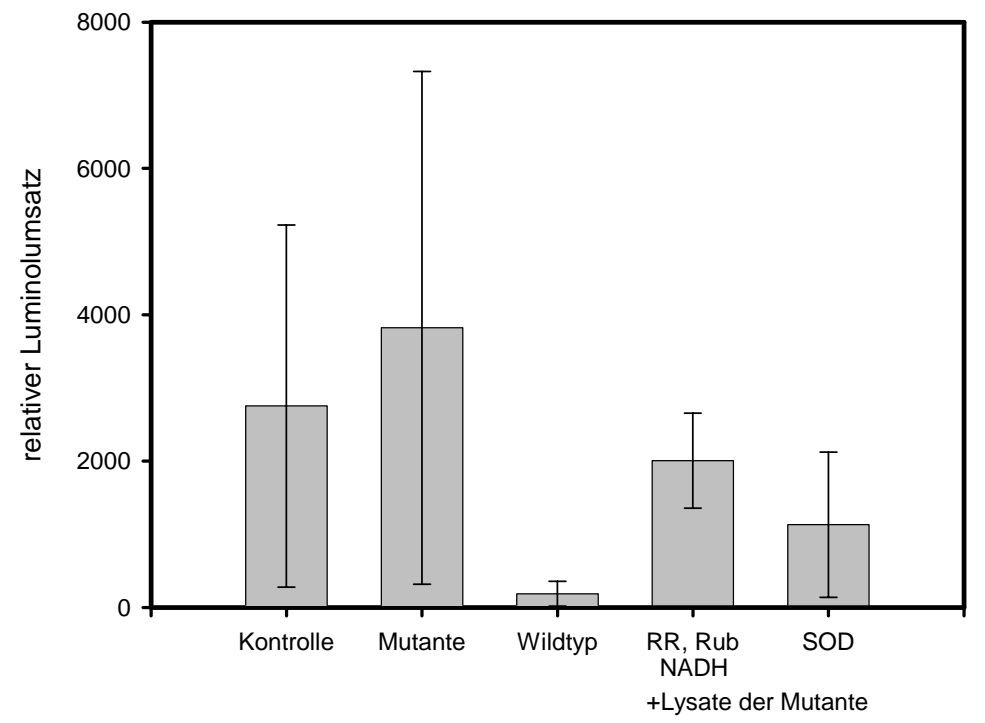

Abb. 4.17: Berechnung des relativen Luminolumsatzes aus den Kurven in den Abbildungen 4.15 und 4.16. Kontrolle: Lumineszenz der Luminolreaktion. Mutante: Zugabe von Lysat der Mutante 41D3. Wildtyp: Zugabe von Lysat des Wildtyps. RR, Rub, NADH: Zugabe von Lysat der Mutante 41D3 und Rubredoxin Reduktase (RR), Rubredoxin (Rub) und NADH. SOD: Zugabe von Lysat der Mutante 41D3 und Superoxid-Dismutase (SOD).

Wie in Abb. 4.17 zu erkennen ist, führt die Zugabe des Lysates der Mutante 41D3 nicht zu einer Attenuation des relativen Luminolumsatzes, während durch die Zugabe des Lysates des Wildtyps der relative Luminolumsatz deutlich reduziert ist. Dies läßt die Vermutung zu, daß 
sich in dem Lysat des Wildtyps Substanzen befinden, die das durch Xanthin/Xanthinoxidase produzierte Superoxid abbauen, während dieser Abbau in dem Lysat der Mutante nicht zu beobachten ist. Da die Zugabe der Proteine Rubredoxin Reduktase, Rubredoxin und des Elektronendonors NADH zu dem Lysat der Mutante in einer Reduktion des relativen Luminolumsatzes resultiert, läßt sich die Hypothese aufstellen, daß sich in beiden Lysaten eine Substanz befindet, die den Abbau von Superoxid bewirken kann, die aber in dem Lysat der Mutante ohne weitere Zugabe von Rubredoxin Reduktase, Rubredoxin und NADH nicht aktiv ist. Weiterhin deuten diese Ergebnisse darauf hin, daß diese Substanz Reduktionsäquivalente von Rubredoxin Reduktase, Rubredoxin und NADH erhält und diese zur Reduktion von Superoxidradikalen verwendet. Da es sich bei dieser Reaktion um eine Redoxreaktion mit spezifischen Partnern handelt, liegt die Vermutung nahe, daß sie durch ein Enzym katalysiert wird. Die Zugabe von SOD zu dem Ansatz hatte einen ähnlichen Effekt wie die Zugabe von Rubredoxin Reduktase, Rubredoxin und NADH, was dafür spricht, daß die Entfernung von Superoxidradikalen aus der Reaktion für das beobachtete Phänomen verantwortlich ist.

Formal kann die beobachtete Attenuation der Luminolreaktion auch auf eine Reduktion des zugegebenen $\mathrm{Fe}^{(\mathrm{III})} \mathrm{zu} \mathrm{Fe} \mathrm{Fe}^{(\mathrm{II})}$ zurückzuführen sein, da $\mathrm{Fe}^{(\mathrm{II})}$ nicht in der Lage ist, eine Lumineszenz des Luminols unter den gewählten Bedingungen zu bewirken (MERENYI und LIND, 1980). Daher wurde untersucht, ob die Zugabe von TB-Lysat zu KaliumHexacyanoferrat $^{(\mathrm{III})}$ eine Reduktion des $\mathrm{Fe}^{(\mathrm{III})} \mathrm{zu}^{\mathrm{F}} \mathrm{Fe}^{(\mathrm{II})}$ bewirkt. Diese Reduktion kann spektrophotometrisch gemessen werden, da Kalium-Hexacyanoferrat ${ }^{\text {(III) }}$ ein Absorptionsmaximum bei $420 \mathrm{~nm}$ besitzt und Kalium-Hexacyanoferrat ${ }^{(\mathrm{II})}$ bei dieser Wellenlänge nicht absorbiert (ZAK et al., 2001). Hierzu wurden $100 \mu \mathrm{l}$ TB-Lysat mit 0,1 $\mu \mathrm{mol}$ Kalium-Hexacyanoferrat ${ }^{(\mathrm{III})}$ in einem Gesamtvolumen von $1 \mathrm{ml}$ PBS für 1 Minute inkubiert und das Spektrum in dem Wellenlängenbereich von 350 bis $450 \mathrm{~nm}$ gemessen. Um den Anteil des Lysates an der Absorption in diesem Wellelängenbereich zu bestimmen, wurde ein Spektrum von $100 \mu \mathrm{l}$ TB-Lysat und $0,1 \mu \mathrm{mol}$ Kalium-Hexacyanoferrat ${ }^{(\mathrm{II})}$ in einem Gesamtvolumen von $1 \mathrm{ml}$ PBS in dem selben Wellenlängenbereich aufgenommen und von dem ersten Spektrum subtrahiert und somit ein Differentialspektrum berechnet. Als Kontrolle wurde analog ein Differentialspektrum bestimmt, bei dem anstatt TB-Lysat das Lysat der Mutante 41D3 verwendet wurde. Diese beiden Spektren sind in Abb. 4.18 dargestellt. Aus dieser Abbildung geht hervor, daß durch die Zugabe des TB-Lysats keine Reduktion des Kalium-Hexacyanoferrats ${ }^{(I I I)}$ bewirkt wird. Dies ist ein eindeutiger Hinweis darauf, daß die beobachtete Attenuation der Lumineszenz auf die Entfernung der Superoxidradikale und

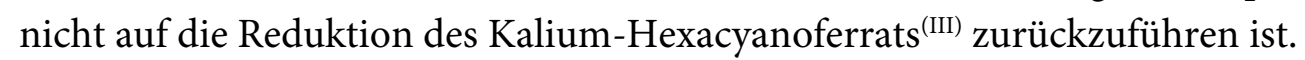




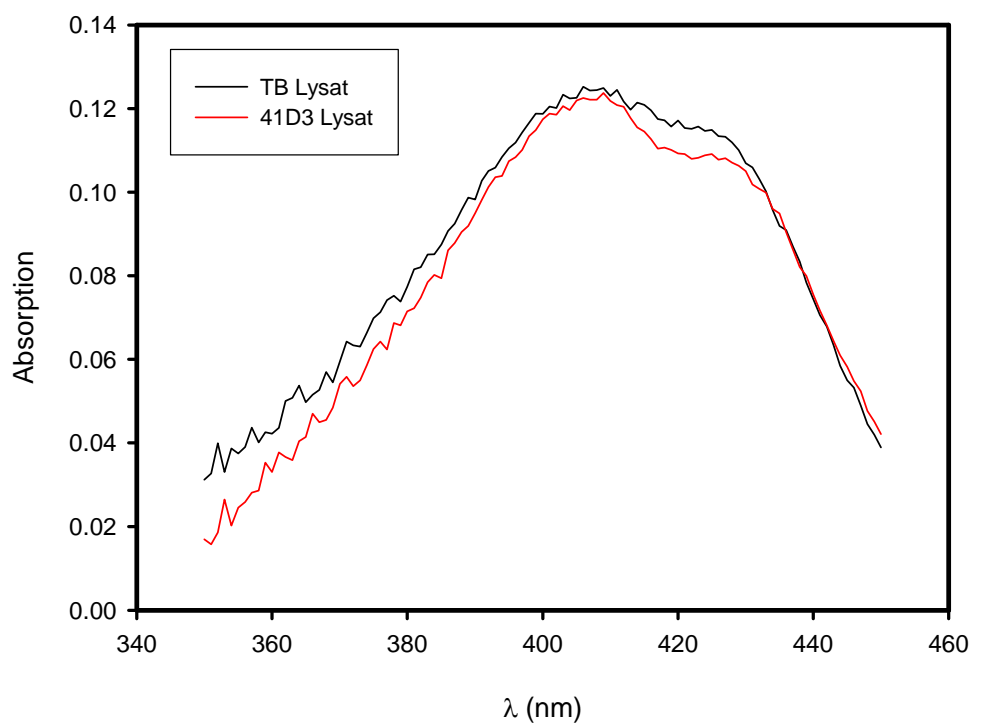

Abb. 4.18: Differentialspektren einer Inkubation von $0,1 \mu$ mol Kalium-Hexacyanoferrat ${ }^{(I I I)}$ mit den Lysaten von TB und der Mutante 41D3.

\subsubsection{Kinetische Charakterisierung von Pa5349}

Eine enzymatische Reaktion läßt sich durch mehrere kinetische Parameter charakterisieren. Die Grundgleichung der Enzymkinetik ist die Michaelis-Menten-Gleichung (4.6). Sie beinhaltet die Parameter $V_{\max }$ und $K_{\mathrm{M}}$, die für jedes Enzym bezüglich eines bestimmten Substrates unter definierten Bedingungen charakteristisch sind. Die maximale Geschwindigkeit des Substratumsatzes $V_{\max }$ einer Reaktion tritt bei hohen Substratkonzentrationen auf, wenn alle Substratbindestellen im Enzym vollständig gesättigt sind und kein freies Enzym, sondern nur Enzym-Substrat Komplexe in der Lösung vorliegen. Der Parameter $K_{\mathrm{M}}$ bezeichnet diejenige Substratkonzentration, bei der die Hälfte der maximalen Geschwindigkeit erreicht wird. Ein Enzym mit kleinem $K_{\mathrm{M}}$-Wert erreicht seine maximale katalytische Wirksamkeit bei kleinen Substratkonzentrationen. Eine weitere Größe für die kinetische Charakterisierung von Enzymen ist die katalytische Konstante $k_{\text {cat, }}$ welche auch als Wechselzahl bezeichnet wird. Hierbei wird die maximale Geschwindigkeit auf die molare Konzentration an vorhandenen aktiven Zentren bezogen. Bei Enzymen mit nur einem aktiven Zentrum wird $k_{\text {cat }}$ errechnet, indem man die maximale Geschwindigkeit durch die totale Enzymkonzentration $[\mathrm{E}]_{\mathrm{T}}$ dividiert. Ein Maß für die katalytische Wirksamkeit eines Enzyms ist der Quotient aus $k_{\text {cat }}$ und $K_{\mathrm{M}}$. Dieser ist die scheinbare Geschwindigkeitskonstante zweiter Ordnung der enzymatischen Reaktion, da die Reaktionshäufigkeit direkt mit der Kollisionshäufigkeit von Enzym und Substrat in der Lösung korreliert. Für die katalytische Effizienz gibt es eine Obergrenze. Die Bildung des Enzym-Substrat Komplex kann nicht schneller erfolgen, als Enzym- und Substratmoleküle in der Lösung miteinander kollidieren. Dieses diffusionskontrollierte Limit liegt im Bereich von $10^{9} \mathrm{M}^{-1} \mathrm{~s}^{-1}$. Dennoch sind nicht wenige Enzyme bekannt, die diese katalytische Perfektion erreicht haben, beispielsweise Acetylcholinesterase, Carboanhydrase oder Triosephosphat-Isomerase (STRYER, 1994). 


$$
V_{o}=\frac{V_{\max }[S]}{K_{M}+[S]}
$$

Im folgenden sollen die kinetischen Parameter der Rubredoxin Reduktase bestimmt werden. Diese hat als Enzym zwei Substrate, zum einen den Elektronendonor NADH oder $\mathrm{NADPH}$ und zum anderen das Protein Rubredoxin. Die Enzymreaktion ist somit eine Reaktion zweiter Ordnung, da die Reaktionsgeschwindigkeit von der Konzentration zweier Reaktanten abhängig ist. Man kann die kinetischen Parameter der Rubredoxin Reduktase bezüglich eines Reaktanten jedoch bestimmen, indem man den jeweils anderen Reaktanten in einer Konzentration, die weit über dessen $K_{\mathrm{M}}$-Wert liegt, in der Reaktion einsetzt. Somit ist die Reaktionsgeschwindigkeit nur noch von der Konzentration des zu charakterisierenden Reaktanten abhängig, es handelt sich also um eine Reaktion pseudo-erster Ordnung.

Die Reduktion des Rubredoxins läßt sich photometrisch bei einer Wellenlänge von $505 \mathrm{~nm}$ bestimmen. Bei dieser Wellenlänge absorbiert nur die oxidierte Form des Proteins Licht, die reduzierte Form hingegen nicht. Weiterhin ist der Einfluß der Rubredoxin Reduktase auf die Absorption bei dieser Wellenlänge vernachlässigbar. Bei $495 \mathrm{~nm}$, dem Absoptionsmaximum des oxidierten Rubredoxins, absorbiert die Rubredoxin Reduktase hingegen ebenfalls. Die kinetischen Parameter des Enzyms bezüglich NADPH, NADH und Rubredoxin wurden photometrisch bestimmt. Während die Konzentration des einen Reaktanten konstant im Überschuß gehalten wurde, wurde die Konzentration des anderen Reaktanten so verändert, daß eine konzentrationsabhängige Geschwindigkeit der Reaktion beobachtet werden konnte. Die Reaktionsgeschwindigkeit $v_{o}$ wurde durch Berechnung der Steigung während des Beginns der Reaktion, wenn noch wenig Produkt gebildet worden war, bestimmt. Hierfür wurde zuerst der molare Extinktionskoeffizient von Rubredoxin bei einer Wellenlänge von $505 \mathrm{~nm}$ ermittelt, in dem die Absorption einer $100 \mu \mathrm{M}$ Rubredoxinlösung gemessen wurde. Hierbei wurde ein Wert von 0,33 ermittelt, woraus sich der Wert von $3300 \mathrm{M}^{-1} \mathrm{~cm}^{-1}$ für den molaren Extinktionskoeffizienten errechnete. Dann konnte aus der Differenz der Absorption die Menge an reduziertem Rubredoxin pro Minute bestimmt werden. Jede Messung wurde im Duplikat durchgeführt.

In Abb. 4.19 sind die berechneten Reaktionsgeschwindigkeiten $V_{0}$ in Abhängigkeit der Konzentration von Rubredoxin, NADH und NADPH dargestellt. Für jeden Meßpunkt wurden zwei Werte errechnet. Mit Hilfe des Programms SigmaPlot wurden aus den ermittelten Werten die Parameter $V_{\max }$ und $K_{\mathrm{M}}$ durch nicht-lineare Regression berechnet. Das Programm verwendet hierbei den sogenannten Marquardt-Levenberg-Algorithmus (MARQUARDT, 1963), um unter Berücksichtigung der Meßwerte durch einen iterativen Prozeß Werte für die Parameter zu berechnen, die am besten zu einer definierten Gleichung, in diesem Fall der Michaelis-Menten-Gleichung (4.6), passen. 
A
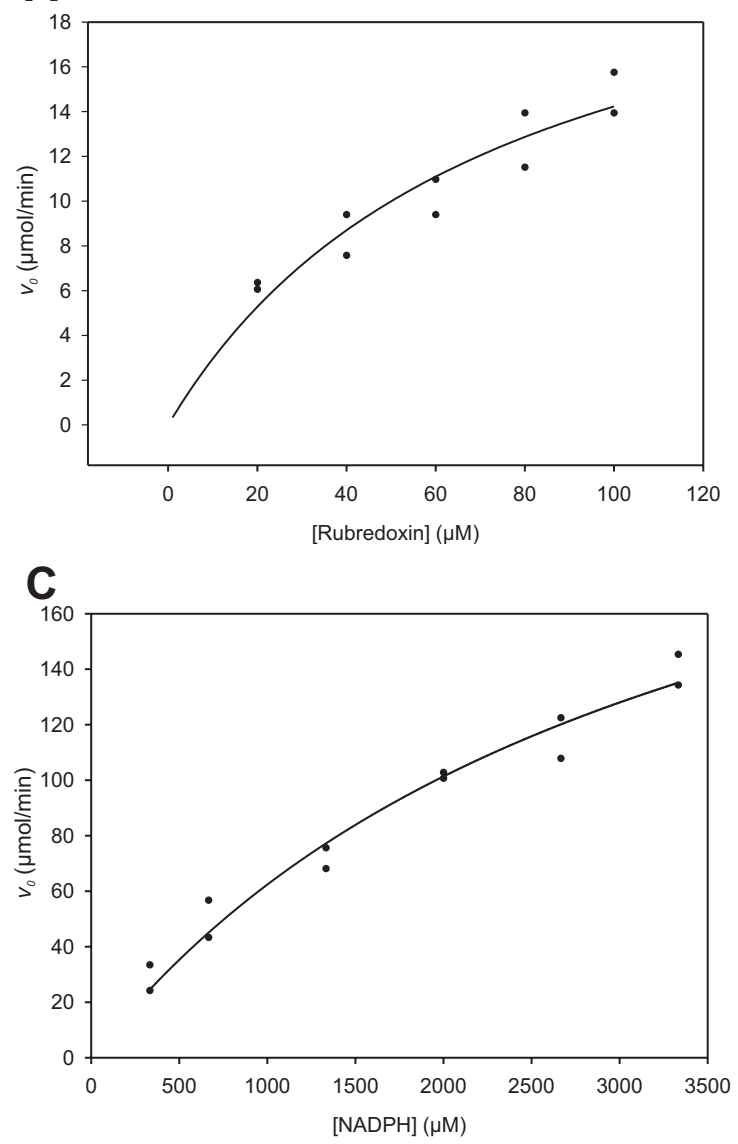

B

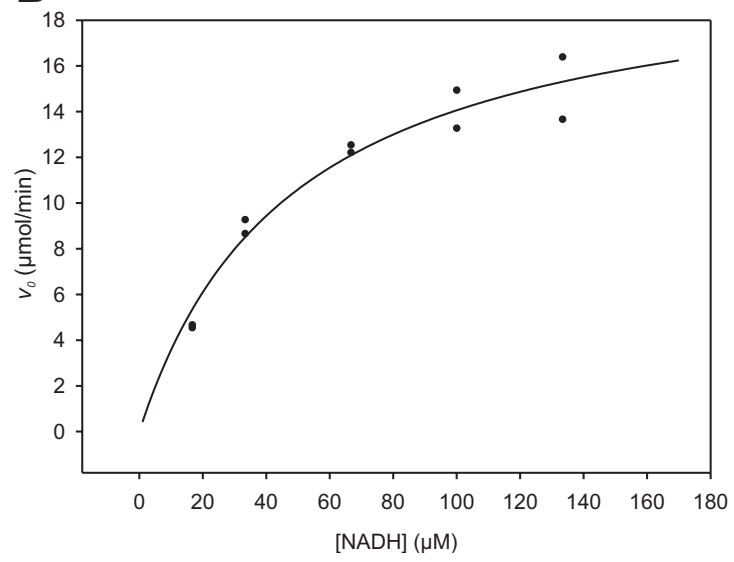

Abb. 4.19: Kinetische Charakterisierung von Rubredoxin Reduktase. Die Reaktionsgeschwindigkeit in Abhängigkeit der Konzentrationen von Rubredoxin (A), NADH (B) und NADPH (C) wurden bestimmt.

Die berechneten Werte für $K_{\mathrm{M}}$ und $V_{\max }$ finden sich in Tabelle 4.1. Die Wechselzahl $k_{\text {cat }}$ des Enzyms konnte unter Berücksichtigung der eingesetzten totalen Enzymkonzentration $[\mathrm{E}]_{\mathrm{T}}$ bestimmt werden, da $k_{\text {cat }}=V_{\max } /[\mathrm{E}]_{\mathrm{T}}$. Die katalytische Effizienz $k_{\text {cat }} / K_{\mathrm{M}}$ ist ebenfalls in der Tabelle 4.1 dargestellt. Bei den Bestimmungen der kinetischen Parameter gibt es jedoch eine intrinsische Limitierung, die die Qualität der gewonnenen Werte beeinflußt: um Bedingungen pseudo-erster Ordnung zu erhalten, aber gleichzeitig ein meßbares spektroskopisches Signal zu schaffen, konnte die Konzentration des Rubredoxins nicht wesentlich unter dessen $K_{\mathrm{M}^{-}}$ Wert abgesenkt werden. Dies führt zwangsweise zu einer beschränkten Bestimmtheit der Kurve bei geringen Rubredoxin-Konzentrationen. Dieses Problem ist allerdings in der Literatur bekannt und kann nicht ohne weiteres umgangen werden (LEE et al., 1998).

\begin{tabular}{|l|l|l|l|}
\hline & Rubredoxin & NADH & NADPH \\
\hline$K_{\mathrm{M}}$ & $66,42 \times 10^{-6} \mathrm{M}$ & $48,46 \times 10^{-6} \mathrm{M}$ & $3,33 \times 10^{-3} \mathrm{M}$ \\
\hline$V_{\max }$ & $3,62 \times 10^{-7} \mathrm{~mol} / \mathrm{s}$ & $3,48 \times 10^{-7} \mathrm{~mol} / \mathrm{s}$ & $4,50 \times 10^{-6} \mathrm{~mol} / \mathrm{s}$ \\
\hline$[\mathrm{E}]_{\mathrm{T}}$ & $6,4 \times 10^{-12} \mathrm{~mol}$ & $6,4 \times 10^{-12} \mathrm{~mol}$ & $21,30 \times 10^{-12} \mathrm{~mol}$ \\
\hline$k_{\text {cat }}$ & $5,66 \times 10^{4} \mathrm{~s}^{-1}$ & $5,44 \times 10^{4} \mathrm{~s}^{-1}$ & $2,11 \times 10^{5} \mathrm{~s}^{-1}$ \\
\hline$k_{\text {cat }} / K_{\mathrm{M}}$ & $0,85 \times 10^{9} \mathrm{M}^{-1} \mathrm{~s}^{-1}$ & $1,12 \times 10^{9} \mathrm{M}^{-1} \mathrm{~s}^{-1}$ & $6,3 \times 10^{7} \mathrm{M}^{-1} \mathrm{~s}^{-1}$ \\
\hline
\end{tabular}

Tabelle 4.1: kinetische Parameter der Rubredoxin Reduktase bezüglich der Substrate Rubredoxin, NADH, NADPH. 
Wie lassen sich diese Werte nun im Hinblick auf eine physiologische Funktion der Rubredoxin Reduktase interpretieren? Als erstes fällt auf, daß das Enzym einen $K_{\mathrm{M}}$-Wert für NADH besitzt, der um zwei Dekaden niedriger liegt als der für NADPH. Die NADHKonzentration in der Zellen beträgt in Escherichia coli ca. $52 \mu \mathrm{M}$, die intrazelluläre NADPH Konzentration wird mit $770 \mu \mathrm{M}$ angegeben (WOODMANSEE und IMLAY, 2002). Somit ist zu vermuten, daß NADH das physiologische Substrat für das Enzym darstellt, da Rubredoxin Reduktase einen $K_{\mathrm{M}}$-Wert von $48 \mu \mathrm{M}$ für $\mathrm{NADH}$ besitzt. $\mathrm{NADH}$ wird in den Zellen hauptsächlich im katabolischen Stoffwechsel verwendet (MADIGAN et al., 2000). Es entsteht zum Beispiel bei der Glykolyse oder im Zitronensäurezyklus (STRYER, 1994). NADPH tritt in den Zellen eher im anabolischen Stoffwechsel in Erscheinung (MADIGAN et al., 2000). Daß Rubredoxin Reduktase in der Lage ist, auch dieses Molekül als Elektronendonor zu verwenden, reflektiert möglicherweise seine evolutive Verwandtschaft $\mathrm{zu}$ Rubredoxin Reduktasen, die in aeroben Mikroorganismen in den Abbauwegen von Alkanen eine Rolle spielen (EGGINK et al., 1990; GEISSDORFER et al., 1995; LEE et al., 1998; MARIN et al., 2003; SMITS et al., 2003). Als physiologisches Substrat wird NADPH aber eher keine Rolle spielen, da es nicht in so hohen Konzentrationen in der Zelle vorkommt, als daß das Enzym in dem Bereich des $K_{\mathrm{M}^{-}}$Wertes zu arbeiten vermag.

Die katalytische Effizienz des Enzyms ist für seine beiden physiologischen Substrate Rubredoxin und NADH sehr hoch und liegt im Bereich der diffusionskontrollierten Grenze von in etwa $10^{9} \mathrm{M}^{-1} \mathrm{~s}^{-1}$. Postuliert man für die Rubredoxin Reduktase eine Beteiligung in der Entgiftung reaktiver Sauerstoffspezies, läßt dieser Befund durchaus eine physiologische Relevanz erkennen. Reaktive Sauerstoffspezies sollten durch zelluläre Mechanismen entgiftet werden, bevor sie mit anderen zellulären Komponenten reagieren und diese schädigen können. Jeder Kontakt eines Enzyms, das eine solche Aufgabe erfüllt, mit einem reaktiven Sauerstoff sollte somit $\mathrm{zu}$ einer Reaktion führen. Zwar konnte gezeigt werden, daß Rubredoxin Reduktase nicht direkt für die Übertragung eines Elektrons auf eine reaktive Sauerstoffspezies verantwortlich ist, dennoch gibt es Hinweise darauf, daß das Protein Teil einer Elektronentransportkette ist, an dessen Ende die Übertragung des Elektrons auf Superoxid steht. Die katalytische Effizienz dieser Kette wäre nur so groß, wie es ihr schwächstes Glied zuläßt. Zumindest Rubredoxin Reduktase erfüllt die formalen Bedingungen, die an jedes Mitglied einer solchen Elektronentransportkette gestellt werden müssen.

\subsubsection{Zusammenfassung und Diskussion der über Rubredoxin Reduktase gewonnenen Erkenntnisse}

Die Mutante 41D3 trägt eine Transposonintegration in dem Gen Pa5349, das für eine Rubredoxin Reduktase kodiert. Dieses Gen liegt zusammen auf einem Operon mit dem Gen für Rubredoxin1 (Pa5350) (Abb. 4.2), wobei Pa5350 das erste Gen in dem Operon ist. Obwohl die kodierende Sequenz von Rubredoxin nicht durch das Transposon unterbrochen wird, ist seine Translation in vivo möglicherweise dennoch beeinflußt, da durch die Insertion die Stabilität der Messenger RNA sowie die Effizienz der Proteinsynthese beeinträchtigt sein 
kann. Rubredoxin Reduktase scheint eine bedeutende Rolle in der Pseudomonas Zelle zu spielen, da die Mutante in zweierlei Hinsicht von Wildtyp abweicht. Zum einen besteht eine erhöhte Sensitivität gegenüber Wasserstoffperoxid, die möglicherweise auch direkt für die beobachtete verringerte Persistenz in Granulozyten verantwortlich ist. Zum anderen findet bei der Mutante keine Produktion von Acyl-Homoserinlactonen mehr statt, das Quorum Sensing ist ausgeschaltet.

Rubredoxin Reduktase ist ein Enzym, welches ein Flavin-Adenin-Mononukleotid (FAD) enthält und $\mathrm{NADH}$ sowie auch mit einer geringeren $K_{\mathrm{M}} \mathrm{NADPH}$ als Elektronendonor akzeptieren kann. Das Elektron wird durch das Enzym von den Elektronendonoren auf das Protein Rubredoxin übertragen, welches somit reduziert wird. Die katalysierte Reaktion ist somit eine klassische Redox-Reaktion, bei der ein Partner, das NADPH oder NADH, oxidiert, und der zweite Partner, das Rubredoxin, reduziert wird.

Da die Mutante 41D3 sensitiver gegenüber Wasserstoffperoxid ist, läßt sich vermuten, daß die Rubredoxin Reduktase eine Rolle in der Entgiftung reaktiver Sauerstoffspezies spielt. In dem Abbau von Wasserstoffperoxid in der Zelle sind zwei Enzyme involviert, zum einen die Katalase, zum anderen die Peroxidase (CABISCOL et al., 2000), wobei bei der letzteren eine Übertragung eines Elektrons von $\mathrm{NADH}$ auf das Wasserstoffperoxid katalysiert wird (MAdigan et al., 2000). Das Proteinpaar Rubredoxin Reduktase/Rubredoxin kann jedoch weder die Funktion einer Katalase, noch die einer Peroxidase übernehmen.

Die schädliche Wirkung von Wasserstoffperoxid kann auch in seinem Umsatz zu Superoxid gesucht werden. In der Fentonreaktion (Reaktionsgleichung 4.1) wird durch $\mathrm{Fe}^{2+}$ der Zerfall des Wasserstoffperoxids zu einem Hydroxid Anion und einem Hydroxylradikal katalysiert. Das Hydroxylradikal kann selber wieder mit Wasserstoffperoxid reagieren, wobei es zu der Bildung von Superoxid kommt (Reaktionsgleichung 4.2). Für die Entgiftung des Superoxidradikals stehen der Zelle auch wieder zwei verschiedene Wege zur Verfügung, wobei der eine, die Dismutation, durch das Enzym Superoxid-Dismutase katalysiert wird (STORZ und IMLAY, 1999). Die zweite Möglichkeit ist die Übertragung eines Elektrons von einem proximalen Elektronendonor, beispielsweise NADH, auf das Superoxidradikal durch das Enzym Superoxid-Reduktase (LuMPPIO et al., 2001). In dieser Arbeit konnte kein Nachweis darüber erbracht werden, daß Rubrexodin Reduktase und Rubredoxin auf direktem Weg die Dismutation oder Reduktion von Superoxid in vitro katalysieren können. Auch konnte das Protein Pa5349 den sodA sodB Phänotyp des Stammes QC774 nicht komplementieren.

Es konnte in dieser Arbeit gezeigt werden, daß das Protein Rubredoxin Reduktase eine indirekte Rolle bei dem Abbau von Superoxidradikalen spielt. Durch Zugabe von Zellysat des $P$. aeruginosa Wildtyp-Stammes TB zu einem Reaktionsansatz wurde die Entfernung von durch Xanthin/Xanthinoxidase generiertem Superoxid bewirkt, während die Zugabe von Lysat der Mutante 41D3 nicht diesen Effekt hatte. Wurden zusätzlich zu dem Lysat der Mutante noch NADH sowie die beiden Proteine Rubredoxin Reduktase und Rubredoxin gegeben, konnte eine Verringerung der Superoxidmenge nachgewiesen werden. Dies deutet darauf hin, daß Rubredoxin Reduktase und Rubredoxin Teil einer Elektronentransportkette 
sind, an deren Ende die Übertragung eines Elektrons auf Superoxid steht und welche eine weitere unbekannte Komponente enthält, die diesen Schritt katalysiert. Postuliert wird die Präsenz eines Enzyms, das in der Lage ist, Reduktionsäquivalente, welche es von NADH via Rubredoxin Reduktase und Rubredoxin erhält, auf Superoxid zu übertragen. Der Mechanismus der Elektronenübertragung könnte wie in Abb. 4.20 dargestellt ablaufen. In diesem Fall wäre das Enzym eine Superoxid-Reduktase (SOR), für die eine Elektronenübertragung nach dem Schema des in der Abbildung 4.20 gezeigten Redoxzyklus nachgewiesen werden konnte (EMERSON et al., 2003).
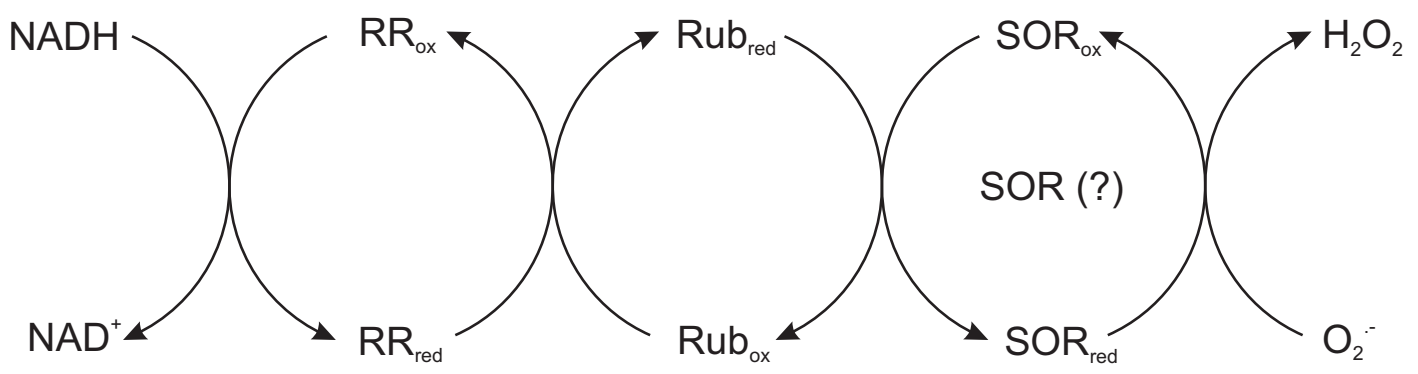

Abb. 4.20: Postulierter Elektronenübertragungsweg in P. aeruginosa TB. RR: Rubredoxin Reduktase (Pa5349), Rub: Rubredoxin (Pa5350), SOR: postulierte Superoxid-Reduktase.

Pseudomonas aeruginosa enthält zwar auch zwei Superoxid-Dismutasen, die ebenfalls für den Abbau von Superoxid zuständig sind, deren Expression steht aber unter Kontrolle des Quorum Sensing. Daher werden diese beiden Enzyme nur bei hoher Zelldichte synthetisiert (HASSETt et al., 1999). So zeigte eine Pseudomonas aeruginosa Mutante, der die SuperoxidDismutase SodA fehlte, in der stationären Phase eine erhöhte Sensitivität gegenüber Paraquat (POLACK et al., 1996). Gerade aber bei der Infektion eines Wirtsorganismus sind die Bakterien schon in der frühen Phase der Infektion, wenn die Zelldichte noch entsprechend gering ist, oxidativem Streß durch Immunzellen ausgesetzt (CLIFFORD und REPINE, 1982). Somit wäre es plausibel, die Existenz einer Superoxid-Reduktase, die in der frühen Phase der Infektion für die Entgiftung von Superoxid zuständig ist, anzunehmen.

Superoxid-Reduktasen stellen eine relativ neue Klasse von Enzymen zur Entgiftung reaktiver Sauerstoffspezies dar und sind bisher nur aus anaeroben und mikroaerophilen Bakterien bekannt und bis dato noch nicht mit aeroben Mikroorganismen in Verbindung gebracht worden. So enthalten beispielsweise Desulfovibrio vulgaris (LuMPPIO et al., 2001) und Treponema pallidum (LOMBARD et al., 2000a) eine Superoxid-Reduktase. Tatsächlich erfolgt die Elektronenübertragung bei diesem Enzym über Rubredoxin und Rubredoxin Reduktase. Eine Superoxid-Reduktase ist aus dem Genom von Pseudomonas aeruginosa jedoch nicht bekannt. Bei der vom Autor dieser Arbeit mit BLAST (blastp) und PSI-BLAST durchgeführten Suche nach Homologien zu Proteinsequenzen bekannter SuperoxidReduktasen im PAO1 Proteom fanden sich keine Kandidaten mit signifikanter Übereinstimmung. Die für den BLAST eingesetzten Sequenzen waren die der SORs aus Desulfovibrio baarsii (Genbank Accession Number Q46495), Pyrococcus furiosus (Genbank 
Accession Number P82385), Thermoanaerobacter tengcongensis (Genbank Accession Number NP_623775) und Pyrococcus abyssi (Genbank Accession Number CAB49807). Obwohl es in P.aeruginosa keine Sequenzhomologe zu diesen Superoxid-Reduktasen zu geben scheint, könnte es sehr wohl Funktionshomologe gegeben. In Pseudomonas wird das Rubredoxin Reduktase / Rubredoxin System im Abbau von Alkanen eingesetzt. Pseudomonas aeruginosa besitzt für die Oxidation von $\mathrm{C}_{12}-\mathrm{C}_{16} \mathrm{n}$-Alkanen zwei Alkanhydroxylasen, AlkB1 und AlkB2 (SMITS et al., 2003). Da vorstellbar war, daß der unbekannte Elektronenakzeptor Sequenzhomologien zu diesen beiden Enzymen besitzt, wurden die Proteinsequenzen für eine BLAST Suche innerhalb des PAO1 Proteoms eingesetzt. Doch auch in diesem Fall fanden sich keine Homologien.

Die gewonnenen kinetischen Daten für die Rubredoxin Reduktase passen gut in das Bild einer Aktivität in der Entgiftung reaktiver Sauerstoffspezies, da die katalytische Effizienz des Enzyms extrem hoch ist, und somit die Vorraussetzung besteht, reaktive Sauerstoffspezies effizient aus dem Weg räumen zu können. Angenommen wird die Präsenz einer Eleltronentransportkette in $P$. aeruginosa, bei der Elektronen von NADH über Rubredoxin Reduktase, Rubredoxin und eine postulierte Superoxid-Reduktase auf die Superoxidradikale übertragen werden. Die katalytische Effizienz dieser Kette wäre nur so groß, wie es ihr schwächstes Glied zuläßt. Zumindest Rubredoxin Reduktase erfüllt die formalen Bedingungen, die an jedes Mitglied einer solchen Elektronentransportkette gestellt werden müssen.

In dieser Arbeit wurden die experimentellen Rahmenbedingungen erarbeitet, die es ermöglichen sollten, die postulierte SOR $\mathrm{zu}$ isolieren und $\mathrm{zu}$ charakterisieren. Um die postulierte Superoxid-Reduktase aus $P$. aeruginosa $\mathrm{zu}$ identifizieren, kann ein Gesamtproteinextrakt chromatographisch fraktioniert werden und die einzelnen Fraktionen biochemisch auf die Präsenz eines Superoxid-reduzierenden Proteins untersucht werden. Die Fraktionierung sollte so lange fortgesetzt werden, bis die Fraktion, welche über die gesuchte Aktivität verfügt, nur noch ein überschaubares Repertoire an Proteinen besitzt. Diese Proteine können dann über massenspektrometrische Verfahren analysiert werden und durch weitere in silico Analysen sollte es möglich sein, das Enzym mit der Superoxid-Reduktase-Aktivität zu identifizieren. Sobald die postulierte SOR identifiziert ist, sollte untersucht werden, ob ein $P$. aeruginosa Stamm, dem diese SOR fehlt, einen zu 41D3 vergleichbaren Phänotyp zeigt.

Über den Zusammenhang zwischen dem Fehlen der funktionellen Rubredoxin Reduktase in der Zelle und dem ausgeschalteten Quorum Sensing gibt es bisher keine Erkenntnisse. Da die Mutante 41D3 nicht mehr in der Lage war, Proteasen zu sekretieren, könnte ein Defekt in dem lasRI-System des Quorum Sensing vorliegen, da die Sekretion von Proteasen durch dieses System kontrolliert wird (Nouwens et al., 2003), welches in der Hierarchie des Quorum Sensing an oberster Stelle steht (WHITEHEAD et al., 2001). Der Defekt könnte sowohl in der Synthese der AHL wie auch in der Antwort auf die Stimulation durch AHL liegen, wobei eine Diskriminierung zwischen diesen beiden Phänomen in der Zelle schwierig ist, da die Synthese der AHL einer autoregulatorischen, positiven Rückkopplung unterliegt (DE KIEviT und IGLEwSKI, 2000). Die Expression von Proteasen wird durch Anlagerung des LasRezeptors, der durch die Bindung von 3-Oxo-C12-HSL aktiviert wurde, an eine spezifische 
Promotorregion der durch das Las-System kontrollierten Gene ausgelöst (WHITEHEAD et al., 2001). Eine Rolle für Rubredoxin Reduktase ist unter den derzeit bekannten Bedingungen der Genregulation nicht ohne weiteres vorstellbar.

Der Syntheseweg der Acyl-Homoserinlactone in P. aeruginosa ist aufgeklärt. Die Synthese der AHL erfolgt durch das Enzym AHL-Synthase aus den beiden Vorstufen SAdenosylmetheonin (SAM) und einem Fettsäurederivat (WHITEHEAD et al., 2001). Das Fettsäurederivat ist an das Acyl-Carrier-Protein (ACP) gebunden und stammt aus der Fettsäurebiosynthese. Letztere verläuft in Bakterien in zwei Phasen. In der ersten Phase, der Initiation, wird Acetyl-CoA durch das Enzym Acetyl-CoA Carboxylase zu Malonyl-CoA umgesetzt. Aus dem Malonyl-CoA und dem Acyl-Carrier-Protein (ACP) wird dann durch das Enzym Malonyl-CoA:ACP Transacylase das Malonyl-ACP synthetisiert. (HoANG und SCHWEIZER, 1997). Dieses kann dann in die zweite Phase, die zyklische Elongation, eintreten. Hierbei laufen vier chemische Reaktionen nacheinander ab: (I) eine Kondensation, die durch eine $\beta$-Ketoacyl-ACP Synthase, (II) eine Reduktion durch eine NADPH-abhängige $\beta$ Ketoacyl-ACP Reduktase, (III) eine Dehydratation, die durch eine $\beta$-Hydroxyacyl-ACP Dehydratase katalysiert wird und (IV) eine zweite Reduktion, die von einer NADHabhängigen Enoyl-ACP Reduktase katalysiert wird (HOANG und SCHWEIZER, 1999). Diese Reaktion kann mehrfach hintereinander ablaufen, jedes Mal wird die Acylkette um einen Kohlenstoff verlängert. Pseudomonas aeruginosa, dem die Enoyl-ACP Reduktase fehlt, kann nur noch eine sehr geringe Menge AHL produzieren (HOANG und SCHWEIZER, 1999).

Kürzlich gelang es Hoang und Kollegen, 3-Oxo-C12-HSL im Reagenzglas zu erzeugen, in dem sie die Enzyme der Pseudomonas aeruginosa Fettsäurebiosynthese heterolog in E. coli exprimierten und zusammen mit Malonyl-CoA und SAM in einem in vitro Ansatz einsetzten. Durch Analyse der gebildeteten AHL mittels Dünnschichtchromatographie konnte die Synthese von 3-Oxo-C12-HSL nachgewiesen werden (HOANG und SCHWEIZER, 1999). Die Autoren geben an, daß die Determination der Kettenlänge dadurch zustande kommt, daß die AHL-Synthase die größte Spezifität für das ACP mit dem entsprechenden Acylrest besitzt (HoAng et al., 2002). Da der Minimalsatz an Enzymen und Metaboliten für die Synthese von AHL charakterisiert ist, ist eine Rolle von Rubredoxin Reduktase sehr unwahrscheinlich. Auch in der Synthese von SAM dürfte die Rubredoxin Reduktase bedeutlungslos sein, da diese Verbindung in einem Schritt aus Metheonin und ATP synthetisiert wird (STRYER, 1994). Vermutlich ist die Rolle von Rubredoxin/Rubredoxin Reduktase auf das Quorum Sensing eher indirekt.

\subsubsection{Untersuchungen der Mutante B7D3}

\subsubsection{Phäntoypen der Mutante und genomische Organisation des betroffenen} Gens $\mathrm{Pa} 0740$

Die Mutante B7D3, die eine Transposonintegration in dem Gen Pa0740 trägt, zeigt einen ungewöhnlichen Phänotyp. Bei dieser Mutante war das Quorum Sensing verstärkt. Auch die Sekretion von durch das Quorum Sensing kontrollierten Proteasen war auf einem höheren 
Niveau als beim Wildtyp (Wiehlmann, 2001). In einer Kultur von Pseudomonas aeruginosa Wildtyp Zellen nimmt die Menge von Acyl-Homoserinlactonen (AHL) mit steigender Zelldichte in der exponentiellen Phase zu, um dann nach einiger Zeit in der stationären Phase wieder abzusinken (YATES et al., 2002). Der Mechanismus, der hinter diesem Phänomen steht, ist bisher nicht vollständig aufgeklärt, wird aber dem Anstieg des $\mathrm{pH}$-Wertes im Medium während des Zellwachstums zugeschrieben, da AHL bei basischen pH-Werten nicht stabil sind (YATES et al., 2002). Im Gegensatz zu dieser Annahme steht die Beobachtung, daß bei der Mutante kein Absinken der AHL-Konzentration im Medium nach verlängertem Wachstum zu beobachten war, obwohl der pH-Wert im Medium genauso wie beim Wildtyp mit der Zeit anstieg (Lutz Wiehlmann, persönliche Kommunikation). Die Synthese von AHL in den Zellen wird durch eine positive Rückkopplung gesteuert, d.h. daß bei Vorhandensein von AHL im Medium deren Synthese in der Zelle noch verstärkt wird. Eine Möglichkeit, wie diese positive Rückkopplung unterbrochen und die Synthese der AHL eingestellt werden könnte, wäre, die Menge an freiem AHL zu reduzieren. Diese Aufgabe könnte von einem AHL-abbauenden Enzym übernommen werden, welches dieser Mutante fehlen würde.

Das in der Mutante B7D3 von der Transposonintegration betroffene Genprodukt wurde im Hinblick auf eine AHL-abbauende Aktivität untersucht. Das Genprodukt von Pa0740 ist als putative $\beta$-Laktamase annotiert und besitzt Homologien zu dem hypothetischen Protein YjcS aus E. coli (62\% Ähnlichkeit) und zu einem konservierten hypothetischen Protein aus Vibrio cholerae (56 \% Ähnlichkeit). Bei der CD-BLAST Suche (MARCHLER-BAUER et al., 2003) finden sich konservierte Domänen mit hoher Ähnlichkeit zur Familie der Metallo- $\beta$ Laktamasen sowie der Familie der Zink-abhängigen Metallohydrolasen (Abb. 4.21). In der Primärsequenz von $\mathrm{Pa} 0740$ findet sich, genau wie in der Sequenz von AiiA, das Zinkbindemotif HXHXDH (MELINO et al., 1998). Mit Hilfe des Programms PSORT (NAKAI und HorTON, 1999) wurde das Vorhandensein einer periplasmatischen Signalsequenz für Pa0740 vorhergesagt.

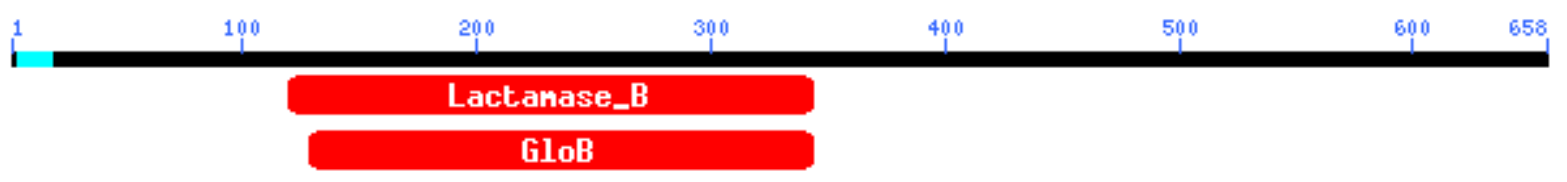

Abb. 4.21: Konservierte Domänen in Pa0740: Lactamase_B ist eine konservierte Region aus der Familie der Metallo- $\beta$-Laktamasen, GloB ist eine konservierte Domäne aus der Familie der Zink-abhängigen Metallohydrolasen.

Pa0740 ist das einzige Gen in seiner Region, daß auf dem Minusstrang kodiert ist, weiterhin findet man eine Promotor- sowie eine Terminatorsequenz, was dafür spricht, daß durch die Transposonintegration keine weiteren Gene betroffen sind.

Das Protein Pa0740 wurde gereinigt und auf seine Fähigkeit AHL abzubauen, untersucht. Zwei verschiedene Acyl-Homoserinlactone standen für die Untersuchungen zur Verfügung. Dies war zum einen das kommerziell erhältliche N-Dodecanoyl-L-Homoserinlacton (C12HSL), zum anderen waren auch geringe Mengen des nicht käuflichen N-(3-Oxododecanoyl)L-Homoserinlacton (3-Oxo-C12-HSL) vorhanden, das freundlicherweise von Birgit Huber zur Verfügung gestellt wurde. 3-Oxo-C12-HSL ist der physiologische Quorum Sensing 
Autoinducer aus Pseudomonas aeruginosa (DE KIEVIT und IGLEWSKI, 2000). Das las-System, das 3-Oxo-C12-HSL als Autoinducer verwendet, ist dem rhl-System hierarchisch übergeordnet (Siehe Abschnitt 1.2). Nimmt man eine AHL-abbauende Aktivität für Pa0740 an, muß in jedem Fall 3-Oxo-C12-HSL abgebaut werden können. Wenn das Protein nur den Autoinducer des rhl-Systems, C4-HSL, abbauen würde, hätte dies keinen Einfluß auf die Synthese von 3-Oxo-C12-HSL. Im umgekehrten Fall würde bei Abbau von 3-Oxo-C12-HSL auch die Synthese von C4-HSL zum Erliegen kommen, da diese von dem las-System als übergeordnetem Regulator gesteuert wird.

Da 3-Oxo-C12-HSL aber nicht in ausreichenden Mengen zur Verfügung stand, wurde in einigen Fällen auf das kommerziell erhältliche C12-HSL ausgewichen. Die Lewis-Strukturen der Autoinducer sind in Abb. 4.22 dargestellt. Weiterhin wurde nachgeprüft, ob das Enzym eine $\beta$-Laktamase-Aktivität besitzt.

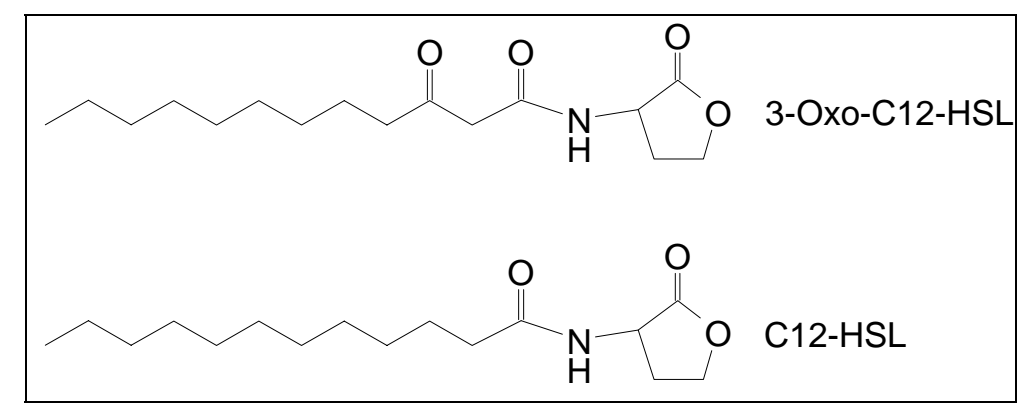

Abb. 4.22: Lewisstrukturen der beiden in dieser Arbeit eingesetzten Autoinducer. N-(3-Oxododecanoyl)-LHomoserinlacton (3-Oxo-C12-HSL) und N-Dodecanoyl-L-Homoserinlacton (C12-HSL).

\subsubsection{Klonierung und Reinigung von $\mathrm{Pa} 0740$}

Die Klonierung der kodierenden Sequenz von Pa0740 in den Expressionsvektor pBBR22bII erfolgte ähnlich wie für Pa5350 (4.1.1.4) beschrieben. Die kodierende Sequenz von Pa0740 wurde durch PCR mit den beiden Oligonukleotiden Pa0740Ndeup und Pa0740lo mit dem thermostabilen Enzym LaTaq (TaKaRa) amplifiziert. Als Matrize diente genomische DNA von $P$. aeruginosa PAO1. Die für die Klonierung notwendigen Erkennungsstellen für NdeI und BglII wurden durch die Oligonukleotide eingeführt. Das resultierende PCR-Produkt wurde durch Phenol/Chloroform Extraktion (3.2.1.3) und Ethanolpräzipitation gereinigt (3.2.1.1). Anschließend erfolgte die Klonierung in pCR4-TOPO (Invitrogen, 3.3.5), da sich eine direkte Klonierung des PCR-Produktes in pBBR22bII als erfolglos darstellte. Einzelne Transformanten wurden vermehrt und die Plasmide präpariert (3.2.5). Die Identifikation von positiven Klonen erfolgte durch Verdau der Plasmide mit den Restriktionsenzymen NdeI und BglII. Die Sequenz der positiven Klone wurde durch Nukleotidsequenzanalyse verifiziert.

Für die Klonierung von Pa0740 in pBBR22bII wurde das Akzeptorplasmid pBBR22bIIPa5349 mit den Restriktionsendonukleasen NdeI und BglII verdaut. Das Vektorfragment wurde aus einem Agarosegel gereinigt (3.2.3). Das Plasmid pCR4- 
TOPOPa0740 wurde ebenfalls mit NdeI und BglII gespalten und das Fragment, welches das Pa0740-Gen trug, aus einem Agarosegel gereinigt. Es erfolgte eine Ligation der beiden Fragmente (3.3.3) sowie die Transformation von 71-18 Zellen. Einzelne Transformanten wurden vermehrt und die Plasmide präpariert (3.2.5). Die Identifikation von positiven Klonen erfolgte durch Verdau der Plasmide mit den Restriktionsenzymen NdeI und BglII. Die Sequenz der positiven Klone wurde durch Nukleotidsequenzanalyse verifiziert.

Mittels immobilisierter Metallionen-Affinitätschromatographie (IMAC) wurde das Fusionsprotein, bestehend aus dem Pa0740 Strukturgen, dem Sendai-Epitop und dem Hexahistidinanhängsel aus einer $1000 \mathrm{ml}$ Kultur von BL21(DE3) mit dem Plasmid pBBR22bIIPa0740 im wesentlichen wie in Abschnitt 3.4.8 beschrieben, gereinigt. Da die Primärsequenz von Pa0740 die Signatur einer Zinkbindestelle (HXHXDH, MELINO et al., 1998) enthielt, wurde die IMAC-Reinigung mittels einer mit Zink beladenen Säule durchgeführt. Ansonsten bestünde die Gefahr, daß das Nickel von der IMAC-Säule das Zink aus dem Protein verdrängt und das Protein damit möglicherweise inaktiv wird. Die Reinigungsfraktionen wurden auf einem 12,5 \%igen Acrylamid-Gel analysiert (3.4.6). In Abbildung 4.23 ist ein Beispiel für eine Gelanalyse einer Reinigung von Pa0740 gezeigt.

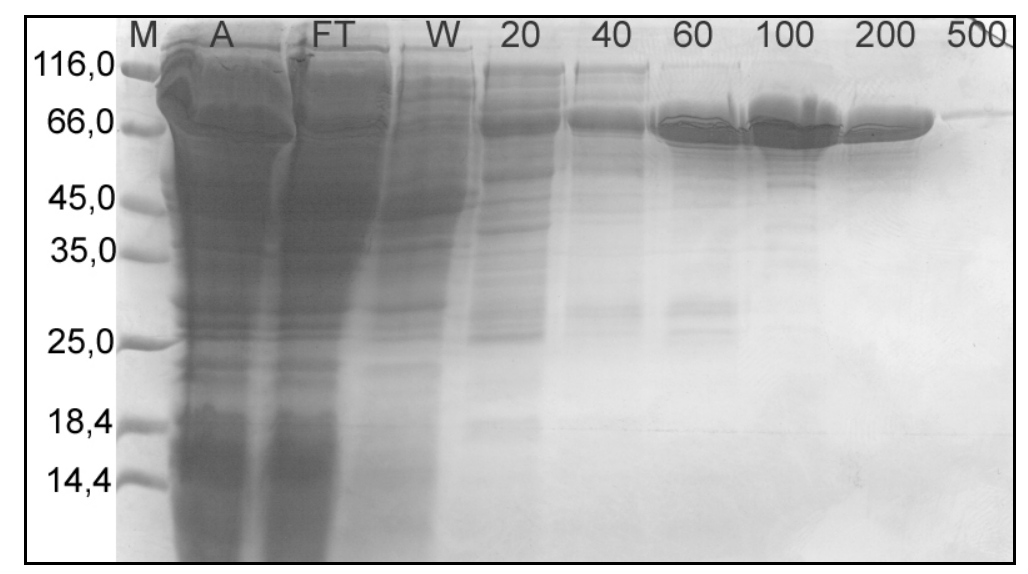

Abb. 4.23: Zn-IMAC Reinigung von Pa0740 und Analyse durch SDS-PAGE. M: Proteinlängenstandard, A: Auftrag, FT: Durchlauf, W: Waschfraktion, 20-500: Elution mit 20, 40, 60, 100, 200 und $500 \mathrm{mM}$ Imidazol, respektive.

In den Elutionsfraktionen der Zink-Chelatsäule, welche $60 \mathrm{mM}, 100 \mathrm{mM}$ und $200 \mathrm{mM}$ Imidazol enthielten, fand sich eine Proteinbande, die der erwarteten Größe des Fusionproteins von 75000 relativem Molekulargewicht entsprach. Diese Fraktionen wurden vereinigt und gegen $4000 \mathrm{ml} 100 \mathrm{mM}$ Phosphatpuffer, $\mathrm{pH} 8,0 ; 100 \mathrm{mM} \mathrm{NaCl}$ dialysiert (3.4.10). Nach der Dialyse wurde die Proteinlösung einkonzentriert (3.4.10) und durch Eintropfen in flüssigen Stickstoff schockgefroren (3.4.11). Somit stand das Protein für nachfolgende Analysen zur Verfügung. Die Ausbeute betrug ca. $5 \mathrm{mg}$ aus einem Liter Bakterienkultur. 


\subsubsection{Klonierung und Reinigung von Pa0740 ohne Sendai-Epitop}

Es wurde eine Variante des Pa0740 Proteins ohne Sendai-Epitop hergestellt. Zum einen sollte diese Variante für die Erzeugung von Proteinkristallen an der GBF in Braunschweig dienen, zum anderen besteht die Möglichkeit, daß die Anwesenheit des Sendai-Epitopes eine mögliche enzymatische Aktivität von Pa0740 negativ beeinflussen könnte. Hierzu wurde das Plasmid pBBR22bIIPa0740 mit den Restriktionsenzymen BglII und BamHI verdaut, deren Erkennungsstellen das Sendai-Epitop flankieren. Das Plasmidfragment wurde aus einem Agarosegel ausgeschnitten (3.2.3) und die durch die Spaltung erzeugten kompatiblen Enden mit T4-DNA-Polymerase religiert (3.3.3). Es erfolgte die Transformation von 71-18 Zellen (3.1.4). Einzelne Transformanten wurden vermehrt und die Plasmide präpariert (3.2.5). Durch Verdau der Plasmide mit den Restriktionsenzymen NdeI und HindIII konnten solche Klone identifiziert werden, die ein Insert der richtigen Länge trugen. Durch erneute Restriktionsspaltung mit NdeI und BgIII konnten Klone identifiziert werden, die keine Erkennungsstelle für BglII mehr besaßen. Die Sequenz der positiven Klone wurde durch Nukleotidsequenzanalyse verifiziert.

Die Reinigung des Proteins Pa0740 $\Delta$ Sendai über IMAC erfolgte analog zu der für das Protein Pa0740 beschriebenen. Die Fraktionen wurden auf einem 15 \%igen Acrylamidgel analysiert (Abb. 4.24).

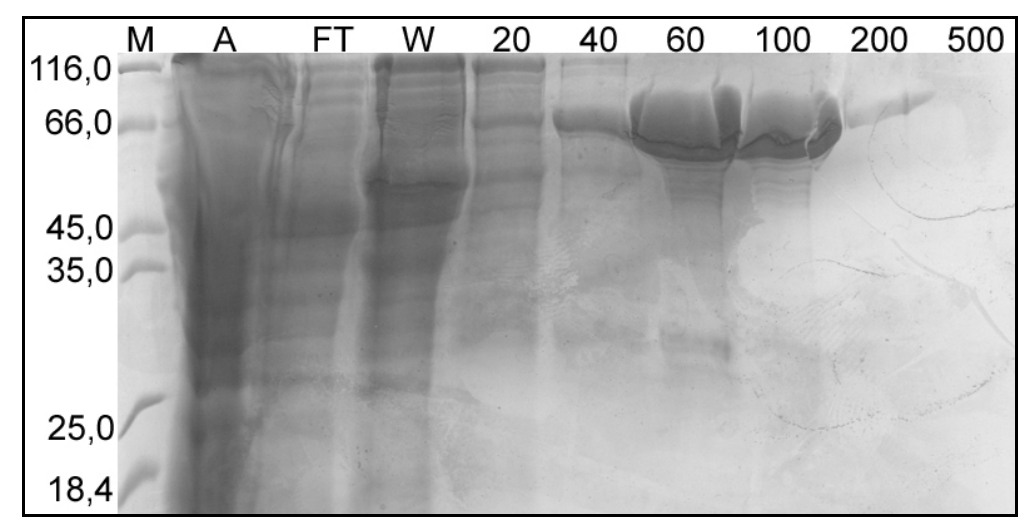

Abb. 4.24: Zn-IMAC Reinigung von Pa0740 $\Delta$ Sendai und Analyse durch SDS-PAGE. M: Proteinlängenstandard, A: Auftrag, FT: Durchlauf, W: Waschfraktion, 20-500: Elution mit 20, 40, 60, 100, 200 und 500 mM Imidazol, respektive.

Obwohl das Protein nach der IMAC-Reinigung schon in relativ hoher Reinheit vorlag, wurde noch ein weiterer Reinigungsschritt angeschlossen, um das Protein zum Zweck der Kristallisation und Enzymanalyse so rein wie möglich $\mathrm{zu}$ erhalten. Hierfür wurde eine Anionenaustauscher-Chromatographie mit einer MonoQ-Säule (Pharmacia) durchgeführt. Zuerst wurden die Elutionsfraktionen der Zink-Chelatsäule, die 60, 100 und $200 \mathrm{mM}$ Imidazol enthielten und in denen sich eine Bande der erwarteten Größe des Fusionproteins befand, vereinigt und gegen $4000 \mathrm{ml} 50 \mathrm{mM}$ Tris- $\mathrm{Cl}, \mathrm{pH}$ 8,0 dialysiert. Da das Protein einen isoelektrischen Punkt von 5,74 hat, ist es bei basischen $\mathrm{pH}-$ Werten negativ geladen. Anschließend wurde das Protein auf die MonoQ Säule gepumpt und mit einem zweiphasigen, 
kontinuierlichen Gradienten von $0-1,5 \mathrm{M} \mathrm{NaCl}$ in $50 \mathrm{mM}$ Tris- $\mathrm{Cl}, \mathrm{pH}$ 8,0 eluiert und die Fraktionen aufgefangen. Das Chromatogramm ist in Abb. 4.25 dargestellt. Aliquots der Fraktionen 18-21 wurden zusätzlich auf einem 15 \%igen Acrylamidgel analysiert (Abb. 4.26). Die Ausbeute betrug ca. $4 \mathrm{mg}$ aus einem Liter Bakterienkultur.

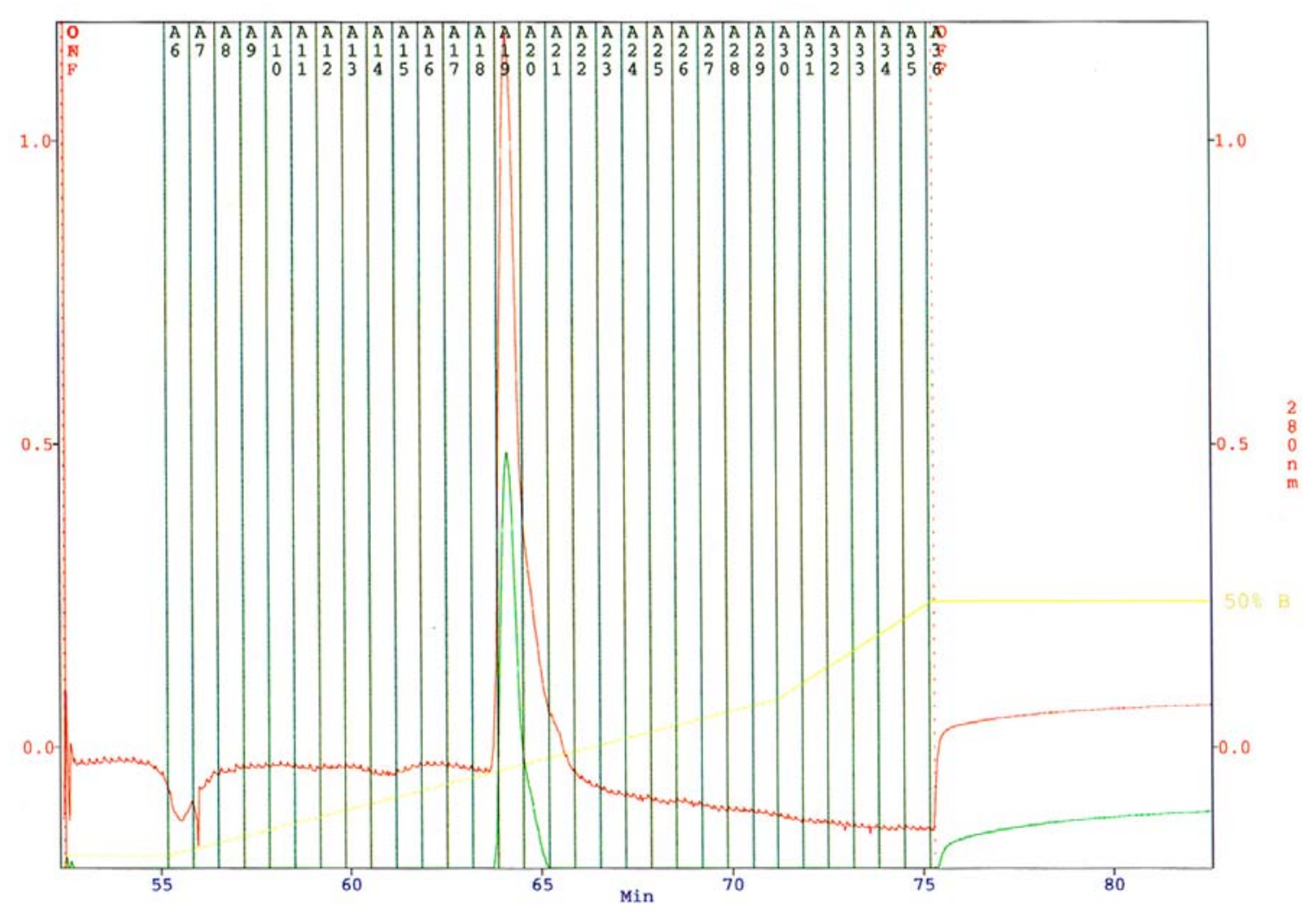

Abb. 4.25: Chromatogramm der Reinigung von Pa0740 $\Delta$ Sendai über eine MonoQ Säule. A6 bis A36 bezeichnet die während des Laufs aufgefangenen Fraktionen. Die gelbe Linie zeigt den prozentualen Anteil des Puffers B an, der $3 \mathrm{M} \mathrm{NaCl}$ enthielt.

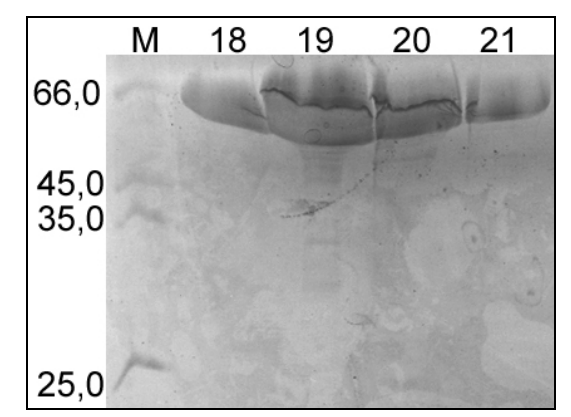

Abb. 4.26: Analyse der Fraktionen 19-21 aus der Anionenaustauscherchromatographie auf einem 15 \%igen SDSPolyacrylamidgel.

Die Fraktionen 18-21 wurden vereinigt und zum Entfernen des Salzes gegen $4000 \mathrm{ml}$ Tris$\mathrm{Cl}, \mathrm{pH}$ 8,0 dialysiert (3.4.10). Am nächsten Tag wurden das Volumen der Proteinlösung durch Zentrifugation in einem VivaSpin Konzentrator (3.4.10) eingeengt. Die Proteinlösung wurde entweder gleich verwendet oder durch Eintropfen in flüssigen Stickstoff gelagert (3.4.11). 


\subsubsection{Test von $\mathrm{Pa} 0740$ auf mögliche $\beta$-Laktamase Aktivität}

Da das Protein Pa0740 als eine putative $\beta$-Laktamase annotiert ist, wurde seine Fähigkeit, verschiedene $\beta$-Laktame zu hydrolysieren, untersucht. Das chromogene Substrat PADAC (Calbiochem), ein Cephalosporinderivat, wird von einer Reihe von $\beta$-Laktamasen aus diversen Organismen hydrolysiert (LEE und ROSENBLATT, 1983). Hierbei kommt es zu einer Verschiebung des Absoptionsmaximum von $570 \mathrm{~nm}$ nach $475 \mathrm{~nm}$, was photometrisch gemessen werden kann (3.6.7). $50 \mu$ leiner Proteinlösung $(0,92 \mathrm{mg} / \mathrm{ml}$, in IMAC I Puffer), entsprechend 0,6 nmol, wurden mit $1 \mu \mathrm{l}$ PADAC Substratlösung $(1 \mathrm{mg} / \mathrm{ml}$ in DMF) versetzt und nach einer Inkubationszeit von 15 Minuten das Absorptionsspektrum aufgenommen. Als Negativkontrolle wurden $50 \mu \mathrm{l}$ IMAC I Puffer verwendet, als Positivkontrolle wurden $50 \mu \mathrm{l}$ einer Proteinlösung von Bla-PhoA Fusionsprotein $(\sim 0,1 \mathrm{mg} / \mathrm{ml})$, entsprechend 0,06 nmol, aus Laborbeständen eingesetzt. Auch bei den Kontrollen wurde nach gleicher Inkubationszeit das Absorptionsspektrum aufgenommen. Die Spektren sind in Abb. 4.27 dargestellt.

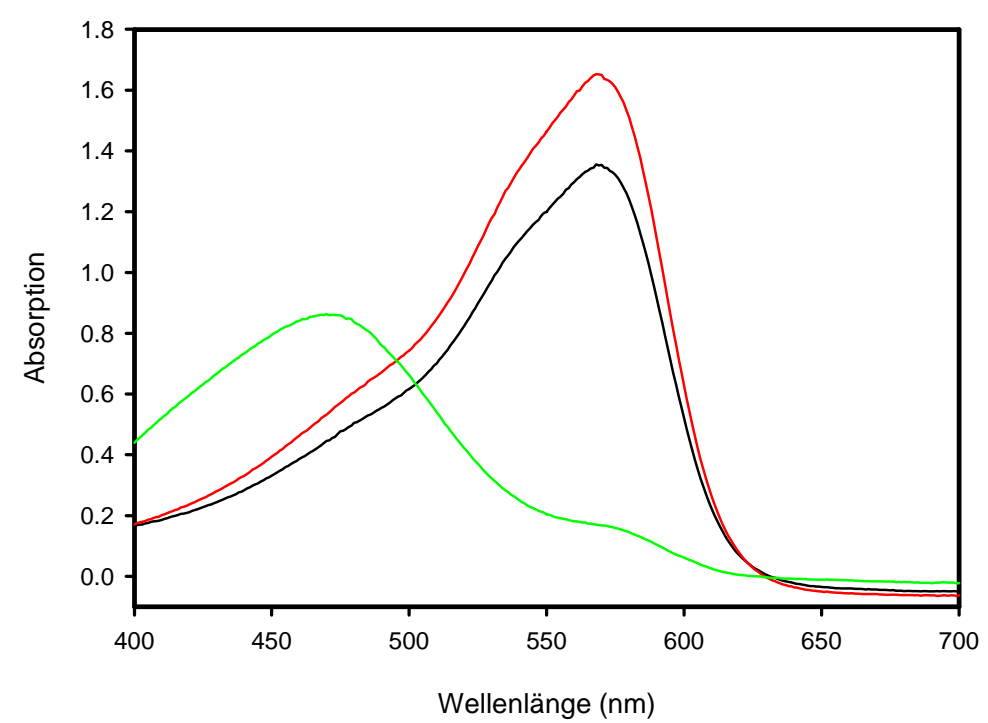

Abb. 4.27: Absoptionsspektren des PADAC Substrates, welches entweder mit Pa0740 Fusionsprotein (rote Kurve), Bla-PhoA (grüne Kurve) oder PBS (schwarze Kurve) inkubiert worden war.

Während bei der Positivkontrolle der Farbumschlag bereits nach wenigen Sekunden zu beobachten war, konnte auch bei einer verlängerten Inkubationszeit von 15 Minuten kein Farbumschlag bei Zugabe des Proteins Pa0740 festgestellt werden, das Absorptionsspektrum ist mit dem der Negativkontrolle identisch. Somit kann festgestellt werden, daß Pa0740 nicht in der Lage ist, die Hydrolyse des Substrates PADAC zu katalysieren.

Anschließend wurde die Fähigkeit von Pa0740 untersucht, das Substrat Penicillin G zu hydrolysieren. Das Hydrolyseprodukt von Penicillin G hat bei einer Wellenlänge von $232 \mathrm{~nm}$ einen geringeren molaren Extinktionskoeffizienten als Penicillin G (WALEY, 1974). Somit kann durch differentielle Messung in einem Zweistrahlphotometer die Hydrolyse nachgewiesen werden (3.6.7). In der einen Küvette befanden sich $1 \mathrm{mM}$ Penicillin $\mathrm{G}$ in $250 \mu \mathrm{l}$ IMAC I Puffer, in der anderen $1 \mathrm{mM}$ Penicillin $\mathrm{G}$ und $20 \mu \mathrm{l}$ einer Pa0740-Lösung 
(3,4 mg/ml), entsprechend 0,9 nmol, in $250 \mu \mathrm{l}$ IMAC I. Die Messung wurde unmittelbar nach Zugabe des Proteins Pa0740 gestartet und für 35 min wurde die Absorption bei $232 \mathrm{~nm}$ aufgezeichnet. Dann wurden $1 \mu \mathrm{l} 0,1 \mu \mathrm{g} / \mathrm{ml}$ Bla-Send-His ${ }_{6}$-Fusionsprotein (siehe Abschnitt 4.2.2.2.8) zugegeben und die Messung für weitere 10 min durchgeführt. Der Graph ist in Abb. 4.28 gezeigt.

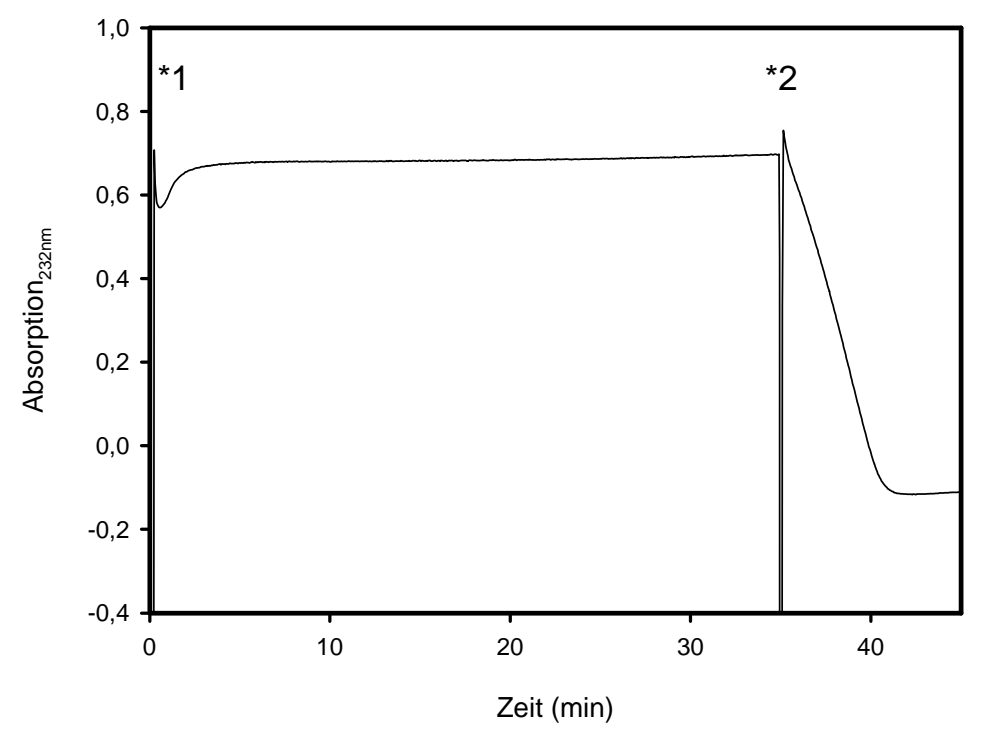

Abb. 4.28: Untersuchung der Hydrolyse von PenicillinG durch Pa0740. ${ }^{\star}$ 1: Zeitpunkt der Zugabe von Pa0740, ${ }^{\star}$ : Zeitpunkt der Zugabe von Bla-Sendai-His ${ }_{6}$ Fusionsprotein.

Wie man aus dem Graphen erkennen kann, erfolgt keine Änderung der Absorption nach Zugabe von Pa0740. Dies ändert sich auch nicht nach 35 Minuten Meßdauer. Bei Zugabe des RTEM-1 $\beta$-Laktamase Fusionsproteins erfolgt eine Abnahme der Absorption, da in der Küvette mit dem Fusionsprotein das Penicillin G hydrolysiert wird. Aus diesen Daten läßt sich ableiten, daß Pa0740 nicht in der Lage ist, Penicillin G zu hydrolysieren.

\subsubsection{Voruntersuchungen zum Einfluß von Pa0740 auf das Quorum Sensing}

Um eine mögliche AHL-abbauende Aktivität von $\mathrm{Pa} 0740 \mathrm{zu}$ untersuchen, wurde eine Proteinpräparation zu Birgit Huber aus der Arbeitsgruppe von Leo Eberl an der Technischen Universität München gesandt, da dort bereits Verfahren etabliert waren, die eine schnelle Untersuchung der Proteinaktivität bezüglich eines Abbaus von AHL ermöglichen. In dieser Arbeitsgruppe wurde auch die Quorum Sensing-Aktivität der Pseudomonas aeruginosa Transposonmutanten untersucht.

Das angewandte Testverfahren basiert auf der Verwendung eines biologischen AHLSensors (Abb. 4.29), der im folgenden näher beschrieben werden soll. Bei dem Sensor handelt es sich um einen GFP-basierten Monitorstamm, der einen in situ Nachweis von AHL 
ermöglicht. Ein Pseudomonas putida Stamm, der keine endogenen AHL produziert, wurde mit einem Plasmid, das in Anwesenheit von AHL die Expression eines Reportergens bewirkt, transformiert. Das entsprechende Plasmid besitzt das Gen für einen AHL-Repressor und die dementsprechende Promotorsequenz vor der kodierenden Region des Green Fluorescent Protein (GFP) (TsIEN, 1998). Bei Anwesenheit von AHL dissoziiert der Repressor von der Promotorregion und die Transkription des gfp-Gens kann stattfinden. Für die Wahrnehmung von 3-Oxo-C12-HSL kam das Plasmid pKR-C12 in Pseudomonas putida (RIEDEL et al., 2001) zum Einsatz. Dieser Sensor ist sehr spezifisch für das Dodecanoylhomoserinlacton und dereprimiert bei dessen Anwesenheit gfp. Das nicht-physiologische C12-HSL kann ebenfalls mit einer etwas niedrigeren Sensitivität gemessen werden (B. Huber, persönliche Kommunikation).

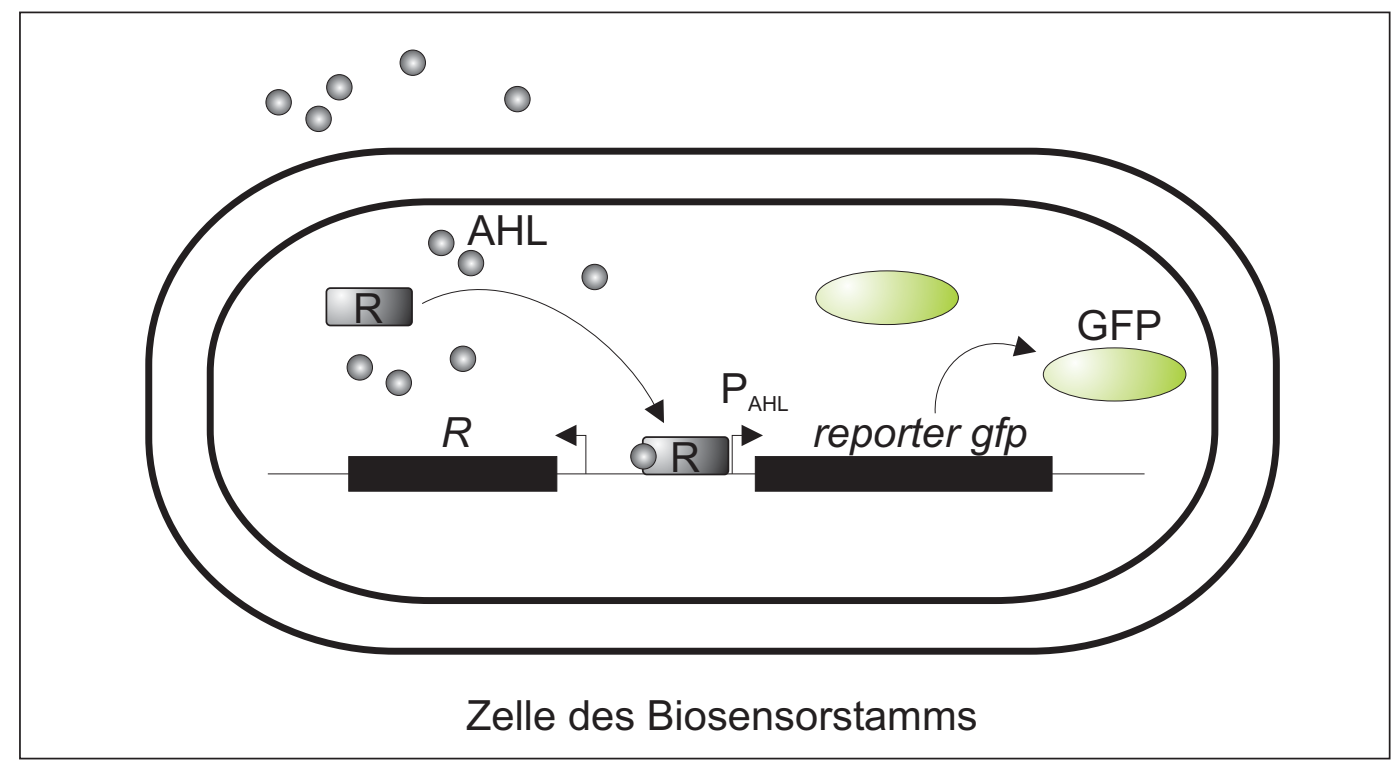

Abb. 4.29: Schema der Detektion von Acyl-Homoserinlactonen (AHL) durch einen Biosensorstamm: Bei Anwesenheit von AHL im Medium erfolgt die Bindung an das konstitutiv produzierte R-Protein, welches dadurch aktiviert wird und die Transkription des Reporters gfp bewirkt, der unter der Kontrolle eines AHLabhängigen Promotors $\left(\mathrm{P}_{\mathrm{AHL}}\right)$ steht.

Um einen möglichen Pa0740-vermittelten Abbau von 3-Oxo-C12-HSL zu untersuchen, wurde der Sensorstamm P. putida (pKR-C12) mit zwei verschiedenen Konzentrationen des Autoinducers in drei verschiedenen Ansätzen inkubiert. In dem ersten Ansatz wurden AHL ohne vorherige Behandlung zugegeben. In dem zweiten Ansatz wurden die AHL vor der Zugabe mit $100 \mu \mathrm{l}$ einer Proteinlösung von Pa0740 (3,7 mg/ml), entsprechend 4,9 nmol, inkubiert. Im dritten Ansatz wurden die AHL mit dem Überstand einer mit IPTG induzierten Kultur von BL21(DE3) mit dem Plasmid pBBR22bIIPa0740 inkubiert. Diese Ansätze wurden dann zu dem Monitorstamm gegeben und die Fluoreszenz wurde nach 4 bzw. 24 Stunden gemessen. Die zugegebenen Mengen Homoserinlacton sind aus der Abb. 4.30 zu entnehmen. Es wurde eine $100 \mathrm{mM}$ Stammlösung eingesetzt, jedoch ist das Lösungsmittel 
Essigsäureethylester extrem flüchtig, so daß das Volumen der Lösung auch in mit großer Sorgfalt verschlossenen Behältern stetig ab- und die Konzentration der Autoinducer darin zunahm. Die von B. Huber generierten und freundlicherweise zu Verfügung gestellten Daten sind in Abb. 4.30 gezeigt.
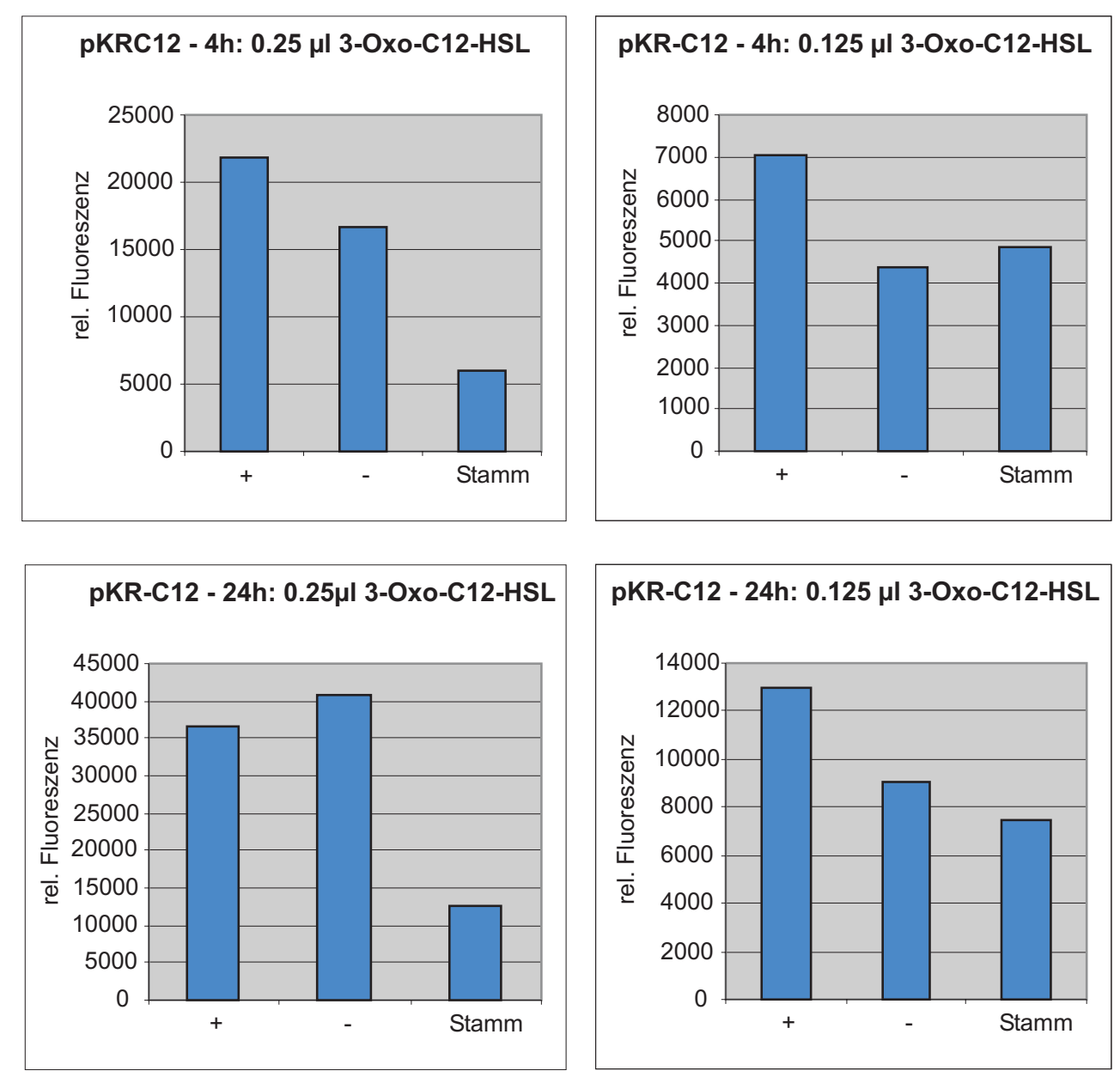

Abb. 4.30: GFP-Fluoreszenz des Monitorstammes P. putida (pKR-C12). Die Ansätze wurden mit den angegebenen Mengen der AHL versetzt, welche zuvor wie folgt behandelt wurden: Inkubation mit Pa0740 Protein (+), Inkubation mit dem Überstand des Stammes BL21(DE3) (pBBR22bIIPa0740). (Quelle: Birgit Huber).

Die in München gewonnen Daten sind nicht eindeutig. So gibt es Fälle, in denen die Zugabe das gereinigten Proteins zu einer Abnahme der Fluoreszenz führte. So war bei der Zugabe von 0,25 $\mu$ l 3-Oxo-C12-HSL nach 24 Stunden die Fluoreszenz niedriger als ohne Zugabe von Protein, wobei in den übrigen drei Fällen die Fluoreszenz der Kontrolle niedriger war als die bei der Zugabe von Protein. Weiterhin kann man erkennen, daß bei Zugabe des Überstandes die Fluoreszenz in allen bis auf einen $(0,125 \mu \mathrm{l}$ 3-Oxo-C12-HSL nach $4 \mathrm{~h})$ die Fluoreszenz niedriger war als bei der Kontrolle. Diese Daten sind natürlich generell vorsichtig zu behandeln, da sie auf Einzelmessungen basieren, und lassen mehrere Interpretationen zu. Zum einen könnte es der Fall sein, daß das gereinigte Protein keine oder kaum Aktivität bezüglich des Abbaus von 3-Oxo-C12-HSL mehr hatte. Der Überstand enthielte dann möglicherweise aktives Protein, daß entweder durch aktive Sekretion oder durch die partielle Lyse von Zellen während des Wachstums in das Medium gelangt sein könnte. Zum anderen könnte es auch sein, daß durch die fortschreitende Alkalisierung des Medium Bedingungen 
geschaffen wurden, die zu einer Unstabilität der AHL führten. Weiterhin kam man feststellen, daß die Beobachtungen nicht konsistent sind, d.h. daß in einem Fall die Zugabe des Proteins zu einer verringerten durch 3-Oxo-C12-HSL bewirkten Fluoreszenz geführt hat, während in den drei anderen Fällen die Fluoreszenz sogar noch höher war als bei der Kontrolle.

Somit bestand die Notwendigkeit, eine möglicherweise vorhandene AHL-abbauende Aktivität bei dem Protein Pa0740 nochmals näher zu untersuchen.

\subsubsection{Untersuchung einer AHL-abbauenden Aktivität von Pa0740 mittles AHL- Monitorstämmen}

Die im folgenden beschriebenen Experimente dienten dazu, die Fähigkeit von Pa0740, C12-HSL und 3-Oxo-C12-HSL abzubauen, $\mathrm{zu}$ untersuchen. Hierfür wurde der Monitorstamm P. putida (pKR-C12) verwendet, der für Acyl-Homoserinlactone mit einer Kettenlänge von 12 Kohlenstoffen sensitiv ist. Als erstes wurde die Sensitivität des Monitorstammes gegenüber dem C12-HSL untersucht. Hierzu wurden Zellkulturen von $P$. putida (pKR-C12) mit verschiedenen Konzentration C12-HSL inkubiert und deren Fluoreszenz bestimmt, wie in Abschnitt 3.5.5 beschrieben. Der Quotient aus der gemessenen relativen Fluoreszenz und der optischen Dichte der Kultur wurde ermittelt und gegen die Konzentration aufgetragen (Abb. 4.31).

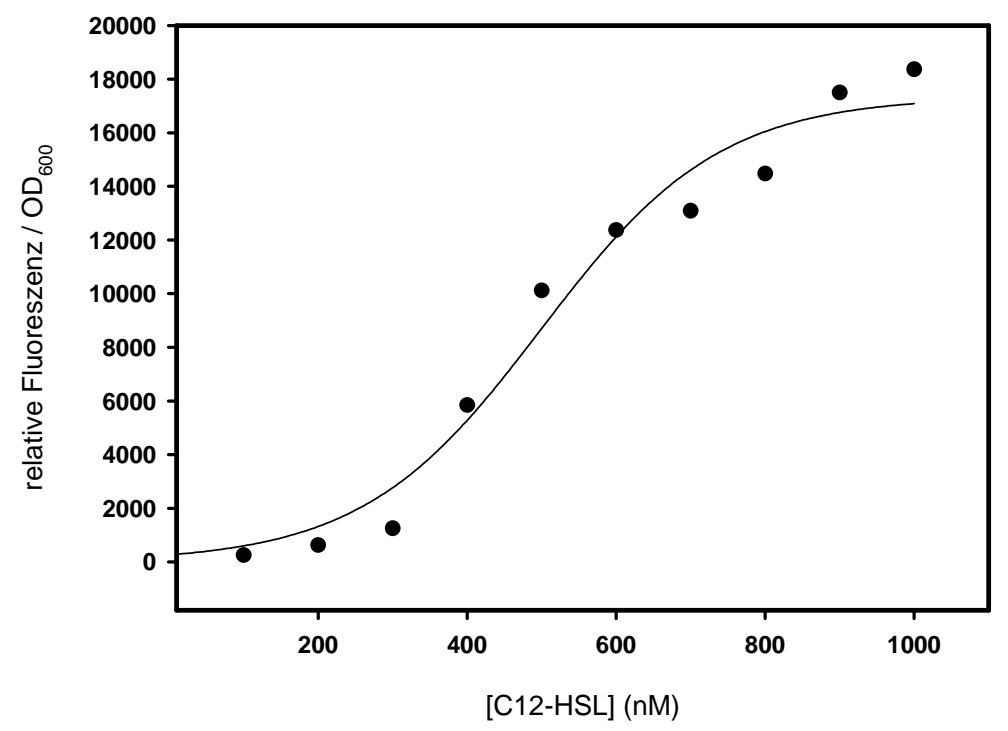

Abb. 4.31: relative Fluoreszenz des Monitorstammes P. putida (pKR-C12), bezogen auf die Zelldichte, in Abhängigkeit der Konzentration von C12-HSL.

Mit Hilfe des Programms SigmaPlot wurde eine sigmoide Kurve durch die gemessenen Werte gelegt. Wie man erkennen kann, wird die halbmaximale Fluoreszenz bei einer Konzentration von ca. 500 nM C12-HSL erreicht. Dies bedeutet, daß in der späteren Messung die Konzentration der AHL im der Kultur des Monitorstammes nicht niedriger als dieser Wert sein sollte, um ein auswertbares Fluoreszenzsignal zu erhalten. Bei der Untersuchung 
einer möglichen Degradation der AHL durch Pa0740 sollte die eingesetzte Konzentration in der Monitorkultur um $1 \mu \mathrm{M}$ liegen, da bei einer deutlich höheren Konzentration möglicherweise der Rest an nicht abgebautem AHL noch für eine volle Induktion der Genexpression des gfp ausreichen würde. Eine solche Dose-Response Abhängigkeit konnte für den Autoinducer 3-Oxo-C12-HSL nicht bestimmt werden, da von diesem nur eine sehr geringe Menge zur Verfügung stand und die Substanz käuflich nicht zu erwerben ist. Es ist aber bekannt, das P. putida (pKR-C12) noch um den Faktor drei sensitiver für 3-Oxo-C12HSL ist (B. Huber, persönliche Kommunikation).

Es wurde untersucht, ob die Präinkubation der AHL mit dem Protein Pa0740 einen Effekt auf die Fluoreszenz des Monitorstammes $P$. putida (pKR-C12) hat. Hierfür wurden in zwei unabhängigen Ansätzen jeweils $3 \mathrm{mM} \mathrm{C12-HSL} \mathrm{mit} \mathrm{ca.} 690 \mathrm{pmol} \mathrm{Pa} 0740 \Delta$ Sendai in einem Gesamtvolumen von $100 \mu \mathrm{l}$ PBS über Nacht bei $30^{\circ} \mathrm{C}$ inkubiert. Als Kontrolle wurden zwei Ansätze ohne Protein nach demselben Schema inkubiert. Am nächsten Tag wurden die Ansätze zu dem Monitorstamm gegeben und die Fluoreszenz im Triplikat bestimmt, wie in Abschnitt 3.5.5 beschrieben. Die Endkonzentration von C12-HSL wurde einmal auf $1 \mu \mathrm{M}$ und einmal auf $2 \mu \mathrm{M}$ eingestellt. Die Ergebnisse dieser zwei unabhängigen Messungen sind als Balkendiagramm in Abb. 4.32 dargestellt. Auf den ersten Blick scheint es hier die Tendenz zu geben, daß die Fluoreszenz bei Präinkubation der AHL mit Pa0740 geringer ist. Dennoch läßt sich bei genauerer Betrachtungsweise dieses Ergebnis nicht bestätigen. Zum einen sind die Fehler innerhalb dieser Bestimmung relativ hoch und der Wert der mittleren Fluoreszenz der Kontrolle liegt in den meisten Fällen noch innerhalb des Fehlerbereiches des Ansatzes mit dem Protein. Zum anderen ist zwar in drei von vier Fällen die mittlere Fluoreszenz des Ansatzes mit Protein geringer als die der Kontrolle, in Fall von Ansatz 1, Zugabe von $2 \mu \mathrm{M}$ AHL ist das Verhältnis aber genau umgekehrt. Da man bei der Zugabe zweier unterschiedlicher Volumina desselben Ansatzes zum dem Monitorstamm gegensätzliche Aussagen erhält, kann dieser Effekt also nicht auf der Menge der anwesenden AHL beruhen, sondern muß in der Fluktuation der gfp-Expression begründet sein. Weiterhin gilt zu bedenken, daß, falls man einen Effekt durch Zugabe des Proteins Pa0740 annehmen würde, die enzymatische Aktivität des Proteins extrem gering sein müßte, da die Konzentration von Pa0740 mit 6,9 $\mu \mathrm{M}$ im Vergleich zu der AHL-Konzentration (3 mM) hoch ist. Für den Abbau aller AHL-Moleküle in dem Ansatz über Nacht müßte ein Enzymmolekül nur alle 9,5 Minuten eine Reaktion katalysieren. Doch selbst diese Rate wird nicht erreicht. Die Konzentration der zugegeben AHL liegt in einem Bereich, in dem die volle Induktion der gfpExpression gerade eben erreicht wird. Ein Abbau der AHL müßte somit sehr gut mit Hilfe dieses Monitorstamms nachgewiesen werden können. Es läßt sich somit festhalten, daß für das Protein Pa0740 keinerlei Aktivität im Hinblick auf den Abbau von C12-HSL ermittelt werden konnte. 


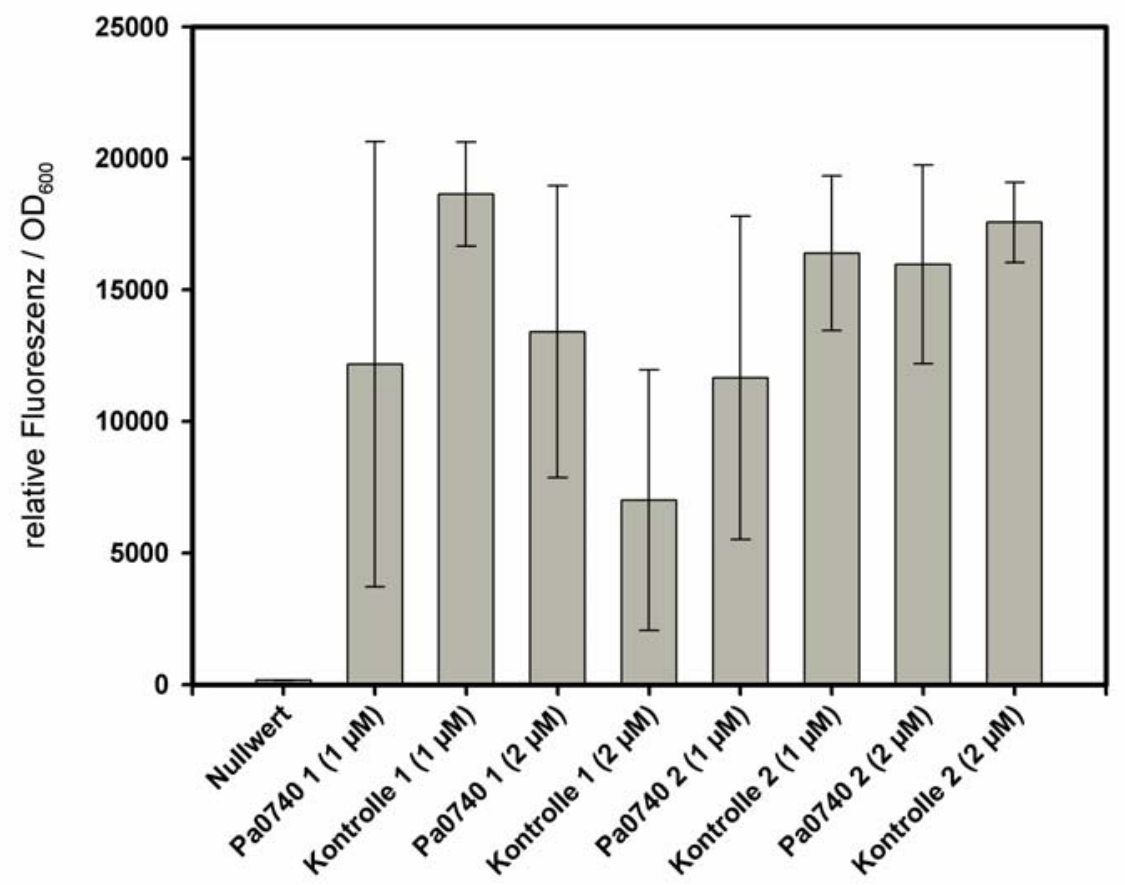

Abb. 4.32: GFP-Fluoreszenz des Monitorstammes P. putida (pKR-C12), bezogen auf die Zelldichte. In zwei unabhängigen Ansätzen wurde das C12-HSL mit dem Protein Pa0740 inkubiert, bevor jeweils 1 oder $2 \mu \mathrm{M}$ (Endkonzentration) der AHL aus diesen Inkubationsansätzen $\mathrm{zu}$ den Zellkulturen gegeben wurden. Als Kontrolle erfolgte die Zugabe von C12-HSL, welches ohne Zugabe von Enzym inkubiert worden war. Nullwert: Fluoreszenz des Monitorstammes ohne Zugabe von C12-HSL.

Nicht C12-HSL, sondern 3-Oxo-C12-HSL ist der physiologische Autoinducer von $P$. aeruginosa. Beide Moleküle unterscheidet nur die Anwesenheit einer Carbonylgruppe an der C3-Position des Alkylrestes in 3-Oxo-C12-HSL. Dennoch ist es vorstellbar, daß ein Enzym nur die 3-Oxo-Form als Substrat akzeptiert. Aus diesem Grunde wurde untersucht, ob Pa0740 in der Lage ist, den Abbau von 3-Oxo-C12-HSL zu katalysieren. Hierfür wurden

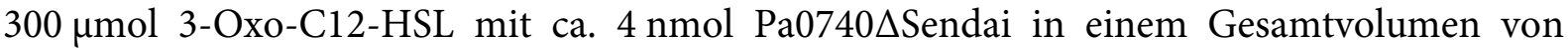
$100 \mu \mathrm{l}$ PBS über Nacht bei $30^{\circ} \mathrm{C}$ inkubiert. Als Kontrolle wurde ein Ansatz ohne Protein nach demselben Schema inkubiert. Am nächsten Tag wurden die Ansätze zu dem Monitorstamm gegeben und die Fluoreszenz im Triplikat bestimmt, wie in Abschnitt 3.5.5 beschrieben. Die Endkonzentration von 3-Oxo-C12-HSL wurde einmal auf $0,5 \mu \mathrm{M}$ und einmal auf $1 \mu \mathrm{M}$ eingestellt. Die Ergebnisse dieser Messungen sind als Balkendiagramm in Abb. 4.33 dargestellt. In diesem Fall ist bei der Zugabe des Proteins sogar eine höhere Fluoreszenz als bei der Kontrolle zu beobachten. Somit kann auch in diesem Fall im Rahmen der Meßgenauigkeit ausgesagt werden, daß das Protein Pa0740 nicht in der Lage ist, den Abbau von 3-Oxo-C12HSL zu katalysieren. 


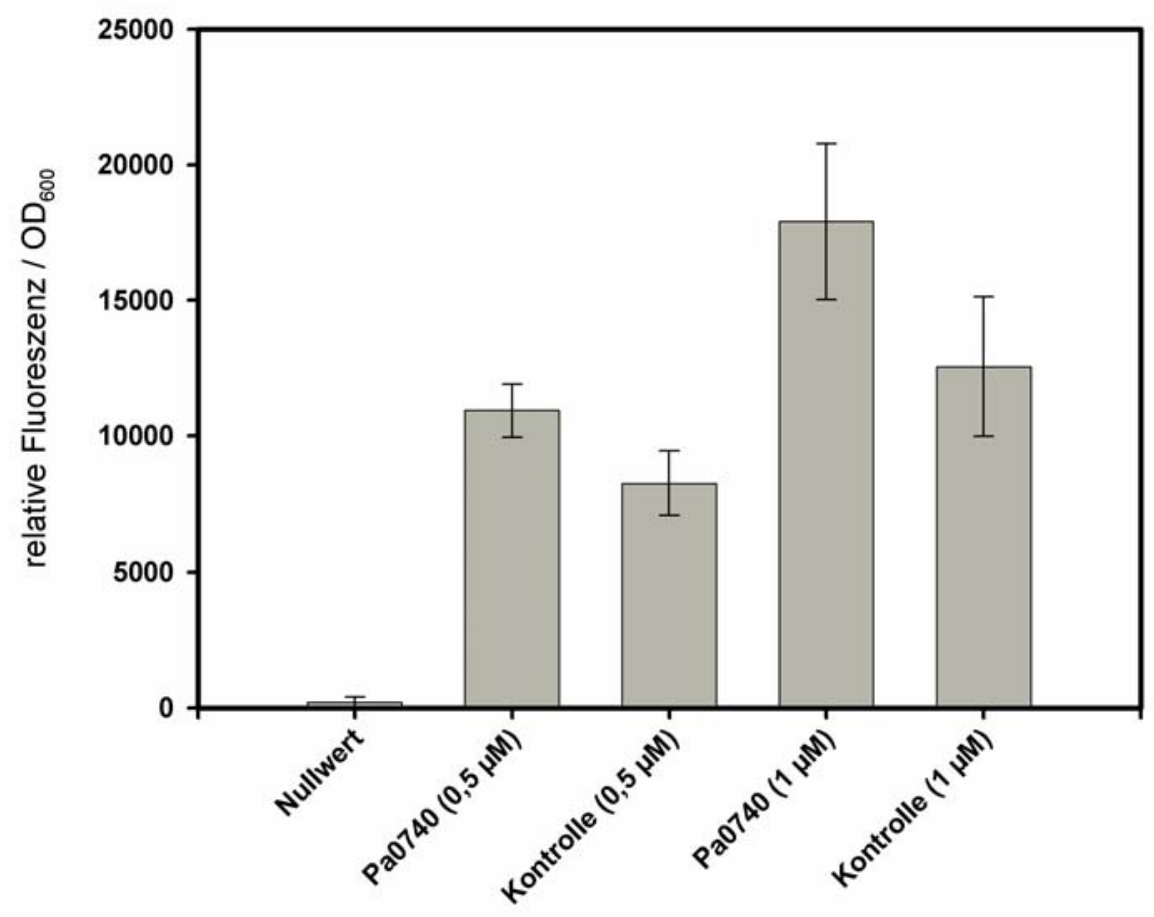

Abb. 4.33: GFP-Fluoreszenz des Monitorstammes P. putida (pKR-C12), bezogen auf die Zelldichte. C12-HSL wurde mit dem Protein Pa0740 inkubiert, bevor jeweils 0,5 oder $1 \mu \mathrm{M}$ Endkonzentration des AHL zu den Zellkulturen gegeben wurden. Als Kontrolle erfolgte die Zugabe von C12-HSL, welches ohne Zugabe von Enzym inkubiert worden war. Nullwert: Fluoreszenz des Monitorstammes ohne Zugabe von 3-Oxo-C12-HSL.

\subsubsection{Untersuchungen zum AHL-Abbau unter semiphysiologischen Bedingungen}

Möglicherweise benötigt das Protein Pa0740 einen unbekannten Kofaktor, damit es den Abbau von Acyl-Homoserinlactonen katalysieren kann. Weiterhin ist es auch möglich, daß ein Abbau von AHL nur stattfinden kann, wenn diese in physiologischen Konzentrationen auftreten. Um einen möglicherweise notwendigen Kofaktor zur Verfügung zu stellen, wurde ein Zellextrakt aus Pseudomonas aeruginosa zu dem Ansatz gegeben. Zum anderen sollte als Quelle von AHL ein Kulturüberstand von $P$. aeruginosa eingesetzt werden, da in diesem die Autoinducer in physiologischen Konzentrationen vorkommen.

$50 \mathrm{ml}$ dYT wurden mit Pseudomonas aeruginosa PAO1 inokuliert und bei $37^{\circ} \mathrm{C}$ über Nacht inkubiert. Am nächsten Morgen wurden die Zellen durch Zentrifugation pelletiert und das Medium durch einen Filter der Porengröße 0,2 $\mu \mathrm{m}$ sterilfiltriert. $500 \mu \mathrm{l}$ dieses Mediums wurden mit $200 \mu \mathrm{l} \mathrm{Pa0740} \mathrm{(3,65} \mathrm{mg/ml),} \mathrm{entsprechend} \mathrm{9,7} \mathrm{nmol,} \mathrm{und} 200 \mu \mathrm{l}$ Zellextrakt aus $P$. aeruginosa (3.4.5) für $3 \mathrm{~h}$ bei $37^{\circ} \mathrm{C}$ inkubiert. Als Kontrolle wurde anstatt der Proteinlösung $200 \mu \mathrm{l}$ PBS zugegeben. Die Reaktionen wurden im Duplikat angesetzt. Nach der Inkubation wurden Aliquots zu $350 \mu \mathrm{zu}$ dem Monitorstamm P. putida (pKR-C12) gegeben. Die Fluoreszenz des Monitorstammes wurde wie in Abschnitt 3.5.5 beschrieben bestimmt. Die Ergebnisse sind in Form eines Balkendiagramms in Abb. 4.34 gezeigt. Wie man aus der 
Abbildung erkennen kann, zeigt sich nur in einem Fall ein leichter Rückgang der Fluoreszenz bei Zugabe des Proteins zu dem Kulturüberstand, bei dem zweiten Ansatz ist das Verhältnis umgekehrt.

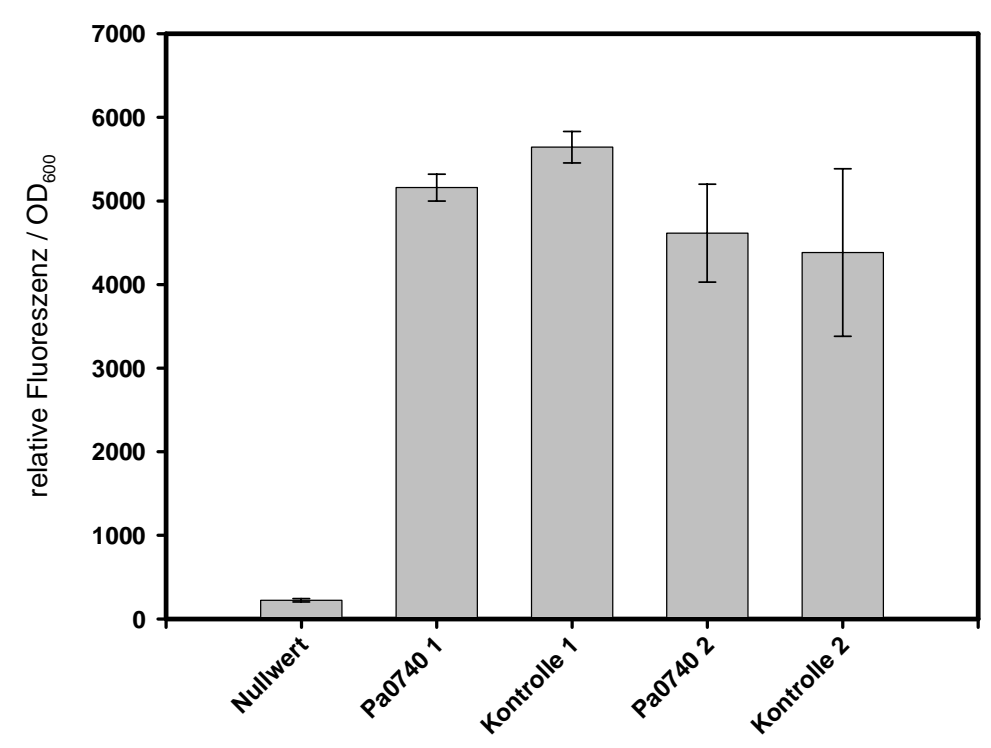

Abb. 4.34. Messung der Fluoreszenz des Monitorstammes P. putida (pKR-C12) nach Zugabe von PAO1 Kulturüberstand und Zellextrakt (Kontrolle) oder PAO1 Kulturüberstand, Zellextrakt und Pa0740 Protein (Pa0740). Nullwert: Keine Zugabe von Kulturüberstand.

Aus der Literatur ist bekannt, daß die Konzentration an 3-Oxo-C12-HSL im Wachstumsmedium von Pseudomonas aeruginosa ca. $1 \mu \mathrm{M}$ beträgt (PEARSON et al., 1995). Die im Ansatz vorhandene Konzentration Pa0740 war 6,9 $\mu$ M. Somit beträgt also die Konzentration des Proteins im Ansatz das Vielfache der Konzentration des 3-Oxo-C12-HSL. Selbst wenn jedes Proteinmolekül nur eine einzige Reaktion katalysieren könnte, wäre dies ausreichend, um das komplette AHL in dem Ansatz abzubauen. Somit kann man davon ausgehen, daß in diesem Experiment kein Abbau von 3-Oxo-C12 stattfand. Falls das Protein $\mathrm{Pa} 0740$ einen Kofaktor benötigt, so war dieser nicht oder in $\mathrm{zu}$ geringer Menge in dem Zellextrakt von $P$. aeruginosa vorhanden oder inaktiv.

\subsubsection{Untersuchungen zum AHL-Abbau mittels HPLC Analytik und Massenspektrometrie}

Da ein Nachweis einer AHL-abbauenden Aktivität von Pa0740 mit den Biosensoren nicht möglich war, wurde ein alternativer Weg beschritten, um nach möglichen Abbauprodukten der AHL nach Inkubation zu suchen. Acyl-Homoserinlactone lassen sich über eine ReversedPhase-HPLC mit einer $\mathrm{C}_{18}$-Säule auftrennen. Das hierbei zugrunde liegende Prinzip ist die hydrophobe Interaktion der Acylkette mit den hydrophoben $\mathrm{C}_{18}$-Ketten der Säulenmatrix. Bei einem enzymatischen Verdau der AHL sollte sich das Laufverhalten der Produkte deutlich 
von dem des Edukts unterscheiden, da es sowohl bei einer Acylase als auch bei einer Lactonase zu einer Hydrolyse kommt. Acyl-Homoserinlactone können isokratisch bei einer für das AHL bestimmten Methanolkonzentration aufgetrennt werden. Ein Vorteil der HPLC Analyse ist, daß die Substanzen nach der Chromatographie aufgefangen und einer Massenanalyse zugeführt werden können. So könnte, in Fall eines enzymatischen Verdaus der AHL, der Mechanismus der enzymatischen Reaktion aus den Massen der Produkte deduziert werden. In Abb. 4.35 sind beide möglichen Reaktionen des enzymatischen Abbaus von C12HSL dargestellt. Bei der Reaktion einer Lactonase kommt es zu der Hydrolyse des Lactonringes. Die beiden Massen der Edukte addieren sich. Eine Acylase hydrolysiert die Amidbindung. Dabei entsteht eine Dodacanoylsäure mit einer relativen Molmasse von 200,32 und ein Homoserinlacton mit einer relativen Molmasse von 101,11.

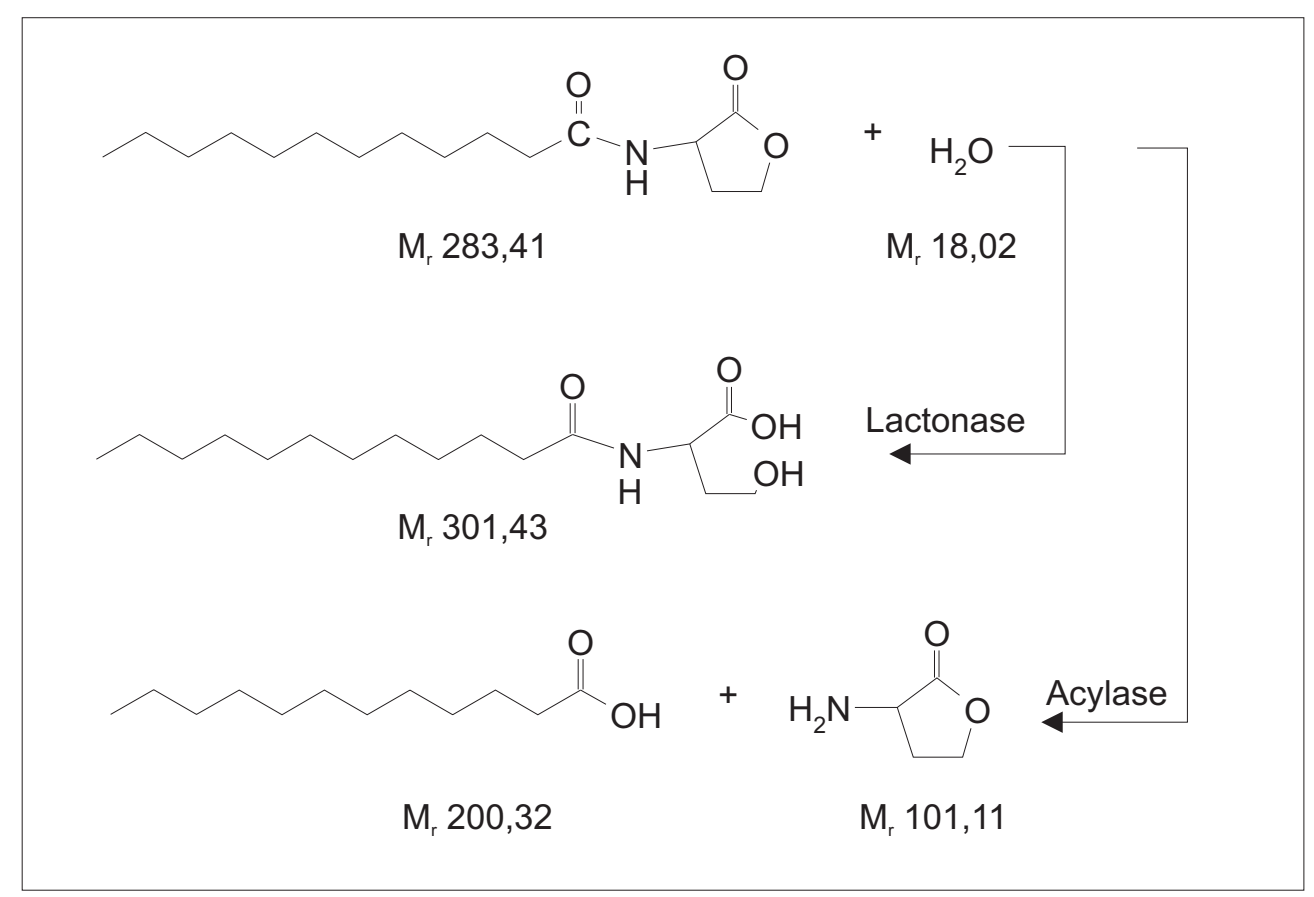

Abb. 4.35: Mögliche Reaktionen eines enzymatischen Abbaus von Acyl-Homoserinlactonen durch eine Lactonase oder Acylase.

Bevor die analytischen und präparativen HPLC Läufe durchgeführt werden konnten, mußte zuerst ermittelt werden, bei welcher Wellenlänge das AHL detektiert werden kann. Dazu wurde das Spektrum einer 1,5 mM Lösung von C12-HSL in absolutem Methanol gemessen. Von diesem Spektrum wurde das Spektrum von absolutem Methanol subtrahiert, da Methanol ebenfalls bei bestimmten Wellenlängen absorbiert. Das Differentialspektrum ist in Abb. 4.36 dargestellt. Das Maximum der Absorption liegt bei $207 \mathrm{~nm}$. Somit stand fest, daß der HPLC Detektor auf diese Wellenlänge eingestellt werden mußte. 


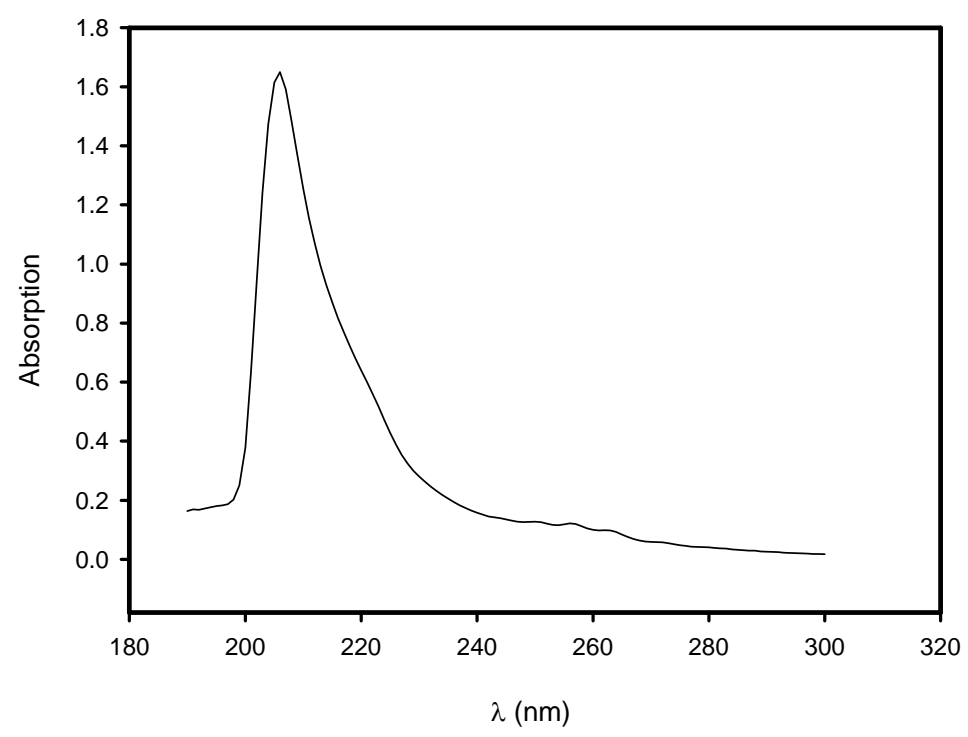

Abb 4.36: Differentielles Absorptionsspektrum einer 1,5 mM Lösung von C12-HSL in Methanol.

Für das C12-HSL wurde die Methanolkonzentration ermittelt, bei der anschließend die isokratische Auftrennung durchgeführt werden sollte. Hierzu wurde die Substanz in die HPLC injiziert und mittels eines Gradienten von 20-100 \% Methanol in Wasser eluiert. Die am besten für die isokratische Chromatographie geeignete Methanolkonzentration liegt um $10 \%$ unter der Methanolkonzentration, bei der das AHL eluiert (SCHAEFER et al., 2000) . Der HPLC-Lauf ist in Abb. 4.37 gezeigt.

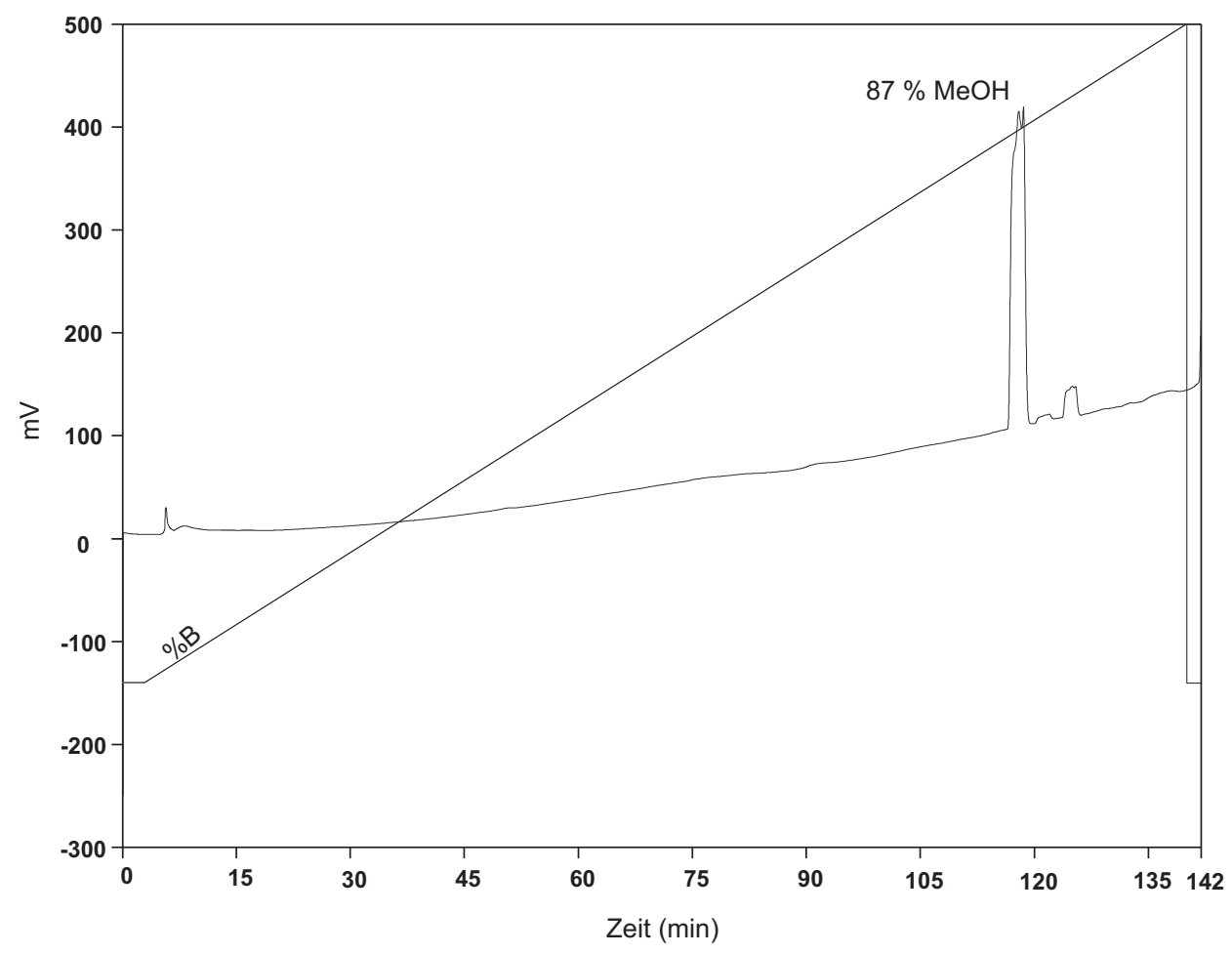

Abb. 4.37: Ermittlung des Elutionsverhaltens von C12-HSL mit einem MeOH-Gradienten. 
Aus dem HPLC-Diagramm kann man ermitteln, daß C12-HSL bei einer Methanolkonzentration von $87 \%$ eluiert, dementsprechend wurde für die isokratische Chromatographie als einzusetzende Methanolkonzentration 77 \% gewählt. Es wurden zwei Reaktionsansätze vorbereitet. In den einen Ansatz wurden $300 \mu \mathrm{mol}$ C12-HSL und $52 \mu \mathrm{g}$ Pa0740, entsprechend $690 \mathrm{pmol}$, in einem Gesamtvolumen von $200 \mu \mathrm{l}$ PS gegeben. In dem zweiten Ansatz, der Kontrolle, wurde die Proteinlösung durch PBS ersetzt. Nach einer Inkubation bei $30^{\circ} \mathrm{C}$ über Nacht wurden die AHL wie in 3.6.6 beschrieben mit Essigsäureethylester extrahiert. Um den Einfluß des Puffers auf die nachfolgende Chromatographie ermitteln zu können, wurden $200 \mu$ l PBS ebenso mit Essigsäure Ethylester extrahiert. Es erfolgte der Auftrag der Proben auf die RP-Säule und eine Chromatographie für 30 Minuten. Die Läufe des Ansatzes mit Pa0740, der Kontrolle und des Pufferprofils sind in Abb. 4.38 dargestellt.

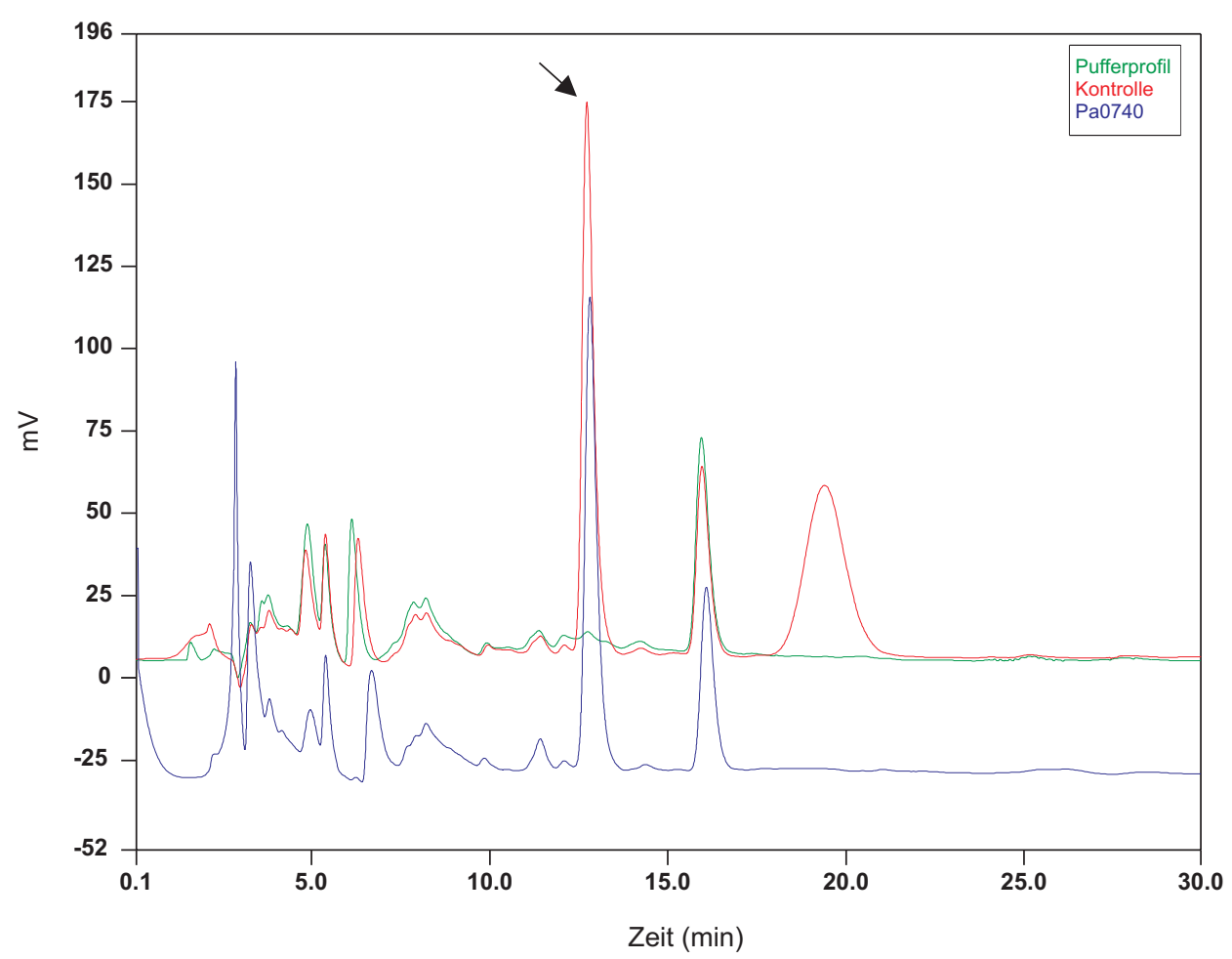

Abb. 4.38: Isokratische HPLC von C12-HSL, das mit Pa0740 inkubiert wurde (blau). Die Kontrolle (rot) wurde nur mit Puffer inkubiert. In grün ist das Pufferprofil dargestellt. Der Pfeil weist auf den Peak, der aufgefangen und der Massenanalyse zugeführt wurde.

Wie man aus dem Chromatogramm erkennen kann, gibt es bei der Kontrolle und dem Ansatz mit Pa0740 einen Peak bei 12,7 Minuten, der in dem Pufferprofil nicht vorkommt. Dieser Peak ist demnach dem C12-HSL zuzuordnen. Weiterhin ist bei der Kontrolle noch ein weiterer Peak bei 19,4 Minuten zu erkennen. Dieser Peak ist wahrscheinlich durch eine Verunreinigung entstanden. Da in der Chromatographie des Ansatzes, dem Pa0740 zugegeben wurde, kein zusätzlicher Peak auszumachen war, wurden beide dem C12-HSL korrespondierenden Peaks aufgefangen. Die AHL wurden mit Essigsäureethylester aus dem Eluat extrahiert (3.6.6) und das Lösungsmittel abgezogen. Der so gewonnene Feststoff wurde zur Massenanalyse in das Institut für Organische Chemie der Universität gegeben. Dort 
wurde die Masse der Substanz durch Electrospray-Ionisation-Massenspektrometrie (ESI-MS) bestimmt. ESI ist eine schonende Ionisierungstechnik für kleine Substratmengen und eignet sich zur Auftrennung von relativ großen und/oder labilen Molekülen, wie zum Beispiel Peptide, Organometalle und Polymere. Die zu analysierende Substanz kann in Wasser aufgenommen werden. Falls sie von sich aus nicht ionisch ist, muß eine Protonenquelle, in diesem Fall $\mathrm{Na}^{+}$, zugegeben werden. Die Probe wird dann in das ESI-MS Gerät injiziert und durch eine nadelförmige Elektrode, an der ein Potential zwischen 2,5 - $4 \mathrm{kV}$ anliegt, gepumpt. Dadurch kommt es zum Versprühen der Probe und einer gleichzeitigen Aufladung der Oberfläche der so gebildeteten Tröpfchen. Diese werden dann in Richtung der Gegenelektrode beschleunigt. In der Kammer kommt es zur Evaporation des Lösungsmittels und zu einer Verringerung der Oberfläche des Tröpfchens. Da die Ladung des Tröpfchens aber gleich bleibt, steigt dementsprechend die Ladungsdichte auf der Oberfläche an. Das kann sie aber nur bis zu einem bestimmten Punkt, dem sogenannten Raleigh'schen Limit, das die maximale Ladungsdichte auf der Oberfläche darstellt. Bei fortschreitender Evaporation des Lösungsmittels kommt es dann aufgrund der Abstoßung der Ladungen zu einer „Explosion“ des Tröpfchens, wodurch wiederum Tröpfchen mit einer geringeren Oberfläche entstehen. Dieser Prozeß kann sich so lange fortführen, bis die geladene, lösungsmittelfreie Substanz vorliegt. Durch eine Öffnung in der Gegenelektrode gelangt die geladene Probe dann in den Analysator. Als Analysator kommt ein Quadrupol zum Einsatz, der im Prinzip ein Massenfilter ist, der unter vorgegebenen physikalischen Bedingungen nur Ionen mit einem bestimmen Massen/Ladungsverhältnis durchlassen kann.

Die massenspektroskopische Analyse der beiden Proben ist in Abb. 4.39 dargestellt. Wie man erkennen kann, finden sich in beiden Fällen Substanzen, die der Masse des Ausgangsproduktes plus Natrium $\left(M_{r} 22,99\right)$ entsprechen. Es findet sich weder eine Masse, die dem Produkt einer Lactonase-Reaktion, noch dem einer Acylase-Reaktion entsprechen würde. Somit kann man davon ausgehen, daß das Protein Pa0740 keine C12-HSL abbauende Funktion inne hat. 

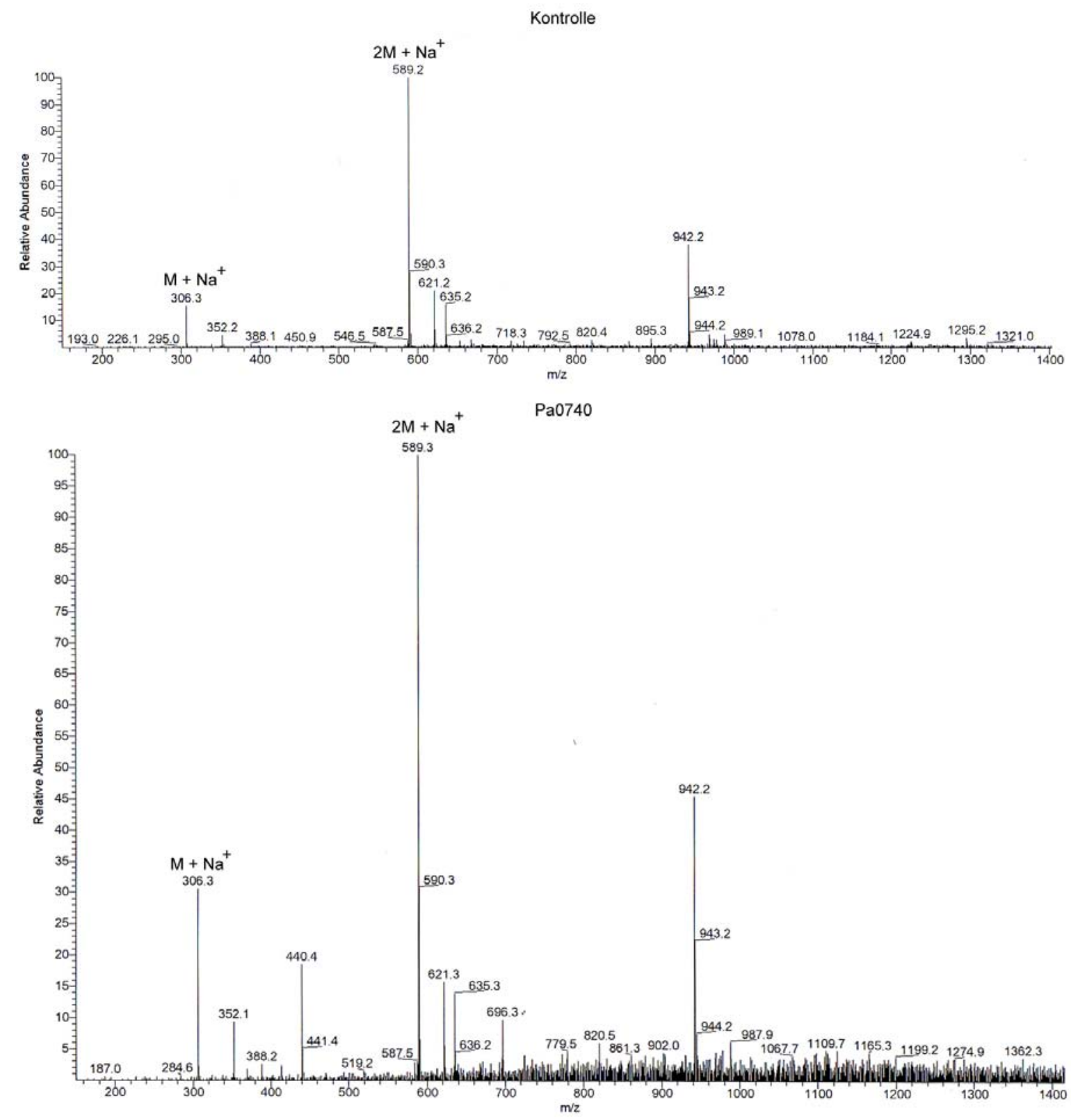

Abb. 4.39: Massenspektrometrische Analyse der beiden Peaks aus dem HPLC Lauf in Abb. 4.38. Oben findet sich die Analyse der Kontrolle, während unten die Analyse des AHL nach der Inkubation mit Pa0740 dargestellt ist.

\subsubsection{Zusammenfassung und Diskussion der über $\mathrm{Pa0740}$ gewonnenen Erkenntnisse}

Bei der Kultivierung von Pseudomonas aeruginosa in Flüssigmedium endet in der stationären Phase die Synthese von Autoinducern und damit auch das Quorum Sensing (YATES et al., 2002). Dies wurde in einer Kultur der Mutante B7D3 nicht beobachtet, hier findet das Quorum Sensing kontinuierlich statt. Als Arbeitshypothese wurde angenommen, daß das in der Mutante ausgeschaltete Gen Pa0740 eine Funktion im Abbau der Autotransporter hat, da für das Ende des Quorum Sensing die Synthese der Autoinducer, die 
durch einen Mechanismus der positiven Rückkopplung gesteuert wird, gestoppt werden muß. Ein plausibles Modell, wie die Synthese zu Erliegen kommen kann, ist, daß die Autoinducer durch enzymatischen Abbau komplett entfernt werden und damit auch keine weitere Transkription der AHL-Synthase stattfinden kann.

Tatsächlich sind aus der Literatur mittlerweile Beispiele solcher AHL-degradierenden Enzyme bekannt. Das erste entdeckte Enzym dieser Art war AiiA aus Bacillus sp. 240B1 (DONG et al., 2000). Dieses Enzym wurde entdeckt, indem man über 400 Umweltisolate auf ihre Fähigkeit hin untersuchte, das Quorum Sensing in dem Pflanzenpathogen Erwinia carotovora $\mathrm{zu}$ inhibieren. Die Zellysate aus Bacillus sp. 240B1 waren in der Lage, die Signalübertragung durch AHL zu blockieren. Durch Klonierung der genomischen DNA von 240B1 in Cosmidbibliotheken und deren Expression in Escherichia coli konnte die Region auf dem Genom von 240B1 eingeschränkt und durch nachfolgende Subklonierung das entsprechende Gen isoliert werden. Das Gen aiiA kodiert für ein Protein von 250 Aminosäuren Länge und dem Zinkbindemotif HXHXDH (MELINO et al., 1998), welches sich auch in der Primärsequenz von Pa0740 wiederfindet. Der enzymatische Mechanismus von AiiA ist aufgeklärt. Durch massenspektroskopische Analyse konnte gezeigt werden, daß das Enzym als AHL-Lactonase fungiert und der Lactonring der AHL durch AiiA hydrolysiert wird (Dong et al., 2001). Die Expression des aiiA-Gens in Tomaten- und Kartoffelpflanzen schützte diese vor der Infektion durch E. carotovora (DoNG et al., 2001). Auch in den beiden Bacillus sp. Isolaten A23 und A24 konnte das Enzym AiiA nachgewiesen werden (REIMMANN et al., 2002). Die Expression von AiiA aus diesen Stämmen in Pseudomonas aeruginosa führte zu einer drastischen Reduktion der 3-Oxo-C12-HSL Synthese. Die Akkumulation des zweiten Autoinducers, Butyryl-Homoserinlacton, wurde vollständig unterbunden. Auch die Produktion der durch das Quorum Sensing kontrollierten Virulenzfaktoren Elastase, Rhamnolipid, Hydrogencyanid und Pyocyanin fand nicht mehr statt, wenn aiiA in $P$. aeruginosa exprimiert wurde (REIMMANN et al., 2002).

Auch aus Agrobacterium tumefaciens ist eine AHL-Lactonase bekannt (ZHANG et al., 2002). Der Transfer des Ti-Plasmides in A. tumefaciens wird durch das Quorum Sensing Signal 3-Oxo-Octanoyl-Homoserinlacton kontrolliert. Die Konjugation des Plasmids ist in der mid-exponentiellen Phase am intensivsten und stoppt in der stationären Phase. Der Mechanismus der Terminierung des Quorum Sensing ist bisher nicht bekannt. Eine konstitutive Expression der Lactonase führte zu einem kompletten Ausfall des Ti-PlasmidTransfers, was darauf hindeutet, daß das Ende des Quorum Sensing in A. tumefaciens durch die Expression dieses Enzyms eingeläutet wird (ZHANG et al., 2002).

Variovorax paradoxus kann AHL als alleinige Kohlenstoffquelle verwenden. Für den AHL-Meatbolismus besitzt das Bakterium zwei noch nicht näher charakterisierte Enzyme, eine Aminoacylase, welches das Homoserin von der Aclykette abspaltet, und eine Lactonase, welche die Hydrolyse des Lactonringes katalysiert (LEADBETTER und GREENBERG, 2000). Auch in Pseudomonas aeruginosa, welches auf 3-Oxo-C12-HSL als alleiniger Kohlenstoffquelle wachsen kann, existiert eine AHL-Acylase (HUANG et al., 2003). Die konstitutive Expression dieses Enzyms mit der Bezeichnung PvdQ (Pa2385) verhinderte die Akkumulation des 3Oxo-C12-HSL Autoinducers im Medium. Dennoch konnten PvdQ-Mutanten weiterhin auf 
3-Oxo-C12-HSL wachsen, was für das Vorhandensein eines weiteren AHL-degradierenden Enzyms in $P$. aeruginosa spricht (HUANG et al., 2003). Auch aus Ralstonia sp. XJ12B wurde eine AHL-Acylase isoliert, die die Amidbindung der AHL hydrolysiert. Die heterologe Expression dieses Enzyms in P. aeruginosa PAO1 führte zu einer Abschwächung des Quorum Sensing in diesem Stamm (LiN et al., 2003).

Da das in der Hierarchie des Quorum Sensing ganz oben angesiedelte lasRI-System den Autoinducer 3-Oxo-C12-HSL verwendet, muß für ein Erliegen des Quorum Sensing dieser aus dem Medium entfernt werden. Dementsprechend wurde das Protein Pa0740 auf seine Fähigkeit, 3-Oxo-C12-HSL bzw. das kommerziell erhältliche C12-HSL abzubauen, untersucht. Der Abbau der Autoinducer wurde mit Hilfe eines AHL-Monitorstammes untersucht. Hierbei konnte weder ein Abbau von 3-Oxo-C12-HSL noch von C12-HSL nachgewiesen werden. Mittels RP-HPLC und massenspektrometrischer Analyse wurde untersucht, ob die Inkubation von C12-HSL mit Pa0740 in der Bildung eines Produktes resultierte. Dies war nicht der Fall. Somit kann zusammenfassend gesagt werden, daß das in dieser Arbeit untersuchte Protein Pa0740 nicht in der Lage war, die getesteten AHL abzubauen. Dies könnte zu einen daran liegen, daß die gewählten Reinigungsmethoden nicht $\mathrm{zu}$ einem aktiven Enzym führten. Beispielsweise könnte das Vorhandensein des Hexahistidinanhängsels die Aktivität des Proteins völlig unterbinden. Es ist aber auch denkbar, daß das Protein Pa0740 selber keine AHL-abbauende Aktivität besitzt, sondern eine unbekannte Rolle in einem Prozeß spielt, der in den Abbau der AHL involviert ist. Weiterhin könnte auch die Bildung eines Komplexes mit anderen, noch zu identifizierenden Proteinen für die Aktivierung notwendig sein. Auch die durch Homologievergleiche vorhergesagte mögliche $\beta$-Laktamase-Aktivität konnte weder für das Substrat PADAC, noch für das Substrat Penicillin G gezeigt werden. Um einen Ansatzpunkt für weitere Untersuchungen zu bekommen, wäre es hilfreich zu wissen, ob Pa0740 möglicherweise einen Interaktionspartner im Proteom von $P$. aeruginosa besitzt. Außerdem soll in naher Zukunft zur weiteren Funktionsaufklärung eine Röntgenstrukturanalyse von Pa0740-Kristallen, welche an der Gesellschaft für Biotechnologische Forschung in Braunschweig aus im Rahmen dieser Arbeit produziertem und gereinigtem Protein bereits gewonnen worden sind, durchgeführt werden.

\subsubsection{Untersuchungen der Mutante 19C2}

In diesem Abschnitt wird der Phänotyp der Mutante 19C2 und die Funktionen des in dieser Mutante ausgeschalteten Proteins, Pa1572, beschrieben.

\subsubsection{Phäntoypen der Mutante und genomische Organisation von Pa1572}

Die Mutante 19C2 zeigt im Vergleich zum Wildtyp eine um das sechzehnfache reduzierte Überlebensfähigkeit in Granulozyten. Der Quotient aus dem Überleben in AB-Serum und Granulozyten beträgt 20 und ist der höchste unter allen gefundenen Mutanten, demnach ist bei dieser Mutante das intrazelluläre Wachstum in Granulozyten am deutlichsten eingeschränkt. Bei der Untersuchung des Quorum Sensing zeigte sich, daß die Produktion von Acyl-Homoserinlactonen deutlich niedriger als bei dem Wildtyp liegt und auch die 
Proteasesekretion stark reduziert ist. Durch externe Supplementation mit AHL konnte die Mutante dazu angeregt werden, selber wieder AHL $\mathrm{zu}$ synthetisieren und Protease $\mathrm{zu}$ sekretieren (WIEHLMANN, 2001).

Das bei der Mutante 19C2 ausgeschaltete Gen ist Pa1572. Dieses Gen besitzt eine Promotor- und Terminatorsequenz und wird daher wahrscheinlich singulär transkribiert. Bei der BLAST Suche nach konservierten Domänen (MARCHLER-BAUER et al., 2003) findet man die Sequenz einer konservierten Region (Abb 4.40) mit hoher Ähnlichkeit ( $\mathrm{S}=125, \mathrm{E}=6 \mathrm{x}$ $\left.10^{-30}\right) \mathrm{zu}$ Proteinen der Familie der ATP-NAD Kinasen (EC 2.7.1.23). Enzyme dieser Klasse katalysieren die Phosphorylierung von NAD zu NADP und verwenden ATP als Phosphorquelle. Pa1572 ist annotiert als konserviertes Protein mit unbekannter Funktion. Die größten Homologien hat es zu einem 377 Aminosäuren langen hypothetischen Protein aus Pyrococcus horikoshii.

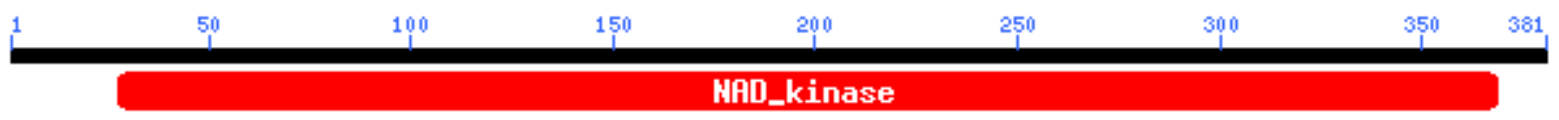

Abb. 4.40: Konservierte Domäne aus der Familie der NAD-Kinasen in Pa1572.

Das Protein Pa1572 wurde gereinigt und biochemisch untersucht.

\subsubsection{Klonierung und Reinigung von Pa1572}

Die Klonierung von Pa1572 in den Expressionsvektor pBBR22bII erfolgte ähnlich wie für Pa5350 (4.1.1.4) beschrieben. Die kodierende Sequenz von Pa1572 wurde durch PCR mit den beiden Oligonukleotiden Pa1572Ndeup und Pa1572lo unter Verwendung von genomischer DNA von $P$. aeruginosa PAO1 amplifiziert. Als thermostabiles Enzym wurde die LaTaq Polymerase der Firma TaKaRa eingesetzt. Die für die Klonierung notwendigen Erkennungsstellen für NdeI und BglII wurden durch die Oligonukleotide eingeführt. Das resultierende PCR-Produkt wurde durch Phenol/Chloroform Extraktion (3.2.1.3) und Ethanolpräzipitation gereinigt (3.2.1.1). Anschließend erfolgte die Klonierung in pCR4-TOPO (Invitrogen, 3.3.5). Einzelne Transformanten wurden vermehrt und die Plasmide präpariert (3.2.5). Die Identifikation von positiven Klonen erfolgte durch Restriktionsspaltung mit NdeI und BglII und anschließende Analyse der DNA Fragmente durch Agarosegelelektrophorese (3.2.2). Der resultierende Vektor wurde als pCR4-TOPOPa1572 bezeichnet. Eine Zwischenklonierung in den Vektor pCR4-TOPO wurde in Betracht gezogen, da sich eine direkte Klonierung von PCR Produkten, welche $P$. aeruginosa DNA Sequenzen beinhalteten, in pBBR22bII in mehreren anderen Fällen als erfolglos erwiesen hatte.

Für die Klonierung des Pa1572 Strukturgens in pBBR22bII wurde das Akzeptorplasmid pBBR22bIIPa5349 mit den Enzymen NdeI und BglII verdaut. Das Vektorfragment wurde aus einem Agarosegel gereinigt (3.2.3). Das Plasmid pCR4-TOPOPa1572 wurde nach demselben Muster prozessiert, nur das in diesem Fall nicht das Vektorfragment, sondern das Fragment, welches das Pa1572-Gen trug, aus dem Agarosegel gereinigt wurde. Es erfolgte eine Ligation der beiden Fragmente (3.3.3) sowie die Transformation von 71-18 Zellen. Einzelne 
Transformanten wurden vermehrt und die Plasmide präpariert (3.2.5). Die Identifikation von positiven Klonen erfolgte durch Verdau der Plasmide mit den Restriktionsenzymen NdeI und BglII. Die Sequenz der positiven Klone wurde durch Nukleotidsequenzanalyse verifiziert.

Mittels immobilisierter Metallionen Affinitätschromatographie (IMAC) wurde das Fusionsprotein aus dem Pa1572 Strukturgen, dem Sendai-Epitop und dem Hexahistidinanhängsel aus einer $1000 \mathrm{ml}$ Kultur von BL21(DE3) mit dem Plasmid pBBR22bIIPa1572 im wesentlichen wie in Abschnitt 3.4.8 beschrieben, gereinigt. Wichtig war, die Inkubationstemperatur der Zellen auf maximal $18^{\circ} \mathrm{C}$ abzusenken, da sich ansonsten das Fusionsprotein in Einschlußkörpern (Inclusion Bodies) einlagert. In diesen Inclusion Bodies werden Protein in Form ungefalteter Aggregate eingelagert (SCHLIEKER et al., 2002). Die Fraktionen wurden auf einem 12,5 \%igen SDS Gel analysiert (3.4.6). In Abbildung 4.41 ist ein Beispiel für eine Gelanalyse einer Reinigung von Pa1572 gezeigt.

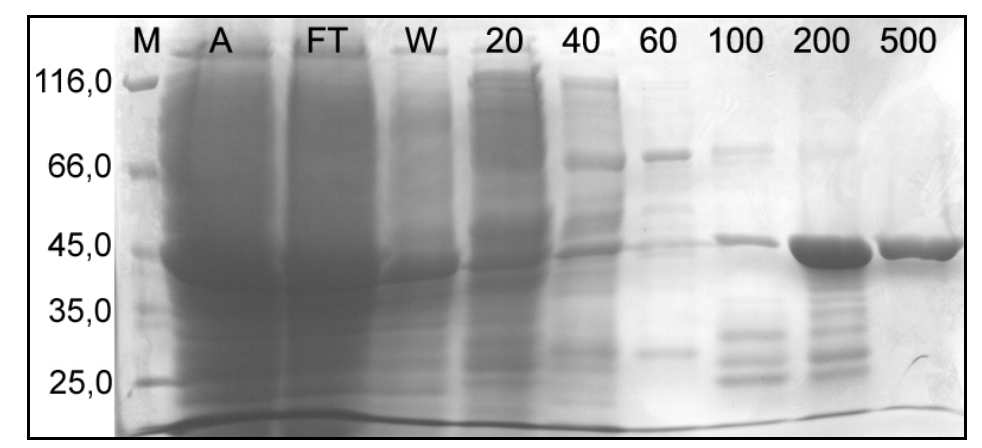

Abb. 4.41: IMAC Reinigung von Pa1572 und Analyse durch SDS-PAGE. M: Proteinlängenstandard, A: Auftrag, FT: Durchlauf, W: Waschfraktion, 20-500: Elution mit 20, 40, 60, 100, 200 und 500 mM Imidazol, respektive.

In den Elutionsfraktionen der Nickel-Chelatsäule, welche $60 \mathrm{mM}, 100 \mathrm{mM}$ und $200 \mathrm{mM}$ Imidazol enthielten, fand sich eine Bande, die der erwarteten Größe des Fusionproteins von 43600 relativem Molekulargewicht entsprach. Die Abbaubanden, die in den Fraktionen 100 und $200 \mathrm{zu}$ sehen, sind wahrscheinlich durch Kontamination der Proben durch Proteasen entstanden, da diese Banden bei weiteren Reinigungen, die nach dem selben Schema durchgeführt worden waren, nicht mehr auftraten. Die Fraktionen wurden vereinigt und gegen $4000 \mathrm{ml} 100 \mathrm{mM}$ Phosphatpuffer, $\mathrm{pH}$ 8,0; $100 \mathrm{mM} \mathrm{NaCl}$ dialysiert (3.4.10). Nach der Dialyse wurde die Proteinlösung einkonzentriert und sofort für die weitere Analyse eingesetzt, da das Protein unstabil ist. So war nach dem Einfrieren und Auftauen keine Aktivität mehr vorhanden, auch nach mehrtägiger Lagerung auf Eis war keine Aktivität mehr vorhanden. Die Ausbeute betrug ca. $5 \mathrm{mg}$ aus einem Liter Bakterienkultur.

\subsubsection{Untersuchungen der Enzymaktivität von $\mathrm{Pa} 1572$}

\subsection{NAD-Kinase-Aktivität}

Da bei dem computergestützten Sequenzvergleich in der Primärsequenz von Pa1572 die Signatur einer konservierten NAD-Kinase-Domäne gefunden wurde, wurde untersucht, ob 
Pa1572 tatsächlich eine NAD-Kinase-Aktivität besitzt. Zur Messung der Phosphorylierung von NAD kam ein gekoppelter in vitro Enzymtest zum Einsatz. Eine NADP-abhängige Isocitrat Dehydrogenase wandelt Isocitrat in Oxalsuccinat um. Dabei wird pro Mol verbrauchtem Isocitrat ein Mol NADP zu NADPH reduziert (STRYER, 1994). In dem gekoppelten Enzymtest wird die zu untersuchende, putative NAD-Kinase zusammen mit ATP, NAD, Isocitrat und Isocitrat-Dehydrogenase eingesetzt. Nur wenn das NAD phosphoryliert, wenn also NADP gebildet wird, kann Isocitrat von der ICDH zu Oxalsuccinat umgesetzt werden. Das bei dieser Reaktion gebildete NADPH kann, ebenso wie NADH, photometrisch bei einer Wellenlänge von $340 \mathrm{~nm}$ gemessen werden (ZIEGENHORN et al., 1976). Der Enzymtest wurde wie in Abschnitt 3.6.4 beschrieben durchgeführt und die Absorption bei $340 \mathrm{~nm}$ für 4 Minuten verfolgt. In Abb. 4.42 ist der Graph dieser Messung dargestellt. Wie man aus der Abbildung erkennen kann, steigt der Graph langsam aber kontinuierlich an. Dies liegt an der Bildung von NADH, da NAD ebenfalls als Kofaktor akzeptiert wird, wenngleich auch mit einer wesentlich geringeren Effizienz als NADP (Hurley et al., 1996). Bei Zugabe des Proteins Pa1572 ist keine Erhöhung der Geradensteigung zu beobachten. Dies deutet darauf hin, daß Pa1572 keine NAD-Kinase Aktivität besitzt, da ansonsten NADP gebildet würde und die durch die Isocitrat Dehydrogenase katalysierte Reaktion deutlich schneller ablaufen könnte.

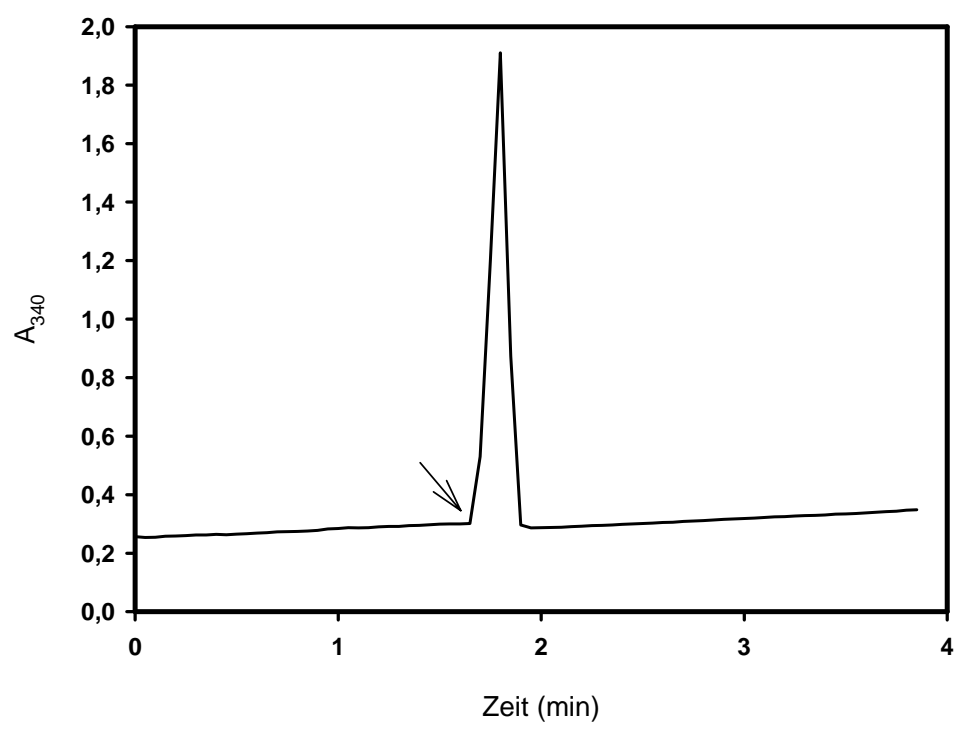

Abb. 4.42: Messung der NAD-Kinase Aktivität von Pa1572. Der Zeitpunkt der Zugabe von Pa1572 ist durch den Pfeil gekennzeichnet.

\subsection{NADPH-Oxidoreduktase-Aktivität}

In den im folgenden beschriebenen Experimenten wurde untersucht, ob das Protein Pa1572 eine NADPH-Oxidoreduktase-Aktivität aufweist. Da der Elektronenakzeptor einer möglicherweise durch Pa1572 katalysierten Redoxreaktion unbekannt war, wurden Zellysate 
von Escherichia coli eingesetzt, in der Hoffnung, der Elektronenakzeptor befände sich in diesen. Optimal wäre die Verwendung von Pseudomonas aeruginosa Lysaten gewesen, deren Gewinnung in den Räumlichkeiten des Institutes für Mikrobiologie und Genetik aufgrund einer fehlenden Anzuchtsgenehmigung für diesen Organismus aber nicht möglich war.

Für die Messung der Oxidation von NADPH wurde ebenfalls der gekoppelte Isocitrat Dehydrogenase Enzymtest eingesetzt (siehe Abschnitt 4.1.3.3.1). Eine Zugabe des Enzyms Isocitrat Dehydrogenase war bei der Verwendung von Zellysaten nicht notwendig, da Escherichia coli eine NADP-spezifische Isocitrat-Dehydrogenase (ICDH) enthält (REEVES et al., 1972). Das Enzym akzeptiert zwar auch NAD als Kofaktor, jedoch mit einer 7000-fach schlechteren Affinität (HURLEY et al., 1996). Eine ICDH in E. coli, die NADP als physiologischen Kofaktor akzeptiert, ist aus der Literatur nicht bekannt. Das in dieser Reaktion gebildete NADPH könnte bei einer vorhandenen NADPH-OxidoreduktaseAktivität von Pa1572 sogleich wieder oxidiert werden. Dieser Prozeß läßt sich photometrisch verfolgen.

Zellysate aus jeweils $500 \mathrm{ml}$ Zellkultur von BL21(DE3) und BL21(DE3) mit dem Plasmid pBBR22bIIPa1572 wurden bei $15^{\circ} \mathrm{C}$ inkubiert, nach $3 \mathrm{~h}$ mit $1 \mathrm{mM}$ IPTG versetzt und für weitere $15 \mathrm{~h}$ inkubiert. Die Lysate wurden wie in 3.4.5 beschrieben hergestellt, wobei die Zelldichte, gemessen durch die $\mathrm{OD}_{600}$, in beiden Kulturen zuvor auf denselben Wert gebracht wurde. Die Reaktionen wurden wie in Abschnitt 3.6.5 beschrieben angesetzt, die Reaktionen durch Zugabe von NADP gestartet und die Absorption bei $340 \mathrm{~nm}$ über die Zeit verfolgt. Abb. 4.43 zeigt die gemessenen Werte.

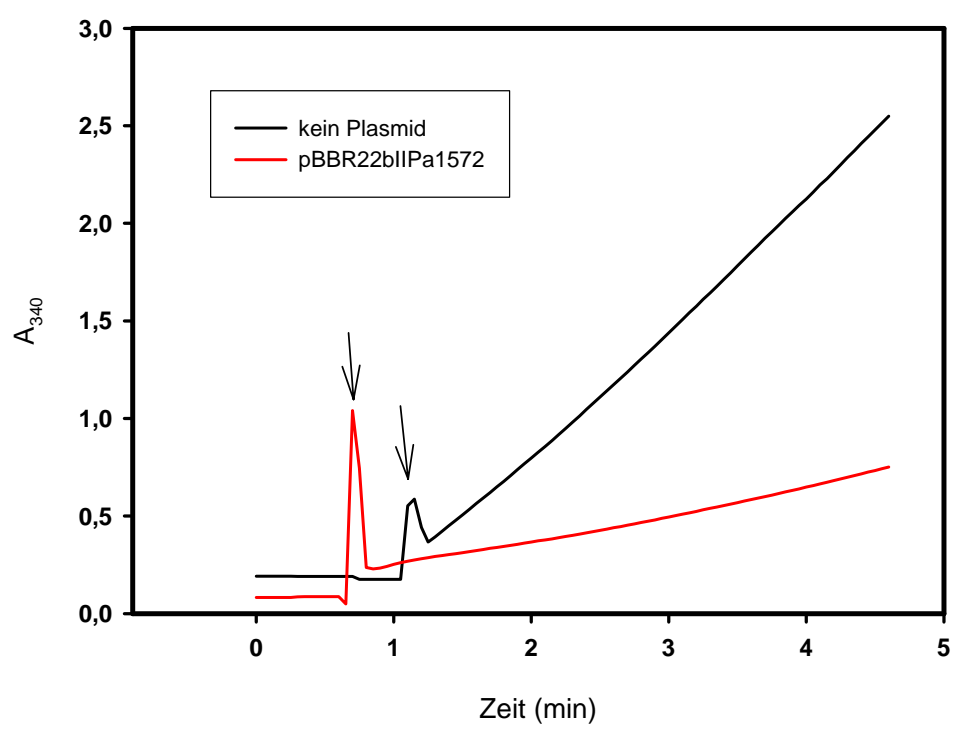

Abb. 4.43: Messung der NADPH-Bildung mit dem gekoppelten ICDH Enzymtest in Zellysaten von BL21 ohne Plasmid (schwarze Kurve) und mit pBBR22bII (rote Kurve). Der Zeitpunkt der Zugabe von NADP ist durch die Pfeile gekennzeichnet. $\mathrm{A}_{340}$ : Absorption bei $340 \mathrm{~nm}$. 
Bei Verwendung des Lysates des Pa1572 exprimierenden Stammes ist die beobachtete Zunahme der Absorption, die durch die Bildung von NADPH hervorgerufen wird, deutlich geringer als bei dem Lysat von BL21(DE3) (pBR22bIIPa1572). Dies deutet darauf hin, daß das von der Isocitrat Dehydrogenase gebildete NADPH durch Pa1572 gleich wieder abgebaut wird. Es ist aber auch möglich, daß in dem Stamm, der Pa1572 exprimiert, die Menge an ICDH geringer als im Wildtyp ist. Um zu ermitteln, ob der beobachtete Effekt auf die Anwesenheit von Pa1572 zurückzuführen ist, wurde untersucht, ob das gereinigte Pa1572 Protein in der Lage war, die Oxidation von NADPH zu katalysieren. Auch diese Messungen wurden wieder mit Zellysaten durchgeführt (3.6.5). In einem Zweistrahlphotometer wurden zwei Ansätze differentiell vermessen. In der eine Küvette befanden sich Lysat von BL21(DE3), Isocitrat und NADP. In der zweiten Küvette befanden sich identische Mengen derselben Reagenzien nebst $200 \mu \mathrm{l}$ einer Pa1572-Proteinlösung (ca. $5 \mathrm{mg} / \mathrm{ml}$ ). Die Reaktion wurde durch Zugabe von NADP gestartet. Der aus den Daten abgeleitete Graph ist in Abb. 4.44 gezeigt.

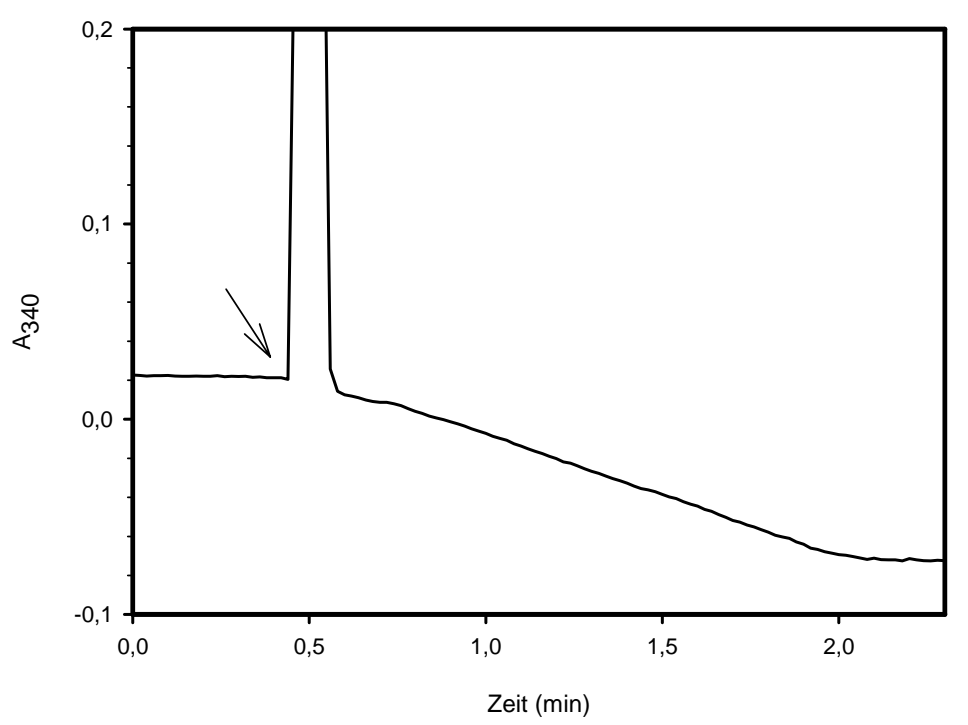

Abb. 4.44: Differentielle Messung der Bildung von NADPH. Der Pfeil weist auf den Zeitpunkt der Zugabe der NADP-Lösung. $\mathrm{A}_{340}$ : Absorption bei $340 \mathrm{~nm}$.

Wie man aus der Abbildung ersehen kann, fällt die Kurve nach Zugabe der NADPLösung zu den Ansätzen ab. Dies ist der Fall, weil die Bildung von NADPH in der Küvette, zu der Pa1572 zugegeben wurde, langsamer von statten geht. Dies spricht dafür, daß Pa1572 tatsächlich die Funktion einer NADPH-Oxidoreduktase hat. Dennoch ist es auch möglich, daß das Protein die Aktivität der ICDH inhibiert und daß deswegen weniger NADPH gebildet werden kann als in dem Kontrollansatz. Daher wurde untersucht, ob eine Bindung von NADPH an Pa1572 nachgewiesen werden kann. Die Bindung der Dihydronicotinhälfte des Kofaktors an ein Protein führt zu einer Reduktion der Absorption bei $340 \mathrm{~nm}$ (SEYDOUX et al., 1976). Für diesen Nachweis wurde ebenfalls eine Messung in einem Zweistrahlphotometer durchgeführt. In die eine Küvette wurden $5 \mu \mathrm{l}$ einer $20 \mathrm{mM}$ NADPH Stammlösung, und $1095 \mu \mathrm{l} 100 \mathrm{mM}$ Phosphatpuffer, $\mathrm{pH}$ 8,0, $100 \mathrm{mM} \mathrm{NaCl}$ gegeben. In die zweite Küvette 
wurden $5 \mu$ l einer $20 \mathrm{mM}$ NADPH Stammlösung, $995 \mu 100 \mathrm{mM}$ Phosphatpuffer, pH 8,0, $100 \mathrm{mM} \mathrm{NaCl}$ und $100 \mu \mathrm{l}$ einer Pa1572-Lösung mit einer Konzentration von ca. $5 \mathrm{mg} / \mathrm{ml}$ gegeben. Es wurde ein differentielles Spektrum aufgenommen, das in Abb. 4.45 dargestellt ist. Als Kontrolle wurde in einem weiteren Ansatz das NADPH ausgelassen, wobei wiederum eine Messung in dem Zweistrahlphotometer durchgeführt wurde. In die eine Küvette wurden $1095 \mu \mathrm{l} 100 \mathrm{mM}$ Phosphatpuffer, $\mathrm{pH}$ 8,0, $100 \mathrm{mM} \mathrm{NaCl}$ gegeben. In die zweite Küvette wurden $995 \mu \mathrm{l} 100 \mathrm{mM}$ Phosphatpuffer, pH 8,0, $100 \mathrm{mM} \mathrm{NaCl}$ und $100 \mu \mathrm{l}$ einer Pa1572Lösung mit einer Konzentration von ca. $5 \mathrm{mg} / \mathrm{ml}$ gegeben.

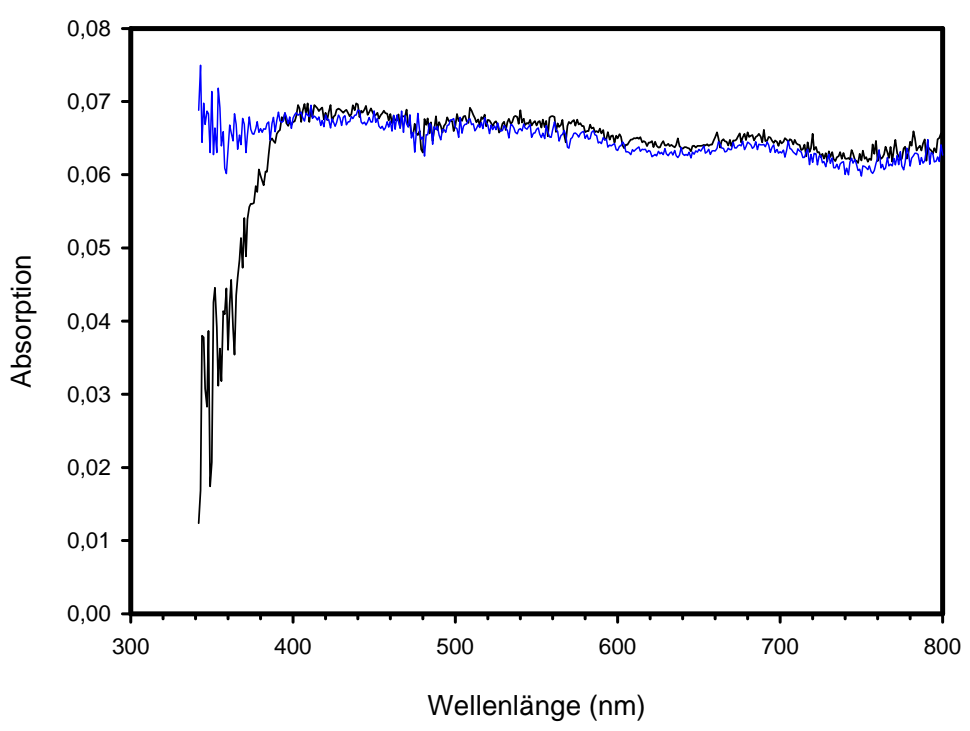

Abb. 4.45: Differentialspektrum zur Bestimmung der Bindung von NADPH an das Protein Pa1572 (schwarze Kurve) und Kontrolle ohne Zugabe von NADPH (blaue Kurve).

In dem Differentialspektrum erkennt man, daß die Absorption unterhalb einer Wellenlänge von $400 \mathrm{~nm}$ abnimmt und gegen $340 \mathrm{~nm}$ den kleinsten Wert erreicht. Durch die Bindung von NADPH an ein Protein kommt es zu einer Reduktion der Absorption bei 340 nm (SEYDOUX et al., 1976). Bei der Kontrolle, die kein NADPH enthielt, war dieser Abfall der Absorption nicht zu erkennen. Das Spektrum läßt die Interpretation zu, daß NADPH von Pa1572 gebunden wird.

\subsubsection{Zusammenfassung und Diskussion der über Pa1572 gewonnenen Erkenntnisse}

Das Protein Pa1572 ist als konserviertes Protein mit unbekannter Funktion annotiert. Durch in silico Analyse wurde eine zu einer NAD-Kinase-Domäne homologe Sequenz ermittelt. In den durchgeführten biochemischen Untersuchungen konnten keine Evidenzen 
einer NAD-Kinase-Aktivität von Pa1572 gewonnen werden. Statt dessen konnte demonstriert werden, daß Pa1572 wahrscheinlich eine NADPH-Oxidoreduktase ist. So konnte gezeigt werden, daß in Gegenwart von Pa1572 die Bildung von NADPH durch Isocitrat Dehydrogenase verringert ist. Dies deutet darauf hin, daß das gebildetet NADPH von Pa1572 gleich wieder konsumiert wird. Das gemessene Differentialspektrum zeigte eine Bindung von NADPH an das Protein Pa1572. Vor allem die Tatsache, daß eine Bindung von NADPH an Pa1572 gezeigt werden konnte, spricht dafür, daß die beobachtete verringerte Bildung von NADPH im ICDH Enzymtest nicht das Resultat einer Inhibition der ICDH, sondern der Oxidation von NADPH ist. Der Elektronenakzeptor der katalysierten Redoxreaktion ist noch unbekannt. Für eine weitere Funktionsaufklärung von Pa1572 könnte es hilfreich sein, einen möglichen Interaktionspartner durch Analyse von proteomweiten Protein-ProteinInteraktionen zu identifizieren. 


\subsection{Funktionsaufklärung durch Analyse von Protein-Protein-Wechsel- wirkungen}

\subsubsection{Verfahren zur Analyse von Protein-Protein-Interaktionen}

Bei den Untersuchungen der Proteine Pa5349, Pa5350, Pa0740 und Pa1572 wurden zwar teilweise aussagekräftige Ergebnisse erlangt, die zumindest ein Einordnung in bestimmte Aufgabenbereiche in der Zelle und im Fall von Pa5349, Pa5350 und Pa1572 auch eine biochemische Charakterisierung ermöglichen, doch konnte in keinen Fall eine komplette Funktionsaufklärung erzielt werden. Um weitere Hinweise auf die Funktion der Proteine zu erlangen, wäre es wünschenwert, $\mathrm{zu}$ untersuchen, ob die Proteine eine Rolle in regulatorischen Netzwerken spielen oder Interaktionen mit anderen Proteinen eingehen. Die Einordnung der Proteine in Funktionseinheiten könnte zur Aufklärung ihrer zellulären Funktion beitragen. Gerade Virulenzfaktoren spielen oftmals eine Rolle in einem Verbund von Proteinen. Als ein Beispiel sei das Typ-III-Sekretionssystem genannt, das aus mehr als zwanzig verschiedenen Proteinen besteht (BLOCKER et al., 2001). Um einen Einfluß eines bestimmtes Proteins oder dessen kodierenden Gens auf das zelluläre Repertoire an Genprodukten zu ermitteln, können prinzipiell zwei Ansätze gewählt werden. Zum einen kann eine Analyse sämtlicher Transkripte des Genoms zu einem bestimmten Zeitpunkt durchgeführt werden, zum anderen können Protein-Protein-Wechselwirkungen innerhalb des Proteoms untersucht werden.

Bei der Transkriptomanalyse wird ein Vergleich der Gesamtheit der mRNA des WildtypBakteriums mit der Mutante durchgeführt. Somit kann ein Einfluß des entsprechenden Proteins auf die Transkription von Genen untersucht werden. Das Transkriptom wird mit Hilfe eines sogenannten DNA-Microarrays untersucht. Auf diesem ist einzelstängige DNA, entweder Oligonukleotide oder denaturierte PCR-Produkte oder cDNA, auf der Oberfläche eines Trägermaterials immobilisiert. Im Idealfall ist die Gesamtheit der Gene eines Organismus auf einem Microarray abgebildet, es existieren aber auch Arrays, auf denen nur bestimmte Subsätze, beispielsweise nur für die Pathogenität relevante Gene, repräsentiert sind. Für die Analyse des Transkriptoms wird die mRNA aus dem Organismus präpariert, mit einer Fluoreszenzmarkierung versehen und mit der einzelsträngigen DNA auf dem Microarray hybridisiert. Die Fluoreszenz des Arrays wird ausgewertet, um eine Information über die Expression der einzelnen Gene zu erhalten (Cummings und RELMAN, 2000). Microarrays eignen sich für einen Vergleich der Genexpression von zwei verschiedenen Zuständen und nicht unbedingt für eine absolute quantitative Auswertung des Transkriptoms in einem gegeben Zustand (CONWAY und SCHOOLNIK, 2003). Im wesentlichen gibt es drei Anwendungsbereiche dieser Zwei-Zustands-Experimente in der Mikrobiologie: Untersuchung der differentiellen Antwort auf verschiedene Kultivierungsbedingungen, Reaktionen auf Zugabe von chemischen Agenzien wie Antibiotika, und der Vergleich des Transkriptoms in Wild-Typ und Mutante (CONWAY und SCHOOLNIK, 2003). Somit lassen sich die Einflüsse eines bestimmten Gens in regulatorischen und metabolischen Netzwerken untersuchen. Am besten eignet sich die Transkriptomanalyse für die Untersuchung von Transkriptionsfaktoren, doch auch der Ausfall von anderen Strukturgenen kann einen Einfluß auf das Transkriptom der entsprechenden Mutante haben. Bakterien sind in der Regel 
sehr adaptionsfähig und können unter Umständen den Ausfall eines Gens durch die Überexpression von anderen Genen kompensieren, die dann dessen Aufgabe übernehmen. Diese Veränderungen im Expressionslevel der bestimmten Gene können einen Hinweis über die Funktion des ausgefallenen Gens liefern (CONWAY und SCHOOLNIK, 2003). Gerade in hierarchisch aufgebauten Netzwerken wie dem des Quorum Sensing hat auch der Ausfall von anderen Genen als Transkriptionsfaktoren einen Einfluß auf die Transkription von Komponenten dieses Systems. Beispielsweise bewirkt der Ausfall der AHL-Synthetase LasI in Pseudomonas aeruginosa, daß die in der Hierarchie untergeordneten Gene ebenfalls nicht transkribiert werden (DE KIEVIT und IGLEWSKI, 2000; LATIFI et al., 1996). Die Verwendung von Microarrays bringt jedoch auch Probleme mit sich, die hauptsächlich experimenteller Natur sind. Die Präparation der mRNA aus den Zellen ist ein kritischer Schritt, da die Halbwertszeit der Transkripte in Bakterien relativ kurz ist. In E. coli liegt diese für $80 \%$ der mRNA im Bereich von 3 bis 8 Minuten (BERNSTEIN et al., 2002). Außerdem müssen die zahlreichen Parameter der Bakterienvermehrung sehr sorgfältig kontrolliert werden, damit der gemessene Unterschied der Transkription nicht die Antwort der Bakterien auf unkontrollierte Variabeln reflektiert, sondern tatsächlich auf das zu untersuchende Ereignis zurückzuführen ist (CONWAY und SCHOOLNIK, 2003). Ein weiterer allgemeiner Kritikpunkt des Verfahrens ist, daß die Menge der Transkripte nicht unbedingt die Menge der entsprechende Proteine reflektiert. Dies ist für Genprodukte, die posttranslationell modifiziert werden, der Fall. In zahlreichen Studien, in denen Transkriptomdaten direkt mit Proteomdaten verglichen worden sind, konnte jedoch festgestellt werden, daß die Regulation der meisten Gene mit der Menge der von ihnen kodierten Proteine korreliert (EYMANN et al., 2002; Hommais et al., 2001; YoshIDA et al., 2001). So haben mehrere Studien gezeigt, daß die Anzahl der Enzymmoleküle in der Zelle direkt von der Transkription ihres entsprechenden Gens abhängt (ARFIN et al., 2000; KHODURSKY et al., 2000; SMULSKI et al., 2001; TAO et al., 1999).

Neben der Transkriptionsanalyse eignet sich vor allem die Analyse von Protein-ProteinWechselwirkungen für eine funktionelle Einordnung eines Proteins in das Repertoire der gesamten zellulären Proteine, da Proteine, die miteinander interagieren, normalerweise auch in gleiche zelluläre Prozesse involviert sind. Die Untersuchung von Protein-ProteinInteraktionen innerhalb eines Organismus spielt in der als Proteomik bezeichneten Disziplin eine wichtige Rolle. Die Proteomik, d.h. die Erforschung der Gesamtheit aller in einer Zelle oder einem Organismus vorhandenen Proteine, ist seit dem Beginn der Postgenomära, welche mit der Offenbarung der humanen Genomsequenz (LANDER et al., 2001; VENTER et al., 2001) eingeläutet wurde, eine der sich am schnellsten entwickelnden Disziplinen der molekularen Biologie. Dementsprechend finden methodische und technische Innovationen für die Analyse von Wechselwirkungen zwischen Proteinen Eingang in den Laboralltag (PHIZICKY et al., 2003). Zur Zeit gibt es in der Proteomik vier verschiedene funktionelle Ansätze, um ProteinProtein-Wechselwirkungen auf Proteomebene zu erforschen: Den sogenannten Two-HybridAssay, fluoreszenzbasierte Methoden, Protein-Microarrays und massenspektroskopische Methoden (PHIZICKY et al., 2003). Diese Methoden sollen im folgenden kurz erläutert werden. 


\subsubsection{Der Hefe Two-Hybrid-Assay}

Der Hefe Two-Hybrid-Assay (FIELDS und SONG, 1989) ist eine genetische Herangehensweise an die Identifikation und Analyse von Protein-Protein-Wechselwirkungen. Er beruht auf der modularen Natur der eukaryotischen Transkriptionsfaktoren, die sowohl eine ortsspezifische DNA-Bindedomäne als auch eine Transkriptionsaktivierungsdomäne, die für die Rekrutierung der Transkriptionsmaschinerie verantwortlich ist, enthalten. In dem Two-Hybrid System wird Protein $\mathrm{X}$ an die DNA-Bindedomäne und Protein $\mathrm{Y}$ an die Transkriptionsaktivierungsdomäne fusioniert. Die Bindung von $\mathrm{X}$ und $\mathrm{Y}$ führt zu einer Aktivierung des Transkriptionsfaktors und zu einer Transkription von Reportergenen, die eine Erkennungsstelle für die entsprechende DNA-Bindedomäne enthalten. Als Reportergene kommen solche Gene zum Einsatz, die das Wachstum von prototrophen Stämmen unter Selektionsbedingungen erlauben, beispielsweise LEU2, URA3 oder CYH2 (COLAS und BRENT, 1998; VIDAL et al., 1996). In einer typischen Anwendung wird ein Repertoire von Genen, die an die Transkriptionsaktivierungsdomäne fusioniert sind auf Bindung des Proteins von Interesse, das an die DNA-Bindedomäne fusioniert ist, durchmustert. Die Hauptvorteile dieser Methode liegen in der Flexibilität und Sensitivität. Letztere ist bedingt durch die Überproduktion der Proteine in vitro, deren Lokalisation im Nukleus, in dem die Interaktionen nachgewiesen werden, die große Anzahl an verschiedenen Interaktionen, die gleichzeitig überprüft werden können, und die Detektion der Interaktionen durch genetische Selektion. Aufgrund der hohen Sensitivität können noch Interaktionen mit Dissoziationskonstanten in der Größenordnung von $10^{-7} \mathrm{M}$ nachgewiesen werden (PHIZICKY et al., 2003). Dieses Verfahren ist sensitiver als eine Immunpräzipitätion oder gleichzeitige Aufreinigung von Komplexen, da auch eine transiente Interaktion wahrgenommen werden kann, während bei den beiden letztgenannten Verfahren ein stabiler Komplex über eine relativ lange Zeitdauer vorliegen muß. Flexibilität erlangt das Two-Hybrid System durch die Kalibrierung des Systems für Interaktion von variabler Affinität durch Variation der Expressionsstärke der Hybrid-Proteine, durch Verwendung verschiedener DNABindedomänen von unterschiedlich starker Bindung an die Promotorregion und durch die Auswahl verschiedener Selektionsmedien (PHIZICKY et al., 2003). Der Nachteil des TwoHybrid Systems ist das unvermeidbare Auftreten relativ vieler falsch-positiver und falschnegativer Ereignisse. Falsch-Negative enthalten Membranproteine und Proteine des Sekretionsapparates, die normalerweise nicht in den Nukleus gelangen können, da ihre eigene Signalsequenz dafür sorgt, daß diese Proteine in anderen Zellkompartimenten lokalisiert werden. Proteine, die als Hybrid nicht korrekt falten können und solche, die weitere Faktoren oder postranslationelle Modifikationen für die Interaktion benötigen, lassen sich normalerweise auch nicht mit der Two-Hybrid-Methode identifizieren. $\mathrm{Zu}$ falsch-Positiven zählen Kolonien, die nicht aus einer echten Protein-Protein-Interaktion resultieren sowie detektierte Protein-Protein-Interaktionen, die in vivo keine Relevanz haben. Der größte Teil der falsch-Positiven entsteht durch akzidentelle Transkription des Reportergens ohne Zutun irgendeiner Interaktion der Hybridproteine (PHIZICKY et al., 2003). Modifizierte Two-Hybrid Systeme stehen seit einiger Zeit zur Verfügung. Diese erlauben nicht nur die Suche nach Interaktionspartnern eines bestimmten Proteins, sondern die gesamte Kartierung des Netzwerkes von Proteininteraktionen einer Zelle, welches nach der seit einiger Zeit 
prävalenten Nomenklatur in der „Ära des Om“ in zunehmendem Maß als Interaktom (LU et al., 2004) bezeichnet wird. Durch Kreuzung von DNA-Bindedomänen-Hybriden, die in haploiden Hefen eines Kreuzungstyps exprimiert werden, mit Transkriptionsaktivierungsdomänen, die in haploiden Hefen des anderen Kreuzungstyps exprimiert werden, kommt es zur Bildung von diploiden Kreuzungspartnern, in welchem die Protein-Protein-Interaktionen abgefragt werden können. (MENDELSOHN und BRENT, 1999). Dieses Kreuzungsschema ist eingesetzt worden, um Protein-Protein-Interaktionen innerhalb des Bakteriophagen T7 (BARTEL et al., 1996), des mRNA-Spleiß-Apparates von $S$. cerevisiae (FromONT-RACINE et al., 2000) oder des gesamten Proteoms von S. cerevisiae (UETZ et al., 2000) zu untersuchen.

\subsubsection{Analyse von Protein-Protein-Wechselwirkungen durch FRET}

Eine weitere generelle Methode, um Protein-Protein-Interaktionen aufzudecken, ist der Nachweis der Verschiebung der Fluoreszenz zweier fluoreszierender Markierungen an den Interaktionspartnern durch Fluoresezenz-Resonanz-Energietransfer (FRET). FRET ist ein Prozeß, bei dem Energie von einer angeregten Donor-Fluorophore auf eine AkzeptorFluorophore, die sich in einem Abstand von weniger als $60 \AA$ befindet, übertragen wird (Wouters et al., 2001). Die Detektion von FRET nach der Anregung der Donor-Fluorophore erfolgt durch Messung der Fluoreszenz der Akzeptor-Fluorophore oder durch Bestimmung der Halbwertszeit der Fluoreszenz der ersten Fluorophore. Die beiden in diesem Verfahren am häufigsten verwendeten Fluorophoren sind die GFP-Varianten CFP (cyan fluorescent protein) und YFP (yellow fluorescent protein) (TsIEN, 1998). Für die Untersuchung von Protein-Protein-Wechselwirkungen wird der FRET-Donor an das eine zu untersuchende Protein gekoppelt, während der FRET-Akzeptor an das andere zu untersuchende Protein fusioniert wird. Die Auswertung der Experimente erfolgt durch FRETFluoreszenzmikroskopie (WOUTERS et al., 2001). Durch Einsatz der FRET-Methode konnten zahlreiche Protein-Protein-Interaktionen direkt in der Zelle nachgewiesen werden, so zum Beispiel die Oligomerisierung des Fas-Rezeptors (SIEGEL et al., 2000), die Interaktion der Apoptose-Regulatoren Bcl-2 und Bax in Mitochondrien (MAHAJAN et al., 1998) sowie die Interaktion der Transkriptionsfaktoren Pit-1 und Ets-1 im Nukleus (DAY, 1998). Das Potential der FRET-Methodologie ist aus zwei Gründen beachtenswert. Erstens kann sie für die Visualisierung der Protein-Protein-Wechselwirkungen in situ, d.h. in der lebenden Zelle in dem Milieu und unter den Bedingungen, in denen die Interaktionen normalerweise stattfinden, eingesetzt werden. Zweitens können transiente Interaktionen unter hoher zeitlicher Auflösung in der Zelle verfolgt werden. Neben der Untersuchung von Wechselwirkungen eines definierten Proteinpaares sind zwei Hochdurchsatzapplikationen dieser Technik vorstellbar. Erstens kann eine Fusion von cDNA-Banken an die kodierenden Regionen der entsprechenden fluoreszenten Proteine zur Untersuchung von proteomweiten Protein-Interaktionen herangezogen werden (MENDELSOHN und BRENT, 1999). Zweitens können posttranslationelle Modifikationen detektiert werden. Hierzu wird cDNA an die kodierende Sequenz eines FRET-Donors, in diesem Fall ein Antikörper, fusioniert, und eine Wechselwirkung mit einem FRET-Akzeptor, der an ein Protein fusioniert ist, daß die entsprechenden Modifikation erkennen kann, untersucht. Die Limitierungen des FRET- 
Systems liegen in dem geringen Signal-Rausch-Vehältnis der beiden verwendeten GFPVarianten (Pollok und Heim, 1999; Tsien, 1998), dem schnellen Ausbleichen des GFP und seinen Varianten und in der maximal zur Verfügung stehenden Distanz, in der FRET noch stattfinden kann, weswegen Interaktionen von Proteinen nicht detektiert werden können, wenn die beiden Fluorophoren zu weit auseinander liegen.

\subsubsection{Analyse von Protein-Protein-Wechselwirkungen mit Protein-Microarrays}

Protein-Microarrays enthalten einen definierten Satz an Proteinen, die in hoher Dichte auf ein Trägermaterial aufgebracht sind. Man unterscheidet zwei Klassen von ProteinMicroarrays. die sogenannten Protein-Profiling-Arrays und funktionelle Proteinarrays (SCHWEITZER et al., 2003). Protein-Profiling-Arrays bestehen normalerweise aus Antikörpern, die auf einem Glassträger immobilisiert sind und der Messung der Proteinkonzentration in einer Probe oder der Wahrnehmung von Modifikationen, beispielsweise einer Phosphorylierung, dienen (SCHWEITZER und Kingsmore, 2002). Funktionelle Proteinarrays können aus jeder Art von Proteinen hergestellt werden und haben ein breiteres Anwendungsspektrum. Die Vorteile dieser Technik liegen in dem geringen Materialbedarf, der schnellen Interpretation der Ergebnisse und den einfach zu kontrollierenden experimentellen Parametern (SCHWEITZER et al., 2003). Der Hauptvorteil liegt in der Möglichkeit, innerhalb kurzer Zeit eine große Anzahl von Proteinen nach biochemischer Aktivität, Protein-Protein-Interaktionen, Protein-Lipid-Interaktionen, Protein-NukleinsäureInteraktionen, und Wechselwirkungen von Proteinen und kleinen Molekülen durchmustern zu können. Im Prinzip könnte man mit Hilfe eines Microarrays, das alle Proteine eines Proteoms enthält, in einem einzigen Experiment ein komplettes Protein-Interaktionsnetzwerk bestimmen, alle Substrate für eines modifizierenden Enzyms ermitteln oder alle potentiellen Bindungspartner eines pharmakologischen Wirkstoffes identifizieren (SCHWEITZER et al., 2003). Das bis dato einzige in der Literatur beschriebene Protein-Microarray, das nahezu das gesamte Proteom eines Organismus abdeckt, ist das von Zhu et. al entwickelte Saccharomyces cerevisiae-Proteinarray, bei dem ca. 5000 verschiedene Proteine auf der Oberfläche eines Glassträgers immobilisiert wurden (ZHU et al., 2001). In der Praxis wurde dieses Array eingesetzt, um die Spezifität von elf verschiedenen poly- und monoklonalen Antikörpern gegen Hefe-Proteine zu untersuchen (Michaud et al., 2003). Die Herstellung eines ProteinMikroarrays ist relativ aufwendig, da alle auf dem Träger zu immobilisierenden Protein zuerst rekombinant hergestellt werden müssen. Anders als bei DNA-Microarrays ist es nicht ausreichend, ein Fragment des entsprechenden Proteins herzustellen, da die Hybridisierung nicht linear erfolgt und daher das Protein in seiner gesamten Länge zur Verfügung stehen muß. Während die Klonierung der Gene bei Prokaryonten noch relativ leicht durchführbar ist, müssen bei Eukaryonten die entsprechenden cDNAs kloniert werden. Schon dieser erste Schritt stellt einen Flaschenhals dar, da sich seltene und verhältnismäßig lange cDNAs schlechter klonieren lassen als kurze, abundante cDNAs. Weiterhin lassen sich in einem konventionellen Escherichia coli System zur rekombinanten Produktion von heterologen Proteinen nicht alle Proteine erfolgreich in löslicher Form herstellen (SCHWEITZER et al., 2003). Nach der Klonierung werden die Proteine in einem automatisierbaren Verfahren 
(PHIZICKY et al., 2003) aufgereinigt und kovalent an das Trägermaterial gekoppelt. Hierfür stehen mehrere Möglichkeiten zur Verfügung. Die Proteine können entweder auf Polyvinylen-Difluorid (Holt et al., 2000), Agarose (AfANASSIEV et al., 2000), oder Polyacrylamidkissen (GuSCHIN et al., 1997) fixiert werden. Die Kopplung an das Trägermaterial Glas erfolgt über aktivierte Aldehydgruppen (MACBEATH und SCHREIBER, 2000), Polylysin (Joos et al., 2000) oder einen homofunktioneller Crosslinker (HAAB et al., 2001). Das zu untersuchende Protein wird markiert und mit dem Microarray inkubiert. Der Nachweis der Bindung erfolgt durch Nachweis von Chemilumineszenz, Radioaktivität oder Fluoreszenz, wobei letzterem Verfahren der generell der Vorzug gegeben wird (SCHWEITZER et al., 2003). Neben dem hohen Produktionsaufwand hat dieses Verfahren noch weitere Nachteile. So werden Proteinvarianten, die durch alternatives Spleißen entstehen, nicht auf dem Microarray repräsentiert. Weiterhin werden, in Abhängigkeit des gewählten Expressionssystems, posttranslationelle Modifikationen nicht berücksichtigt.

\subsubsection{Analyse von Protein-Protein-Wechselwirkungen durch massenspektro- metrische Methoden}

Vor der Analyse von Protein-Protein-Wechselwirkungen durch massenspektroskopische Methoden steht die Isolation der Komplexe durch Immunpräzipation oder Affinitätschromatographie und die spätere Auftrennung der individuellen Proteine durch zweidimensionale Gelelektrophorese (BARNOUIN, 2004). Nach der Gewinnung der Proteine aus den Komplexen werden diese sowie tryptische Fragmente davon durch MALDI-TOF charakterisiert (ANDERSEN et al., 1996). Um eine Proteinbestimmung durch Massenspektrometrie durchführen zu können, muß die Genomsequenz des entsprechenden Organismus bekannt sein, da aus den Gensequenzen die entsprechenden Proteinmassen berechnet werden können. Umgekehrt kann dann aus den ermittelten Massen die korrespondierende Gensequenz deduziert werden. Diese Methode zur Identifikation von Proteinen ist sehr sensitiv, da noch femtomolare Proteinkonzentrationen für die Analyse ausreichend sind (MENDELSOHN und BRENT, 1999). Neben den hohen Kosten für die notwendigen Gerätschaften liegen die bedeutendsten Limitationen in der Proteinaufarbeitung, denn für die massenspektrometrische Analyse ist eine vorherige Auftrennung der Proteine durch Elektrophorese notwendig (SHEVCHENKO et al., 1996). Viele Proteine sind $\mathrm{zu}$ rar, groß, klein, sauer oder basisch, um durch zweidimensionale Gelektrophorese aufgetrennt werden zu können, oder die Interaktion ist zu schwach oder transient, so daß sie während einer Affinitätsaufreinigung nicht bestehen bleibt (MENDELSOHN und BRENT, 1999).

\subsubsection{Analyse von Protein-Protein-Interaktionen durch bakterielle Zelloberflächenpräsentation}

In dieser Arbeit soll ein Verfahren für die Analyse von Protein-ProteinWechselwirkungen etabliert werden, welches auf bakterieller Zelloberflächenpräsentation von 
Passagierproteinen beruht. Hierbei wird der eine Interaktionspartner auf der Zelloberfläche fixiert, während der andere Partner in löslicher Form zugegeben wird. Der Nachweis der Bindung erfolgt mit einem Antikörper gegen das lösliche Protein oder durch Biotinylierung des löslichen Proteins und dessen Nachweis mit einem Streptavidin, R-PhycoerythrinKonjugat. Mit diesem Verfahren könnten Interaktionen zwischen definierten Interaktionspartnern untersucht werden, die Stärke der Methode liegt jedoch in der Möglichkeit, ein Repertoire von oberflächenexponierten Varianten zu erzeugen, die das gesamte Proteom eines Organismus repräsentieren, und die Interaktionspartner anschließend aus dem Ensemble zu isolieren. Im folgenden soll ein kurzer Überblick über die Methode der Zelloberflächenpräsentation gegeben werden. Das in der Arbeit verwendete Intimin'-System zur bakteriellen Oberflächenpräsentation und die Evaluation seiner Verwendbarkeit zur Analyse von Protein-Protein-Wechselwirkungen werden im Detail in den nachfolgenden Kapiteln beschrieben.

\subsubsection{Verfahren zur Zelloberflächenpräsentation von Proteinen}

Die Präsentation von heterologen Proteinen auf der Zelloberfläche von Bakterien und Hefen ist eine relativ neue Methode in den Disziplinen der angewandten Mikrobiologie, Biotechnologie und Enzymologie. Es wurden diverse Strategien zur Verankerung von Proteinen auf der Oberfläche von selbstreplizierenden Einheiten entwickelt, die die genetische Information zur Herstellung der Proteine enthalten. Das 1985 vorgestellte Verfahren zur Präsentation von Proteinen auf der Oberfläche von Bakteriophagen (Phage-Display) (SMITH, 1985) ist die bis heute gebräuchlichste Methode, die sich die Idee der Genotyp-Phänotyp Kopplung zu eigen macht. Diese Kopplung der genetischen Information mit dem Phänotyp des kodierten Proteins ist die Basis des evolutiven Methodenspektrums, da sie die Durchführung mehrerer Runden von Vermehrung und Selektion ermöglicht. Heutzutage ist eine große Auswahl an Expressionsorganismen und Grundgerüsten für die Oberflächenpräsentation verfügbar. Diese beinhalten sowohl Prokaryonten als auch Eukaryonten, Bakteriophagen und Protein-Nukleinsäure-Konjugate für die zellfreie Expression (SCHAFFITZEL et al., 1999; WINTER et al., 1994; WITTRUP, 2001). Ein großer Vorteil der mikrobiellen Zelloberflächenpräsentation liegt in der Möglichkeit, fluoreszenzaktivierte Zellsortierung (FACS) für die Durchmusterung der molekularen Repertoires einzusetzen, da Bakteriophagen und Protein-Nukleinsäure-Konjugate zu klein sind, um von der Optik des Zytometers erkannt zu werden. Mit modernen Geräten können bis zu 100.000 Zellen pro Sekunde analysiert und sortiert werden (ASHCROFT und LOPEZ, 2000).

Es gibt zahlreiche Expressionssysteme für die zelluläre Oberflächenpräsentation in Escherichia coli (Abb. 4.46), dem am besten geeigneten Organismus für die Erzeugung, Vermehrung und Aufrechterhaltung von großen molekularen Repertoires, die aus mehr als $10^{10}$ Primärtransformanten bestehen können (ADAMS et al., 2004). In anderen Organismen ist die Größe der Repertoires aufgrund der niedrigeren Transformationseffizienz im Vergleich zu E. coli eingeschränkt. Um auf der Oberfläche der Bakterienzelle präsentiert zu werden, muß das Protein der Wahl, im folgenden als Passagierprotein bezeichnet, nach seiner Synthese im 
Zytoplasma die zytoplasmatische und die äußere Membran überwinden. Erreicht wird dies im allgemeinen durch Fusion des Passagierproteins an eine Translokatordomäne, die in der äußeren Membran sitzt und in das extrazelluläre Milieu herausragt.

Porine eignen sich als Gerüst für die genetische Insertion der Zielsequenz, um die Verankerung der Passagierproteine in der äußeren Membran zu bewerkstelligen (LANG, 2000). Porine sind abundante Proteine der äußeren Membran, die eine $\beta$-Faß-Struktur besitzen, wobei die Schleifen, welche die einzelnen $\beta$-Stränge miteinander verbinden, entweder in Richtung des Periplasmas oder der extrazellulären Seite zeigen (COWAN et al., 1992). Peptide können in die extrazellulären Schleifen integriert und somit auf die Zelloberfläche dirigiert werden. Die Länge der integrierten Sequenz ist jedoch auf 60-70 Aminosäuren beschränkt (GEORGIOU et al., 1997), da längere Insertionen die Faltung der Porine negativ beeinflussen. Da beide Termini der Porine in das Periplasma weisen, eignen sich diese Proteine nicht für die amino- oder carboxyterminale Fusion von Passagierdomänen. Georgiou und Mitarbeiter (FRANCISCO et al., 1992) haben eine Fusion aus Lpp'- und OmpA entwickelt, die aus den ersten neun Aminosäuren des Lipoproteins Lpp aus der äußeren Membran von E. coli und einer verkürzten Version von OmpA besteht. Dieses System wurde erfolgreich eingesetzt, um das Enzym $\beta$-Laktamase (FrANCISCO et al., 1992), bakterielle Alkalische Phosphatase (PhoA) (STATHOPOUlos et al., 1996), die Exoglucanase Cex aus Cellumonas fimi und seine Zellulosebindedomäne (FrANCISCO et al., 1993), Antiköperfragmente (scFV) (DAUGHERTY et al., 1998) und den Proteaseinhibitor EETI-II (CHRISTMANN et al., 1999) auf der Zelloberfläche von E. coli zu präsentieren.

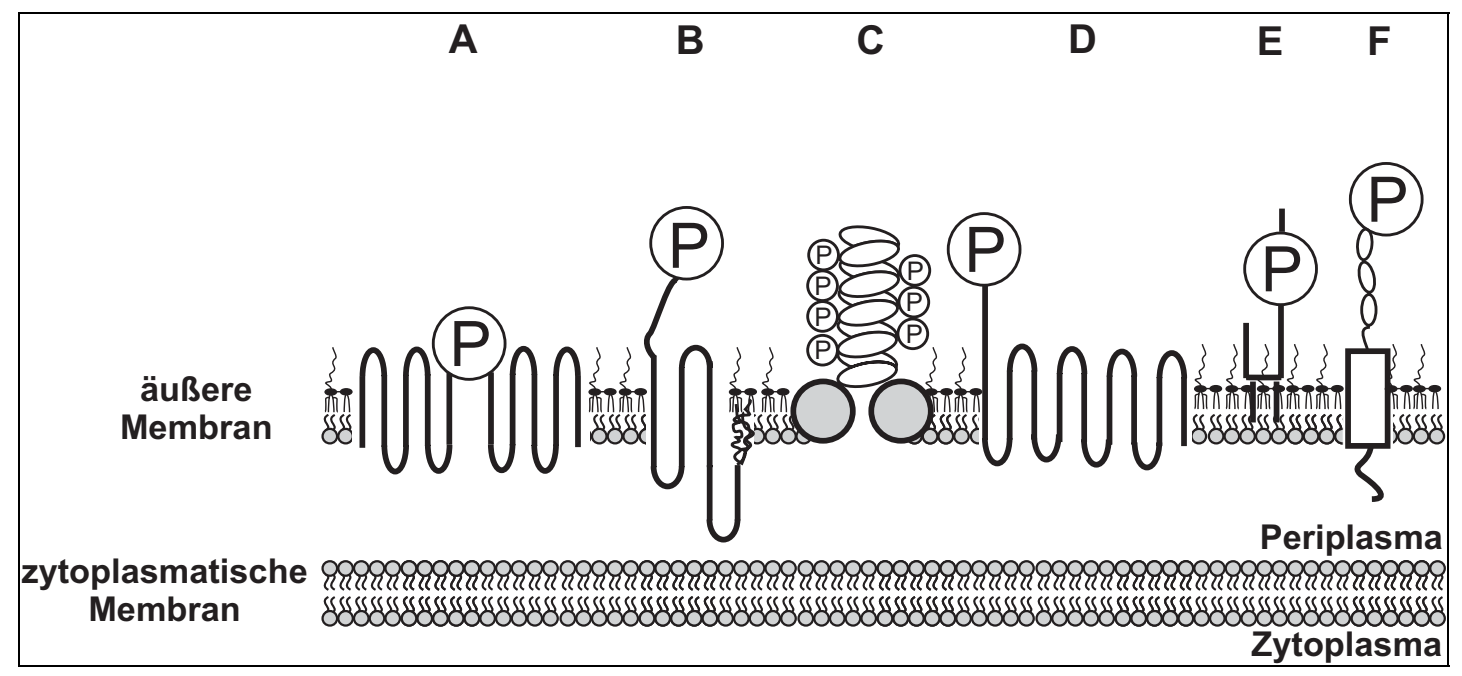

Abb. 4.46: Formate zur Zelloberflächenpräsentation auf E. coli: (A) Porine, (B) Lpp'-OmpA-Fusion, (C) Fimbrien, (D) Autotransporter, (E) Ice-Nucleation-Protein, (F) Intimin. (P) Passagierprotein.

Autotransporterproteine eignen sich ebenfalls als Membrananker für heterologe Passagierproteine. Sie bestehen alle aus drei funktionellen Domänen: der aminoterminalen Signalsequenz, der sekretierten Domäne und der carboxyterminalen Domäne, die eine $\beta$-FaßStruktur ausbildet, durch welche die sekretierte Domäne hindurchtreten kann (HENDERSON et al., 1998). Der Archetyp aller Autotransporterdomänen ist die IgA Protease aus Neisseria 
gonorrhoeae, dessen Proteasedomäne nach autoproteolytischer Spaltung in die Umgebung entlassen wird (PoHLNER et al., 1987). Diese Proteasedomäne kann durch ein Passagierprotein ersetzt werden, das auf der Oberfläche von E. coli präsentiert werden soll. Dieses Verfahren wurde erfolgreich für die Oberflächenpräsentation einer Untereinheit des Cholera Toxins B (KLAuser et al., 1992) und des EETI-II Proteaseinhibitors (ChristmanN et al., 1999) angewendet. Ein weiterer Autotransporter, AIDA aus E. coli, ist ebenfalls für die Membrantranslokation verschiedener Passagierproteine eingesetzt worden. Mit diesem System konnten T-Zell- Epitope sowie eine Untereinheit des E. coli Proteins LTB (KoNIECZNY et al., 2000), eine enzymatisch aktive $\beta$-Laktamase (LATTEMANN et al., 2000) und ebenfalls die Untereinheit des Cholera Toxins B (MAURER et al., 1997) auf der Bakterienzelle präsentiert werden. Es wurde jedoch festgestellt, daß die Überlebensfähigkeit der Zellen, die eine AIDAFusion exprimierten, stark eingeschränkt war, so daß sich dieses System nicht für die Erstellung größerer molekularer Repertoires eignet (CHRISTMANN et al., 1999). Neben Porinen und Autotransportern wurde auch das Ice-Nucleation-Protein aus Pseudomonas syringae als Membrananker für die Präsentation von Levansucrase (JUNG et al., 1998), Carboxymethylzellulase (KIM et al., 2000), dem HIV gp120 (KWAK et al., 1999), Oberflächenantigenen aus dem Hepatitis B Virus (KIM und YoO, 1999) und synthetischen Phytochelatinen (BAE et al., 2002) eingesetzt.

Fimbrien und Flagellen sind ebenfalls als Grundgerüst für die Oberflächenpräsentation von Proteinen und Peptiden geeignet (Klemm und Schembri, 2000b; WesterlundWikstrom, 2000). Große Peptide können in die variable Domäne der Flagellenuntereinheit FliC integriert werden, ohne daß die Synthese und Integrität der Flagellen kompromittiert wird. Eine Insertion innerhalb des Leserasters in eine permissive Stelle innerhalb des $f l i C$ Gens erlaubt eine Oberflächenpräsentation von Peptiden und Proteinen einer Länge von 30300 Aminosäuren (Westerlund-Wikstrom et al., 1997). Aufgrund der Möglichkeit, relativ große Proteine auf der Zelloberfläche zu präsentieren, hat sich die Oberflächenpräsentation mit Hilfe von Flagellen als wertvolles Werkzeug für Epitopkartierungen und die Analyse von Wechselwirkungen von Rezeptoren mit ihren Liganden erwiesen (WESTERLUND-WIKSTROM, 2000). Mit Hilfe von Fimbrien konnten Metallbindemotive auf der Zelloberfläche präsentiert werden (KJAERGAARD et al., 2001; SCHEMBRI und KLEMM, 1998). Die rekombinanten Bakterien könnten dazu eingesetzt werden, mit Schwermetallen verseuchte Böden zu regenerieren (KJAERGAARD et al., 2000; SCHEMBRI et al., 1999).

Zelloberflächenpräsentation auf Gram-positiven Bakterien ist ebenfalls möglich. Die Hauptanwendungen liegen in der Entwicklung von Lebendimpfstoffen. In der Literatur sind Studien mit abgeschwächten Mykobakterien, nicht-pathogenen Staphylokokken, Streptokokken und Bacillus subtilis beschrieben (HANSSON et al., 2001). Antikörperfragmente (GUNNERIUSSON et al., 1996) und die Zellulosebindedomäne der Zellulase aus Trichoderma reesei wurden auf rekombinanten Staphylokokken präsentiert (LEHTIO et al., 2001), was der Entwicklung kostengünstiger Diagnostika und neuartiger mikrobieller Biokatalysatoren dienlich sein könnte. Unter den Eukaryonten ist Saccharomyces cerevisiae der bevorzugte Organismus für die Oberflächenpräsentation heterologer Proteine (BODER und WITTRUP, 1997; 2000). Der Einsatz von S. cerevisiae ist in der industriellen Produktion von Proteinen und Chemikalien weit verbreitet. Somit können enzymbedeckte Hefezellen als Katalysatoren 
für Biotransformationen eingesetzt werden. Um heterologe Proteine auf der Zelloberfläche zu fixieren, wurde von Tanaka und Mitarbeitern ein System entwickelt, das auf einem dreiteiligen Fusionsprotein bestehend aus einer Signalsequenz für die Sekretion, dem Passagierprotein und dem Glycosyl-Phosphatidylinositol (GPI)-Anker des nativen Zellwandproteins a-Agglutinin basiert (MURAI et al., 1997). Eine weitere Möglichkeit für die Zelloberflächenpräsentation in Hefe ist die Verwendung der Aga2p-bindenden Domäne des a-Agglutinins, die zwei Disulfidbrücken zu dem Agalp Zellwandprotein ausbildet, als Ankerdomäne (BODER und WiTTRUP, 1997). A-Agglutinin ist ein Mannoprotein, das eine Rolle in der Kreuzung von Typ a-Hefezellen mit Typ a-Zellen spielt. Beispiele für heterologe Proteine, die auf Hefezellen präsentiert worden sind, beinhalten Antikörperfragmente (scFV) (BODER und WiTtrup, 1997), T-Zell Rezeptoren (Holler et al., 2000), Lipase (WASHIDA et al., 2001), Glukoamylase (MURA et al., 1999; SHIBASAKI et al., 2000), $\beta$-Glukosidase und Carboxymethylzellulase (MURAI et al., 1998).

Bisher ist in der Literatur noch kein Beispiel für den Einsatz eines zellbasierten Oberflächenpräsentationssystems für die proteomweite Analyse von Protein-ProteinWechselwirkungen beschrieben. Solch ein System bietet aber gegenüber den vorhergenannten Methoden zur Analyse von Protein-Protein-Wechselwirkungen diverse Vorteile. Die proteinproduzierenden Einheiten können in einem einzelnen Klonierungs- und Transformationsschritt erstellt werden und es ist keine weitere Aufreinigung von Proteinen notwendig. Bei Organismen mit einer zu handhabenden Genomgröße ist auch keine gerichtete Klonierung notwenig, da das Genom zufallsmäßig fragmentiert werden kann und die Klone, die eine Insertion außerhalb des Leserasters enthalten, in der späteren Durchmusterung nicht zu positiven Ereignissen führen sollten. Es ist keine gerichtete Anordnung der einzelnen Klone notwendig, da diese einfach in Flüssigmedium kultiviert werden. Dennoch ist eine gerichtete Anordnung, die in späteren Stadien der Analyse vorteilhaft sein kann, durch Anordnung der Klone beispielsweise in Mikrotiterplatten, einfach $\mathrm{zu}$ erreichen. Durch die Präsentation vieler Kopien eines Interaktionspartners auf der Oberfläche besteht auch die Möglichkeit, schwache Interaktionspartner zu detektieren. Der Einsatz von fluoreszenzbasierten Markierungsverfahren ermöglicht eine Quantifizierung der Bindung. Nicht zuletzt ist die hohe Geschwindigkeit, mit der die Analyse individueller Klone im FACS erfolgen kann, ein Vorteil dieses Systems. In den folgenden Abschnitten werden eigene Untersuchungen zur Evaluation der Untersuchung von Protein-ProteinWechselwirkungen mit Hilfe bakterieller Oberflächenpräsentation vorgestellt.

4.2.2.2

Evaluation der bakteriellen Oberflächenpräsentation von Proteinen mit Hilfe des Intimin' Systems zur Analyse von Protein-ProteinWechselwirkungen

Ziel der im nachfolgenden beschriebenen Experimente war es zu eruieren, ob das in der Arbeitsgruppe Kolmar entwickelte System zur Oberflächenpräsentation von Proteinen dazu herangezogen werden kann, um Protein-Protein-Interaktionen zu untersuchen. Dieses System beruht auf der Verwendung eines verkürzten Intimins aus enteroheamorrhagischen 
E. coli O157:H7 zur Oberflächenpräsentation von anfusionierten Domänen in Laborstämmen von Escherichia coli (WENTZEL et al., 2001). Da es für die Untersuchung von proteomweiten Protein-Protein-Wechselwirkungen notwendig ist, daß die Proteine auch tatsächlich auf der Bakterienzelloberfläche präsentiert werden, wurde anhand mehrerer Passagierproteine untersucht, ob und unter welchen Bedingungen sich diese auf der Zelloberfläche präsentierten lassen.

\subsection{Beschreibung des Intimin’ Oberflächenpräsentationssystems}

Pathogene Gram-negative Bakterien haben im Laufe der Evolution eine Reihe von Sekretionsmechanismen entwickelt, um Bindedomänen, die mit komplementären Rezeptoren der Zielzelle interagieren, auf ihrer Oberfläche zu präsentieren (KLEMM und SCHEMBRI, 2000a). Unter diesen gehören die Intimine und Invasine zu einer Familie von bakteriellen Adhäsinen, die spezifisch an Rezeptoren auf eukaryotischen Zellen binden können (VALlANCE und Finlay, 2000). Enteropathogene (EPEC) und enteroheamorrhagische E. coli (EHEC) produzieren sogenannte attaching and effacing lesions an der Darmschleimhaut des Wirtsorganismus (Moon et al., 1983). Die Bildung dieser Läsionen wird durch die Bindung des EHEC Proteins Intimin and den Translocated Intimin Receptor (TIR), der in die Zellmembran der Wirtszellen integriert ist, initiiert (KENNY et al., 1997). Mindestens fünf verschiedene Intimin-Subtypen sind in der Literatur beschrieben (ADU-BOBIE et al., 1998; OswALD et al., 2000). Diese sind mit ihrem Aminoterminus in die äußere Membran von E. coli integriert, während die 280 carboxyterminalen Aminosäuren auf der Oberfläche exponiert werden (FRANKEL et al., 1994).

Das im Rahmen dieser Arbeit verwendete EaeA Intimin aus EHEC O157:H7 besteht aus 939 Aminosäuren, wobei den 280 carboxyterminalen Aminosäuren eine Rolle in der Bindung des Rezeptors zugeschrieben wird (FrANKel et al., 1994). Man nimmt an, daß die 550 aminoterminalen Aminosäuren eine porinähnliche Struktur bilden, die aus antiparallelen $\beta$-Strängen besteht (SCHIRMER, 1998). Die Struktur der carboxyterminalen Domänen wurde durch Röntgenstrukturanalyse und NMR aufgeklärt. Das gesamte extrazelluläre Segment bildet eine langgestreckte Struktur, die aus drei immunglobulinähnlichen Domänen und einer lektinähnlichen Domäne besteht (BATCHELOR et al., 2000; KELLY et al., 1999; LUO et al., 2000). Die äußerste Domäne, die für die Bindung des Rezeptors verantwortlich ist, sitzt somit auf einem relativ rigiden Arm, der mit der Transmembrandomäne durch ein flexibles Scharnier, das aus zwei Glycinresten besteht, verbunden ist (LUO et al., 2000). Eine schematische Darstellung des Intimin, das in Lösung Dimere bildet (Touze et al., 2004), findet sich in Abb. 4.47 A. Durch seinen strukturellen Aufbau bietet sich Intimin als Träger für die Oberflächenpräsentation heterologer Passagierdomänen an. Hierfür wurde das Intimin auf Genebene so modifiziert, daß die drei carboxyterminalen Domänen entfernt und durch eine Passagierdomäne nach Wahl ersetzt werden können. Dieses modifizierte Intimin wird als Intimin' bezeichnet (Abb. $4.47 \mathrm{~B}$ ). Die Passagierdomäne wird von zwei Epitopen flankiert, durch deren immunochemischen Nachweis die Oberflächenexposition der Passagierdomäne gezeigt werden kann (WENTZEL et al., 2001). 


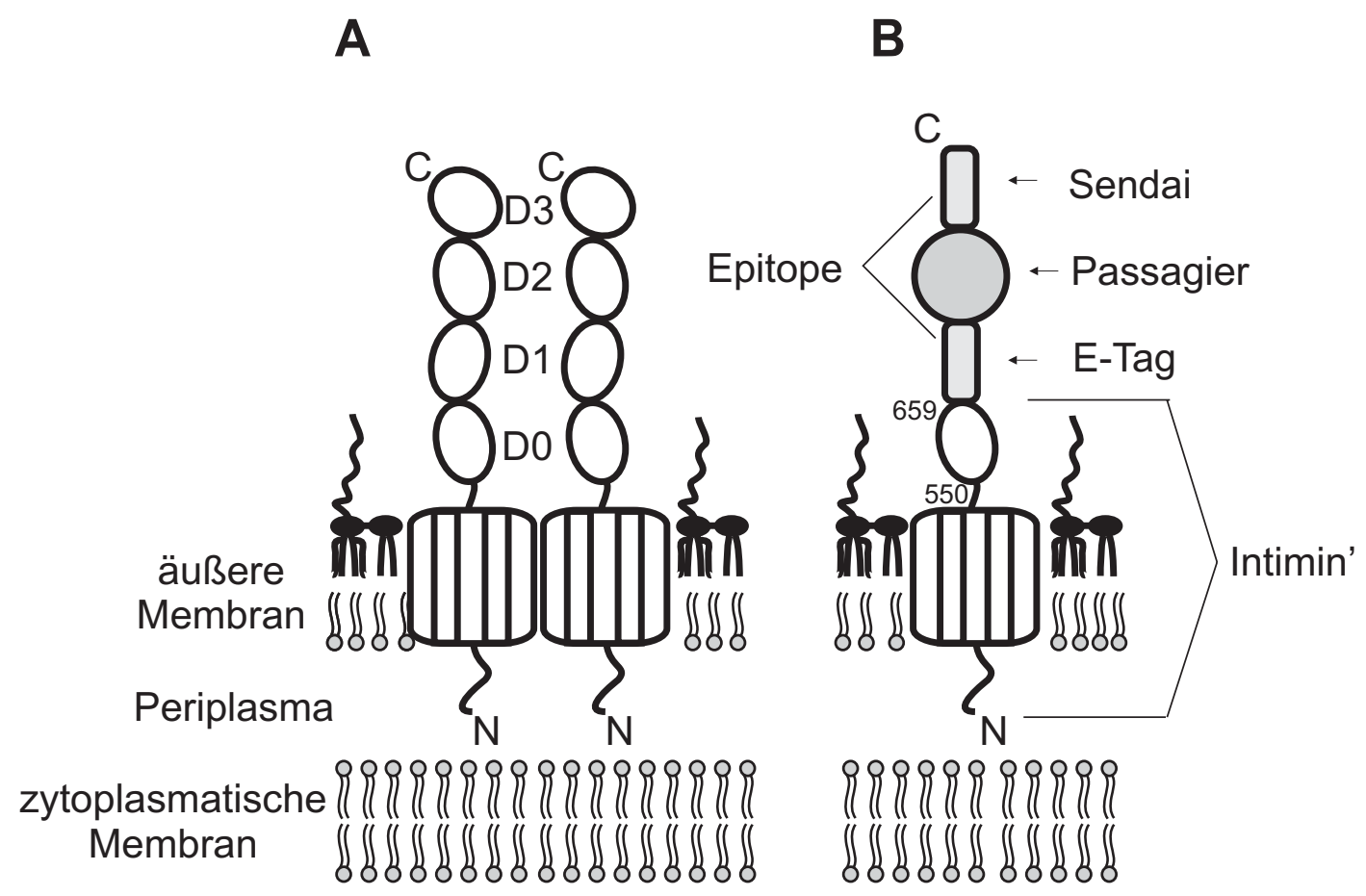

Abb. 4.47: (A) Schematische Abbildung eines EHEC Intimin Dimers. Jedes Monomer besteht aus einer Transmembranregion und einem extrazellulären Stab, der aus drei immunoglobulinähnlichen (D0-D2) und einer lectinähnlichen Domäne (D3) aufgebaut ist. Abbildung modifiziert nach Luo et al. (Luo et al., 2000). (B) Schematische Illustration eines verkürzten Intimin (Intimin')-Monomers, der aus den Aminosäuren 1 bis 659 besteht und für die Präsentation von Passagierproteinen verwendet wurde. Die Passagierdomäne wird von den beiden Epitopen E-Tag und Sendai flankiert. Die Aminosäure 550 ist die letzte der Transmembrandomäne.

\subsection{Untersuchung des Intimin' Systems in Hinblick auf die Präsentation verschiedener Passagierdomänen}

Es wurden Fusionsproteine, die aus Intimin' und einer Passagierdomäne, die von Sendai und E-Tag-Epitopen flankiert waren, konstruiert. Die Zelloberflächenlokalisation dieser Passagierproteine wurde untersucht. Als Passagierdomänen kamen die Immunglobulinvariante $\mathrm{REI}_{\mathrm{v}}$ (REI), Ubiquitin (Ubi), Calmodulin (Cal), $\beta$-Laktamase Inhibitor Protein (BLIP) sowie die RTEM-1 $\beta$-Laktamase (Bla) zum Einsatz. Die Passagierproteine unterscheiden sich durch ihre Größe und die Anzahl der Disulfidbrücken (Tabelle 4.2). Durch Verwendung von Agenzien, die die Faltung der Passagierdomänen beeinflussen, konnte ein Einfluß der Proteinfaltung auf die erfolgreiche Oberflächenpräsentation untersucht werden. 


\begin{tabular}{|l|l|l|l|}
\hline Passagierdomäne & Herkunft & Kettenlänge (AS) & $\begin{array}{l}\text { Anzahl } \\
\text { Disulfidbrücken }\end{array}$ \\
\hline Bence-Jones Protein $\mathrm{REI}_{\mathrm{v}}(\mathrm{REI})$ & Homo sapiens & 108 & 1 \\
\hline Ubiquitin $(\mathrm{Ubi})$ & Homo sapiens & 76 & 0 \\
\hline Calmodulin $(\mathrm{Cal})$ & Homo sapiens & 131 & 0 \\
\hline$\beta$-Laktamase Inhibitor Protein (BLIP) & Streptomyces clavuligerus & 165 & 2 \\
\hline RTEM-1 $\beta$-Laktamase (Bla) & Escherichia coli & 287 & 1 \\
\hline
\end{tabular}

Tabelle 4.2: Verwendete Passagierdomänen, deren Herkunft, Länge und Anzahl der Disulfidbrücken.

Das Plasmid pASKInt100 (siehe Abschnitt 2.2.1) bildet die Grundlage für alle Oberflächenpräsentationsvektoren. Dieses Plasmid ermöglicht die bakterielle Synthese von Fusionsproteinen für die Zelloberflächenexposition durch eine Fusion des Passagiers an die carboxyterminal verkürzte Version des Intimins (Intimin'). Das Plasmid enthält die kodierende Sequenz für das verkürzte intimin' Gen, dem die drei carboxyterminalen Domänen fehlen, und für das von zwei Epitopsequenzen flankierte Gen des Passierproteins. Als carboxyterminales Epitop wird das Sendai-Epitop eingesetzt, eine 13 Aminosäure lange, C-terminale Sequenz aus dem Sendai Virus L-Protein, gegen die der monoklonale AntiSendai Antikörper VII-E-7 gerichtet ist (EINBERGER et al., 1990). Als Epitopsequenz zwischen Intimin' und dem Passagierprotein wird die E-Tag Sequenz verwendet, gegen die ein kommerziell erhältlicher monoklonaler Antikörper (Amersham Pharmacia) gerichtet ist. Die Expression der Genkassette steht unter der Kontrolle des Tetrazyklinpromotors, der eine genaue Regulation der Genexpression ermöglicht (SKERRA, 1994). Die Genexpression läßt sich somit durch Zugabe des Induktors Anhydrotetrazyklin induzieren. Die für diesen Teil der Arbeit verwendeten Plasmide sind der Übersichtlichkeit halber in der Tabelle 4.3 aufgelistet. Die Plasmide sind zum Teil von dem Verfasser dieser Arbeit in früheren Zeiten selber hergestellt worden, zum Teil stammen sie von Alexander Wentzel (WENTZEL, 2003) und Harald Kolmar. Ihre Erzeugung ist in Wentzel et al., 2001 (WENTZEL et al., 2001) und Adams et al., 2005 (ADAMs. et al., 2005 (im Druck)) beschrieben. 


\begin{tabular}{|c|c|c|}
\hline Plasmid & Beschreibung & Referenz \\
\hline pASKInt100 & $\begin{array}{l}\text { Vektor für die Expression von Fusionsproteinen unter tetA- } \\
\text { Promoter/Operator Kontrolle, enthält Chloramphenicol } \\
\text { Resistenzgen, tetR Gen }\end{array}$ & $\begin{array}{l}\text { (WENTZEL et } \\
\text { al., 2001) }\end{array}$ \\
\hline pASKInt100- $\Delta \mathrm{P}$ & $\begin{array}{l}\text { Vektor zur Expression von E-Tag und Sendai-Epitopen ohne } \\
\text { dazwischenliegende Passagierdomäne }\end{array}$ & 4.2.2.2.4 \\
\hline pASKInt100-REI & $\begin{array}{l}\text { Vektor für die Expression vom Bence-Jones Protein } \mathrm{REI}_{\mathrm{v}} \text {, Derivat } \\
\text { von pASKInt100 }\end{array}$ & $\begin{array}{l}\text { (WENTZEL et } \\
\text { al., 2001) }\end{array}$ \\
\hline pASKInt100-Ubi & $\begin{array}{l}\text { Vektor für die Expression von humanem Ubiquitin, Derivat von } \\
\text { pASKInt100 }\end{array}$ & $\begin{array}{l}\text { (ADAMS et al., } \\
2005 \quad \text { (im } \\
\text { Druck) }\end{array}$ \\
\hline pASKInt100-Cal & $\begin{array}{l}\text { Vektor für die Expression von humanem Calmodulin, Derivat von } \\
\text { pASKInt100 }\end{array}$ & $\begin{array}{l}\text { (ADAMS et al., } \\
2005 \quad \text { (im } \\
\text { Druck)) }\end{array}$ \\
\hline $\begin{array}{l}\text { pASKInt100- } \\
\text { Cal } \Delta \text { send }\end{array}$ & $\begin{array}{l}\text { Vektor für die Expression von humanem Calmodulin ohne Sendai- } \\
\text { Epitop, Derivat von pASKInt } 100\end{array}$ & 4.2.2.2.6 \\
\hline pASKInt100-BLIP & $\begin{array}{l}\text { Vektor für die Expression von } \beta \text {-Laktamase Inhibitor Protein aus } \\
\text { Streptomyces clavuligerus, Derivat von pASKInt } 100\end{array}$ & $\begin{array}{l}\text { (ADAMS et al., } \\
2005 \quad \text { (im } \\
\text { Druck) }\end{array}$ \\
\hline pASKInt100-Bla & $\begin{array}{l}\text { Vektor für die Expression von RTEM-1 } \beta \text {-Laktamase, Derivat von } \\
\text { pASKInt100 }\end{array}$ & $\begin{array}{l}\text { (ADAMS et al., } \\
2005 \quad \text { (im } \\
\text { Druck)) }\end{array}$ \\
\hline pBBR22bII-Blawt & $\begin{array}{l}\text { Vektor für die Expression von löslicher wildtyp RTEM-1 } \beta \text { - } \\
\text { Laktamase mit Sendai-Epitop und Hexahistidinanhängsel }\end{array}$ & 4.2.2.2.8 \\
\hline pBBR22bII-BlaC98Y & $\begin{array}{l}\text { Vektor für die Expression von löslicher C98Y RTEM-1 } \beta \text { - } \\
\text { Laktamase mit Sendai-Epitop und Hexahistidinanhängsel }\end{array}$ & 4.2.2.2.8 \\
\hline
\end{tabular}

Tabelle 4.3: In diesem Abschnitt verwendete Plasmide.

\subsection{Produktion von Intimin'-Passagierprotein-Fusionen in Escherichia coli}

Um zu untersuchen, ob die Fusionsproteine in voller Länge in der äußeren Membran von E. coli akkumulieren, und um die Empfindlichkeit gegenüber Proteolyse zu untersuchen, wurden Zellen, die das entsprechende Expressionsplasmid trugen, in dYT angezogen und bei einer $\mathrm{OD}_{600}$ von ca. 0,2 wurde die Genexpression induziert. Um einen Einfluß der in den späteren Experimenten verwendeten Reagenzien EGTA und $\beta$-Mercaptoethanol auf die Expression und den Abbau der Fusionsproteine zu ermitteln, wurde den Zellen, welche die Intimin'-Cal-Fusion exprimierten, in einem Ansatz 20 mM EGTA zugegeben. In eine Kultur mit den Intimin'-BLIP exprimierenden Zellen wurden $20 \mathrm{mM} \beta$-Mercaptoethanol gegeben. Nach drei weiteren Stunden Wachstum wurde eine Präparation der Membranfraktionen durchgeführt (3.4.2) und diese durch SDS-PAGE (3.4.6) und anschließenden Westernblot mit Anti-Sendai Antikörper analysiert (3.4.7).

Wie durch die Pfeilspitzen in Abb. 4.48 indiziert, konnte jedes Fusionsprotein in seiner vollen Länge in der entsprechenden Membranfraktion nachgewiesen werden, wobei die Nettomenge unterschiedlich ist. Allerdings läßt sich auch ein signifikanter Anteil von proteolytisch abgebautem Protein nachweisen. Die Proteolyse wird weder durch die 
Anwesenheit von EGTA noch von $\beta$-Mercaptoethanol beeinflußt. Da der Anti-Sendai Antikörper den Carboxyterminus der Fusionsproteine erkennt, entsprechen die nachgewiesenen Proteolyseprodukte Fusionsproteinen mit einem verkürzten Aminoterminus.

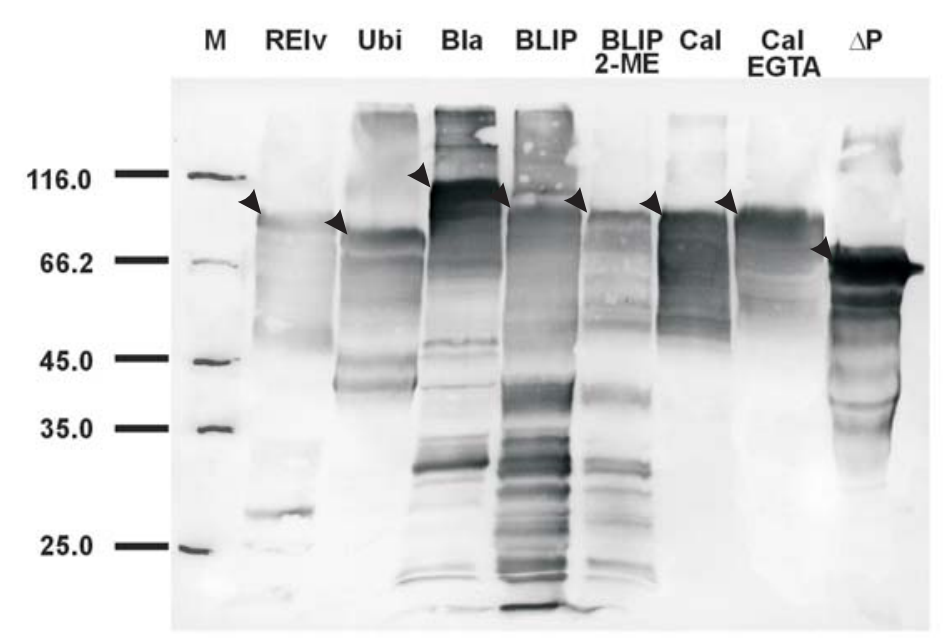

Abb. 4.48: Westernblot Analyse mit Anti-Sendai Antikörper von Gesamtzellmembranen von induzierten 71-18 Zellen, die die Plasmide pASKInt100-REI, pASKInt100-Ubi, pASKInt100-Bla, pASKInt100-BLIP, pASKInt100Cal, oder pASKInt100- $\triangle \mathrm{P}$ trugen. Inkubation erfolgte in Gegenwart oder Abwesenheit von $20 \mathrm{mM} \beta$-ME oder 20 mM EGTA, wie angegeben. M: Marker Proteine (Nach Ponceau-S-Färbung mit Kugelschreiber angezeichnet) in den angegebenen Größen (in tausend). Pfeilspitzen weisen auf Vollängenproteine.

\subsection{Untersuchung der Zelloberflächenpräsentation von Passagierdomänen}

Ziel der nachfolgend beschriebenen Versuche war es zu untersuchen, ob Intimin' die Translokation der Passagierdomänen durch die äußere Membran vermitteln konnte. Kulturen von Zellen, die das entsprechende Expressionsplasmid trugen, wurden bis zum Erreichen einer $\mathrm{OD}_{600}$ von ca. 0,2 inkubiert. Dann wurde die Expression der Intimin'-Passagier-Fusion induziert (3.5.1). Nach einer weiteren Stunde des Wachstums wurden die Zellen geerntet und die E-Tag- sowie die Sendai-Epitope durch Markierung der Zellen mit den entsprechenden Antikörpern nachgewiesen (3.5.3). An den monoklonalen ersten Antikörper aus der Maus konnte sich ein zweiter, biotinylierter Anti-Maus Antikörper aus der Ziege spezifisch anlagern. Durch Inkubation mit Streptavidin, R-Phycoerythrin-Konjugat konnte eine Fluoreszenzmarkierung der oberflächenexponierten Epitope erzielt werden. Als eine Kontrolle für die Oberflächenexposition diente der Klon pASKInt100- $\Delta$ P. Bei diesem Klon wurde die Passagierdomäne auf DNA-Ebene entfernt, in dem das Plasmid pASKInt100-IL4 (WENTZEL et al., 2001) mit den Enzymen AvaI und BglII gespalten (3.3.1) und nach Auffüllen der überstehenden DNA-Enden mit T4-DNA Polymerase (3.3.2) religiert (3.3.3) wurde. Die Analyse der markierten Zellen erfolgte mittels FACS (3.5.4), die Diagramme sind in Abb. 4.49 dargestellt. 

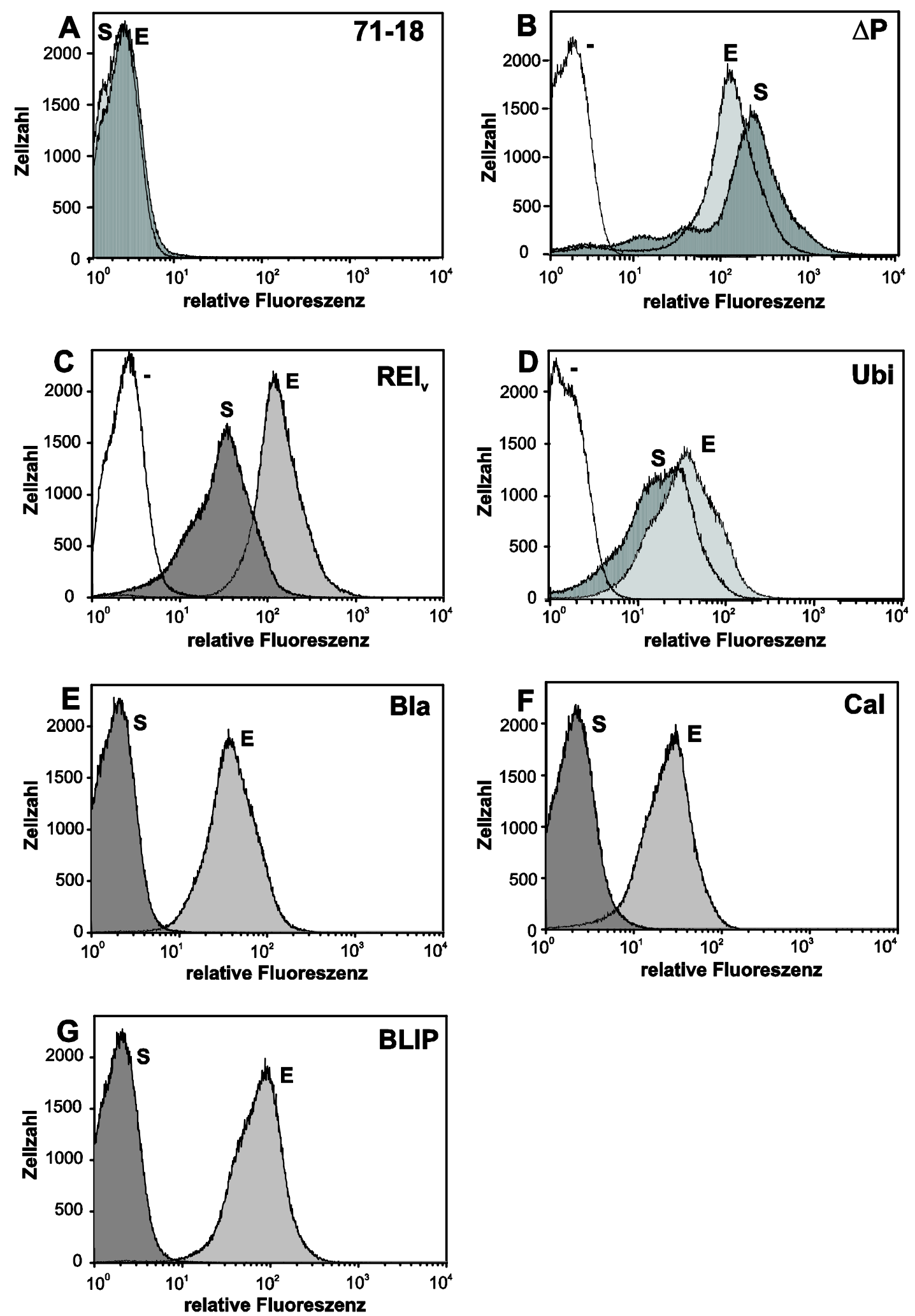

Abb. 4.49: Intimin'-vermittelte Zelloberflächenpräsentation von Passagierproteinen. FACS Histogramme von E. coli 71-18 ohne Plasmid (A), mit dem Plasmid pASKInt100- AP (B), pASKInt100-REI (C), pASKInt100-Ubi (D), pASKInt100-Bla (E), pASKInt100-Cal (F) oder pASKInt100-BLIP (G). Induzierte Zellen wurden mit dem Anti-Sendai Antikörper (S) oder Anti-E-Tag Antikörper (E), fluoreszenzmarkiert. Unmarkierte 71-18 Zellen dienten als Kontrolle (-) in B-D. 
Wie man aus der Abbildung entnehmen kann, konnten alle Zellen mit dem Anti-E-Tag Antikörper fluoreszenzmarkiert werden, während die Intensität des Fluoreszenzsignals mit dem Anti-Sendai Antikörper sehr variabel war. Im Fall von REI $_{v}$ und Ubiquitin konnten beide Epitope detektiert werden, was eine Zelloberflächenlokalisation dieser beiden Passagiere anzeigt. Im Fall der Passagierproteine Calmodulin, BLIP oder $\beta$-Laktamase konnte hingegen keine Immunfluoreszenz bei der Markierung mit dem Antikörper gegen das carboxyterminale Sendai-Epitop gezeigt werden. Dieses Ergebnis impliziert, daß durch die Fusion der Passagierproteine die Integration der Intimin'-Domäne in die äußere Membran nicht behindert wird, da ansonsten kein Nachweis des E-Tag-Epitops möglich wäre. Unter den gewählten Bedingungen konnte eine Translokation der Passagierdomänen REI $\mathrm{v}_{\mathrm{v}}$ und Ubi stattfinden, während keine Oberflächenexposition von Cal, BLIP und Bla zu beobachten war. Die Tatsache, daß eine E-Tag Fluoreszenzmarkierung in allen Fällen beobachtet und daß die Produktion des Vollängenproduktes nachgewiesen werden konnte, läßt die Vermutung zu, daß Cal, BLIP und Bla im Periplasma oder der äußeren Membran lokalisiert sind. Ein Modell dieses Zustandes ist in Abb. 4.50 A dargestellt.

Um diese Hypothese zu testen, wurden Zellen, welche die Plasmide pASKInt100-REI, pASKInt100-Bla und pASKInt100-Cal trugen, induziert und mit Trypsin behandelt (3.5.2). Die periplasmatischen Proteine wurden isoliert (3.4.3) und mittels SDS-PAGE (3.4.6) und Westernblot analysiert (3.4.7). Der Westernblot wurde mit Anti-E-Tag Antikörper entwickelt und ist in Abb. 4.50 B gezeigt. Nur im Falle von Bla und Cal konnte eine Bande detektiert werden, im Falle von REI erfolgte kein Nachweis. Die Größen dieser Banden korrespondieren mit Fragmenten, wie sie durch tryptische Spaltung der Proteine im Bereich der oberflächenständigen Domäne D0 resultieren würden. Im Schema in Abb. 4.50 C ist dargestellt, an welcher Stelle das Fusionprotein gespalten werden müßte, um Banden der entsprechenden Größe zu erhalten. Um auszuschließen, daß eine Resistenz gegenüber Trypsin für das Auftreten der Bande verantwortlich ist, wurde die äußere Membran der Zellen, die das Intimin'-Cal Konstrukt exprimierten, vor dem Verdau mit Trypsin durch Behandlung mit EDTA permeabilisiert (3.5.2). Anschließend erfolgte der Trypsin-Verdau und die Analyse mit SDS-PAGE und Westernblot wie beschrieben. Hierbei zeigte sich, daß bei vorhergehender Permeabilisierung der Zellen die entsprechende Bande nicht auftrat und daß das Fusionsprotein von sich aus nicht resistent gegenüber Trypsin war. Dieser Westernblot ist in Abb. $4.50 \mathrm{D}$ gezeigt. Bei diesem Blot wurde im Vergleich zu dem in B) gezeigten Blot weniger Probe aufgetragen. Aus diesem Grund sind die Banden deutlich schwächer als in vergleichbaren Blots, beim Scannen der Membran mußte der Kontrast stark erhöht werden. Zusammengenommen sprechen diese Ergebnisse dafür, daß sich die Passagierdomänen, die nicht oberflächenexponiert werden, im Periplasma befinden und durch Trypsinbehandlung von der Transmembrandomäne getrennt werden. 
A

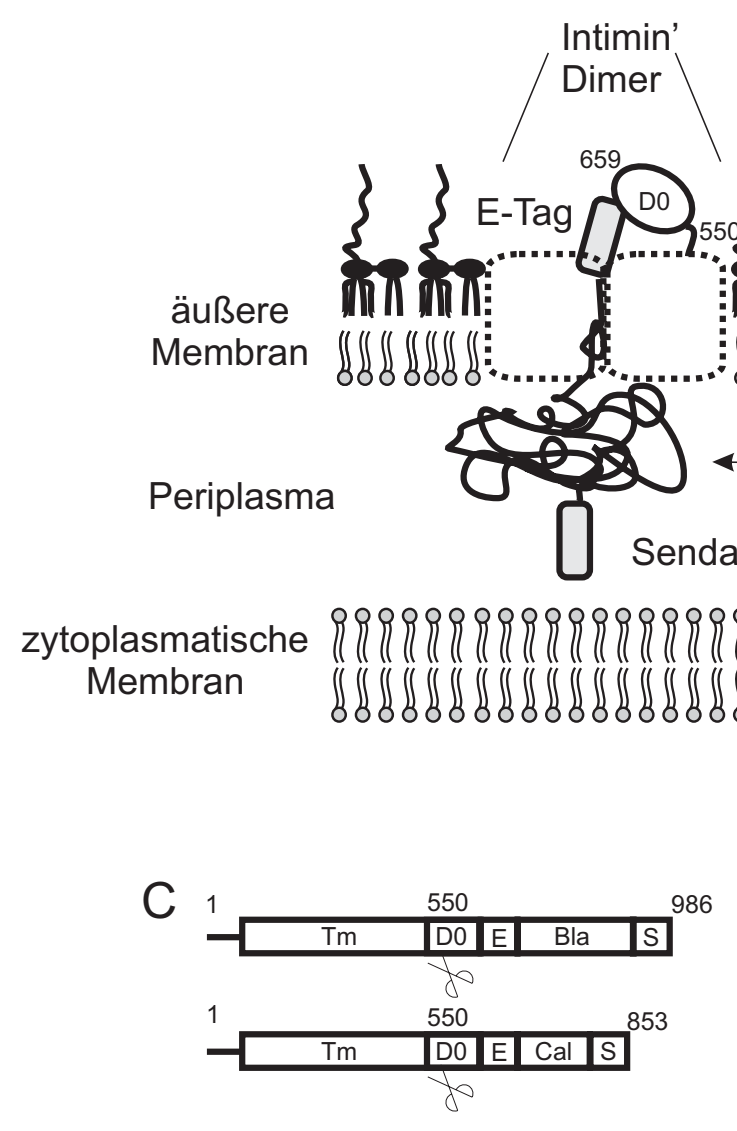

B

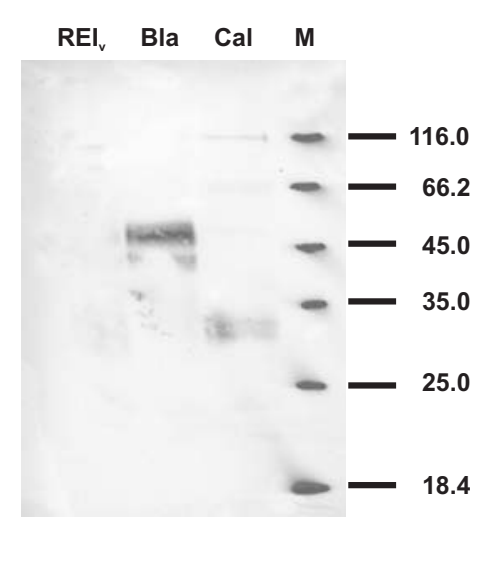

Abb. 4.50: (A) Modell einer Intimin'-Fusion mit im Periplasma eingeschlossener Passagierdomäne. Intimin' (unterbrochene Linien) ist als Dimer dargestellt, wobei die linke extrazelluläre Domäne aus Gründen der Übersichtlichkeit ausgelassen wurde. Die Domäne D0 and der E-Tag sind auf der Zelloberfläche lokalisiert, während sich der Passagier und das Sendai-Epitop im Periplasma befinden. Aminosäure 550 ist die letzte Aminosäure der Transmembranregion und AS 659 ist die letzte Aminosäure von Intimin'. Die Dimensionen sind nicht proportional. (B) Westernblot mit Anti-E Antikörper von Periplasmapräparationen der Proteine induzierter 71-18-Zellen mit den Plasmiden pASKInt100-REI, pASKInt100-Bla oder pASKInt100-Cal. Die Zellen wurden vor dem osmotischen Schock mit Trypsin behandelt. M: Marker Proteine (Nach Ponceau-SFärbung mit Kugelschreiber angezeichnet) in den angegebenen Größen (in tausend). (C) Lineare Darstellung von Intimin'-Bla (oben) und Intimin'-Cal (unten). Die putative Trypsinspaltstelle, wie aus (B) abgeleitet, ist durch das Scherensymbol darstellt. Tm: Transmembranregion; E: E-Tag-Epitop; S: Sendai- Epitop. (D) Trypsinbehandlung von E. coli Zellen. Um zu untersuchen, ob das Fusionsprotein eine intrinsische Resistenz gegenüber einem Verdau mit Trypsin besitzt, wurden vier parallele Ansätze von induzierten 71-18 (pASKInt100Cal) Zellen zum Teil mit Trypsin behandelt (1. Trypsin), anschließend permeabilisiert (2. permeab.) und erneut mit Trypsin behandelt (3. Trypsin). Die Ansätze wurden anschließend auf einem SDS-Polyacrylamidgel aufgetrennt und ein Westernblot mit Anti-E-Tag Antikörper durchgeführt. Die Markenbanden sind analog zu dem Westernblot in (B).

\subsection{Untersuchung der Oberflächenexposition von BLIP}

Klauser und Mitarbeiter untersuchten die Oberflächenpräsentation der CholeratoxinUntereinheit CtxB, die mit dem Neisseria gonorrhoeae IgA Protease Autotransporter fusioniert worden war (KLAUSER et al., 1990). Eine erfolgreiche Oberflächenexposition konnte nur beobachtet werden, wenn entweder $\beta$-Mercaptoethanol zu dem Wachstumsmedium 
gegeben oder ein Escherichia coli Stamm ohne das Enzym DsbA eingesetzt wurde. DsbA ist eine periplasmatische Oxidoreduktase, die die Ausbildung von Disulfidbrücken katalysiert (BARDWELL et al., 1991).

Um den Einfluß der Ausbildung von periplasmatischen Disulfidbrücken auf die Zelloberflächenpräsentation von Passagierproteinen $\mathrm{zu}$ untersuchen, wurden Zellen der Stämme 71-18 und 71-18dsbA mit den entsprechenden pASKInt100 Expressionsplasmiden mit und ohne $20 \mathrm{mM} \beta$-Mercaptoethanol ( $\beta$-ME) im Medium inkubiert. Die Genexpression wurde bei einer $\mathrm{OD}_{600}$ von 0,2 induziert (3.5.1) und die Oberflächenexposition der Passagierproteine durch Fluoreszenzmarkierung (3.5.3) und FACS (3.5.4) untersucht. Um eine Flut von FACS-Diagrammen in diesem Ergebnisteil zu vermeiden, werden die erzielten Ergebnisse in Tabelle 4.4 wiedergegeben. Mit der Ausnahme von BLIP war durch die Zugabe von $\beta$-Mercaptoethanol oder die Verwendung von 71-18dsbA keine Oberflächenpräsentation von Passagierdomänen, die vorher nicht auf der Oberfläche exponiert worden waren, ermöglicht worden.

\begin{tabular}{|l|c|c|c|c|c|c|}
\hline \multirow{2}{*}{} & \multicolumn{3}{|c|}{$71-18$} & \multicolumn{3}{c|}{$71-18$ dsbA } \\
\cline { 2 - 7 } & - & $\beta-M E$ & EDTA & - & $\beta-M E$ & EDTA \\
\hline REI $_{\mathrm{v}}$ & + & + & + & + & + & + \\
\hline Ubiquitin & + & n.b. & n.b. & + & n.b. & n.b. \\
\hline Calmodulin & - & - & + & - & - & + \\
\hline BLIP & - & + & - & + & + & - \\
\hline $\begin{array}{l}\text { RTEM-1 } \beta- \\
\text { Laktamase }\end{array}$ & - & - & - & - & - & - \\
\hline
\end{tabular}

Tabelle 4.4: Oberflächenexposition von Passagierdomänen bei Zugabe von $20 \mathrm{mM} \beta$-Mercaptoethanol oder Verwendung des Stammes 71-18dsbA. +: Oberflächenexposition wurde durch Fluoreszenzmarkierung mit AntiSendai Antikörper nachgewiesen, -: keine Oberflächenexposition. n.b.: nicht bestimmt.

Die Zugabe von $20 \mathrm{mM} \beta$-Mercaptoethanol zu dem Medium, in dem 71-18 mit dem Plasmid pASKInt100-BLIP vermehrt wurde, resultierte in einem leichten Anstieg der Fluoreszenz mit dem Anti-Sendai Antikörper im Vergleich zu Medium ohne $\beta$-ME. Wurde die Expression in 71-18dsbA durchgeführt, ergab sich eine noch höhere Fluoreszenz, und bei der Verwendung von 71-18dsbA und der Zugabe von $20 \mathrm{mM} \beta$-Mercaptoethanol zum Medium schließlich ließ sich die höchste Fluoreszenz erzielen. Die entsprechenden FACSDiagramme sind in Abb. 4.51 A dargestellt. Durch die Verwendung des reduzierenden Agens $\beta$-ME, sowie des Stammes 71-18dsbA wird wahrscheinlich die Bildung der Disulfidbrücken (EPPENs et al., 1997) und somit auch die Faltung des Proteins verlangsamt. Diese Ergebnisse lassen sich so deuten, daß eine Korrelation zwischen der Faltung von BLIP und seinem Export über die äußere Membran besteht. Wurde als reduzierendes Agens $1 \mathrm{mM}$ Tris(2-Carboxyethyl)Phosphin (TCEP) statt $\beta$-ME eingesetzt, war ebenfalls eine Oberflächenexposition von BLIP zu erzielen, siehe Abb. $4.51 \mathrm{~B}$. 
A

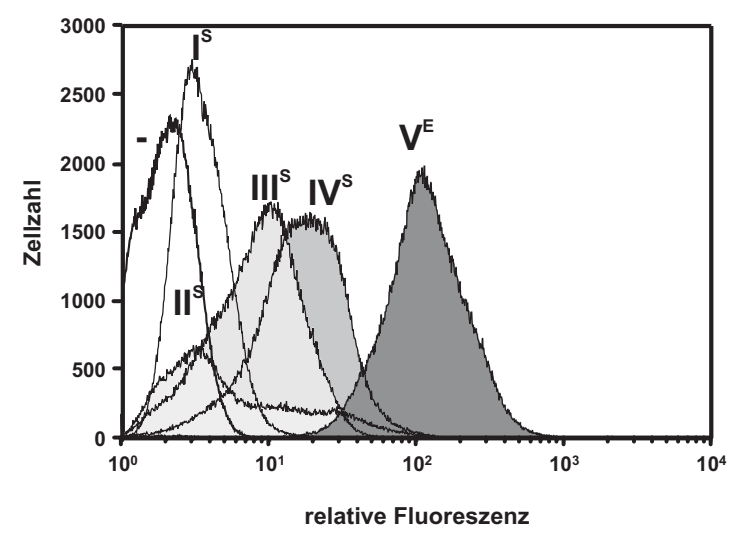

B

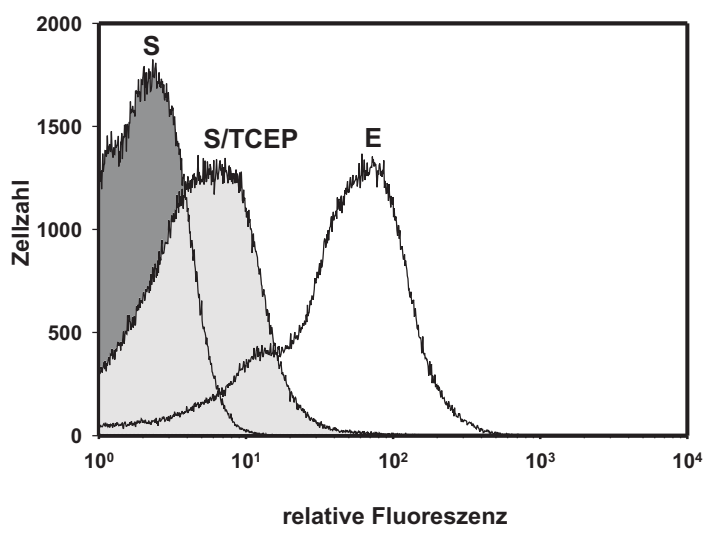

Abb. 4.51: Intimin'-vermittelte Zelloberflächenpräsentation von BLIP. FACS Histogramme rekombinanter 7118 oder 71-18dsbA Zellen mit dem Plasmid pASKInt100-BLIP. (A) Induzierte Zellen wurden mit Anti-Sendai Antikörper oder Anti-E-Tag Antikörper fluoreszenzmarkiert. $\left(\mathrm{I}^{\mathrm{S}}\right)$ 71-18 (pASKInt100-BLIP) inkubiert in dYT, markiert mit Anti-Sendai Antikörper. (II $\left.{ }^{\mathrm{S}}\right) 71-18$ (pASKInt100-BLIP) inkubiert in dYT mit $20 \mathrm{mM} \beta$-ME, markiert mit Anti-Sendai Antikörper. (III ${ }^{\mathrm{S}}$ ) 71-18dsbA (pASKInt100-BLIP) inkubiert in dYT, markiert mit AntiSendai Antikörper. $\left(I^{S}\right.$ ) 71-18dsbA (pASKInt100-BLIP) inkubiert in dYT mit $20 \mathrm{mM} \beta$-ME, markiert mit AntiSendai Antikörper. $\left(\mathrm{V}^{\mathrm{E}}\right)$ 71-18 (pASKInt100-BLIP) inkubiert in dYT, markiert mit Anti-E-Tag Antikörper. Unmarkierte 71-18 Zellen dienten als Kontrolle (-). (B) Induzierte Zellen wurden mit Anti-Sendai Antikörper oder Anti-E-Tag Antikörper fluoreszenzmarkiert. (S) 71-18 (pASKInt100-BLIP) inkubiert in dYT, markiert mit Anti-Sendai Antikörper. (S/TCEP) 71-18 (pASKInt100-BLIP) inkubiert in dYT mit $1 \mathrm{mM}$ Tris(2Carboxyethyl)Phosphin (TCEP), markiert mit Anti-Sendai Antikörper. (E) 71-18 (pASKInt100-BLIP) inkubiert in dYT, markiert mit Anti-E-Tag Antikörper.

\subsection{Untersuchungen des Exports von Calmodulin}

Da für BLIP gezeigt werden konnte, daß eine inverse Korrelation zwischen der periplasmatischen Faltung und einer erfolgreichen Oberflächenpräsentation besteht, wurde getestet, ob ein solcher Zusammenhang auch für die Oberflächenpräsentation von Calmodulin etabliert werden kann. Die Faltungsstabilität von Calmodulin ist von dem Vorhandensein von Kalziumionen abhängig. Während die Apoform des Calmodulin bei normalen Temperaturen größtenteils entfaltet ist, ist die ligandengebundene Form sehr stabil (GUERINI und KREBS, 1983). Hat das Calmodulin die Kalziumionen gebunden, wird es weder bei Temperaturen von über $90^{\circ} \mathrm{C}$ noch bei einer Harnstoffkonzentration von $9 \mathrm{M}$ denaturiert. Somit existiert eine Möglichkeit, durch den Einsatz von Kalziumchelatoren die Faltung des Calmodulins zu beeinflussen. Die Passage von Calmodulin durch die Zytoplasmamembran von E. coli wird durch die An- oder Abwesenheit von Kalzium nicht beeinflußt (NeRI et al., 1995). Um den Einfluß von Kalziumionen, und damit auch der Faltung, auf die Translokation des Calmodulin durch die äußere Membran zu untersuchen, wurden 71-18 Zellen mit dem Plasmid pASKInt100-Cal mit oder ohne $20 \mathrm{mM}$ Ethylendiamintetraessigsäure (EDTA) im Medium vermehrt. Die Induktion der Genexpression (3.5.1) erfolgte bei einer $\mathrm{OD}_{600}$ von 0,2 für eine Dauer von $2 \mathrm{~h}$. Anschließend wurden die Zellen mit dem Anti-E-Tag oder dem AntiSendai Antikörper fluoreszenzmarkiert (3.5.3) und im FACS vermessen (3.5.4).

Wie sich in Abb. 4.52 erkennen läßt, konnte eine Oberflächenexposition des Fusionsproteins nur beobachtet werden, wenn dem Medium $20 \mathrm{mM}$ EDTA zugegeben 
wurden. Bei Inkubation der Zellen ohne Zusatz von EDTA konnte keine Oberflächenexposition nachgewiesen werden. Die Integration des Intimins in die äußere Membran hingegen konnte in beiden Fällen durch Markierung der Zellen mit dem Anti-ETag Antikörper gezeigt werden.
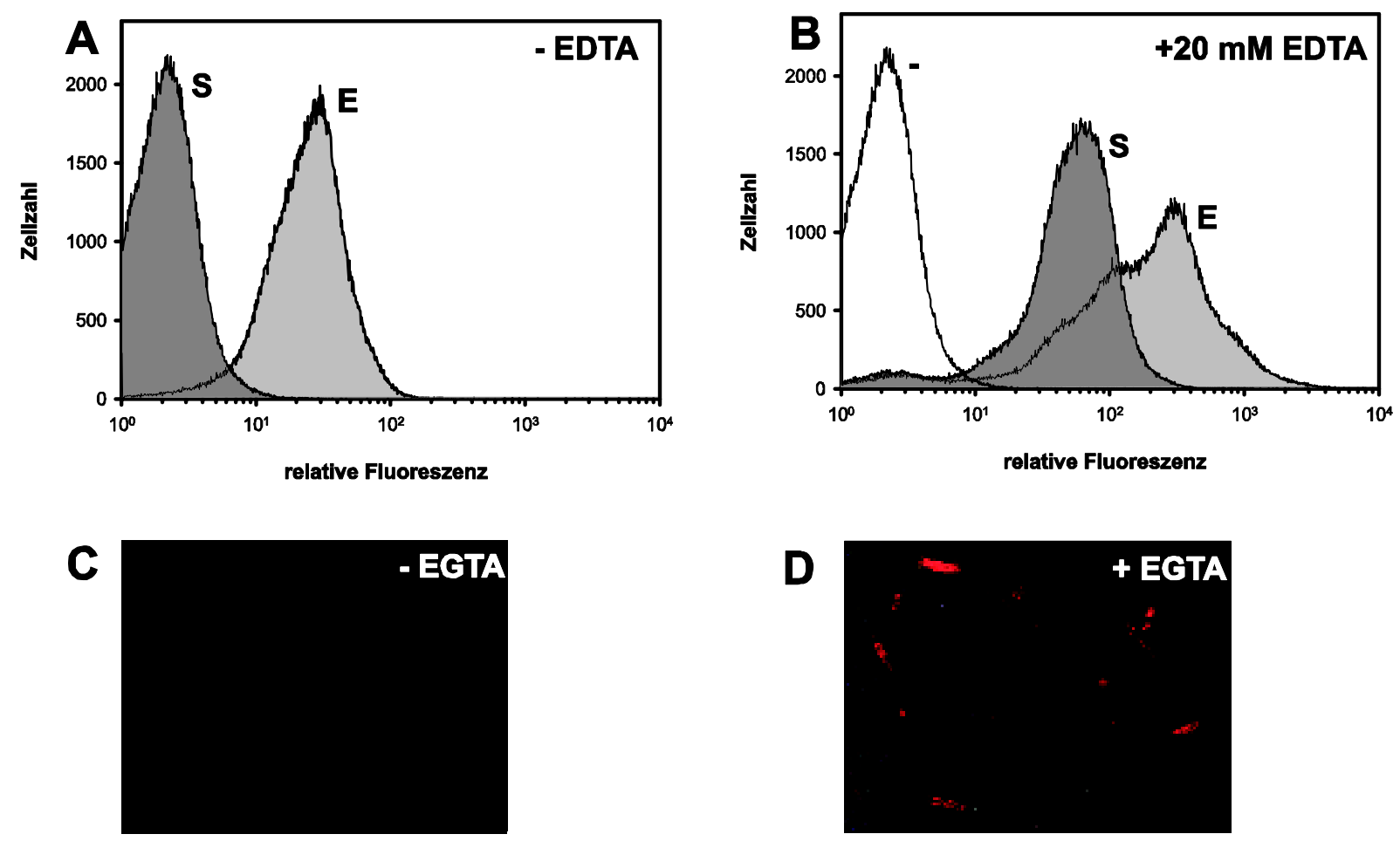

Abb. 4.52: (A,B) Intimin'-vermittelte Zelloberflächenpräsentation von humanem Calmodulin. 71-18 Zellen mit dem Plasmid pASKInt100-Cal wurden in Abwesenheit (A) oder Anwesenheit (B) von 20 mM EDTA inkubiert. Induzierte Zellen wurden mit Anti-Sendai Antikörper (S) oder Anti-E-Tag Antikörper (E), fluoreszenzmarkiert und mit FACS analysiert. Unmarkierte 71-18 Zellen dienten als Kontrolle (-). (C,D) Bindung von MykBla ${ }^{\text {Send }}$ an oberflächenexponiertes Calmodulin ohne Sendai-Epitop. Induzierte Zellen wurden in Abwesenheit (C) oder Anwesenheit (D) von $20 \mathrm{mM}$ EGTA inkubiert. Die Zellen wurden gewaschen, in $50 \mathrm{mM} \mathrm{CaCl} \mathrm{C}_{2}$ resuspendiert und mit $\mathrm{MykBla}^{\text {send }}$ inkubiert. Die Bindung des Fusionsproteins an Calmodulin wurde durch Fluoreszenzmikroskopie nachgewiesen, nachdem die Zellen mit Anti-Sendai Antikörper, biotinyliertem AntiMaus Antikörper und Streptavidin, R-Phycoerythrin Konjugat markiert worden waren.

Ein natürliches Substrat für die Bindung durch Calmodulin ist das Molekül Myk, ein kurzes Peptid aus der leichten Kette der Myosinkinase (IKURA et al., 1992). Es sollte untersucht werden, ob das oberflächenständige Calmodulin dieses Peptid binden konnte. Es lag ein Fusionsprotein aus Myk, $\beta$-Laktamase und dem Sendai-Epitop (Myk-Bla ${ }^{\text {Send }}$ ) vor, mit dem die Bindung von Myk an Calmodulin untersucht werden konnte. Um dieses Experiment durchführen zu können, mußte zuvor eine Intimin'-Calmodulin-Fusion erstellt werden, die kein eigenes Sendai-Epitop mehr besaß. Dazu wurde das Plasmid pASKInt100-Cal mit den Enzymen BglII und BamHI verdaut (3.3.1) und das Plasmidfragment über ein Agarosegel aufgereinigt (3.2.2). Da durch die Spaltung mit den genannten Enzymen kompatible Enden entstehen, konnte das Plasmidfragment durch Ligation mit T4-DNA-Ligase (3.3.3) wieder zyklisiert werden. Positive Klone wurden durch Nukleotidsequenzanalyse verifiziert. Das resultierende Plasmid wurde als pASKInt100-Cal $\Delta$ send bezeichnet. 
Um die Bindung von Myk an oberflächenpräsentiertes Calmodulin zu testen, wurden 71-18 Zellen mit dem Plasmid pASKInt100-Cal $\Delta$ send wie oben beschrieben in Medium, welches kein oder $20 \mathrm{mM}$ Ethylenglycol-bis(2-Aminoethylether)-Tetraessigsäure (EGTA) enthielt, inkubiert und induziert. EGTA ist ebenfalls ein Kalziumchelatbildner, der spezifischer für $\mathrm{Ca}^{2+}$ als EDTA ist. Nach der Induktion wurden die Zellen gewaschen und in PBS, das $50 \mathrm{mM} \mathrm{CaCl} 2$ enthielt, resuspendiert und für $30 \mathrm{~min}$ auf Eis inkubiert. Nach erneutem Waschen erfolgte eine Inkubation der Zellen mit dem Myk-Bla ${ }^{\text {Send }}$ Fusionsprotein, und anschließend mit dem Anti-Sendai Antikörper (3.5.3). Die Zellen wurden unter dem Fluoreszenzmikroskop betrachtet und fotografisch dokumentiert (Abb 4.52 C,D). Nur die Zellen, welche in EGTA gewachsen waren und das Calmodulin auf ihrer Oberfläche präsentierten, konnten fluoreszenzmarkiert werden. Daß für die Bindung des Fusionsproteins

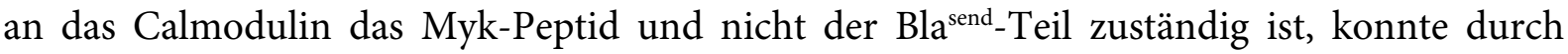

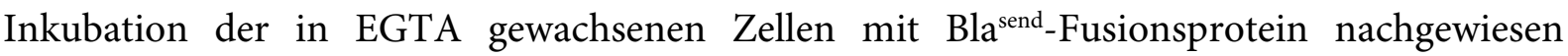
werden; in diesem Fall konnte keine Fluoreszenzmarkierung erzielt werden. Wie man aus der Tabelle 4.4 ersehen kann, wurde durch die Zugabe von EDTA nur die Oberflächenpräsentation von Calmodulin, nicht aber der anderen Passagierdomänen, ermöglicht. Dies deutet darauf hin, daß der Export von Cal in Anwesenheit von EDTA/EGTA nicht auf die Destabilisierung der äußeren Membran, sondern auf die geringe Faltungsstabilität der Apoform des Calmodulins zurückzuführen ist.

\subsection{Untersuchung der Oberflächenpräsentation von Bla}

Das Protein $\beta$-Laktamase ist als Referenzprotein für die Zelloberflächenpräsentation von Passagierdomänen mit dem AIDA Autotransporter (LATTEMANN et al., 2000) oder einer verkürzten Variante des OmpA Porins (GeORgIOU et al., 1996) verwendet worden. Eine Oberflächentranslokation mit dem Intimin'-System war jedoch unter allen getesteten Bedingungen erfolglos (Tab 4.4). Da für BLIP und Cal ein Zusammenhang zwischen der Faltung des Passagiers und der Oberflächenexposition gezeigt werden konnte, lag es nahe, die Hypothese aufzustellen, daß eine Faltung von Bla im Periplasma die Translokation über die äußere Membran verhinderte. In diesen Fall könnte es möglich sein, durch evolutive Verfahren Bla-Varianten mit veränderter Faltungscharakteristik zu isolieren. Die im nachfolgenden beschriebenen Experimente wurden gemeinsam mit $\mathrm{H}$. Kolmar und A. Wentzel durchgeführt. Um nach translokationskompatiblen Bla-Varianten zu suchen, wurde eine Strategie der zufälligen Mutagenese eingesetzt. 71-18mutS Zellen, die das Plasmid pASKInt100-Bla trugen, wurden mit einem zweiten Plasmid, pZA22-mutD5*, transformiert. Dadurch entstand ein Hypermutatorstamm, der in der DNA-Mißpaarungs-Reparatur defizient ist, da er eine Tn10-Transposonintegration in dem mutS Locus trägt (KRAMER et al., 1984). Zusätzlich trägt er auf dem Plasmid das dnaQ Gen mit der mutD5 Mutation, welches eine dominant-negative $\varepsilon$-Untereinheit der Korrekturelese-Exonuklease der DNA Polymerase III kodiert und unter Kontrolle des lac-Promotors steht (SElifonova et al., 2001). Durch Vermehrung der Zellen mit dem Induktor IPTG konnte eine Population von Mutanten generiert werden (3.5.6) und aus dieser durch Markierung mit Anti-Sendai Antikörper und anschließende FACS Analyse konnten in drei Runden Klone isoliert werden, die Bla- 
Varianten auf ihrer Oberfläche trugen (3.5.6). Die Plasmid DNA dieser Klone wurde isoliert und die Sequenz der bla-Gene bestimmt (Tabelle 4.5). Insgesamt wurden acht Klone analysiert. Von diesen waren die Klone 1, 3, 6, 7 und 8 identisch, bei ihnen war das Cystein an der Position 98 gegen Arginin ausgetauscht. Der Klon 2 trug ebenfalls diese Mutation, zusätzlich aber noch eine stille Mutation im Codon der Aminosäure Threonin an der Position 84. Bei dem Klon 5 war das Cystein an der Position 98 gegen Tyrosin ausgetauscht und bei dem Klon 4 schließlich das Cystein an der Position 52 ebenfalls gegen Arginin. Die Aminosäurepositionen orientieren sich an dem reifen Bla Protein ohne Signalsequenz.

\begin{tabular}{|l|c|c|}
\hline Klon Nr. & Austausch (Protein) & Austausch (DNA) \\
\hline 1 & C98R & TGC->CGC \\
\hline 2 & C98R & TGC->CGC \\
& T84T & ACA->ACG \\
\hline 3 & C98R & TGC->CGC \\
\hline 4 & C52R & TGT->CGT \\
\hline 5 & C98Y & TGC->TAC \\
\hline 6 & C98R & TGC->CGC \\
\hline 7 & C98R & TGC->CGC \\
\hline 8 & C98R & TGC->CGC \\
\hline
\end{tabular}

Tabelle 4.5: Aminosäureaustausche in den acht gefundenen Bla-Varianten, die auf der Zelloberfläche präsentiert wurden.

Bei dieser Durchmusterung der Population der Bla-Varianten wurden somit vier verschiedene Klone mit drei verschiedenen Aminosäureaustauschen gefunden, denen der Austausch eines der beiden Cysteine gemeinsam ist. Auffällig ist, daß die Cysteine gegen die beiden raumfüllenden Aminosäuren Arginin und Tyrosin ausgetauscht sind, und nicht etwa gegen kleinere Aminosäuren. Dies kann bedeuten, daß nicht nur eine Elimination der Disulfidbrücken, sondern auch eine weitere Destabilisierung des Proteins für eine erfolgreiche Oberflächenexposition notwendig ist. Die Oberflächenpräsentation von BlaC52R, BlaC98R und BlaC98Y wurde mittels Markierung mit Anti-Sendai Antikörper untersucht und mit der Oberflächenpräsentation des Wildtyps verglichen. Hierzu wurden 71-18 Zellen, die die entsprechenden pASKInt100 Plasmide trugen und die Fusionsproteine exprimierten, mit dem Anti-Sendai Antiköper markiert (3.5.3) und die Fluoreszenz der Zellen mit dem FACS vermessen (3.5.4). Die FACS Diagramme (Abb 4.53) zeigen, daß alle drei selektierten Klone zur Oberflächenpräsentation befähigt sind, während die Wildtypform nicht exportiert wird. 


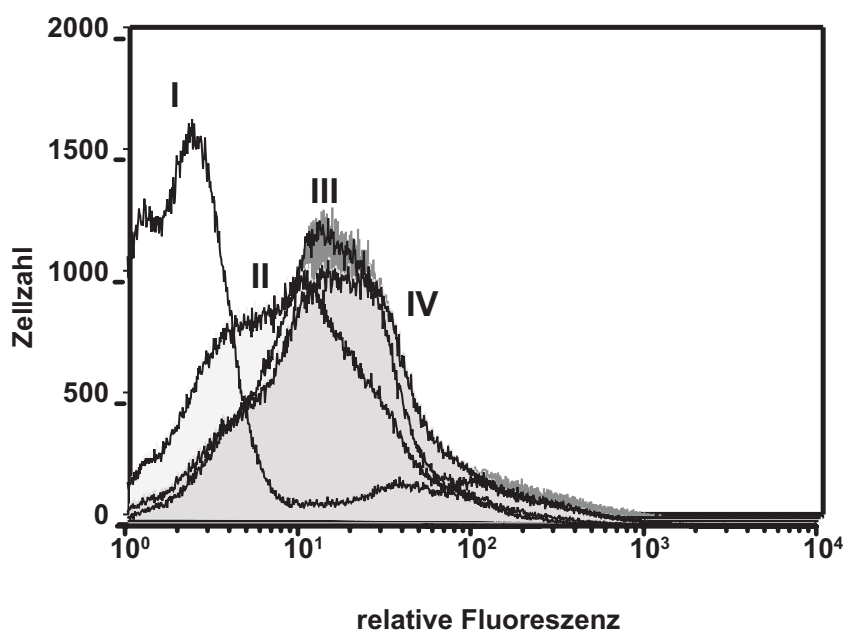

Abb. 4.53: Intimin'-vermittelte Zelloberflächenexposition von $\beta$-Laktamase-Varianten . FACS Histogramme von 71-18 Zellen mit dem Wildtyp-Plasmid pASKInt100-Bla (I), und den Plasmiden, die für die Varianten C52R (II), C98R (III) oder C98Y(IV) kodieren. Die Fluoreszenzmarkierung der Zellen erfolgte mit dem Anti-Sendai Antikörper.

\subsection{Untersuchung der Faltungsstabilität von Bla}

Das Wildtyp-Bla und die Variante C98Y wurden als lösliche Proteine hergestellt. Hierzu wurden die Gene in das Plasmid pBBR22bII (2.2.2.2) kloniert. Die kodierenden Sequenzen der bla-Gene wurden mit den Oligonukleotiden BlaSigNdeup und BlaBgl12dwn unter Verwendung der Plasmide pASKInt100-Bla bzw. pASKInt100-BlaC98Y durch PCR amplifiziert. Die PCR Produkte wurden mit Phenol/Chloroform (3.2.1.3) extrahiert, mit Ethanol gefällt (3.2.1.1) und anschließend mit den Enzymen NdeI und BglII verdaut und in das mit den selben Enzymen gespaltene Plasmid pBBR22bIIPa5349 ligiert (3.3.3). Hieraus resultierten die Vektoren pBBR22bII-Blawt und pBBR22bII-BlaC98Y. Diese wurden, nachdem ihre Sequenz durch Nukleotidsequenzanalyse bestätigt worden war, zur Transformation des Stammes BL21(DE3) eingesetzt. Mittels immobilisierter Metallionen Affinitätschromatographie (IMAC) wurden die beiden Proteine Bla und Bla-C98Y aus jeweils einer $1000 \mathrm{ml}$ Kultur wie in Abschnitt 3.4.8 beschrieben, gereinigt und gegen $4000 \mathrm{ml} 100 \mathrm{mM}$ Phosphatpuffer, $\mathrm{pH} 8,0 ; 100 \mathrm{mM} \mathrm{NaCl}$ dialysiert (3.4.10). Nach der Dialyse wurde das Volumen der Lösungen eingeengt (3.4.10).

Die relative enzymatische Aktivität der Proteine in An- und Abwesenheit von $1 \mathrm{M}$ Harnstoff in der Lösung wurde bestimmt. Hierzu wurde die Hydrolyse des Substrates PADAC kolorimetrisch bei $450 \mathrm{~nm}$ verfolgt (3.6.7). In jedem Ansatz wurden äquimolare Konzentrationen der jeweiligen Enzymvariante und des Substrats eingesetzt. Die Reaktionsgeschwindigkeit wurde durch Ermittlung der Steigung während der Phase des Fließgleichgewichtes bestimmt und für das Wildtyp-Protein ohne Zugabe von Harnstoff auf den Wert 100 gesetzt und die Reaktionsgeschwindigkeiten der anderen Ansätze auf diesen Wert normiert. In Tabelle 4.6 sind die ermittelten Reaktionsgeschwindigkeiten aufgeführt. 


\begin{tabular}{|c|c|c|}
\hline Bla Variante & \multicolumn{2}{|c|}{ Relative Enzymatische Aktivität } \\
\hline & O M Harnstoff & 1 M Harnstoff \\
\hline Wildtyp & 100 & 80 \\
\hline C98Y & 0.02 & 0.002 \\
\hline
\end{tabular}

Tabelle 4.6: Relative enzymatische Aktivität des Bla-Wildtyp-Proteins und der Variante C98Y in An- und Abwesenheit von $1 \mathrm{M}$ Harnstoff, bestimmt durch Hydrolyse des Substrates PADAC. Die enzymatische Aktivität des Wildtyps wurde auf den Wert 100 normiert und die anderen ermittelten Aktivitäten in ein Verhältnis dazu gesetzt.

Die Variante C98Y zeigt eine sehr deutlich reduzierte enzymatische Aktivität im Vergleich zum Wildtyp. Interessant ist vor allem, daß durch die Zugabe von Harnstoff die Aktivität des Wildtyp auf $80 \%$ reduziert wird, während die Aktivität der Mutante bei Zugabe von Harnstoff nur rund $10 \%$ des Wertes ohne Harnstoffzugabe erreicht. Dies ist ein Hinweis darauf, daß die Mutante eine stark reduzierte Stabilität aufweist.

Zusammengenommen lassen diese Beobachtungen den Schluß $\mathrm{zu}$, daß eine Oberflächenpräsentation von Bla durch Fusion an das Intimin' nur dann erzielt werden kann, wenn die Faltungsstabilität von Bla im Periplasma reduziert ist und die Bildung von Disulfidbrücken verhindert wird.

\subsection{Interpretation und Diskussion der Beobachtungen der Faltungsstudie}

Die Untersuchungen der Oberflächenpräsentation der verschieden Passagierdomänen weisen darauf hin, daß sowohl die periplasmatische Faltung der Passagiere als auch die Ausbildung der Disulfidbrücken einen Einfluß auf eine erfolgreiche Translokation durch die äußere Membran haben. Durch die Verwendung eines Expressionssystems, bei dem die zu untersuchende Passagierdomäne, flankiert von zwei distinkten Epitopen, an das Intimin' fusioniert wird, kann eine Translokation durch die äußere Membran direkt durch Immunfluoreszenz nachgewiesen werden (WENTZEL et al., 2001). Während $\mathrm{REI}_{\mathrm{v}}$ und Ubiquitin mit hoher Effizienz exportiert werden, war der Export von BLIP sehr ineffizient und der von Calmodulin und $\beta$-Laktamase vollständig unterbunden. Bei allen Konstrukten, unabhängig von einer Oberflächenpräsentation, findet man ein Fluoreszenzsignal mit dem Anti-E-Tag Antikörper, dessen Epitop sich an der Verbindung zwischen dem Intimin' und dem Passagierprotein befindet. Dies deutet darauf hin, daß sich das Intimin' in der äußeren Membran befindet und seine Domäne D0 auf der extrazellulären Seite lokalisiert ist. Durch eine Westernblot Analyse konnte für alle Konstrukte ein Produkt der gesamten Kettenlänge nachgewiesen werden, unabhängig davon, ob die Passagiere auf der Oberfläche präsentiert wurden. Obwohl in diesen Experimenten ein deutlicher proteolytischer Abbau der Fusionsproteine nachgewiesen werden konnte, ist dies höchstwahrscheinlich nicht der Grund für eine erfolglose Oberflächenexposition. Es konnte im Fall von Calmodulin und BLIP gezeigt werden, daß unter Bedingungen, bei denen eine Oberflächenpräsentation zu beobachten ist, der proteolytische Abbau der Fusionsproteine im selben Maß vonstatten geht wie unter Standardbedingungen, bei denen keine Membrantranslokation der Proteine 
stattfindet. Es konnte weiterhin gezeigt werden, daß die Calmodulin und $\beta$-Laktamase Passagierdomänen nach einer Trypsinbehandlung von intakten Zellen in der periplasmatischen Fraktion anzutreffen sind. Dies ist ein weiterer Hinweis darauf, daß solche Passagierdomänen, die nicht auf der Zelloberfläche präsentiert werden, im Periplasma eingeschlossen sind.

Durch Erzeugung von reduzierenden Bedingungen im Periplasma konnte die Oberflächenexposition von BLIP, welches zwei Disulfidbrücken enthält, verbessert werden. Im Gegensatz dazu war die Oberflächenpräsentation von Bla, das eine Disulfidbrücke enthält, nicht durch die Schaffung eines reduzierenden Milieus zu erzielen. Die Bildung der Disulfidbrücken ist ein später Schritt während der Proteinfaltung (MA und ANDERSON, 1997). Dementsprechend konnte die Erzeugung von Bedingungen, die die Bildung von Disulfidbrücken verlangsamen oder verhindern und damit die vollständige Faltung der Passagiere im Periplasma verlangsamen, die Oberflächenexposition von BLIP positiv beeinflussen. Es ist sehr wahrscheinlich, daß der beobachtete Effekt tatsächlich auf der Beeinflussung der Disulfidbrückenbildung beruht und nicht etwa auf einer Destabilisierung der äußeren Membran durch $\beta$-Mercaptoethanol, da sich dieser Effekt im Falle von Calmodulin, welches keine Disulfidbrücken besitzt, nicht beobachten ließ. Calmodulin konnte nur durch die Zugabe der Kalziumchelatbildner EDTA und EGTA in einen für die Membranpassage kompetenten Zustand versetzt werden. Diese Substanzen selbst haben keinen Einfluß auf die Oberflächenexposition der übrigen Passagierdomänen, deren Faltung nicht durch Metallionen stabilisiert wird.

Unter diesem Gesichtspunkt ist die Intimin'-vermittelte Oberflächenpräsentation von Passagierdomänen ähnlich dem Transport von Proteinen durch die Zytoplasma- und Mitochondrienmembran. Eilers und Schatz (EILERS und SCHATZ, 1986) zeigten, daß Methotrexat, ein Folat-Antagonist, den Import von Dihydrofolatreduktase, die an eine mitochondriale Präsenquenz fusioniert worden war, in Mitochondrien blockieren konnte. Diese Blockade war das Resultat einer konformationellen Stabilisierung der Dihydrofolatreduktase-Domäne. Nur eine teilweise entfaltete Dihydrofolatreduktase konnte über die Membran sekretiert werden. In einem ähnlichen Experiment gelang es Randall und Hardy, eine Korrelation zwischen der Ausprägung einer stabilen Tertiärstruktur des Maltosebindeprotein und dessen Export in das Periplasma zu etablieren (RANDALL und HARDY, 1986).

Aus den hier beschriebenen Experimenten läßt sich jedoch keine generelle Aussage über den Export von disulfidbrückenhaltigen Passagierproteinen unter Bedingungen, die die Ausbildung der Disulfidbrücken unterbinden, herleiten. Das disulfidbrückenhaltige Bla wird in Anwesenheit von reduzierenden Agenzien nicht exportiert, während $\mathrm{REI}_{\mathrm{v}}$ und das Cystinknotenprotein EETI-II (WENTZEL et al., 2001) auch in Abwesenheit von reduzierenden Agenzien effizient exportiert werden, obwohl letzteres drei Disulfidbrücken in ihrer nativen Struktur enthält. Die Faltungskinetik von $\mathrm{REI}_{\mathrm{v}}$ wurde experimentell untersucht. Es konnte gezeigt werden, daß die Bildung der Disulfidbrücken der zeitbestimmende Schritt der Faltung ist, wobei die in vitro Halbwertszeit bis zur Ausbildung der Disulfidbrücken $200 \mathrm{~s}$ beträgt (SCHMIDT, 1995). Somit ergibt sich ein Zeitfenster, in dem der Export der Passagierdomäne in 
einem ungefalteten Zustand stattfinden kann. Das selbe gilt für EETI-II, bei dem die Bildung der Disulfidbrücken ebenfalls ein eher langsamer Prozeß ist (WENTZEL et al., 1999). Die Situation von $\beta$-Laktamase hingegen ist anders. Bla enthält, wie $\mathrm{REI}_{v}$, eine Disulfidbrücke. Die Oberflächenpräsentation von Bla war jedoch unter allen getesteten Bedingungen nicht zu erzielen. Es konnte gezeigt werden, daß die in vitro Faltung von Bla ein relativ schneller Prozeß mit einer Halbwertszeit von weniger als einer Minute ist (LAMINET und PLÜCKTHUN, 1989). Während der periplasmatischen Faltung in situ wird die Bildung der Disulfidbrücke durch das Enzym DsbA katalysiert (AKIYAMA et al., 1992; BARDWELL et al., 1991; FRECH et al., 1996). Es konnte jedoch gezeigt werden, daß reduzierte und oxidierte $\beta$-Laktamase mit identischen Kinetiken in ihre native Struktur falten und ähnliche Stabilität aufweisen (FRECH et al., 1996). Somit erreicht Bla seine native und enzymatisch aktive Konformation auch in Anwesenheit von $\beta$-Mercaptoethanol und/oder Abwesenheit von DsbA. Die schnelle Faltung der reduzierten und der oxidierten Form des Proteins könnte möglicherweise mit dem Export des ungefalteten Moleküls über die äußere Membran konkurrieren. Das verbleibende Zeitfenster für den Export wäre in diesem Fall zu klein, das heißt, es kann kein Export stattfinden. Bei dem Screening einer Population von Bla Varianten nach solchen, die zu einem Export über die äußere Membran befähigt sind, fanden sich nur solche Varianten, bei denen eines der beiden Cysteine gegen ein Arginin oder Tyrosin ausgetauscht war. Diese Aminosäuren gehören zu den raumfüllendsten der zwanzig in Proteinen vorkommenden Aminosäuren. Die auf ihre enzymatische Aktivität getestete Variante C98Y zeigt eine weit geringere Aktivität als der Wildtyp und war vor allem wesentlich anfälliger für eine Denaturierung durch Harnstoff, was auf eine deutlich verringerte Faltungsstabilität der Mutante hinweist, die mit einer Kompetenz für den Export über die äußere Membran einhergeht. Die Tatsache, daß außer Cysteinmutanten keine weiteren Aminosäureaustausche gefunden worden sind, deutet jedoch darauf hin, daß eine Abwesenheit von Disulfidbrücken in diesem Fall notwendig ist. Generell stehen diese Beobachtungen im Einklang mit dem Vorhandensein eines durch Intimin gebildeten Kanals, welcher nur ungefaltete Proteine, nicht aber Proteine mit einer bestimmten, raumfüllenden Tertiärstruktur, aufnehmen kann. Dies deckt sich mit der Beobachtung, daß Intimin eine im Elektronenmikroskop sichtbare Ringstruktur in der äußeren Membran und einen Kanal mit einer Leitfähigkeit für Ionen in einer Lipiddoppelschicht ausbildet (ToUZE et al., 2004). Für Autotransporterproteine ist das Vorhandensein eines Kanals, welcher konformationell eingeschränkte Proteine nur mit einer reduzierten Effizienz aufnehmen kann, aus der Literatur bekannt. So konnten an den IgA Protease Autotransporter anfusionierte scFv Fragmente nur mit einer stark reduzierten Effizienz exportiert werden, wenn ihre Disulfidbrücken vor dem Transport bereits gebildet waren (VEIGA et al., 1999).

\subsubsection{Konsequenzen dieser Ergebnisse für den Einsatz des Intimin'-Systems zum Zwecke der Protein-Protein-Interaktionsanalyse}

Die zuvor beschriebenen Ergebnisse zeigen an, daß sich das Intimin' System nur bedingt für die Präsentation beliebiger Protein und Proteindomänen auf der Zelloberfläche von E. coli eignet. So konnten zwar für die meisten Passagierdomänen Bedingungen gefunden werden, 
unter denen eine Präsentation möglich war, doch ließen sich diese Bedingungen nicht vorhersagen, sondern mußten experimentell bestimmt werden. Weiterhin war es im Fall von Bla nur durch ein aufwendiges Durchmusterungsverfahren möglich, exportkompatible Varianten $\mathrm{zu}$ isolieren.

Um eine proteomweite Oberflächenpräsentations-Bibliothek von Proteinen und Proteindomänen zum Zweck der Interaktionsanalyse einsetzen zu können, muß man fordern, daß das gesamte Proteom weitmöglich abgedeckt wird, um möglichst viele relevante Interaktionspartner auffinden zu können. Bei der Verwendung des Intimin'-Systems ist diese Bedingung nicht erfüllt, da man nicht vorhersagen kann, wie groß der Anteil an exportkompatiblen Elementen in der Bibliothek sein wird. Obwohl es möglich erscheint, mit diesem System einige Interaktionspartner auffinden zu können, ist die Verwendung des Systems für die proteomweite Analyse von Protein-Protein-Wechselwirkungen nicht empfehlenswert und auch nicht erfolgversprechend.

\subsubsection{ALD, ein neues System zur Oberflächenpräsentation}

In dem nun folgenden Abschnitt soll die Etablierung eines neues Systems vorgestellt werden, mit dem man beliebige Proteine und Proteinfragmente auf der Zelloberfläche von $E$. coli präsentieren kann, um diese einer Interaktionsanalyse zugänglich zu machen. Wie in dem vorangegangenen Abschnitt dargelegt, ist bei dem Intimin'-Sytem zur bakteriellen Oberflächenpräsentation von Passagierdomänen die Passage durch die äußere Membran der limitierende Faktor. Diese Passage kann nur erfolgen, wenn das Protein zum Zeitpunkt seiner Translokation in einem ungefalteten oder metastabilen Zustand vorliegt. Ein System zur Präsentation beliebiger Proteine dürfte diese Limitierung nicht haben. Vorstellbar wäre, ein Transportersystem einzusetzen, das generell alle Proteine über die äußere Membran exportiert. Ein solches Transportersystem ist in der Literatur bisher nicht beschrieben. Eine andere Möglichkeit ist, die Passagierproteine zytoplasmatisch oder periplasmatisch zu synthetisieren und durch Lyse aus den Zellen freizusetzen.

In diesem Abschnitt wird die Entwicklung eines Systems beschrieben, das auf der Freisetzung der zu präsentierenden Proteine durch Lyse basiert und deswegen die Bezeichnung "Autolysis-Display“ (ALD) erhalten hat. Dieses System muß mehrere Anforderungen erfüllen. Zum einen muß das Passagierprotein unter Umgehung der Translokation über die äußere Membran auf der Zelloberfläche fixiert werden. Dieses soll durch Lyse eines Teils der klonalen Bakterienpopulation erfolgen. Aus diesen Zellen wird dann das zu präsentierende Protein freigesetzt, während der andere Teil der Zellen intakt bleibt und die im Medium befindlichen Proteine auf seine Oberfläche dirigieren muß. Hierzu muß ein spezifisch miteinander wechselwirkendes Protein- oder Peptidpaar eingesetzt werden, wobei sich der eine Teil des Paares auf der Zelloberfläche befindet, während der andere Teil an das lösliche Protein fusioniert wird. Die Interaktion zwischen den beiden Partnern muß so spezifisch sein, daß die Bindung aus dem durch Lyse der Zellen entstehenden komplexen Gemisch heraus stattfinden kann. 
Weiterhin muß auch in diesem System eine Genotyp-Phänotyp-Kopplung gewährleistet sein, da ansonsten keine Selektion oder Durchmusterung eines Repertoires möglich wäre. Um Kreuzinteraktionen zwischen Proteinen, die nicht aus derselben klonalen Population stammen, zu unterbinden, müssen die Klone physikalisch getrennt voneinander wachsen und lysieren können. Wie diese abstrakten Anforderungen umgesetzt worden sind, wird in den nachfolgenden Kapiteln beschrieben. Das Schema in Abb. 4.54 illustriert die einzelnen Schritte, die für die Durchführung des Autolysis-Displays notwendig sind.

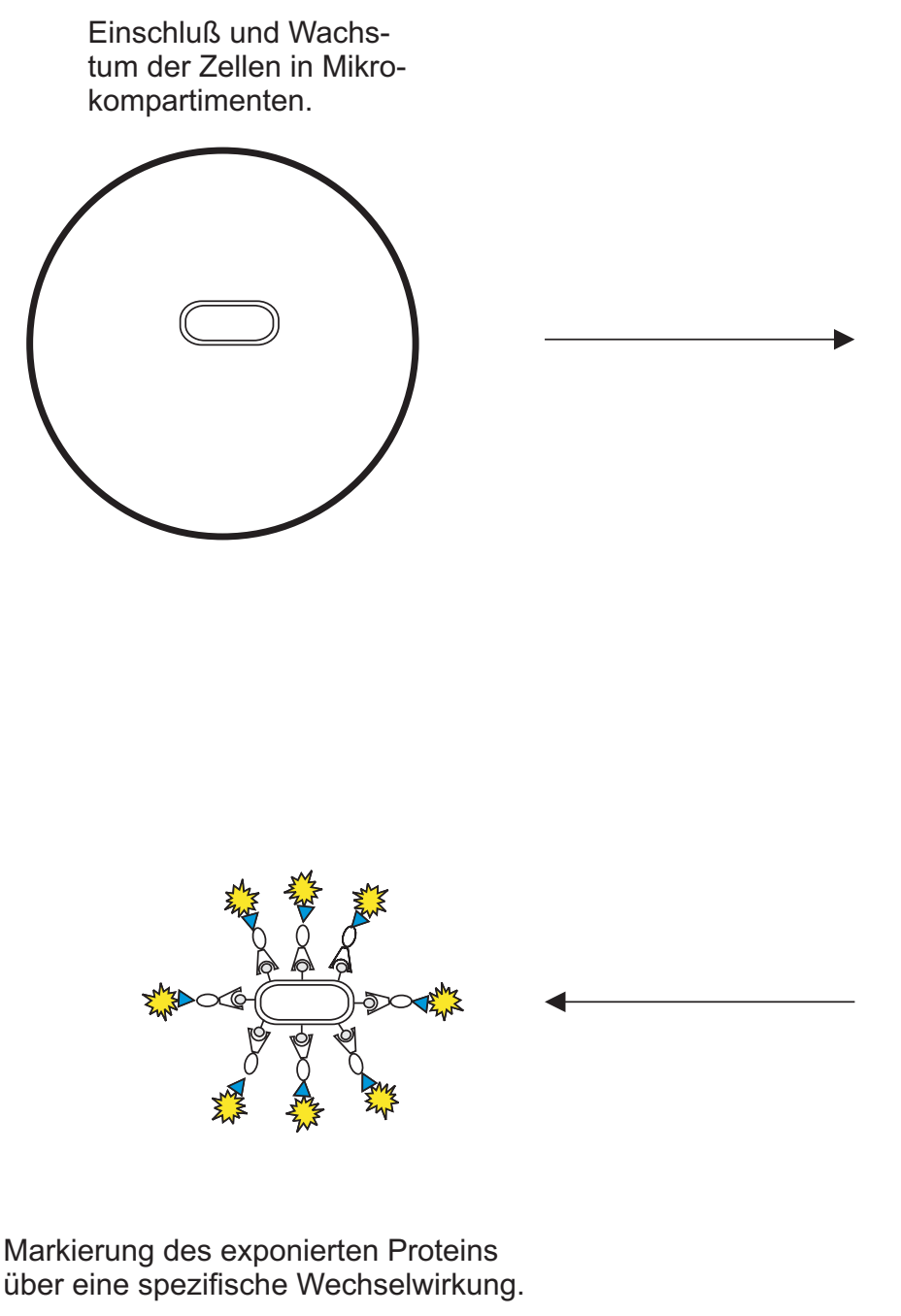
Bildung des Membranankers,
Induktion des löslichen Proteins,
partielle Lyse der Zellpopulation.

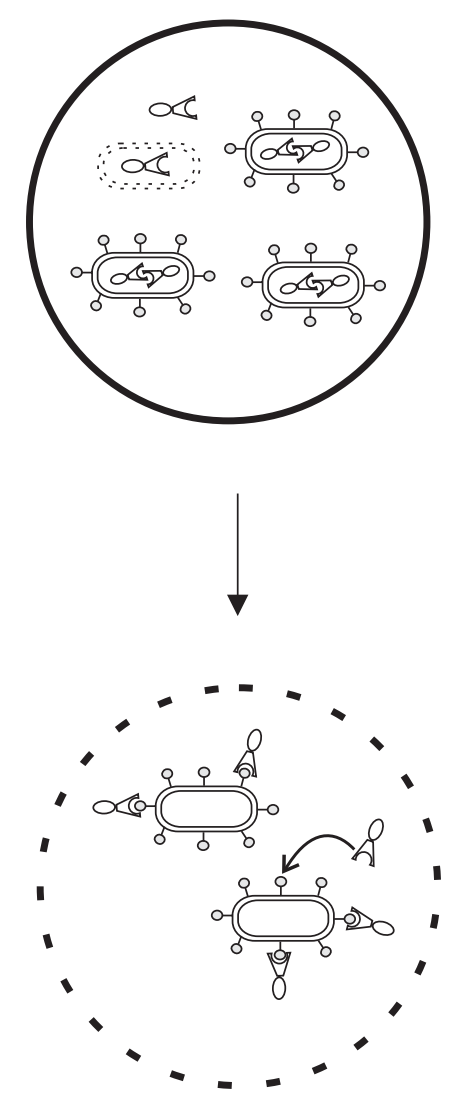

Fixierung des löslichen Proteins auf der Zelloberfläche, Auflösen der Mikrokompartimente.

Abb. 4.54: Darstellung der einzelnen Schritte des Autolysis-Displays.

\subsubsection{Erläuterung der einzelnen Komponenten des Systems}

4.2.3.1.1 Fixierung des löslichen Proteins auf der Zelloberfläche durch einen Heterodimer aus E-Coil und K-Coil

Die Fixierung des löslichen, zu präsentierenden Proteins auf der Zelloberfläche sollte durch eine spezifische Protein-Protein-Interaktion bewerkstelligt werden, wobei sich der eine 
Interaktionspartner auf der Zelloberfläche befindet, während der andere auf Genebene an das zu präsentierende Protein fusioniert wird. Die Exposition des Oberflächenankers beruht auf der Verwendung des in Abschnitt 4.2.2.2.1 ausführlich beschrieben Intimin' Systems. Um die Fixierung eines löslich produzierten Proteins auf der Zelloberfläche zu bewerkstelligen, wird dieses als Fusionsprotein mit einem Trägerprotein bereitgestellt, welches mit hoher Affinität an einen Teil des Oberflächenankers binden kann. Die Interaktion zwischen dem löslichen Protein und dem Oberflächenanker sollte mit Hilfe eines synthetischen Heterodimers erfolgen. Dieses Heterodimer besteht aus zwei Alphahelices zu jeweils 35 Aminosäuren, die wiederum aus fünf Wiederholungen von sieben Aminosäuren aufgebaut sind (TRIPET et al., 1996). Während die eine Alphahelix reicher an Glutamat ist, kommt in der anderen Helix die Aminosäure Lysin öfters vor, daher bekamen die Helices die Namen E-Coil und K-Coil (IRVIN et al., 1996). Die Interaktion der beiden Helices beruht auf zweierlei Eigenschaften. Zum einen kommt es zu einer elektrostatischen Anziehung zwischen dem negativ geladenen Glutamat und dem positiv geladenen Lysin. Zum zweiten entsteht eine hydrophobe Interaktion zwischen den Aminosäuren Leucin und Valin. Diese hydrophobe Interaktion kann sich auch in einem Homodimer ausbilden. Daher wurde bei der Entwicklung des Verfahrens darauf geachtet, Aminosäurepaare zu verwenden, deren hydrophobe Interaktion nicht zu stark ist, so daß die elektrostatische Anziehung einen ausreichend großen Anteil an den gesamten auftretenden Kräften hat, um eine Heterodimerisierung zu bevorzugen (IRVIN et al., 1996). Das Schema der Interaktion ist für jeweils eine Windung der Helix in Abb. 4.55 A dargestellt. Bei den eingesetzten Varianten folgen fünf solcher Windungen aufeinander. Bei der Charakterisierung der Bindungseigenschaften ermittelte man eine Dissoziationskonstante zwischen 0,3 und 1,3 nM mit einer hohen Bindungsrate und einer niedrigen Dissoziationsrate (TRIPET et al., 1996). Die beiden Helices können sich sowohl in paralleler als auch in antiparalleler Anordnung anlagern, wobei die parallele Anordnung eine leichte Präferenz hat (IRvIN et al., 1996). Zusätzlich folgt den beiden Helices im Abstand von drei Aminosäuren ein Cystein. Bei der Ausbildung des parallelen Heterodimers werden diese beiden Cysteine in räumlicher Nähe zueinander positioniert und können zu einem Cystin oxidiert werden. Um das E-Coil auf der Zelloberfläche zu exponieren, wird eine Fusion an das Intimin' Protein erzeugt, die zusätzlich noch die kodierende Sequenz des E-Tag-Epitopes trägt. Durch Markierung der Bakterienzellen, die dieses Fusionsprotein synthetisieren, mit Anti-E-Tag Antikörper kann eine Oberflächenexposition nachgewiesen werden. Das Passagierprotein hingegen wird mit dem K-Coil und dem Sendai-Epitop fusioniert. Die einzelnen Funktionseinheiten der Fusionsproteine sind durch kurze Abschnitte von mehreren Aminosäuren, den sogenannten Spacern, voneinander getrennt. In Abb. 4.55 B sind die Sequenzkontexte, in denen sich E-Coil und K-Coil befinden, dargestellt. Abb. 4.55 C zeigt, wie sich die Fusionsproteine im Verhältnis zur Bakterienzelle anordnen. Da das auf der Bakterienzelle befindliche E-Coil, das an einen Köder erinnert, dem Fangen der Beute, dem KCoil Fusionsprotein, dient, wurden von A. Wentzel die Begriffe BAIT und PREY für die beiden Proteine geprägt. 
A intermolekulare elektrostatische Wechselwirkungen

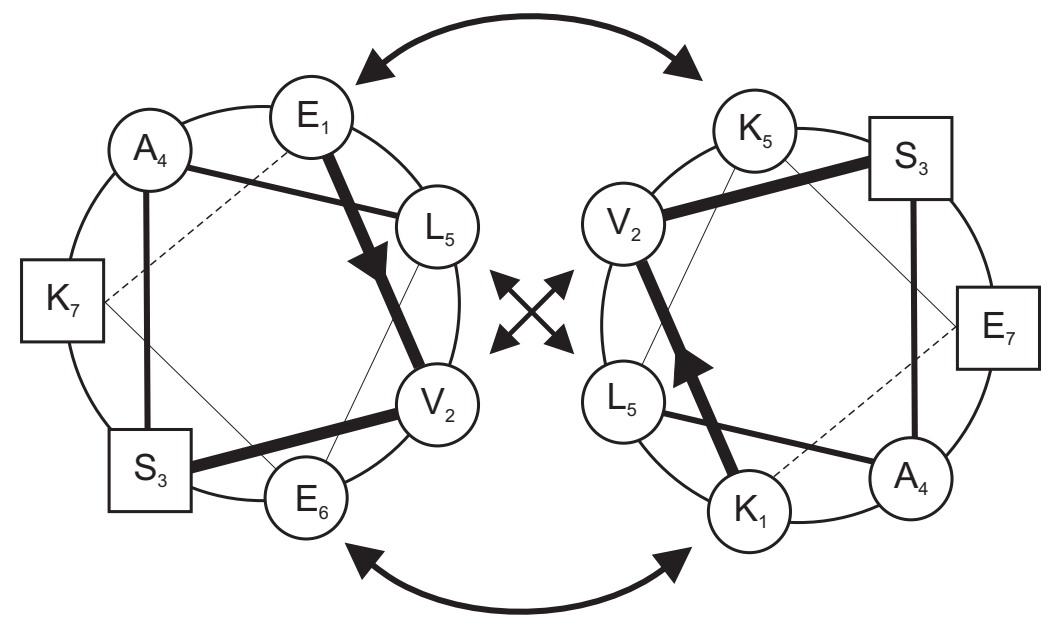

B

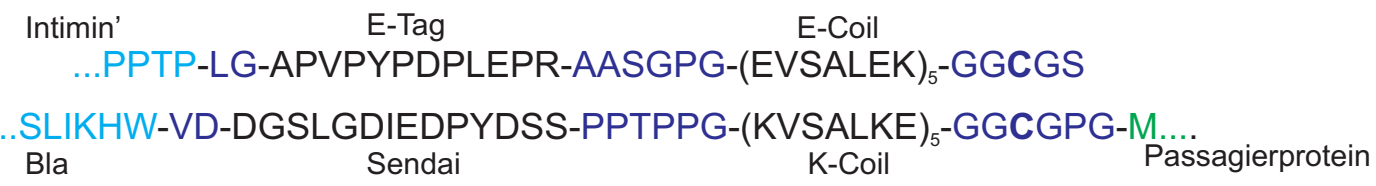

C

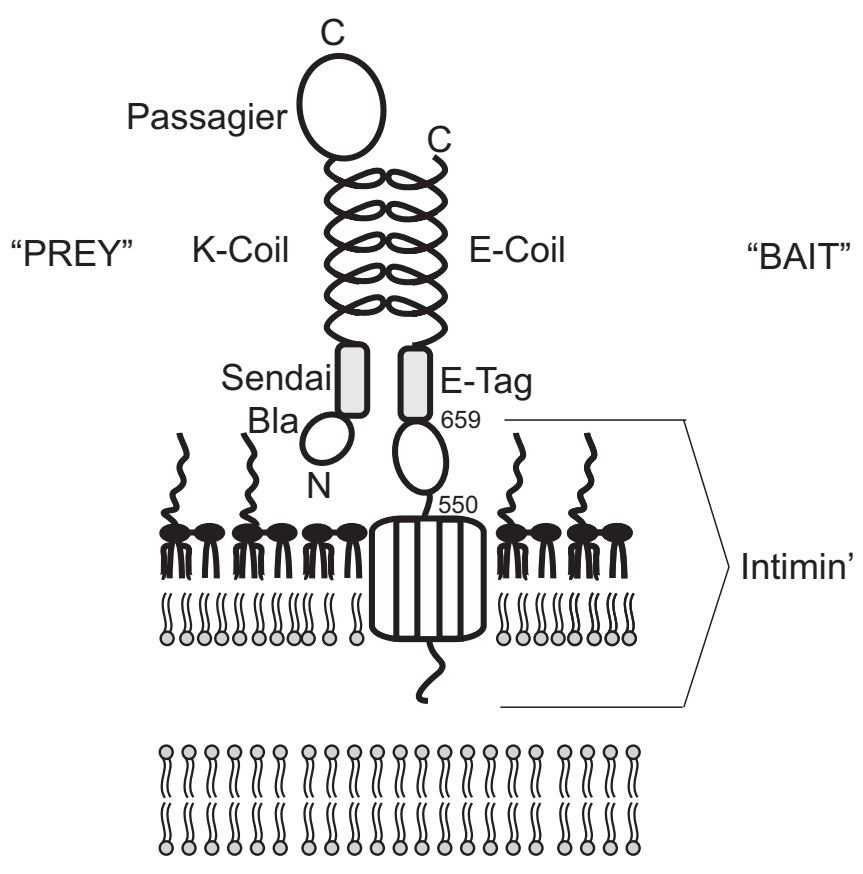

Abb. 4.55 (A) Die Interaktion innerhalb des synthetischen Heterodimers aus E-Coil (links) und K-Coil (rechts) beruht auf der elektrostatischen Anziehung zwischen den Lysin- und Glutamat-Resten (geschwungene Pfeile) sowie auf den hydrophoben Interaktionen zwischen den Leucin- und Valin-Resten (überkreuzter Doppelpfeil). Dargestellt ist jeweils eine Windung der Helix, die unterschiedlichen Stärken der Verbindungslinien sollen die räumliche Ausdehnung der Helix visualisieren. Abbildung modifiziert nach IRviN et al., 1996. (B) Sequenzkontext der Intimin'-E-Tag-E-Coil (oben) und Bla-Send-K-Coil-Passagier Fusionsproteine (unten). Die Lage der beiden Epitope sowie der Sequenzen von E-Coil und K-Coil sind angegeben. In blau dargestellt sind die Spacer-Regionen. Das grün hervorgehobene M stellt das die erste Aminosäure des Passagierproteins dar. (C) Schema der Interaktion des Membranankers mit dem löslichen Protein über die Wechselwirkung zwischen KCoil und E-Coil. 
Das Intimin'-E-Coil Fusionsprotein sowie das lösliche PREY-Protein werden von den beiden Plasmiden pBAIT und pPREY kodiert, die von A. Wentzel konstruiert worden sind und im folgenden beschrieben werden sollen. Die Verwendung von zwei Plasmiden liegt nahe, da pPREY je nach gewünschtem Passagierprotein variabel sein muß, während das Plasmid pBAIT, welches für das Intimin-E-Coil-Fusionsprotein kodiert, in jedem Experiment identisch sein kann.

Als Vektorgrundgerüst von pBAIT (Abb. 4.56 A) dient das Low-Copy-Plasmid pTH19ks5 (Наsнimото-Gотон et al., 2000). Dieses Plasmid besitzt eine Variante des Replikationsursprungs pSC101, bei dem ein Basenaustausch $\mathrm{zu}$ einer erhöhten Temperatursensitivität führte. Die Vermehrung und Segregation des Plasmids erfordert eine Inkubationstemperatur von maximal $30^{\circ} \mathrm{C}$. Das intimin'-e-tag-e-coil-Gen steht unter der Kontrolle des Tetrazyklinpromotors (SKERRA, 1994). Weiterhin befindet sich auf dem Plasmid noch das Gen $11 p$, das unter der Kontrolle seines eigenen Promotors steht. Das Gen für den Lac-Repressor befindet sich ebenfalls auf dem Plasmid und dient der Repression des PREYFusionsproteins auf dem anderen Plasmid, pPREY. Die Anwesenheit des Plasmids vermittelt eine Resistenz gegen das Antibiotikum Kanamycin.

pPREY (Abb. 4.56 B) ist ein Derivat des High-Copy-Plasmids pHKREI (Kolmar et al., 1992) mit einem Lac-Promotor zur Kontrolle der Expression des Gens, welches für das Fusionsprotein aus löslicher $\beta$-Laktamase mit Signalsequenz für die periplasmatische Lokalisation, Sendai-Epitop, K-Coil und dem entsprechenden Passagierprotein kodiert. Das Plasmid besitzt einen ColE1 Replikationsursprung und das Gen für die ChloramphenicolAcetyltransferase, das den Bakterien, welche dieses Plasmid tragen, eine Resistenz gegen Chloramphenicol verleiht. Weiterhin ist auf diesem Plasmid noch das Gen für den TetRepressor lokalisiert, welcher sich an den tet-Operator auf dem Plasmid pBAIT anlagern kann. Als Stamm für die heterologe Expression des Passagierproteins kam 71-18mutS zum Einsatz. Dieser Stamm verfügt über eine Tetrazyklinresistenz und ermöglicht daher die Verwendung von Tetrazyklin als Induktor, welches stabiler als Anhydrotetrazyklin und daher für die Verwendung bei längeren Induktionsszeiten, wie sie bei diesem Experiment auftreten, besser geeignet ist. 
A

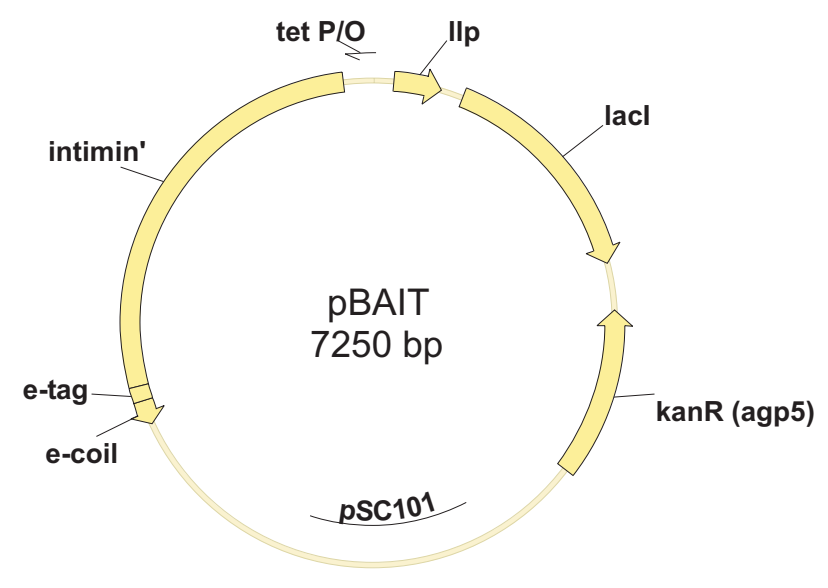

B

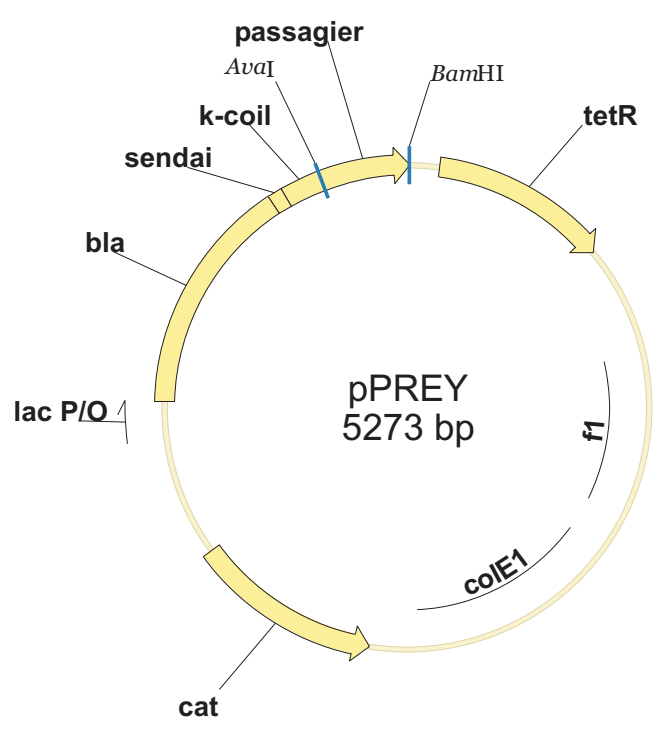

Abb. 4.56: Schematische Darstellung der beiden Plasmide pBAIT und pPREY. (A) Die genetischen Elemente auf pBAIT: intimin', verkürztes Intimin aus EHEC O157:H7 von Codon 1 bis 659; e-tag, E-tag-Epitop kodierende Sequenz; e-coil: kodierende Sequenz für die synthetische $\alpha$-Helix E-Coil; pSC101: Replikationsursprung; kanR(agp5): Kanamycin-Resistenzmarker; lacI: Gen des Lac-Repressors; Ilp: kodierende Region für Braun'sches Lipoprotein, TetP/O: Tetrazyklin-Promotor/Operator Sequenz. (B) Die genetischen Elemente auf pPREY: cat, Chloramphenicol Acetyl Transferase-Gen; colE1, ColE1 Replikationsursprung; f1: Replikationsursprung des filamentösen Phagen f1; tetR, Gen, das für den Tetrazyklin Repressor kodiert; bla: kodierende Region der $\beta$-Laktamase, sendai, 13-Aminosäuren langes Epitop des Sendai-Virus-L-Proteins; $k$-coil: kodierende Sequenz für die synthetische $\alpha$-Helix K-Coil; passagier: Gen des Passagierproteins.

\subsection{Lyse der Zellen, Wachstum in Mikrokompartimenten}

Für die Freisetzung des löslichen Proteins aus den Zellen ist die Auflösung eines Teil der klonalen Population notwendig, wobei die Anzahl an verbleibenden intakten Zellen hoch genug sein muß, um eine spätere Selektion durchführen zu können. Das lösliche, auf der Oberfläche zu verankernde Protein wird an $\beta$-Laktamase als Trägerprotein fusioniert. Da die $\beta$-Laktamase über eine periplasmatische Signalsequenz verfügt, wäre es ausreichend, die äußere Membran der Zellen soweit zu perforieren, daß das lösliche Protein ins Medium freigesetzt werden kann.

Eine teilweise Lyse der Zellen soll durch die Synthese des Proteins Llp, das den Zellen eine Resistenz gegenüber einer Infektion durch den Phagen T5 verleiht (BRAUN et al., 1994), erreicht werden. Llp ist ein im phagengenom kodiertes Protein, daß sich in die äußere Membran der Bakterienzellen integriert und dort den bakteriellen Phagenrezeptor FhuA inaktiviert und somit eine multiple Infektion der Zelle verhindert (DECKER et al., 1994). Vormals war der Gedanke, Ilp von einem temperatursensitiven Plasmid aus zu exprimieren und die Zellen, die nach Erhöhung der Temperatur in den weiteren Teilungen das Plasmid verloren hatten, durch Zugabe des Phagen T5 zu lysieren, während die ursprünglichen Zellen, die das Plasmid noch trugen, gegen die Infektion resistent waren. Es zeigte sich dann aber in Versuchen von A. Wentzel, daß alleine die bakterielle Produktion von Llp im Verbund mit 
dem Intimin'-E-Tag-E-Coil und dem löslichen Fusionsprotein bestehend aus dem Trägerprotein Bla, K-Coil und dem Passagierprotein schon ausreichend war, um eine teilweise Lyse der Zellen zu erzielen. Möglicherweise kommt es durch die Überexpression von Ilp zu einer Destabilisierung der äußeren Membran und durch die daraus resultierende Permeabilisierung derselben zu einer Freisetzung des löslichen Passagierproteins. Auch die Einlagerung von des Intimin'-Fusionsproteins in die äußere Membran könnte einen Teil zur deren Destabilisierung beitragen.

Während des Wachstums der Zellen muß die Integrität eines Klones innerhalb einer Population sichergestellt sein, das heißt, daß ein individuelles Passagierprotein nur auf den Zellen fixiert wird, die die genetische Information $\mathrm{zu}$ seiner Herstellung beinhalten. Kreuzinteraktionen zwischen verschiedenen Klonen innerhalb der Population müssen möglichst gering gehalten werden. Dies erreicht man durch eine räumliche Trennung der einzelnen Zellen voneinander. Hierzu werden die Zellen in Kompartimente eingeschlossen, in denen sie sich multiplizieren können. Die Kompartimente müssen dergestalt sein, daß sie inpermeabel für Moleküle der Größe des PREY-Fusionsproteins sind. Eine Möglichkeit der Kompartimentalisierung wäre der Einsatz von Mikrotiterplatten, ein Verfahren, daß in der Pharmaindustrie Anwendung findet. Ohne Automatisierung lassen sich große Zellzahlen in Mikrotiterplatten jedoch nicht handhaben, da die Anzahl der notwendigen Platten zu groß wäre. Bei einem Repertoire von $10^{7}$ individuellen Klonen wären bei einer zehnfachen Abdeckung der Klone über Zweihunderttausend Mikrotiterplatten mit 384 Kavitäten notwendig. Auch der Platz für die Inkubation einer solchen Anzahl der Platten ist im realen Laborbetrieb nicht bereitzustellen. Eine weitere Möglichkeit wäre, Agarplatten mit Bakterien in einer solchen Dichte zu inokulieren, daß ein individuelles Zellwachstum möglich wäre, und die Zellen nach der Inkubation von den Agarplatten abzulösen. In diesem Fall erfolgte die Kompartimentalisierung durch Beschränkung des Diffusionsweges der löslichen Proteine. Bei einer Dichte von 100 Kolonien $/ \mathrm{cm}^{2}$ bräuchte man eine Fläche von $10 \mathrm{~m}^{2}$, um alle individuellen Klone eines Repertoires mit $10^{7}$ zehnmal abzubilden. Auch dies würde sich im Laboralltag als unpraktikabel erweisen.

Eine weitere Möglichkeit ist das Einschließen von individuellen Bakterienzellen in Mikrosphären aus einem semipermeablen Material und Inkubation der Mikrokompartimente in Nährmedium. Diese Mikrosphären müssen mehrere Anforderungen erfüllen. Sie müssen permeabel für die Nährstoffe, aber undurchlässig für die löslichen PREY-Proteine sein. Die Außenhülle der Mikrosphären sollte so rigide sein, daß sie den während der Inkubation auftretenden mechanischen Belastungen widerstehen kann, während das Innere einer Teilung der Zellen nicht entgegenwirken darf. Ferner müssen sie unter Bedingungen herstellbar sein, die mit einem Überleben der Bakterienzellen in Einklang stehen und nach Ende der Inkubationsphase auch wieder auflösbar sein. Alle diese Anforderung erfüllen Mikrosphären, die aus dem Biopolymer Alginat hergestellt sind. Alginat ist ein natürliches Polysaccharid, das aus Algen extrahiert wird und aus den beiden Untereinheiten $\beta$-D-Mannuronsäure ( $M$ ) und $\alpha$-L-Guluronsäure $(G)$ besteht. Die Monomere sind als Blöcke entlang der Kette angeordnet, wobei sich homopolymere (M- oder G-Blöcke) mit heteropolymeren Blöcken (MG-Blöcke) abwechseln (SMIDSRøD und HAUG, 1972). Die Zusammensetzung und Sequenz der Alginate ist sehr variabel und hängt von dem Organismus und dem Gewebe, aus dem sie gewonnen 
wurden, ab (SMIDSRøD und SKJAK-BRAEK, 1990). Die Blockstruktur und Zusammensetzung des Alginats bestimmen seine funktionellen Eigenschaften. Alginate haben normalerweise keine sich regelmäßig wiederholende Sequenz und werden durch die Frequenz der verschiedenen möglichen Dimere und Trimere, die sich spektroskopisch bestimmen läßt, charakterisiert. Mit einer Carboxylatfunktion in jeder M oder G Untereinheit ist das Polymer stark negativ geladen. Eine intermolekulare Quervernetzung kann durch Bindung von divalenten Kationen wie $\mathrm{Ca}^{2+}, \mathrm{Zn}^{2+}$ und $\mathrm{Cu}^{2+}$ erfolgen. Die der KationenBindungseigenschaften des Alginats sind von seiner Zusammensetzung abhängig. Die Bindung erfolgt präferentiell an G-Blöcke. Die diaxial verbundenen G-Untereinheiten bilden Kavitäten, die als Bindestellen für die Kationen fungieren (Abb. 4.57 A). Bindungen bilden sich zwischen solchen Stellen auf dem selben und auch auf dem benachbarten Molekül aus, so daß Überkreuzungsregionen in dem Gelnetzwerk entstehen können (SMIDSRøD und SKJAKBRAEK, 1990). Diese durch Kationen vermittelte Bindung von G-Blöcken aneinander wird in der Literatur übereinstimmend als Eierschachtel-Modell bezeichnet und ist in Abb. 4.57 B schematisch dargestellt. In diesem Modell entsprechen die Kavitäten in den G-Blöcken den einzelnen Vertiefungen in der Eierschachtel, während die Kalziumionen die Eier darstellen sollen. Die Länge von G-Blöcken ist somit der bestimmende Faktor für die Stabilität der Alginatgele.

A

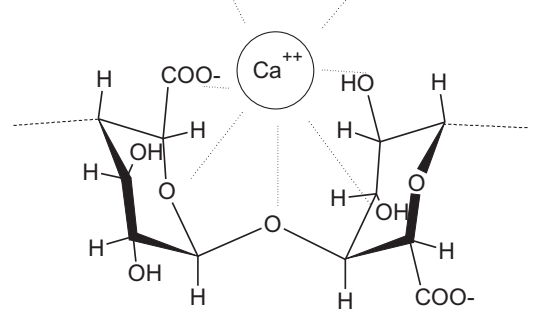

B

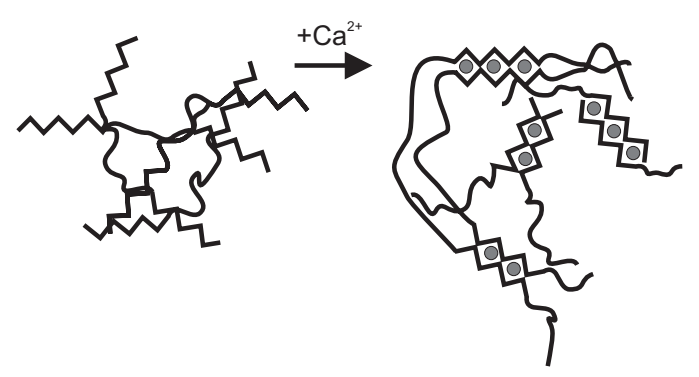

Abb. 4.57: (A) GG-Einheit des Alginatpolymers mit gebundenem $\mathrm{Ca}^{2+}$-Atom. Das $\mathrm{Ca}^{2+}$ bildet elektrostatische Wechselwirkungen mit benachbarten GG-Untereinheiten aus. (B) „Eierschachtel“-Modell der Gelierung des Alginats. Kalziumionen (graue Kreise) lagern sich an die GG-Blöcke der Polymerase an und bewirken die Ausbildung lokaler Überkreuzungsregion in der Matrix. Abbildung modifiziert nach (SMIDSRøD und SKJAKBRAEK, 1990).

Alginat wird häufig als Matrix-Polymer für die Mikroverkapselung von Pharmazeutika, Proteinen, DNA und Zellen eingesetzt (CHAN et al., 1997; FUNDUEANU et al., 1998; WAN et al., 1993;1994; WeE und GOMвOTZ, 1998). Es gibt zwei verschiedene Verfahren, um AlginatMikrosphären herzustellen. Zum einen kann eine Alginatlösung in Kalzium durch eine oszillierende Düse eingetropft werden. Zum anderen lassen sich die Mikrokompartimente durch eine Emulgationstechnik herstellen (HENG et al., 2003). Hierzu wird die wäßrige Alginatlösung, die die einzuschließende Probe bereits enthält, in einer organischen Phase verteilt, so daß eine Wasser-in-Öl Emulsion entsteht. Durch Zugabe von Detergenzien wird die Bildung einer Emulsion erleichtert. Anschließend wird eine Kalziumchloridlösung ebenfalls in die organische Phase gegeben, wobei es zur Bildung einer Koemulsion kommt. Wenn ein Alginattröpfchen mit einem Tröpfchen, daß Kalziumchlorid enthält, kollidiert, 
kommt es zur Gelierung des Alginats (Heng et al., 2003). Die in dieser Arbeit eingesetzte organische Phase besteht aus Isooktan mit 3,7 \% (w/w) des Detergenz Sorbitan Trioleat (Span 85). Da die Tröpfchen der wäßrigen Lösung in dieser Emulsion sehr unstabil sind nach kurzer Zeit wieder mit den benachbarten Tröpfchen fusionieren, wird der Emulsion noch ein zweites Detergenz, Polyoxyethylen-20-Sorbitan-Trioleat (Tween 85) zugegeben. Diese Zugabe bewirkt die Anlagerung des Tensids an der Oberfläche der Alginattröpfchen und damit eine Stabilisierung derselben.

Um eine Emulsion von Alginattröpfchen in einer organischen Phase zu erzeugen, muß mechanische Energie zugeführt werden, da die Bildung der Emulsion thermodynamisch ungünstig ist und die Alginattröpfchen dazu neigen, sich wieder zu vereinigen. Diese Energiezufuhr wird durch das Rühren des Ansatzes mit einem automatischen Rührgerät bewerkstelligt. Dieses Rührgerät wurde vom Autor dieser Arbeit selber konstruiert und bestand aus einem carbonfaserverstärktem zweiblätterigem Hydropropeller, welcher normalerweise zum Antrieb von Modellrennbooten eingesetzt wird. Den Antrieb bildete ein Elektromotor, dessen Geschwindigkeit stufenlos zwischen 170 und 1700 UPM eingeregelt werden konnte. Die Verbindung des Motors und des Propellers wurde durch eine gekapselt laufende starre Edelstahlwelle geschaffen, wobei die Welle mit einer Gummimanschette an die Achse des Motors gekoppelt wurde. Die gesamte Einheit wurde mit Hilfe eines konventionellen Laborstativs möglichst torsionsfrei fixiert.

Die Größe der gewonnenen Alginatmikrokompartimenten wird bestimmt durch die Rührgeschwindigkeit und die Beschaffenheit des Rührkopfes, der Viskosität der eingesetzten Alginatlösung und die Konzentration des Kalziumchlorids. Heng et. al produzierten Alginatsphären mit einem Durchmesser von $30 \mu \mathrm{m}$, indem sie eine Emulsion von 2,5 \%iger Alginatlösung in Isooktan/Span 85 und Tween 85 herstellten und die Gelierung des Alginats durch Zugabe von $6 \%$ iger Kalziumchloridlösung initiierten (Heng et al., 2003). Die Konzentration des Polymers ist nicht in allen Teilen der Kugel gleichmäßig. Vielmehr konnte gezeigt werden, daß die Konzentration in einem Gradienten von der Kugeloberfläche in Richtung des Kugelinneren abnimmt. Der Ursprung dieser Inhomogenität ist nicht geklärt, man nimmt aber an, daß es zu einer gleichzeitigen Diffusion der Kalziumionen in Richtung Kugelinneres und einer Diffusion der Polymere in Richtung Kugeläußeres kommt (SMIDSRøD und SKJAK-BRAEK, 1990). Somit entstehen Mikrosphären, die eine Art harte Kruste an ihrem Äußeren aufweisen, während im Inneren eine deutlich niedrige Alginatkonzentration herrscht. Diese Eigenschaften lassen ein Wachstum von Bakterienzellen im Inneren der Mikrosphären zu. Die Alginatmikrokompartimente weisen eine ausreichend hohe mechanische Stabilität auf, die eine Inkubation der Mikrosphären in Flüssigmedium mit der dafür notwendigen Agitation zuläßt. Die Porengröße der Alginatmikrokompartimente ist von dem Gehalt an G-Blöcken abhängig. Je höher deren Gehalt, desto größer auch die Poren in den Mikrokompartimenten. Bei Alginaten mit sehr hohem Gehalt an G-Blöcken können Moleküle mit einem relativen Molekulargewicht von maximal 30000 durch die Poren diffundieren (SMIDSRøD und SKJAK-BRAEK, 1990). Das in dieser Arbeit verwendete PREYFusionsprotein hat aber schon ohne den anfusionierten Passagier ein Molekulargewicht von 36000 und kann daher nur sehr langsam, wenn überhaupt, aus den Alginatmikrosphären heraus diffundieren. Die Mikrosphären sind in Anwesenheit von kalziumchelatierenden 
Agenzien, zu denen auch Phosphat und Citrat gehören, nicht stabil. Auch die Anwesenheit von Natriumionen kann zu der Auflösung des Gels führen, da sich diese an die Polysaccharidmoleküle anlagen und das gebundene Kalzium verdrängen können. Eine relativ einfache Möglichkeit, die Auflösung des Gels während der Inkubationsphase zu verhindern ist, das Medium mit Kalzium zu supplementieren (SMIDSRøD und SKJAK-BRAEK, 1990). Nach dem Ende der Inkubation ist die Auflösung der Mikrosphären aber gewünscht, um die Zellen daraus freizusetzen. Eine Markierung der Zellen innerhalb der Mikrosphären nicht möglich ist, da die Komponenten der Markierungskaskade nicht in die Mikrosphären hinein diffundieren können. Das Auflösen der Mikrosphären kann durch Inkubation in $20 \mathrm{mM}$ EDTA oder EGTA bewerkstelligt werden. Nach dem Auflösen der Zellen stehen diese für eine Interaktionsanalyse zur Verfügung.

\subsubsection{Untersuchung der Bindung von PcrG an PcrV als Modellexperiment}

Die prinzipielle Verwendbarkeit dieses Oberflächenpräsentationssystems wurde anhand eines Modellexperimentes überprüft. Zu diesem Zweck wurde die Protein-Protein-Interaktion der beiden Proteine PcrV und PcrG aus dem Typ III Sekretionsapparat von Pseudomonas aeruginosa betrachtet. Wie die meisten anderen Gram-negativen pathogenen Bakterien besitzt $P$. aeruginosa einen Typ-III-Sekretionsapparat, um Toxine in das Zytoplasma der Wirtszellen zu injizieren (HUECK, 1998). Ein solcher Apparat benötigt mehr als 20 verschiedene Proteine, die zu einer Sekretionsstrukur assembliert werden, welche beide bakteriellen Membranen überspannt und in einer Nadel endet, durch die die Effektormoleküle injiziert werden (BlOCKER et al., 2001; CORDES et al., 2003). Im Zytoplasma der Zielzelle beeinflussen die Toxine (ExoS, ExoT, ExoY und ExoU) die Integrität der Aktinstruktur und stören die Signaltransduktion, was schließlich mit dem Tod der Zielzelle endet (GoeHRING et al., 1999; SATO et al., 2003; YAHR et al., 1998). Das Protein PcrV spielt eine wesentliche Rolle in einem komplexen Mechanismus zur Regulation der Injektion von Effektormolekülen, wobei es anscheinend sowohl für den Aufbau des Sekretionsapparates in der Bakterienzelle als auch extrazellulär für den Kontakt zur Wirtszelle notwendig ist (CORNELIS, 2000; DACHEUX et al., 2001; SAWA et al., 1999). Am besten charakterisiert ist das PcrV-Homolog LcrV aus Yersinia pestis, dem Organismus, in dem die meisten Untersuchungen dem Typ-III-System durchgeführt worden sind (PetTERsson et al., 1999). Sowohl PcrV als auch LcrV sind protektive Antigene gegen eine Infektion mit ihren entsprechenden pathogenen Organismen (FrANK et al., 2002; Hill et al., 1997; SAWA et al., 1999). Die Transkription von LcrV und PcrV wird bei einer Temperatur von $37^{\circ} \mathrm{C}$ aktiviert. Die Proteine sind für eine Translokation der Effektormoleküle in das Zytoplasma der Wirtszelle notwendig.

In Pseudomonas aeruginosa ist die Situation etwas anders, da dort eine Sekretion der Effektormoleküle auch in einem $\Delta p c r V$-Stamm auftritt (SAWA et al., 1999). Dies deutet darauf hin, daß der Sekretionsmechanismus in Pseudomonas nicht unter der Kontrolle des PcrV:PcrG-Komplexes steht oder das die Regulation dort nicht nach dem selben Muster wie in Yersinia pestis stattfindet. PcrG kann jedoch einen Yersinia $\Delta$ lcrG-Stamm komplementieren und auch mit LcrV interagieren (MATSON und NILLES, 2001; 2002). Durch Affinitäts-Immunoblots konnte eine Interaktion zwischen PcrV und PcrG nachgewiesen 
werden (ALLmOND et al., 2003). Weiterhin konnte gezeigt werden, daß PcrG alleine keine Sekundärstrukturen ausbildet, daß aber die Bindung von PcrV and PcrG die Faltung von PcrG induziert und daß die beiden Proteine einen 1:1 Komplex bilden können. In diesem Komplex besitzen die Proteine eine hohe Affinität zueinander, die Dissoziantionskonstante $\mathrm{k}_{\mathrm{D}}$ hat einen Wert von 15,6 nM (NANAO et al., 2003). Die exakte Funktion von PcrG in Pseudomonas ist bisher nicht bekannt, dennoch eignet sich der PcrV:PcrG-Komplex aufgrund der hohen Affinität der beiden Interaktionspartner zueinander als Modell, um zu untersuchen, ob eine Protein-Protein-Interaktion mit Hilfe des Autolysis-Displays nachweisbar ist. Hierbei soll PcrG auf der Zelloberfläche fixiert werden, während PcrV als lösliches Protein eingesetzt wird. Der Grund für dieses Arrangement war rein praktischer Natur, da lösliches PcrV Protein durch A. Christmann zur Verfügung gestellt werden konnte. Auf den nun folgenden Seiten soll die Klonierung von pPREY-pcrG und die durchgeführten Modellexperimente zum Nachweis einer Protein-Protein-Interaktion beschrieben werden.

\subsection{Klonierung von pPRE-pcrG}

Die kodierende Sequenz von pcrG (Pa1705) wurde durch PCR mit den beiden Oligonukleotiden pPREY-pcrG-up und pPREY-pcrG-up unter Verwendung von genomischer DNA von $P$. aeruginosa PAO1 amplifiziert. Als thermostabile Polymerase wurde die LaTaq Polymerase der Firma TaKaRa eingesetzt. Die für die Klonierung notwendigen Erkennungsstellen für AvaI und BamHI wurden durch die Oligonukleotide eingeführt. Das resultierende PCR Produkt wurde durch Phenol/Chloroform Extraktion (3.2.1.3) und Ethanolpräzipitation gereinigt (3.2.1.1). Das von A. Wentzel zur Verfügung gestellte Akzeptorplasmid pPREY-HisJ wurde mit den Restriktionsendonukleasen AvaI und BamHI geschnitten und das Vektorfragment aus einem Agarosegel gereinigt (3.2.3). Es erfolgte eine Ligation der beiden Fragmente (3.3.3) sowie die Transformation von 71-18 Zellen (3.1.4). Einzelne Transformanten wurden vermehrt und die Plasmide präpariert (3.2.5). Die Identifikation von positiven Klonen erfolgte durch Verdau der Plasmide mit den Restriktionsenzymen NdeI und BglII. Die Sequenz der positiven Klone wurde durch Nukleotidsequenzanalyse verifiziert.

\subsection{Verpackung von Zellen, die pPREY-pcrG und pBAIT enthalten, in Alginatmikrokompartimente}

71-18mutS Zellen wurden mit den beiden Plasmiden pPREY-pcrG und pBAIT transformiert und ein einzelner Klon bei einer Temperatur von $30^{\circ} \mathrm{C}$ in $50 \mathrm{ml}$ dYT mit den entsprechenden Antibiotika inokuliert. Die Zellen wurden wie im Detail in Abschnitt 3.5.7 beschrieben, in Alginatmikrosphären verpackt. Mit einer Suspension von Zellen in Alginatlösung wurde eine Wasser-in-Öl Emulsion in dem organischen Lösungsmittel Isooktan, dem die Detergenzien Tween85 und Span85 zugegeben wurden, hergestellt. Die Alginattröpfchen wurden durch Erzeugung einer Koemulsion mit einer $\mathrm{CaCl}_{2}$-Lösung verfestigt. In Abb. $4.58 \mathrm{~B}$ ist ein lichtmikroskopisches Bild dieser Alginatmikrokompartimente 
gezeigt. Wie $\mathrm{zu}$ erkennen ist, kommt es $\mathrm{zu}$ einer Aggregatbildung, da die Mikrokompartimente durch Kalziumionen vermittelte Quervernetzungen zu benachbarten Mikrokompartimenten ausbilden können. Die Integrität der einzelnen Kompartimente ist dadurch aber nicht beeinträchtigt. Um ein bakterielles Repertoire handhaben zu können, muß die Anzahl der Alginatmikrosphären ausreichend sein. Weiterhin sollten die Mikrokompartimente eine Größe haben, die eine mehrfache Teilung der in ihrem Inneren eingeschlossenen Zelle ermöglicht. Die Anzahl und Größe der Mikrokompartimente läßt sich mit einer Neubauer Zählkammer nicht bestimmen, da in der Phasenkontrasteinstellung des Mikroskops, in der die Mikrosphären sichtbar sind, die in das Glas der Zählkammer geätzten Linien nicht erkennbar sind und umgekehrt. Für eine grobe Abschätzung der Größe ist ein Vergleich mit einem Referenzmaterial einer bekannten Größe hinreichend. Zum Vergleich wurden die kommerziell erhältlichen Mikrokugeln M-PVA SAV3 der Firma Chemagen herangezogen. Die Größenverteilung dieser Kugeln aus Polyvinylalkohol gehorcht der GaußVerteilung, wobei der durchschnittliche Durchmesser der Kugeln $6 \mu \mathrm{m}$ beträgt (Abb. $4.58 \mathrm{~A}$ ). Vergleicht man Abb. 4.58 A mit den Alginatmikrokompartimenten, die in den Abb. 4.58 B-D gezeigt sind, so kann man abschätzen, daß deren Durchmesser zwischen 5 und $15 \mu \mathrm{m}$ beträgt. Das Volumen der Mikrokompartimente beträgt dementsprechend zwischen 500 und $14000 \mu \mathrm{m}^{3}$. Ein Bakterium hat ein Volumen von ca. $1 \mu \mathrm{m}^{3}$ (KUBITSCHEK und FrISKE, 1986), somit bieten die erzeugten Kugeln ausreichend Platz, um die Teilung der Bakterien in ihrem Inneren zu ermöglichen. Die Anzahl der Kugeln läßt sich ebenfalls nur grob abschätzen. Wenn man davon ausgeht, daß die Kugeln ein Volumen zwischen 500 und $14000 \mu \mathrm{m}^{3}$, d.h. zwischen 500 und $14000 \mathrm{fl}$ haben, so liegt die maximale Anzahl an Kugeln, die aus den eingesetzten $8 \mathrm{ml}$ Alginatlösung gewonnen werden kann, zwischen $6 \times 10^{8}$ und 1,6 x $10^{10}$. Die für die Einkapselung eingesetzte Anzahl der Zellen beträgt ca. $8 \times 10^{8}$. Wie man in Abb. $4.58 \mathrm{D}$ erkennen kann, sind ca. $3 / 4$ der Mikrokompartimente mit Bakterien bewachsen. Dies zeigt, daß die Anzahl der produzierten Mikrokompartimente wohl um $10^{9}$ liegt, wenn man davon ausgeht, daß die meisten der eingesetzten Bakterien in ein Mikrokompartiment eingeschlossen worden sind.

Für die Vermehrung der Bakterienzellen wurden die Mikrokompartimente direkt in Flüssigkultur gegeben. Zuerst wurde die Expression des intimin'-e-tag-e-coils induziert, $24 \mathrm{~h}$ später die Expression von bla-send-k-coil-pcrG. Die Alginatmikrosphären und die ebenfalls gewachsenen freien Bakterien wurden pelletiert. Abbildung $4.58 \mathrm{C}$ zeigt die Mikrokompartimente nach dem Wachstum der Bakterien. Wie man aus der Abbildung entnehmen kann, ist die Anzahl der Zellen, die sich außerhalb der Mikrokompartimente vermehrt haben, sehr hoch. Zwar wurde in diesem Modellexperiment nur ein Klon eingesetzt, doch soll dieses Verfahren später dazu dienen, einzelne Varianten aus vielfältigen Repertoires von Zellen zu isolieren. Die Genotyp-Phänotyp-Kopplung ist nur für diejenigen Bakterien gewährleistet, die im Inneren der Mikrokompartimente gewachsen sind, da in jeder Kugel anfangs nicht mehr als ein Bakterium enthalten sein sollte. Die Zellen, die außerhalb der Mikrokompartimente gewachsen sind, können jedoch das Passagierprotein auch von lysierten Bakterien eines anderen Genotyps erhalten haben und sollten somit vor einer Durchmusterung des Repertoires entfernt werden. Hierzu wurde die Suspension aus Bakterien und Alginatmikrokompartimenten auf ein Kissen von $20 \%$ igen (w/v) Ficoll400 
geschichtet und zentrifugiert (Abschnitt 3.5.7). Da die Mikrokompartimente eine etwas höhere Dichte als die Zellen aufwiesen, pelletierten diese schneller und konnten somit von den freien Bakterien zwar nicht quantitativ abgetrennt werden, doch konnte die Anzahl der freien Bakterien drastisch reduziert werden. In Abb. 4.58 D ist die Suspension der Zellen und Alginatmikrokompartimente gezeigt. Im Vergleich zu Abb. $4.58 \mathrm{C}$ ist zu erkennen, daß die Anzahl der freien Bakterien nach der Ficoll-Zentrifugation deutlich geringer ist.
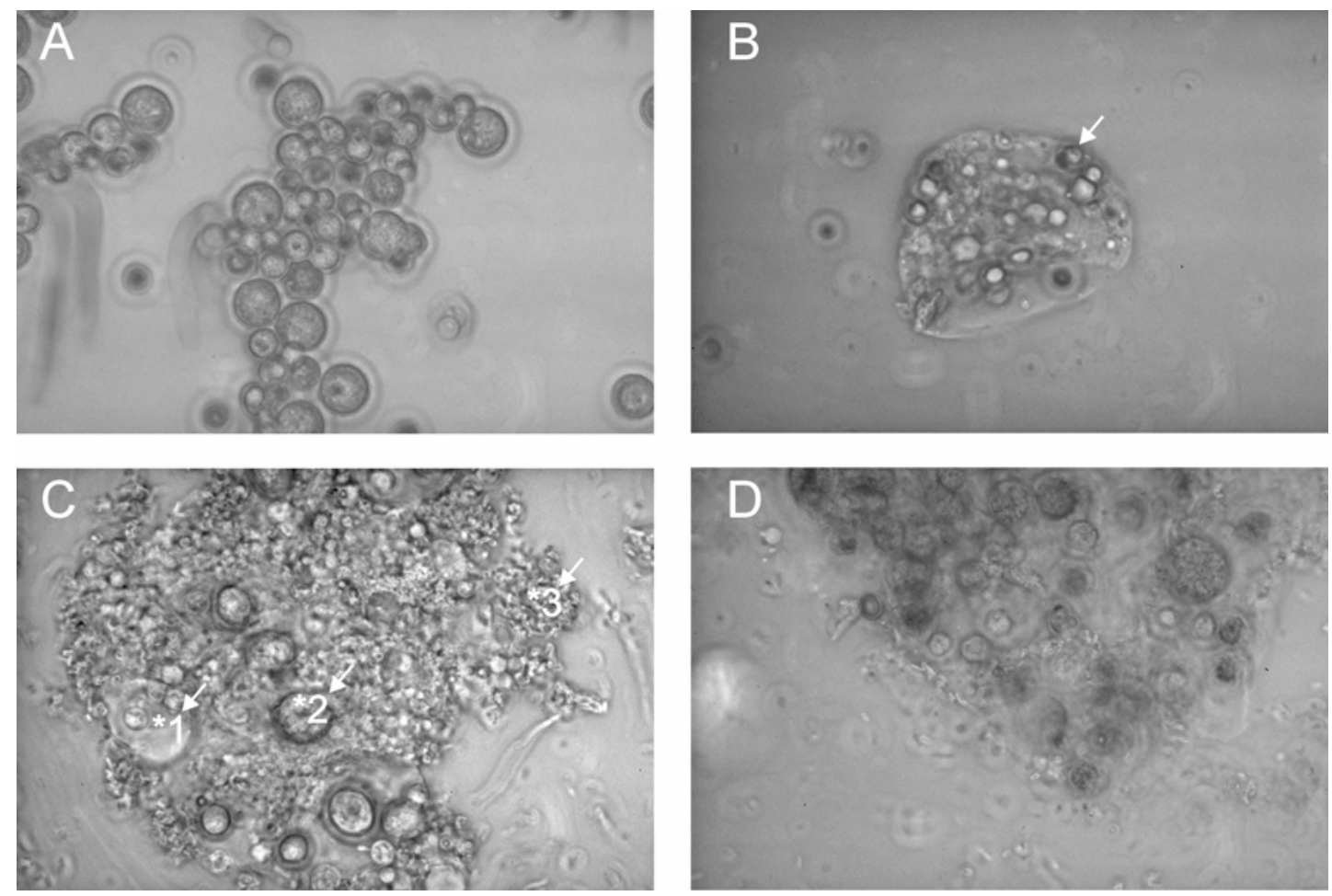

Abb. 4.58: Phasenkontrast-Mikroskopische Aufnahmen (1000-fache Vergrößerung): (A) Als Größenreferenz verwendete M-PVA SAV3 Polyvinylkugeln der Firma Chemagen mit einem mittleren Durchmesser von $6 \mu$ m. (B) Mikrokompartimente aus Alginat, direkt nach der Herstellung. Der Pfeil weist auf ein einzelnes Mikrokompartiment. (C) Alginatmikrokompartimente nach zweitägiger Inkubation. Zu erkennen sind leere Mikrosphären $\left({ }^{*} 1\right)$ sowie mit Bakterien bewachsene $\left({ }^{\star} 2\right)$, die im Durchlicht dunkler und granulös erscheinen. Weiterhin ist eine große Anzahl freier Bakterien ( ${ }^{\star} 3$ ) zu erkennen. (D) Mikrokompartimente aus demselben Ansatz wie C, nach der Abtrennung von freien Bakterien durch eine Zentrifugation in Ficoll.

\subsection{Untersuchung der Bindung von oberflächenständigem PcrG und löslichem PcrV}

Bevor eine Interaktion von pcrG und pcrV untersucht werden konnte, mußten die Alginatmikrokompartimente aufgelöst werden. Um die Bakterien aus den Mikrokompartimenten zu befreien, wurden die Alginatmikrosphären mit EDTA inkubiert (Abschnitt 3.5.7). Anschließend erfolgte eine Fluoreszenzmarkierung der Zellen mit dem Anti-E-Tag Antikörper (Abschnitt 3.5.3) und eine Analyse der Zellen mittels FACS (Abschnitt 3.5.4). Das FACS-Diagramm ist in Abb. 4.59 gezeigt. Wie man erkennen kann, 
lassen sich die Zellen mit dem E-Tag Antikörper markieren. Dies deutet darauf hin, daß das Intimin' in die äußere Membran integriert ist und der E-Tag und E-Coil in das extrazelluläre Milieu weisen. Um eine Interaktion zwischen PcrV und PcrG nachweisen zu können, wurden die Zellen mit $1 \mu \mathrm{M}$ löslichem, biotinyliertem PcrV (ca. $4 \mathrm{Mol}$ Biotin/Mol PcrV) und anschließend mit Streptavidin, R-Phycoerythrin-Konjugat inkubiert und die Fluoreszenz mittels FACS vermessen (Abschnitt 3.5.4). Als Kontrolle wurden induzierte 71-18mutS Zellen, die nur das Plasmid pBAIT trugen, ebenfalls mit biotinyliertem PcrV und Streptavidin, R-Phycoerythrin Konjugat inkubiert und im FACS analysiert.

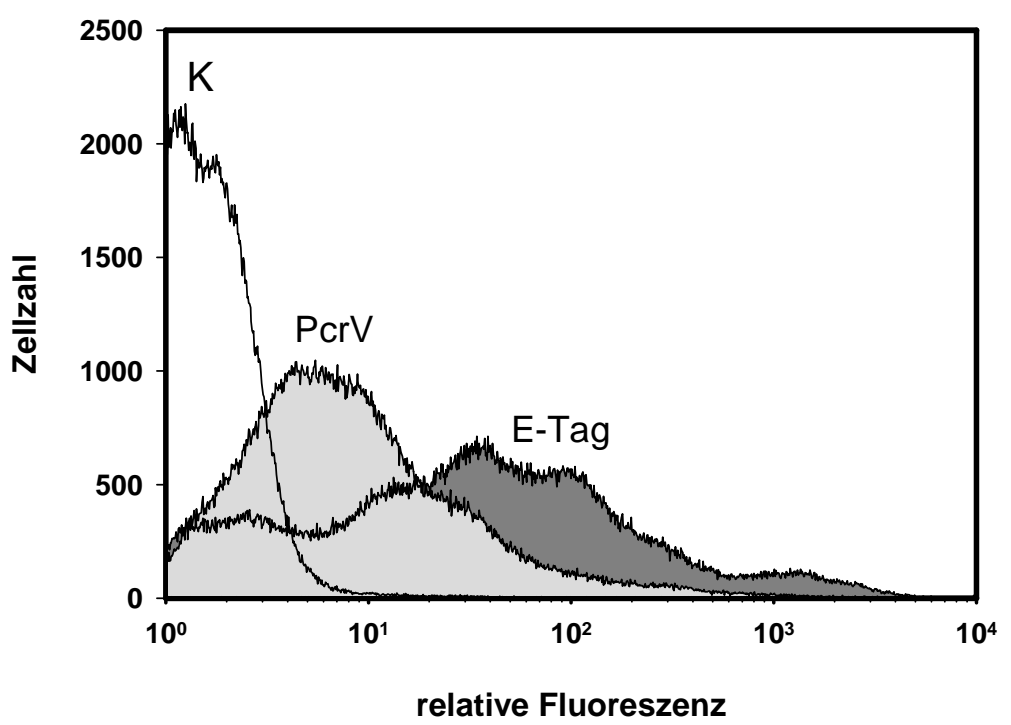

Abb. 4.59: FACS Analyse von induzierten 71-18mutS Zellen: (K) mit dem Plasmid pBAIT, markiert mit biotinyliertem PcrV. (PcrV): mit den Plasmiden pBAIT und pPREY-pcrG, markiert mit biotinyliertem PcrV und Streptavidin, R-Phycoerythrin Konjugat. (E-Tag): mit den Plasmiden pBAIT und pPREY-pcrG, markiert mit Anti-E-Tag Antikörper.

Wie aus dem FACS-Histogramm ersichtlich ist, erfolgt eine Markierung der Zellen, die das lösliche Protein aus Bla-Send-K-Coil-PcrG exprimierten, mit dem biotinylierten PcrV Protein. Da als Kontrolle Zellen eingesetzt wurden, die ebenfalls das Plasmid pBAIT, nicht aber pBAIT-pcrG besaßen, kann man davon ausgehen, daß die Bindung von PcrV aufgrund der Oberflächenlokalisation von PcrG stattgefunden hat.

\subsubsection{Konklusion}

Das Autolysis-Display Verfahren eignet sich für die Untersuchung von Protein-ProteinWechselwirkungen. Anhand eines Modellexperimentes konnte eine Bindung von löslichem PcrV an oberflächenständiges PcrG demonstriert werden. Dieses Verfahren eignet sich ebenfalls zur Präsentation von zytoplasmatischen Proteinen auf der Zelloberfläche. So konnte gezeigt werden, daß das zytoplasmatisch lokalisierte Protein HisF aus Thermotoga maritima mit Hilfe des ALD auf der Zelloberfläche von E. coli präsentiert werden konnte (A. Wentzel, persönliche Kommunikation). Dieses System ist prinzipiell auch geeignet, Homomultimere zu 
präsentieren, falls eine Multimerisierung die Bindung von K-Coil an E-Coil nicht unterbindet. Um eine Eignung des Verfahrens für die Analyse von proteomweiten Protein-ProteinWechselwirkungen $\mathrm{zu}$ untersuchen, wäre die Durchführung eines Modellexperimentes angeraten, bei dem ein spezifischer Interaktionspartner eines definierten löslichen Proteins aus einer großen Überzahl von Klonen, die nicht zur Synthese dieses Interaktionspartners befähigt sind, isoliert wird. 


\section{Zusammenfassung}

In der vorliegenden Arbeit wurden drei ausgewählte potentielle Pathogenitätsfaktoren aus dem opportunistischen Pathogen Pseudomonas aeruginosa biochemisch und funktionell charakterisiert. Die $P$. aeruginosa Mutante 41D3 trägt eine Transposonintegration in dem Gen Pa5349, welches für eine Rubredoxin Reduktase kodiert. Diese Mutante zeigt eine erhöhte Sensitivität gegenüber reaktiven Sauerstoffspezies. Pa5349 konnte eine Funktion in einer Elektronentransportkette zugewiesen werden, welche eine zentrale Rolle in der Reduktion von Superoxidradikalen spielt. Weiterhin konnten erstmals Hinweise auf die Anwesenheit einer Superoxid-Reduktase in Pseudomonas aeruginosa gewonnen werden, einer Klasse von Enzymen, die bisher nur aus anaeroben und mikroaerophilen Mikroorganismen bekannt sind. Eine weitere Mutante trug eine Transposonintegration in dem Gen Pa0740 und war nicht mehr in der Lage, die im Medium befindliche Menge des Quorum Sensing Botenstoffes Acyl-Homoserinlacton (AHL) zu reduzieren. Das Protein Pa0740 wurde im Hinblick auf eine AHL-abbauende Aktivität untersucht, die allerdings nicht nachgewiesen werden konnte. Für das Protein Pa1572, das als konserviertes Protein mit unbekannter Funktion annotiert ist und über eine konservierte Domäne mit hoher Ähnlichkeit zu Proteinen der Familie der ATP-NAD-Kinasen verfügt, konnte gezeigt werden, daß es sich bei diesem Protein um eine NADPH-abhängige Oxidoreduktase handelt, deren Akzeptor in der Zelle bisher noch unbekannt ist.

Des weiteren wurden Verfahren aufgezeigt, die es ermöglichen sollten, durch proteomweite Untersuchung der Wechselwirkungen der Proteine des Erregers untereinander, ausgewählte Pathogenitätsfaktoren in das komplexe Geschehen der Infektion funktionell einzuordnen. Hierzu wurden Möglichkeiten und Grenzen aufgezeigt, Proteine zur Untersuchung ihrer Wechselwirkungen mit Partnern via Fusion an das Intiminprotein der äußeren Membran auf der Oberfläche von E. coli Zellen zu präsentieren. Es konnte gezeigt werden, daß eine Zelloberflächenexposition eine Translokation des jeweiligen Passagierproteins durch die äußere Membran in einem ungefalteten Zustand voraussetzt. Um auch solche Proteine, deren zytoplasmatische oder periplasmatische Faltung einem Export entgegensteht, einer Oberflächenexposition zugänglich $\mathrm{zu}$ machen, wurde ein neues Verfahren entwickelt, welches auf der Freisetzung des Passagierproteins durch Teillyse einer klonalen Bakterienpopulation beruht. Mit dem Nachweis der Interaktion des P. aeruginosa Proteinpaars PcrV/PcrG wurde der Grundstein für den Einsatz dieses Verfahrens für die proteomweite Durchmusterung von Protein-Protein-Interaktionen pathogener Mikroorgansimen gegeben. 


\section{Literatur}

1. Adair, F.W., Geftic, S.G. und Gelzer, J., Resistance of Pseudomonas to quaternary ammonium compounds. I. Growth in benzalkonium chloride solution. Appl Microbiol, 1969. 18(3): S. 299-302.

2. Adams, T.M., Schmoldt, H.U. und Kolmar, H., FACS Screening of Combinatorial Peptide and Protein Libraries Displayed on the Surface of Escherichia coli Cells, in Evolutionary Methods in Biotechnology: Clever Tricks for Directed Evolution, S. Brakmann und A. Schwienhorst, Editoren. 2004, Wiley VCH, Weinheim.

3. Adams, T.M., Wentzel, A. und Kolmar, H., Intimin-mediated export of passenger proteins requires maintenance of a translocation-competent conformation. J Bacteriol, 2005 (im Druck). 187(2).

4. Adu-Bobie, J., Frankel, G., Bain, C., Goncalves, A.G., Trabulsi, L.R., Douce, G., Knutton, S. und Dougan, G. ,Detection of intimins $\alpha, \beta, \gamma$, and $\delta$, four intimin derivatives expressed by attaching and effacing microbial pathogens. JClin Microbiol, 1998. 36(3): S. 662-8.

5. Afanassiev, V., Hanemann, V. und Wolfl, S., Preparation of DNA and protein micro arrays on glass slides coated with an agarose film. Nucleic Acids Res, 2000. 28(12): S. E66.

6. Akiyama, Y., Kamitani, S., Kusukawa, N. und Ito, K., In vitro catalysis of oxidative folding of disulfide-bonded proteins by the Escherichia coli $d s b A$ (ppfA) gene product. J Biol Chem, 1992. 267(31): S. 22440-5.

7. Allmond, L.R., Karaca, T.J., Nguyen, V.N., Nguyen, T., Wiener-Kronish, J.P. und Sawa, T., Protein binding between PcrG-PcrV and PcrH-PopB/PopD encoded by the pcrGVH-popBD operon of the Pseudomonas aeruginosa type III secretion system. Infect Immun, 2003. 71(4): S. 2230-3.

8. Andersen, J.S., Svensson, B. und Roepstorff, P., Electrospray ionization and matrix assisted laser desorption/ionization mass spectrometry: powerful analytical tools in recombinant protein chemistry. Nat Biotechnol, 1996. 14(4): S. 449-57.

9. Arfin, S.M., Long, A.D., Ito, E.T., Tolleri, L., Riehle, M.M., Paegle, E.S. und Hatfield, G.W., Global gene expression profiling in Escherichia coli K12. The effects of integration host factor. J Biol Chem, 2000. 275(38): S. 29672-84.

10. Ashcroft, R.G. und Lopez, P.A., Commercial high speed machines open new opportunities in high throughput flow cytometry (HTFC). J Immunol Methods, 2000. 243(1-2): S. 13-24.

11. Auchere, F. und Rusnak, F., What is the ultimate fate of superoxide anion in vivo? $J$ Biol Inorg Chem, 2002. 7(6): S. 664-7.

12. Auchere, F., Sikkink, R., Cordas, C., Raleiras, P., Tavares, P., Moura, I. und Moura, J.J., Overexpression and purification of Treponema pallidum rubredoxin; kinetic evidence for a superoxide-mediated electron transfer with the superoxide reductase neelaredoxin. J Biol Inorg Chem, 2004. 9(7): S. 839-49.

13. Bae, W., Mulchandani, A. und Chen, W., Cell surface display of synthetic phytochelatins using ice nucleation protein for enhanced heavy metal bioaccumulation. JInorg Biochem, 2002. 88(2): S. 223-7. 
14. Bardwell, J.C., McGovern, K. und Beckwith, J., Identification of a protein required for disulfide bond formation in vivo. Cell, 1991. 67(3): S. 581-9.

15. Barnouin, K., Two-dimensional gel electrophoresis for analysis of protein complexes. Methods Mol Biol, 2004. 261: S. 479-98.

16. Bartel, P.L., Roecklein, J.A., SenGupta, D. und Fields, S., A protein linkage map of Escherichia coli bacteriophage T7. Nat Genet, 1996. 12(1): S. 72-7.

17. Batchelor, M., Prasannan, S., Daniell, S., Reece, S., Connerton, I., Bloomberg, G., Dougan, G., Frankel, G. und Matthews, S., Structural basis for recognition of the translocated intimin receptor (Tir) by intimin from enteropathogenic Escherichia coli. Embo J, 2000. 19(11): S. 2452-64.

18. Beaucamp, K., Bergmeyer, H.U. und Beutler, H.O., Coenzymes, metabolites, and other biochemical reagents, in Methods of Enzymatic Analysis, H.U. Bergmeyer, Editor. 1974, Chemec, Academic Press Inc.: New York, N.Y. S. 532.

19. Bernard, P. und Couturier, M., Cell killing by the F plasmid CcdB protein involves poisoning of DNA-topoisomerase II complexes. J Mol Biol, 1992. 226(3): S. 735-45.

20. Bernard, P., Gabant, P., Bahassi, E.M. und Couturier, M., Positive-selection vectors using the F plasmid ccdB killer gene. Gene, 1994. 148(1): S. 71-4.

21. Bernard, P., Kezdy, K.E., Van Melderen, L., Steyaert, J., Wyns, L., Pato, M.L., Higgins, P.N. und Couturier, M., The F plasmid CcdB protein induces efficient ATP-dependent DNA cleavage by gyrase. J Mol Biol, 1993. 234(3): S. 534-41.

22. Bernstein, J.A., Khodursky, A.B., Lin, P.H., Lin-Chao, S. und Cohen, S.N., Global analysis of mRNA decay and abundance in Escherichia coli at single-gene resolution using two-color fluorescent DNA microarrays. Proc Natl Acad Sci US A, 2002. 99(15): S. 9697-702.

23. Blocker, A., Jouihri, N., Larquet, E., Gounon, P., Ebel, F., Parsot, C., Sansonetti, P. und Allaoui, A., Structure and composition of the Shigella flexneri"needle complex", a part of its type III secreton. Mol Microbiol, 2001. 39(3): S. 652-63.

24. Boder, E.T. und Wittrup, K.D., Yeast surface display for screening combinatorial polypeptide libraries. Nat Biotechnol, 1997. 15(6): S. 553-7.

25. Boder, E.T. und Wittrup, K.D., Yeast surface display for directed evolution of protein expression, affinity, and stability. Methods Enzymol, 2000. 328: S. 430-44.

26. Boettcher, K.J. und Ruby, E.G., Detection and quantification of Vibrio fischeri autoinducer from symbiotic squid light organs. J Bacteriol, 1995. 177(4): S. 1053-8.

27. Botzenhardt, K. und Döring, G., Ecology and Epidemiology of Pseudomonas aeruginosa, in Pseudomonas aeruginosa as an opportunistic pathogen, M. Campa and M. Bendinelli, Editoren. 1993, Plenum Press: New York. S. 1-18.

28. Braun, V., Killmann, H. und Herrmann, C., Inactivation of FhuA at the cell surface of Escherichia coli $\mathrm{K}-12$ by a phage T5 lipoprotein at the periplasmic face of the outer membrane. J Bacteriol, 1994. 176(15): S. 4710-7.

29. Braveny, I. und Krump-Schmidt, W., Pseudomonas aeruginosa. 1985, München: W. Zuckschwerdt Verlag.

30. Brint, J.M. und Ohman, D.E., Synthesis of multiple exoproducts in Pseudomonas aeruginosa is under the control of RhlR-RhlI, another set of regulators in strain PAO1 
with homology to the autoinducer-responsive LuxR-LuxI family. J Bacteriol, 1995. 177(24): S. 7155-63.

31. Brumlik, M.J. und Voordouw, G., Analysis of the transcriptional unit encoding the genes for rubredoxin $(\mathrm{rub})$ and a putative rubredoxin oxidoreductase $(\mathrm{rbo})$ in Desulfovibrio vulgaris Hildenborough. J Bacteriol, 1989. 171(9): S. 4996-5004.

32. Cabiscol, E., Tamarit, J. und Ros, J., Oxidative stress in bacteria and protein damage by reactive oxygen species. Int Microbiol, 2000. 3(1): S. 3-8.

33. Cano, A., Acosta, M. und Arnao, M.B., A method to measure antioxidant activity in organic media: application to lipophilic vitamins. Redox Rep, 2000. 5(6): S. 365-370.

34. Cao, H., Krishnan, G., Goumnerov, B., Tsongalis, J., Tompkins, R. und Rahme, L.G., A quorum sensing-associated virulence gene of Pseudomonas aeruginosa encodes a LysR-like transcription regulator with a unique self-regulatory mechanism. Proc Natl Acad Sci US A, 2001. 98(25): S. 14613-8.

35. Carlioz, A. und Touati, D., Isolation of superoxide dismutase mutants in Escherichia coli: is superoxide dismutase necessary for aerobic life? Embo J, 1986. 5(3): S. 623-30.

36. Chan, L.W., Heng, P.W.S. und Wan, L.S.C., Effect on cellulose derivatives on alginate microspheres prepared by emulsification. JMicroencapsul, 1997. 14: S. 545555.

37. Childs, R.E. und Bardsley, W.G., The steady-state kinetics of peroxidase with 2,2'azino-di-(3-ethyl-benzthiazoline-6-sulphonic acid) as chromogen. Biochem J, 1975. 145(1): S. 93-103.

38. Christmann, A., Walter, K., Wentzel, A., Krätzner, R. und Kolmar, H., The cystine knot of a squash-type protease inhibitor as a structural scaffold for Escherichia coli cell surface display of conformationally constrained peptides. Protein Eng, 1999. 12(9): S. 797-806.

39. Clifford, D.P. und Repine, J.E., Hydrogen peroxide mediated killing of bacteria. Mol Cell Biochem, 1982. 49(3): S. 143-9.

40. Colas, P. und Brent, R., The impact of two-hybrid and related methods on biotechnology. Trends Biotechnol, 1998. 16(8): S. 355-63.

41. Conway, T. und Schoolnik, G.K., Microarray expression profiling: capturing a genome-wide portrait of the transcriptome. Mol Microbiol, 2003. 47(4): S. 879-89.

42. Cordes, F.S., Komoriya, K., Larquet, E., Yang, S., Egelman, E.H., Blocker, A. und Lea, S.M., Helical structure of the needle of the type III secretion system of Shigella flexneri. J Biol Chem, 2003. 278(19): S. 17103-7.

43. Cornelis, G.R., Molecular and cell biology aspects of plague. Proc Natl Acad Sci US $A$, 2000. 97(16): S. 8778-83.

44. Costerton, J.W., Pseudomonas aeruginosa in nature and disease, in Pseudomonas aeruginosa, the organism, the diseases it causes, and their treatment, C.D. Sabath, Editor. 1980, Hans Huber Publishers: Bern, Stuttgart, Wien.

45. Costerton, J.W., Cheng, K.J., Geesey, G.G., Ladd, T.I., Nickel, J.C., Dasgupta, M. und Marrie, T.J., Bacterial biofilms in nature and disease. Annu Rev Microbiol, 1987. 41: S. 435-64. 
46. Cowan, S.W., Schirmer, T., Rummel, G., Steiert, M., Ghosh, R., Pauptit, R.A., Jansonius, J.N. und Rosenbusch, J.P., Crystal structures explain functional properties of two E. coli porins. Nature, 1992. 358(6389): S. 727-33.

47. Cronin, C.N. und McIntire, W.S., Heterologous expression in Pseudomonas aeruginosa and purification of the 9.2-kDa c-type cytochrome subunit of p-cresol methylhydroxylase. Protein Expr Purif, 2000. 19(1): S. 74-83.

48. Cummings, C.A. und Relman, D.A., Using DNA microarrays to study host-microbe interactions. Emerg Infect Dis, 2000. 6(5): S. 513-25.

49. Dacheux, D., Goure, J., Chabert, J., Usson, Y. und Attree, I., Pore-forming activity of type III system-secreted proteins leads to oncosis of Pseudomonas aeruginosainfected macrophages. Mol Microbiol, 2001. 40(1): S. 76-85.

50. Dacheux, D., Toussaint, B., Richard, M., Brochier, G., Croize, J. und Attree, I., Pseudomonas aeruginosa cystic fibrosis isolates induce rapid, type III secretiondependent, but ExoU-independent, oncosis of macrophages and polymorphonuclear neutrophils. Infect Immun, 2000. 68(5): S. 2916-24.

51. Darwin, A.J. und Miller, V.L., Identification of Yersinia enterocolitica genes affecting survival in an animal host using signature-tagged transposon mutagenesis. Mol Microbiol, 1999. 32(1): S. 51-62.

52. Daugherty, P.S., Chen, G., Olsen, M.J., Iverson, B.L. und Georgiou, G., Antibody affinity maturation using bacterial surface display. Protein Eng, 1998. 11(9): S. 825-32.

53. Day, R.N., Visualization of Pit-1 transcription factor interactions in the living cell nucleus by fluorescence resonance energy transfer microscopy. Mol Endocrinol, 1998. 12(9): S. 1410-9.

54. de Kievit, T.R., Seed, P.C., Nezezon, J., Passador, L. und Iglewski, B.H., RsaL, a novel repressor of virulence gene expression in Pseudomonas aeruginosa. J Bacteriol, 1999. 181(7): S. 2175-84.

55. de Kievit, T.R. und Iglewski, B.H., Bacterial quorum sensing in pathogenic relationships. Infect Immun, 2000. 68(9): S. 4839-49.

56. Decker, K., Krauel, V., Meesmann, A. und Heller, K.J., Lytic conversion of Escherichia coli by bacteriophage T5: blocking of the FhuA receptor protein by a lipoprotein expressed early during infection. Mol Microbiol, 1994. 12(2): S. 321-32.

57. Deretic, V., Schurr, M.J. und Yu, H., Pseudomonas aeruginosa, mucoidy and the chronic infection phenotype in cystic fibrosis. Trends Microbiol, 1995. 3(9): S. 351-6.

58. Dong, Y.H., Wang, L.H., Xu, J.L., Zhang, H.B., Zhang, X.F. und Zhang, L.H., Quenching quorum-sensing-dependent bacterial infection by an $\mathrm{N}$-acyl homoserine lactonase. Nature, 2001. 411(6839): S. 813-7.

59. Dong, Y.H., Xu, J.L., Li, X.Z. und Zhang, L.H., AiiA, an enzyme that inactivates the acylhomoserine lactone quorum-sensing signal and attenuates the virulence of Erwinia carotovora. Proc Natl Acad Sci US A, 2000. 97(7): S. 3526-31.

60. Döring, G., Maier, M., Muller, E., Bibi, Z., Tümmler, B. und Kharazmi, A., Virulence factors of Pseudomonas aeruginosa. Antibiot Chemother, 1987. 39: S. 13648.

61. Dower, W.J., Miller, J.F. und Ragsdale, C.W., High efficiency transformation of $E$. coli by high voltage electroporation. Nucleic Acids Res, 1988. 16(13): S. 6127-45. 
62. Downey, N., Extraction of DNA from agarose gels. Methods Mol Biol, 2003. 235: S. 137-9.

63. Dunne, W.M., Jr., Bacterial adhesion: seen any good biofilms lately? Clin Microbiol Rev, 2002. 15(2): S. 155-66.

64. Eberhard, A., Burlingame, A.L., Eberhard, C., Kenyon, G.L., Nealson, K.H. und Oppenheimer, N.J., Structural identification of autoinducer of Photobacterium fischeri luciferase. Biochemistry, 1981. 20(9): S. 2444-9.

65. Eggink, G., Engel, H., Vriend, G., Terpstra, P. und Witholt, B., Rubredoxin reductase of Pseudomonas oleovorans. Structural relationship to other flavoprotein oxidoreductases based on one NAD and two FAD fingerprints. J Mol Biol, 1990. 212(1): S. 135-42.

66. Eilers, M. und Schatz, G., Binding of a specific ligand inhibits import of a purified precursor protein into mitochondria. Nature, 1986. 322(6076): S. 228-32.

67. Einberger, H., Mertz, R., Hofschneider, P.H. und Neubert, W.J., Purification, renaturation, and reconstituted protein kinase activity of the Sendai virus large (L) protein: L protein phosphorylates the NP and P proteins in vitro. J Virol, 1990. 64(9): S. 4274-80.

68. Emerson, J.P., Coulter, E.D., Cabelli, D.E., Phillips, R.S. und Kurtz, D.M., Jr., Kinetics and mechanism of superoxide reduction by two-iron superoxide reductase from Desulfovibrio vulgaris. Biochemistry, 2002. 41(13): S. 4348-57.

69. Emerson, J.P., Coulter, E.D., Phillips, R.S. und Kurtz, D.M., Jr., Kinetics of the superoxide reductase catalytic cycle. J Biol Chem, 2003. 278(41): S. 39662-8.

70. Engebrecht, J. und Silverman, M., Identification of genes and gene products necessary for bacterial bioluminescence. Proc Natl Acad Sci US A, 1984. 81(13): S. 4154-8.

71. Eppens, E.F., Nouwen, N. und Tommassen, J., Folding of a bacterial outer membrane protein during passage through the periplasm. Embo J, 1997. 16(14): S. 4295-301.

72. Eymann, C., Homuth, G., Scharf, C. und Hecker, M., Bacillus subtilis functional genomics: global characterization of the stringent response by proteome and transcriptome analysis. J Bacteriol, 2002. 184(9): S. 2500-20.

73. Farr, S.B. und Kogoma, T., Oxidative stress responses in Escherichia coli and Salmonella typhimurium. Microbiol Rev, 1991. 55(4): S. 561-85.

74. Favero, M.S., Carson, L.A., Bond, W.W. und Petersen, N.J., Pseudomonas aeruginosa: growth in distilled water from hospitals. Science, 1971. 173(999): S. 836-8.

75. Fick, R.B., Jr., Baltimore, R.S., Squier, S.U. und Reynolds, H.Y., IgG proteolytic activity of Pseudomonas aeruginosa in cystic fibrosis. J Infect Dis, 1985. 151(4): S. 58998.

76. Fields, S. und Song, O., A novel genetic system to detect protein-protein interactions. Nature, 1989. 340(6230): S. 245-6.

77. Fleming, A., On the antibaterial action of cultures of a penicillium, with special reference to their use in the isolation of B. influenzae. BrJ Exp Pathol, 1929. X: S. 226. 
78. Flint, D.H., Tuminello, J.F. und Emptage, M.H., The inactivation of Fe-S cluster containing hydro-lyases by superoxide. J Biol Chem, 1993. 268(30): S. 22369-76.

79. Francisco, J.A., Earhart, C.F. und Georgiou, G., Transport and anchoring of $\beta$ lactamase to the external surface of Escherichia coli. Proc Natl Acad Sci US A, 1992. 89(7): S. 2713-7.

80. Francisco, J.A., Stathopoulos, C., Warren, R.A., Kilburn, D.G. und Georgiou, G., Specific adhesion and hydrolysis of cellulose by intact Escherichia coli expressing surface anchored cellulase or cellulose binding domains. Biotechnology (N Y), 1993. 11(4): S. 491-5.

81. Frank, D.W., Vallis, A., Wiener-Kronish, J.P., Roy-Burman, A., Spack, E.G., Mullaney, B.P., Megdoud, M., Marks, J.D., Fritz, R. und Sawa, T., Generation and characterization of a protective monoclonal antibody to Pseudomonas aeruginosa PcrV. J Infect Dis, 2002. 186(1): S. 64-73.

82. Frankel, G., Candy, D.C., Everest, P. und Dougan, G., Characterization of the Cterminal domains of intimin-like proteins of enteropathogenic and enterohemorrhagic Escherichia coli, Citrobacter freundii, and Hafnia alvei. Infect Immun, 1994. 62(5): S. 1835-42.

83. Frech, C., Wunderlich, M., Glockshuber, R. und Schmid, F.X., Competition between DsbA-mediated oxidation and conformational folding of RTEM1 $\beta$ lactamase. Biochemistry, 1996. 35(35): S. 11386-95.

84. Fridkin, S.K. und Gaynes, R.P., Antimicrobial resistance in intensive care units. Clin Chest Med, 1999. 20(2): S. 303-16, viii.

85. Fridovich, I., Superoxide dismutases. An adaptation to a paramagnetic gas. J Biol Chem, 1989. 264(14): S. 7761-4.

86. Fromont-Racine, M., Mayes, A.E., Brunet-Simon, A., Rain, J.C., Colley, A., Dix, I., Decourty, L., Joly, N., Ricard, F., Beggs, J.D. und Legrain, P, Genome-wide protein interaction screens reveal functional networks involving Sm-like proteins. Yeast, 2000. 17(2): S. 95-110.

87. Fundueanu, G., Esposito, E., Mihai, D., Carpor, A., Desbrieres, J., Rinaudo, M. und Nastruzzi, C., Preparation and charaterization of Ca-alginate microspheres by a new emulsification method. Int J Pharm, 1998. 170: S. 11-21.

88. Fuqua, W.C., Winans, S.C. und Greenberg, E.P., Quorum sensing in bacteria: the LuxR-LuxI family of cell density-responsive transcriptional regulators. J Bacteriol, 1994. 176(2): S. 269-75.

89. Gallant, C.V., Raivio, T.L., Olson, J.C., Woods, D.E. und Storey, D.G., Pseudomonas aeruginosa cystic fibrosis clinical isolates produce exotoxin A with altered ADP-ribosyltransferase activity and cytotoxicity. Microbiology, 2000. 146 ( Pt 8): S. 1891-9.

90. Gambello, M.J. und Iglewski, B.H., Cloning and characterization of the Pseudomonas aeruginosa lasR gene, a transcriptional activator of elastase expression. $J$ Bacteriol, 1991. 173(9): S. 3000-9.

91. Gambello, M.J., Kaye, S. und Iglewski, B.H., LasR of Pseudomonas aeruginosa is a transcriptional activator of the alkaline protease gene (apr) and an enhancer of exotoxin A expression. Infect Immun, 1993. 61(4): S. 1180-4. 
92. Geissdorfer, W., Frosch, S.C., Haspel, G., Ehrt, S. und Hillen, W., Two genes encoding proteins with similarities to rubredoxin and rubredoxin reductase are required for conversion of dodecane to lauric acid in Acinetobacter calcoaceticus ADP1. Microbiology, 1995. 141(Pt 6): S. 1425-32.

93. Georgiou, G., Stathopoulos, C., Daugherty, P.S., Nayak, A.R., Iverson, B.L. und Curtiss, R., 3rd, Display of heterologous proteins on the surface of microorganisms: from the screening of combinatorial libraries to live recombinant vaccines. Nat Biotechnol, 1997. 15(1): S. 29-34.

94. Georgiou, G., Stephens, D.L., Stathopoulos, C., Poetschke, H.L., Mendenhall, J. und Earhart, C.F., Display of $\beta$-lactamase on the Escherichia coli surface: outer membrane phenotypes conferred by Lpp'-OmpA'- $\beta$-lactamase fusions. Protein Eng, 1996. 9(2): S. 239-47.

95. Giese, B., Electron transfer in DNA. Curr Opin Chem Biol, 2002. 6(5): S. 612-8.

96. Gill, J.F., Deretic, V. und Chakrabarty, A.M., Alginate production by the mucoid Pseudomonas aeruginosa associated with cystic fibrosis. Microbiol Sci, 1987. 4(10): S. 296-9.

97. Goehring, U.M., Schmidt, G., Pederson, K.J., Aktories, K. und Barbieri, J.T., The $\mathrm{N}$-terminal domain of Pseudomonas aeruginosa exoenzyme $\mathrm{S}$ is a GTPase-activating protein for Rho GTPases. J Biol Chem, 1999. 274(51): S. 36369-72.

98. Goldberg, J.B. und Pler, G.B., Pseudomonas aeruginosalipopolysaccharides and pathogenesis. Trends Microbiol, 1996. 4(12): S. 490-4.

99. Govan, J.R. und Deretic, V., Microbial pathogenesis in cystic fibrosis: mucoid Pseudomonas aeruginosa and Burkholderia cepacia. Microbiol Rev, 1996. 60(3): S. 539-74.

100. Green, S.K., Schroth, M.N., Cho, J.J., Kominos, S.K. und Vitanza-jack, V.B., Agricultural plants and soil as a reservoir for Pseudomonas aeruginosa. Appl Microbiol, 1974. 28(6): S. 987-91.

101. Grinsted, J. und Bennett, P.M., Methods in microbiology: plasmid technology 21. 1988, Academic press, San Diego

102. Grodberg, J. und Dunn, J.J., ompT encodes the Escherichia coli outer membrane protease that cleaves T7 RNA polymerase during purification. J Bacteriol, 1988. 170(3): S. 1245-53.

103. Guedon, E. und Petitdemange, H., Identification of the gene encoding NADHrubredoxin oxidoreductase in Clostridium acetobutylicum. Biochem Biophys Res Commun, 2001. 285(2): S. 496-502.

104. Guerini, D. und Krebs, J., Influence of temperature and denaturing agents on the structural stability of calmodulin. A $1 \mathrm{H}$-nuclear magnetic resonance study. FEBS Lett, 1983. 164(1): S. 105-10.

105. Gunneriusson, E., Samuelson, P., Uhlen, M., Nygren, P.A. und Stahl, S., Surface display of a functional single-chain Fv antibody on staphylococci. J Bacteriol, 1996. 178(5): S. 1341-6.

106. Gunther, M.R., Hanna, P.M., Mason, R.P. und Cohen, M.S., Hydroxyl radical formation from cuprous ion and hydrogen peroxide: a spin-trapping study. Arch Biochem Biophys, 1995. 316(1): S. 515-22. 
107. Guschin, D., Yershov, G., Zaslavsky, A., Gemmell, A., Shick, V., Proudnikov, D., Arenkov, P. und Mirzabekov, A., Manual manufacturing of oligonucleotide, DNA, and protein microchips. Anal Biochem, 1997. 250(2): S. 203-11.

108. Haab, B.B., Dunham, M.J. und Brown, P.O., Protein microarrays for highly parallel detection and quantitation of specific proteins and antibodies in complex solutions. Genome Biol, 2001. 2(2): RESEARCH0004.

109. Hansson, M., Samuelson, P., Gunneriusson, E. und Stahl, S., Surface display on gram positive bacteria. Comb Chem High Throughput Screen, 2001. 4(2): S. 171-84.

110. Hashimoto-Gotoh, T., Yamaguchi, M., Yasojima, K., Tsujimura, A., Wakabayashi, Y. und Watanabe, Y., A set of temperature sensitive-replication/segregation and temperature resistant plasmid vectors with different copy numbers and in an isogenic background (chloramphenicol, kanamycin, lacZ, repA, par, polA). Gene, 2000. 241(1): S. 185-91.

111. Hassett, D.J., Ma, J.F., Elkins, J.G., McDermott, T.R., Ochsner, U.A., West, S.E., Huang, C.T., Fredericks, J., Burnett, S., Stewart, P.S., McFeters, G., Passador, L. und Iglewski, B.H., Quorum sensing in Pseudomonas aeruginosa controls expression of catalase and superoxide dismutase genes and mediates biofilm susceptibility to hydrogen peroxide. Mol Microbiol, 1999. 34(5): S. 1082-93.

112. Hastings, J.W. und Greenberg, E.P., Quorum sensing: the explanation of a curious phenomenon reveals a common characteristic of bacteria. J Bacteriol, 1999. 181(9): S. 2667-8.

113. Hastings, J.W. und Nealson, K.H., Bacterial bioluminescence. Annu Rev Microbiol, 1977. 31: S. 549-95.

114. Henderson, I.R., Navarro-Garcia, F. und Nataro, J.P., The great escape: structure and function of the autotransporter proteins. Trends Microbiol, 1998. 6(9): S. 370-8.

115. Heng, P.W., Chan, L.W. und Wong, T.W., Formation of alginate microspheres produced using emulsification technique. J Microencapsul, 2003. 20(3): S. 401-13.

116. Henry, R.L., Mellis, C.M. und Petrovic, L., Mucoid Pseudomonas aeruginosa is a marker of poor survival in cystic fibrosis. Pediatr Pulmonol, 1992. 12(3): S. 158-61.

117. Hensel, M., Whole genome scan for habitat-specific genes by signature-tagged mutagenesis. Electrophoresis, 1998. 19(4): S. 608-12.

118. Hensel, M., Shea, J.E., Gleeson, C., Jones, M.D., Dalton, E. und Holden, D.W., Simultaneous identification of bacterial virulence genes by negative selection. Science, 1995. 269(5222): S. 400-3.

119. Hickey, W.J. und Focht, D.D., Degradation of mono-, di-, and trihalogenated benzoic acids by Pseudomonas aeruginosa JB2. Appl Environ Microbiol, 1990. 56(12): S. 3842-50.

120. Hill, J., Leary, S.E., Griffin, K.F., Williamson, E.D. und Titball, R.W., Regions of Yersinia pestis $\mathrm{V}$ antigen that contribute to protection against plague identified by passive and active immunization. Infect Immun, 1997. 65(11): S. 4476-82.

121. Hoang, T.T. und Schweizer, H.P., Fatty acid biosynthesis in Pseudomonas aeruginosa: cloning and characterization of the fabAB operon encoding $\beta$ hydroxyacyl-acyl carrier protein dehydratase (FabA) and $\beta$-ketoacyl-acyl carrier protein synthase I (FabB). J Bacteriol, 1997. 179(17): S. 5326-32. 
122. Hoang, T.T. und Schweizer, H.P., Characterization of Pseudomonas aeruginosa enoyl-acyl carrier protein reductase (FabI): a target for the antimicrobial triclosan and its role in acylated homoserine lactone synthesis. J Bacteriol, 1999. 181(17): S. 5489-97.

123. Hoang, T.T., Sullivan, S.A., Cusick, J.K. und Schweizer, H.P., $\beta$-ketoacyl acyl carrier protein reductase (FabG) activity of the fatty acid biosynthetic pathway is a determining factor of 3-oxo-homoserine lactone acyl chain lengths. Microbiology, 2002. 148(Pt 12): S. 3849-56.

124. Hofte, M., Mergeay, M. und Verstraete, W., Marking the rhizopseudomonas strain 7NSK2 with a Mu d(lac) element for ecological studies. Appl Environ Microbiol, 1990. 56(4): S. 1046-52.

125. Hoiby, N., Döring, G. und Schiotz, P.O., The role of immune complexes in the pathogenesis of bacterial infections. Annu Rev Microbiol, 1986. 40: S. 29-53.

126. Holler, P.D., Holman, P.O., Shusta, E.V., O'Herrin, S., Wittrup, K.D. und Kranz, D.M., In vitro evolution of a T cell receptor with high affinity for peptide/MHC. Proc Natl Acad Sci U S A, 2000. 97(10): S. 5387-92.

127. Holt, L.J., Bussow, K., Walter, G. und Tomlinson, I.M., By-passing selection: direct screening for antibody-antigen interactions using protein arrays. Nucleic Acids Res, 2000. 28(15): S. E72.

128. Hommais, F., Krin, E., Laurent-Winter, C., Soutourina, O., Malpertuy, A., Le Caer, J.P., Danchin, A. und Bertin, P., Large-scale monitoring of pleiotropic regulation of gene expression by the prokaryotic nucleoid-associated protein, $\mathrm{H}-\mathrm{NS}$. Mol Microbiol, 2001. 40(1): S. 20-36.

129. Horan, T.C., White, J.W., Jarvis, W.R., Emori, T.G., Culver, D.H., Munn, V.P., Thornsberry, C., Olson, D.R. und Hughes, J.M., Nosocomial infection surveillance, 1984. MMWR CDC Surveill Summ, 1986. 35(1): S. 17SS-29SS.

130. Huang, J.J., Han, J.I., Zhang, L.H. und Leadbetter, J.R., Utilization of acylhomoserine lactone quorum signals for growth by a soil pseudomonad and Pseudomonas aeruginosa PAO1. Appl Environ Microbiol, 2003. 69(10): S. 5941-9.

131. Hueck, C.J., Type III protein secretion systems in bacterial pathogens of animals and plants. Microbiol Mol Biol Rev, 1998. 62(2): S. 379-433.

132. Hurley, J.H., Chen, R. und Dean, A.M., Determinants of cofactor specificity in isocitrate dehydrogenase: structure of an engineered NADP+ --> NAD+ specificityreversal mutant. Biochemistry, 1996. 35(18): S. 5670-8.

133. Huu, T.P., Marquetty, C., Pasquier, C. und Hakim, J., Luminol assay for microdetermination of superoxide dismutase activity: its application to human fetal blood. Anal Biochem, 1984. 142(2): S. 467-72.

134. Ikura, M., Clore, G.M., Gronenborn, A.M., Zhu, G., Klee, C.B. und Bax, A., Solution structure of a calmodulin-target peptide complex by multidimensional NMR. Science, 1992. 256(5057): S. 632-8.

135. Imlay, J.A., How oxygen damages microbes: oxygen tolerance and obligate anaerobiosis. Adv Microb Physiol, 2002. 46: S. 111-53.

136. Imlay, J.A., Pathways of oxidative damage. Annu Rev Microbiol, 2003. 57: S. 395-418.

137. Inoue, H., Nojima, H. und Okayama, H., High efficiency transformation of Escherichia coli with plasmids. Gene, 1990. 96(1): S. 23-8. 
138. Irvin, R.T., Hodges, R.S., Cachia, P.J., Yu, L., Tripet, B., Bautista, D.L. und Houston, M.E., Coiled-Coil Heterodimer Methods And Compositions For The Detection And Purification Of Expressed Proteins. Patent, 1996, Canada.

139. Iyobe, S., Hirai, K. und Hashimoto, H., Drug resistance of Pseudomonas aeruginosa with special reference to new quinolones. Antibiot Chemother, 1991. 44: S. 209-14.

140. Jenney, F.E., Jr., Verhagen, M.F., Cui, X. und Adams, M.W., Anaerobic microbes: oxygen detoxification without superoxide dismutase. Science, 1999. 286(5438): S. 3069.

141. Jones, S., Yu, B., Bainton, N.J., Birdsall, M., Bycroft, B.W., Chhabra, S.R., Cox, A.J., Golby, P., Reeves, P.J. und Stephens, S., The Iux autoinducer regulates the production of exoenzyme virulence determinants in Erwinia carotovora and Pseudomonas aeruginosa. Embo J, 1993. 12(6): S. 2477-82.

142. Joos, T.O., Schrenk, M., Hopfl, P., Kroger, K., Chowdhury, U., Stoll, D., Schorner, D., Durr, M., Herick, K., Rupp, S., Sohn, K. und Hammerle, H., A microarray enzyme-linked immunosorbent assay for autoimmune diagnostics. Electrophoresis, 2000. 21(13): S. 2641-50.

143. Jung, H.C., Lebeault, J.M. und Pan, J.G., Surface display of Zymomonas mobilis levansucrase by using the ice-nucleation protein of Pseudomonas syringae. Nat Biotechnol, 1998. 16(6): S. 576-80.

144. Kaplan, H.B. und Greenberg, E.P., Diffusion of autoinducer is involved in regulation of the Vibrio fischeri luminescence system. J Bacteriol, 1985. 163(3): S. 1210-4.

145. Keele, B.B., Jr., McCord, J.M. und Fridovich, I., Superoxide dismutase from Escherichia coli B. A new manganese-containing enzyme. J Biol Chem, 1970. 245(22): S. 6176-81.

146. Kelly, G., Prasannan, S., Daniell, S., Fleming, K., Frankel, G., Dougan, G., Connerton, I. und Matthews, S., Structure of the cell-adhesion fragment of intimin from enteropathogenic Escherichia coli. Nat Struct Biol, 1999. 6(4): S. 313-8.

147. Kenny, B., DeVinney, R., Stein, M., Reinscheid, D.J., Frey, E.A. und Finlay, B.B., Enteropathogenic E. coli (EPEC) transfers its receptor for intimate adherence into mammalian cells. Cell, 1997. 91(4): S. 511-20.

148. Khodursky, A.B., Peter, B.J., Cozzarelli, N.R., Botstein, D., Brown, P.O. und Yanofsky, C., DNA microarray analysis of gene expression in response to physiological and genetic changes that affect tryptophan metabolism in Escherichia coli. Proc Natl Acad Sci U S A, 2000. 97(22): S. 12170-5.

149. Kim, E.J. und Yoo, S.K., Cell surface display of hepatitis B virus surface antigen by using Pseudomonas syringae ice nucleation protein. Lett Appl Microbiol, 1999. 29(5): S. 292-7.

150. Kim, Y.S., Jung, H.C. und Pan, J.G., Bacterial cell surface display of an enzyme library for selective screening of improved cellulase variants. Appl Environ Microbiol, 2000. 66(2): S. 788-93.

151. Kjaergaard, K., Schembri, M.A. und Klemm, P., Novel $\mathrm{Zn}^{(2+)}$-chelating peptides selected from a fimbria-displayed random peptide library. Appl Environ Microbiol, 2001. 67(12): S. 5467-73.

152. Kjaergaard, K., Sorensen, J.K., Schembri, M.A. und Klemm, P., Sequestration of zinc oxide by fimbrial designer chelators. Appl Environ Microbiol, 2000. 66(1): S. 10-4. 
153. Klauser, T., Pohlner, J. und Meyer, T.F., Extracellular transport of cholera toxin B subunit using Neisseria IgA protease $\beta$-domain: conformation-dependent outer membrane translocation. Embo J, 1990. 9(6): S. 1991-9.

154. Klauser, T., Pohlner, J. und Meyer, T.F., Selective extracellular release of cholera toxin B subunit by Escherichia coli: dissection of Neisseria Iga $\beta$-mediated outer membrane transport. Embo J, 1992. 11(6): S. 2327-35.

155. Kleerebezem, M., Quadri, L.E., Kuipers, O.P. und de Vos, W.M., Quorum sensing by peptide pheromones and two-component signal-transduction systems in Grampositive bacteria. Mol Microbiol, 1997. 24(5): S. 895-904.

156. Klemm, P. und Schembri, M.A., Bacterial adhesins: function and structure. Int JMed Microbiol, 2000a. 290(1): S. 27-35.

157. Klemm, P. und Schembri, M.A., Fimbrial surface display systems in bacteria: from vaccines to random libraries. Microbiology, 2000b. 146 Pt 12: S. 3025-32.

158. Kolmar, H., Ferrando, E., Hennecke, F., Wippler, J. und Fritz, H.J., General mutagenesis/gene expression procedure for the construction of variant immunoglobulin domains in Escherichia coli. Production of the Bence-Jones protein $\mathrm{REI}_{\mathrm{v}}$ via fusion to $\beta$-lactamase. J Mol Biol, 1992. 228(2): S. 359-65.

159. Konieczny, M.P., Suhr, M., Noll, A., Autenrieth, I.B. und Alexander Schmidt, M., Cell surface presentation of recombinant (poly-) peptides including functional T-cell epitopes by the AIDA autotransporter system. FEMS Immunol Med Microbiol, 2000. 27(4): S. 321-32.

160. Krall, R., Schmidt, G., Aktories, K. und Barbieri, J.T., Pseudomonas aeruginosa ExoT is a Rho GTPase-activating protein. Infect Immun, 2000. 68(10): S. 6066-8.

161. Kramer, B., Kramer, W. und Fritz, H.J., Different base/base mismatches are corrected with different efficiencies by the methyl-directed DNA mismatch-repair system of E. coli. Cell, 1984. 38(3): S. 879-87.

162. Kubitschek, H.E. und Friske, J.A., Determination of bacterial cell volume with the Coulter Counter. J Bacteriol, 1986. 168(3): S. 1466-7.

163. Kwak, Y.D., Yoo, S.K. und Kim, E.J., Cell surface display of human immunodeficiency virus type $1 \mathrm{gp} 120$ on Escherichia coli by using ice nucleation protein. Clin Diagn Lab Immunol, 1999. 6(4): S. 499-503.

164. Laemmli, U.K., Cleavage of structural proteins during the assembly of the head of bacteriophage T4. Nature, 1970. 227(259): S. 680-5.

165. Laminet, A.A. und Plückthun, A., The precursor of $\beta$-lactamase: purification, properties and folding kinetics. Embo J, 1989. 8(5): S. 1469-77.

166. Lander, E.S., et al., Initial sequencing and analysis of the human genome. Nature, 2001. 409(6822): S. 860-921.

167. Lang, H., Outer membrane proteins as surface display systems. Int J Med Microbiol, 2000. 290(7): S. 579-85.

168. Latifi, A., Foglino, M., Tanaka, K., Williams, P. und Lazdunski, A., A hierarchical quorum-sensing cascade in Pseudomonas aeruginosa links the transcriptional activators LasR and RhIR (VsmR) to expression of the stationary-phase sigma factor RpoS. Mol Microbiol, 1996. 21(6): S. 1137-46. 
169. Latifi, A., Winson, M.K., Foglino, M., Bycroft, B.W., Stewart, G.S., Lazdunski, A. und Williams, P., Multiple homologues of LuxR and LuxI control expression of virulence determinants and secondary metabolites through quorum sensing in Pseudomonas aeruginosa PAO1. Mol Microbiol, 1995. 17(2): S. 333-43.

170. Lattemann, C.T., Maurer, J., Gerland, E. und Meyer, T.F., Autodisplay: functional display of active $\beta$-lactamase on the surface of Escherichia coli by the AIDA-I autotransporter. J Bacteriol, 2000. 182(13): S. 3726-33.

171. Leadbetter, J.R. und Greenberg, E.P., Metabolism of acyl-homoserine lactone quorum-sensing signals by Variovorax paradoxus. J Bacteriol, 2000. 182(24): S. 69216.

172. Lederberg, J., Infectious history. Science, 2000. 288(5464): S. 287-93.

173. Ledwith, A., Electron Transfer Reactions of Paraquat, in Biochemical Mechanisms of Paraquat Toxicity, A. Autor, Editor. 1977, Academic Press: New York. S. 21-38.

174. Lee, D.T. und Rosenblatt, J.E., A comparison of four methods for detecting $\beta$ lactamase in anaerobic bacteria. Diagn Microbiol Infect Dis, 1983. 1(2): S. 173-5.

175. Lee, H.J., Basran, J. und Scrutton, N.S., Electron transfer from flavin to iron in the Pseudomonas oleovorans rubredoxin reductase-rubredoxin electron transfer complex. Biochemistry, 1998. 37(44): S. 15513-22.

176. Lehtio, J., Wernerus, H., Samuelson, P., Teeri, T.T. und Stahl, S., Directed immobilization of recombinant staphylococci on cotton fibers by functional display of a fungal cellulose-binding domain. FEMS Microbiol Lett, 2001. 195(2): S. 197-204.

177. Lin, Y.H., Xu, J.L., Hu, J., Wang, L.H., Ong, S.L., Leadbetter, J.R. und Zhang, L.H., Acyl-homoserine lactone acylase from Ralstonia strain XJ12B represents a novel and potent class of quorum-quenching enzymes. Mol Microbiol, 2003. 47(3): S. 84960 .

178. Liochev, S.I. und Fridovich, I., A mechanism for complementation of the sodA sodB defect in Escherichia coli by overproduction of the rbo gene product (desulfoferrodoxin) from Desulfoarculus baarsii. J Biol Chem, 1997. 272(41): S. 255735.

179. Lode, E.T. und Coon, M.J., Enzymatic omega-oxidation. V. Forms of Pseudomonas oleovorans rubredoxin containing one or two iron atoms: structure and function in omega-hydroxylation. J Biol Chem, 1971. 246(3): S. 791-802.

180. Lombard, M., Fontecave, M., Touati, D. und Niviere, V., Reaction of the desulfoferrodoxin from Desulfoarculus baarsii with superoxide anion. Evidence for a superoxide reductase activity. J Biol Chem, 2000a. 275(1): S. 115-21.

181. Lombard, M., Touati, D., Fontecave, M. und Niviere, V., Superoxide reductase as a unique defense system against superoxide stress in the microaerophile Treponema pallidum. J Biol Chem, 2000b. 275(35): S. 27021-6.

182. Lory, S. und Tai, P.C., Biochemical and genetic aspects of Pseudomonas aeruginosa virulence. Curr Top Microbiol Immunol, 1985. 118: S. 53-69.

183. Lu, H., Zhu, X., Liu, H., Skogerbo, G., Zhang, J., Zhang, Y., Cai, L., Zhao, Y., Sun, $\mathrm{S}$., $\mathrm{Xu}, \mathrm{J} ., \mathrm{Bu}, \mathrm{D}$. und Chen, $\mathrm{R}$., The interactome as a tree-an attempt to visualize the protein-protein interaction network in yeast. Nucleic Acids Res, 2004. 32(16): S. 480411. 
184. Lu, S.E., Scholz-Schroeder, B.K. und Gross, D.C., Construction of pMEKm12, an expression vector for protein production in Pseudomonas syringae. FEMS Microbiol Lett, 2002. 210(1): S. 115-21.

185. Lumppio, H.L., Shenvi, N.V., Summers, A.O., Voordouw, G. und Kurtz, D.M., Jr., Rubrerythrin and rubredoxin oxidoreductase in Desulfovibrio vulgaris. a novel oxidative stress protection system. J Bacteriol, 2001. 183(1): S. 101-8.

186. Luo, Y., Frey, E.A., Pfuetzner, R.A., Creagh, A.L., Knoechel, D.G., Haynes, C.A., Finlay, B.B. und Strynadka, N.C., Crystal structure of enteropathogenic Escherichia coli intimin-receptor complex. Nature, 2000. 405(6790): S. 1073-7.

187. Lutz, R. und Bujard, H., Independent and tight regulation of transcriptional units in Escherichia coli via the LacR/O, the TetR/O and AraC/I1-I2 regulatory elements. Nucleic Acids Res, 1997. 25(6): S. 1203-10.

188. Ma, K. und Adams, M.W., A hyperactive NAD(P)H:Rubredoxin oxidoreductase from the hyperthermophilic archaeon Pyrococcus furiosus. J Bacteriol, 1999. 181(17): S. 5530-3.

189. Ma, K. und Adams, M.W., NAD(P)H:rubredoxin oxidoreductase from Pyrococcus furiosus. Methods Enzymol, 2001. 334: S. 55-62.

190. Ma, L.C. und Anderson, S., Correlation between disulfide reduction and conformational unfolding in bovine pancreatic trypsin inhibitor. Biochemistry, 1997. 36(12): S. 3728-36.

191. MacBeath, G. und Schreiber, S.L., Printing proteins as microarrays for highthroughput function determination. Science, 2000. 289(5485): S. 1760-3.

192. Madigan, M., Martinko, J. und Parker, J., Brock Biology of Microorganisms. Neunte Auflage. 2000, Prentice Hall, Upper Saddle River, New Yersey.

193. Mahajan, N.P., Linder, K., Berry, G., Gordon, G.W., Heim, R. und Herman, B., $\mathrm{Bcl}-2$ and $\mathrm{Bax}$ interactions in mitochondria probed with green fluorescent protein and fluorescence resonance energy transfer. Nat Biotechnol, 1998. 16(6): S. 547-52.

194. Maier, R.M. und Soberon-Chavez, G., Pseudomonas aeruginosa rhamnolipids: biosynthesis and potential applications. Appl Microbiol Biotechnol, 2000. 54(5): S. 625-33.

195. Marchler-Bauer, A., et al., CDD: a curated Entrez database of conserved domain alignments. Nucleic Acids Res, 2003. 31(1): S. 383-7.

196. Marin, M.M., Yuste, L. und Rojo, F., Differential expression of the components of the two alkane hydroxylases from Pseudomonas aeruginosa. J Bacteriol, 2003. 185(10): S. 3232-7.

197. Marquardt, D.W., An Algorithm for Least Squares Estimation of Parameters. Journal of the Society of Industrial and Applied Mathematics, 1963. 11: S. 431-441.

198. Matson, J.S. und Nilles, M.L., LcrG-LcrV interaction is required for control of Yops secretion in Yersinia pestis. J Bacteriol, 2001. 183(17): S. 5082-91.

199. Matson, J.S. und Nilles, M.L., Interaction of the Yersinia pestis type III regulatory proteins LcrG and LcrV occurs at a hydrophobic interface. BMC Microbiol, 2002. 2(1): S. 16. 
200. Maurer, J., Jose, J. und Meyer, T.F., Autodisplay: one-component system for efficient surface display and release of soluble recombinant proteins from Escherichia coli. J Bacteriol, 1997. 179(3): S. 794-804.

201. McKnight, S.L., Iglewski, B.H. und Pesci, E.C., The Pseudomonas quinolone signal regulates $r h l$ quorum sensing in Pseudomonas aeruginosa. J Bacteriol, 2000. 182(10): S. 2702-8.

202. Melino, S., Capo, C., Dragani, B., Aceto, A. und Petruzzelli, R., A zinc-binding motif conserved in glyoxalase II, $\beta$-lactamase and arylsulfatases. Trends Biochem Sci, 1998. 23(10): S. 381-2.

203. Mendelsohn, A.R. und Brent, R., Protein interaction methods-toward an endgame. Science, 1999. 284(5422): S. 1948-50.

204. Merenyi, G. und Lind, J., Role of Peroxide Intermediate in the Chemiluminescence of Luminol. A Mechanistic Study. J. Am. Chem. Soc., 1980. 102: S. 5830-5835.

205. Messner, K.R. und Imlay, J.A., Mechanism of superoxide and hydrogen peroxide formation by fumarate reductase, succinate dehydrogenase, and aspartate oxidase. $J$ Biol Chem, 2002. 277(45): S. 42563-71.

206. Michaud, G.A., Salcius, M., Zhou, F., Bangham, R., Bonin, J., Guo, H., Snyder, M., Predki, P.F. und Schweitzer, B.I., Analyzing antibody specificity with whole proteome microarrays. Nat Biotechnol, 2003. 21(12): S. 1509-12.

207. Moon, H.W., Whipp, S.C., Argenzio, R.A., Levine, M.M. und Giannella, R.A., Attaching and effacing activities of rabbit and human enteropathogenic Escherichia coli in pig and rabbit intestines. Infect Immun, 1983. 41(3): S. 1340-51.

208. Mulgrave, L., The changing ecology of hospital bacteria and the selective role of cephalosporins. Epidemiol Infect, 1991. 106(1): S. 121-32.

209. Mullis, K.B. und Faloona, F.A., Specific synthesis of DNA in vitro via a polymerasecatalyzed chain reaction. Methods Enzymol, 1987. 155: S. 335-50.

210. Murai, T., Ueda, M., Kawaguchi, T., Arai, M. und Tanaka, A., Assimilation of cellooligosaccharides by a cell surface-engineered yeast expressing $\beta$-glucosidase and carboxymethylcellulase from Aspergillus aculeatus. Appl Environ Microbiol, 1998. 64(12): S. 4857-61.

211. Murai, T., Ueda, M., Shibasaki, Y., Kamasawa, N., Osumi, M., Imanaka, T. und Tanaka, A., Development of an arming yeast strain for efficient utilization of starch by co-display of sequential amylolytic enzymes on the cell surface. Appl Microbiol Biotechnol, 1999. 51(1): S. 65-70.

212. Murai, T., Ueda, M., Yamamura, M., Atomi, H., Shibasaki, Y., Kamasawa, N., Osumi, M., Amachi, T. und Tanaka, A., Construction of a starch-utilizing yeast by cell surface engineering. Appl Environ Microbiol, 1997. 63(4): S. 1362-6.

213. Nakae, T., Multiantibiotic resistance caused by active drug extrusion in Pseudomonas aeruginosa and other gram-negative bacteria. Microbiologia, 1997. 13(3): S. 273-84.

214. Nakai, K. und Horton, P., PSORT: a program for detecting sorting signals in proteins and predicting their subcellular localization. Trends Biochem Sci, 1999. 24(1): S. 34-6.

215. Nanao, M., Ricard-Blum, S., Di Guilmi, A.M., Lemaire, D., Lascoux, D., Chabert, J., Attree, I. und Dessen, A., Type III secretion proteins PcrV and PcrG from 
Pseudomonas aeruginosa form a 1:1 complex through high affinity interactions. BMC Microbiol, 2003. 3(1): S. 21.

216. Nealson, K.H., Platt, T. und Hastings, J.W., Cellular control of the synthesis and activity of the bacterial luminescent system. J Bacteriol, 1970. 104(1): S. 313-22.

217. Needleman, S.B. und Wunsch, C.D., A general method applicable to the search for similarities in the amino acid sequence of two proteins. JMol Biol, 1970. 48(3): S. 44353.

218. Neri, D., de Lalla, C., Petrul, H., Neri, P. und Winter, G., Calmodulin as a versatile tag for antibody fragments. Biotechnology (N Y), 1995. 13(4): S. 373-7.

219. Nickel, J.C., Ruseska, I., Wright, J.B. und Costerton, J.W., Tobramycin resistance of Pseudomonas aeruginosa cells growing as a biofilm on urinary catheter material. Antimicrob Agents Chemother, 1985. 27(4): S. 619-24.

220. Nouwens, A.S., Beatson, S.A., Whitchurch, C.B., Walsh, B.J., Schweizer, H.P., Mattick, J.S. und Cordwell, S.J., Proteome analysis of extracellular proteins regulated by the las and rhl quorum sensing systems in Pseudomonas aeruginosa PAO1. Microbiology, 2003. 149(Pt 5): S. 1311-22.

221. Ochsner, U.A., Koch, A.K., Fiechter, A. und Reiser, J., Isolation and characterization of a regulatory gene affecting rhamnolipid biosurfactant synthesis in Pseudomonas aeruginosa. J Bacteriol, 1994. 176(7): S. 2044-54.

222. Ochsner, U.A. und Reiser, J., Autoinducer-mediated regulation of rhamnolipid biosurfactant synthesis in Pseudomonas aeruginosa. Proc Natl Acad Sci U S A, 1995. 92(14): S. 6424-8.

223. Olson, B., Weinstein, R.A., Nathan, C., Chamberlin, W. und Kabins, S.A., Occult aminoglycoside resistance in Pseudomonas aeruginosa: epidemiology and implications for therapy and control. J Infect Dis, 1985. 152(4): S. 769-74.

224. Oswald, E., Schmidt, H., Morabito, S., Karch, H., Marches, O. und Caprioli, A., Typing of intimin genes in human and animal enterohemorrhagic and enteropathogenic Escherichia coli: characterization of a new intimin variant. Infect Immun, 2000. 68(1): S. 64-71.

225. Pace, C.N., Vajdos, F., Fee, L., Grimsley, G. und Gray, T., How to measure and predict the molar absorption coefficient of a protein. Protein Sci, 1995. 4(11): S. 241123.

226. Palleroni, N.J., Toxonomy of Pseudomonads, in The Bacteria, J.R. Sokatch, Editor. 1985, Academic Press: London, Großbritannien; Orlando, USA.

227. Passador, L., Cook, J.M., Gambello, M.J., Rust, L. und Iglewski, B.H., Expression of Pseudomonas aeruginosa virulence genes requires cell-to-cell communication. Science, 1993. 260(5111): S. 1127-30.

228. Pearson, J., Gray, K., Passador, L., Tucker, K., Eberhard, A., Iglewski, B. und Greenberg, E., Structure of the Autoinducer Required for Expression of Pseudomonas aeruginosa Virulence Genes. Proc Natl Acad Sci US A, 1994. 91(1): S. 197-201.

229. Pearson, J.P., Passador, L., Iglewski, B.H. und Greenberg, E.P., A second Nacylhomoserine lactone signal produced by Pseudomonas aeruginosa. Proc Natl Acad Sci US A, 1995. 92(5): S. 1490-4. 
230. Pearson, J.P., Pesci, E.C. und Iglewski, B.H., Roles of Pseudomonas aeruginosa las and $\mathrm{rhl}$ quorum-sensing systems in control of elastase and rhamnolipid biosynthesis genes. J Bacteriol, 1997. 179(18): S. 5756-67.

231. Pearson, J.P., Van Delden, C. und Iglewski, B.H., Active efflux and diffusion are involved in transport of Pseudomonas aeruginosa cell-to-cell signals. J Bacteriol, 1999. 181(4): S. 1203-10.

232. Pellett, S., Bigley, D.V. und Grimes, D.J., Distribution of Pseudomonas aeruginosa in a riverine ecosystem. Appl Environ Microbiol, 1983. 45(1): S. 328-32.

233. Perlman, D., Chikarmane, H. und Halvorson, H.O., Improved resolution of DNA fragments in polysaccharide-supplemented agarose gels. Anal Biochem, 1987. 163(1): S. 247-54.

234. Pesci, E.C., Milbank, J.B., Pearson, J.P., McKnight, S., Kende, A.S., Greenberg, E.P. und Iglewski, B.H., Quinolone signaling in the cell-to-cell communication system of Pseudomonas aeruginosa. Proc Natl Acad Sci U S A, 1999. 96(20): S. 1122934 .

235. Pesci, E.C., Pearson, J.P., Seed, P.C. und Iglewski, B.H., Regulation of las and rhl quorum sensing in Pseudomonas aeruginosa. J Bacteriol, 1997. 179(10): S. 3127-32.

236. Pettersson, J., Holmstrom, A., Hill, J., Leary, S., Frithz-Lindsten, E., von EulerMatell, A., Carlsson, E., Titball, R., Forsberg, A. und Wolf-Watz, H., The Vantigen of Yersinia is surface exposed before target cell contact and involved in virulence protein translocation. Mol Microbiol, 1999. 32(5): S. 961-76.

237. Phizicky, E., Bastiaens, P.I., Zhu, H., Snyder, M. und Fields, S., Protein analysis on a proteomic scale. Nature, 2003. 422(6928): S. 208-15.

238. Pianzzola, M.J., Soubes, M. und Touati, D., Overproduction of the $r b o$ gene product from Desulfovibrio species suppresses all deleterious effects of lack of superoxide dismutase in Escherichia coli. J Bacteriol, 1996. 178(23): S. 6736-42.

239. Pier, G.B., Pulmonary disease associated with Pseudomonas aeruginosa in cystic fibrosis: current status of the host-bacterium interaction. J Infect Dis, 1985. 151(4): S. 575-80.

240. Pohlner, J., Halter, R., Beyreuther, K. und Meyer, T.F., Gene structure and extracellular secretion of Neisseria gonorrhoeae IgA protease. Nature, 1987. 325(6103): S. 458-62.

241. Polack, B., Dacheux, D., Delic-Attree, I., Toussaint, B. und Vignais, P.M., Role of manganese superoxide dismutase in a mucoid isolate of Pseudomonas aeruginosa: adaptation to oxidative stress. Infect Immun, 1996. 64(6): S. 2216-9.

242. Pollok, B.A. und Heim, R., Using GFP in FRET-based applications. Trends Cell Biol, 1999. 9(2): S. 57-60.

243. Ragsdale, S.W. und Ljungdahl, L.G., Characterization of ferredoxin, flavodoxin, and rubredoxin from Clostridium formicoaceticum grown in media with high and low iron contents. J Bacteriol, 1984. 157(1): S. 1-6.

244. Randall, L.L. und Hardy, S.J., Correlation of competence for export with lack of tertiary structure of the mature species: a study in vivo of maltose-binding protein in E. coli. Cell, 1986. 46(6): S. 921-8. 
245. Ravn, L., Christensen, A.B., Molin, S., Givskov, M. und Gram, L., Methods for detecting acylated homoserine lactones produced by Gram-negative bacteria and their application in studies of AHL-production kinetics. J Microbiol Methods, 2001. 44(3): S. 239-51.

246. Reeves, H.C., Daumy, G.O., Lin, C.C. und Houston, M., NADP + -specific isocitrate dehydrogenase of Escherichia coli. I. Purification and characterization. Biochim Biophys Acta, 1972. 258(1): S. 27-39.

247. Reimmann, C., Ginet, N., Michel, L., Keel, C., Michaux, P., Krishnapillai, V., Zala, M., Heurlier, K., Triandafillu, K., Harms, H., Defago, G. und Haas, D., Genetically programmed autoinducer destruction reduces virulence gene expression and swarming motility in Pseudomonas aeruginosa PAO1. Microbiology, 2002. 148(Pt 4): S. 923-32.

248. Rice, P., Longden, I. und Bleasby, A., EMBOSS: the European Molecular Biology Open Software Suite. Trends Genet, 2000. 16(6): S. 276-7.

249. Riedel, K., Hentzer, M., Geisenberger, O., Huber, B., Steidle, A., Wu, H., Hoiby, N., Givskov, M., Molin, S. und Eberl, L., N-acylhomoserine-lactone-mediated communication between Pseudomonas aeruginosa and Burkholderia cepacia in mixed biofilms. Microbiology, 2001. 147(Pt 12): S. 3249-62.

250. Robinson, P., Cystic fibrosis. Thorax, 2001. 56(3): S. 237-41.

251. Rosenau, F. und Jaeger, K., Bacterial lipases from Pseudomonas: regulation of gene expression and mechanisms of secretion. Biochimie, 2000. 82(11): S. 1023-32.

252. Rosenau, F. und Jaeger, K.E., Overexpression and Secretion of Biocatalysts in Pseudomonas, in Enzyme Functionality: Design, Engineering and Screening, A. Svendsen, Editor. 2004, Marcel Dekker: New York. S. 617-631.

253. Ruby, E.G., The Euprymna scolopes-Vibrio fischeri symbiosis: a biomedical model for the study of bacterial colonization of animal tissue. J Mol Microbiol Biotechnol, 1999. 1(1): S. 13-21.

254. Saiki, R.K., Gelfand, D.H., Stoffel, S., Scharf, S.J., Higuchi, R., Horn, G.T., Mullis, K.B. und Erlich, H.A., Primer-directed enzymatic amplification of DNA with a thermostable DNA polymerase. Science, 1988. 239(4839): S. 487-91.

255. Saiki, R.K., Scharf, S., Faloona, F., Mullis, K.B., Horn, G.T., Erlich, H.A. und Arnheim, N., Enzymatic amplification of $\beta$-globin genomic sequences and restriction site analysis for diagnosis of sickle cell anemia. Science, 1985. 230(4732): S. 1350-4.

256. Sambrook, J., Fritsch, E.F. und Maniatis, T., Molecular Cloning: A Laboratory Manual. Zweite Auflage. 1989: Cold Spring Harbor Laboratory Press.

257. Sato, H., Frank, D.W., Hillard, C.J., Feix, J.B., Pankhaniya, R.R., Moriyama, K., Finck-Barbancon, V., Buchaklian, A., Lei, M., Long, R.M., Wiener-Kronish, J. und Sawa, T., The mechanism of action of the Pseudomonas aeruginosa-encoded type III cytotoxin, ExoU. Embo J, 2003. 22(12): S. 2959-69.

258. Sawa, T., Yahr, T.L., Ohara, M., Kurahashi, K., Gropper, M.A., Wiener-Kronish, J.P. und Frank, D.W., Active and passive immunization with the Pseudomonas V antigen protects against type III intoxication and lung injury. Nat Med, 1999. 5(4): S. 392-8.

259. Schaefer, A.L., Hanzelka, B.L., Parsek, M.R. und Greenberg, E.P., Detection, purification, and structural elucidation of the acylhomoserine lactone inducer of 
Vibrio fischeri luminescence and other related molecules. Methods Enzymol, 2000. 305: S. 288-301.

260. Schaffitzel, C., Hanes, J., Jermutus, L. und Plückthun, A., Ribosome display: an in vitro method for selection and evolution of antibodies from libraries. JImmunol Methods, 1999. 231(1-2): S. 119-35.

261. Schembri, M.A., Kjaergaard, K. und Klemm, P., Bioaccumulation of heavy metals by fimbrial designer adhesins. FEMS Microbiol Lett, 1999. 170(2): S. 363-71.

262. Schembri, M.A. und Klemm, P., Heterobinary adhesins based on the Escherichia coli FimH fimbrial protein. Appl Environ Microbiol, 1998. 64(5): S. 1628-33.

263. Schirmer, T., General and specific porins from bacterial outer membranes. J Struct Biol, 1998. 121(2): S. 101-9.

264. Schlieker, C., Bukau, B. und Mogk, A., Prevention and reversion of protein aggregation by molecular chaperones in the E. coli cytosol: implications for their applicability in biotechnology. J Biotechnol, 2002. 96(1): S. 13-21.

265. Schmidt, A., Konstruktion und Charakterisierung varianter Immunglobulindomänen mit putativ faltungsstabilisierenden Aminosäureaustauschen. Diplomarbeit an der Georg-August-University Göttingen, 1995.

266. Schweitzer, B. und Kingsmore, S.F., Measuring proteins on microarrays. Curr Opin Biotechnol, 2002. 13(1): S. 14-9.

267. Schweitzer, B., Predki, P. und Snyder, M., Microarrays to characterize protein interactions on a whole-proteome scale. Proteomics, 2003. 3(11): S. 2190-9.

268. Seed, P.C., Passador, L. und Iglewski, B.H., Activation of the Pseudomonas aeruginosa lasI gene by LasR and the Pseudomonas autoinducer PAI: an autoinduction regulatory hierarchy. J Bacteriol, 1995. 177(3): S. 654-9.

269. Selifonova, O., Valle, F. und Schellenberger, V., Rapid evolution of novel traits in microorganisms. Appl Environ Microbiol, 2001. 67(8): S. 3645-9.

270. Seydoux, F.J., Kelemen, N., Kellershohn, N. und Roucous, C., Specific interactions of 3-phosphoglyceroyl-glyceraldehyde-3-phosphate dehydrogenase with coenzymes. Eur J Biochem, 1976. 64(2): S. 481-9.

271. Shevchenko, A., Jensen, O.N., Podtelejnikov, A.V., Sagliocco, F., Wilm, M., Vorm, O., Mortensen, P., Boucherie, H. und Mann, M., Linking genome and proteome by mass spectrometry: large-scale identification of yeast proteins from two dimensional gels. Proc Natl Acad Sci US A, 1996. 93(25): S. 14440-5.

272. Shibasaki, Y., Kamasawa, N., Shibasaki, S., Zou, W., Murai, T., Ueda, M., Tanaka, A. und Osumi, M., Cytochemical evaluation of localization and secretion of a heterologous enzyme displayed on yeast cell surface. FEMS Microbiol Lett, 2000. 192(2): S. 243-8.

273. Shuman, S., Recombination mediated by vaccinia virus DNA topoisomerase I in Escherichia coli is sequence specific. Proc Natl Acad Sci US A, 1991. 88(22): S. 101048.

274. Shuman, S., Novel approach to molecular cloning and polynucleotide synthesis using vaccinia DNA topoisomerase. J Biol Chem, 1994. 269(51): S. 32678-84. 
275. Siegel, R.M., Frederiksen, J.K., Zacharias, D.A., Chan, F.K., Johnson, M., Lynch, D., Tsien, R.Y. und Lenardo, M.J., Fas preassociation required for apoptosis signaling and dominant inhibition by pathogenic mutations. Science, 2000. 288(5475): S. 2354-7.

276. Singer, V.L., Lawlor, T.E. und Yue, S., Comparison of SYBR Green I nucleic acid gel stain mutagenicity and ethidium bromide mutagenicity in the Salmonella/mammalian microsome reverse mutation assay (Ames test). Mutat Res, 1999. 439(1): S. 37-47.

277. Skerra, A., Use of the tetracycline promoter for the tightly regulated production of a murine antibody fragment in Escherichia coli. Gene, 1994. 151(1-2): S. 131-5.

278. Smidsrød, O. und Haug, A., Dependence upon the gel-sol state of the ion-exchange properties of alginates. Acta Chem Scand, 1972. 26(5): S. 2063-74.

279. Smidsrød, O. und Skjak-Braek, G., Alginate as immobilization matrix for cells. Trends Biotechnol, 1990. 8(3): S. 71-8.

280. Smith, G.P., Filamentous fusion phage: novel expression vectors that display cloned antigens on the virion surface. Science, 1985. 228(4705): S. 1315-7.

281. Smits, T.H., Witholt, B. und van Beilen, J.B., Functional characterization of genes involved in alkane oxidation by Pseudomonas aeruginosa. Antonie Van Leeuwenhoek, 2003. 84(3): S. 193-200.

282. Smulski, D.R., Huang, L.L., McCluskey, M.P., Reeve, M.J., Vollmer, A.C., Van Dyk, T.K. und LaRossa, R.A., Combined, functional genomic-biochemical approach to intermediary metabolism: interaction of acivicin, a glutamine amidotransferase inhibitor, with Escherichia coli K-12. J Bacteriol, 2001. 183(11): S. 3353-64.

283. Sofianou, D., Tsakris, A., Skoura, L. und Douboyas, J., Extended high-level crossresistance to antipseudomonal antibiotics amongst Pseudomonas aeruginosa isolates in a university hospital. J Antimicrob Chemother, 1997. 40(5): S. 740-2.

284. Srinivasan, C., Liba, A., Imlay, J.A., Valentine, J.S. und Gralla, E.B., Yeast lacking superoxide dismutase(s) show elevated levels of "free iron" as measured by whole cell electron paramagnetic resonance. J Biol Chem, 2000. 275(38): S. 29187-92.

285. Stathopoulos, C., Georgiou, G. und Earhart, C.F., Characterization of Escherichia coli expressing an Lpp'OmpA(46-159)- PhoA fusion protein localized in the outer membrane. Appl Microbiol Biotechnol, 1996. 45(1-2): S. 112-9.

286. Storz, G. und Imlay, J.A., Oxidative stress. Curr Opin Microbiol, 1999. 2(2): S. 18894.

287. Stryer, L., Biochemie. dritte Auflage. 1994, Spektrum Akademischer Verlag, Heidelberg.

288. Studier, F.W. und Moffatt, B.A., Use of bacteriophage T7 RNA polymerase to direct selective high-level expression of cloned genes. JMol Biol, 1986. 189(1): S. 113-30.

289. Swartzman, E., Miyamoto, C., Graham, A. und Meighen, E., Delineation of the transcriptional boundaries of the lux operon of Vibrio harveyi demonstrates the presence of two new lux genes. J Biol Chem, 1990. 265(6): S. 3513-7.

290. Szpirer, C.Y., Faelen, M. und Couturier, M., Mobilization function of the pBHR1 plasmid, a derivative of the broad-host-range plasmid pBBR1. J Bacteriol, 2001. 183(6): S. 2101-10. 
291. Tabor, S. und Richardson, C.C., A bacteriophage T7 RNA polymerase/promoter system for controlled exclusive expression of specific genes. Proc Natl Acad Sci US A, 1985. 82(4): S. 1074-8.

292. Tao, H., Bausch, C., Richmond, C., Blattner, F.R. und Conway, T., Functional genomics: expression analysis of Escherichia coli growing on minimal and rich media. J Bacteriol, 1999. 181(20): S. 6425-40.

293. Taylor, M.S., Challed-Spong, A. und Johnson, E.A., Co-amplification of the amelogenin and HLA DQ $\alpha$-genes: optimization and validation. J Forensic Sci, 1997. 42(1): S. 130-6.

294. Toder, D.S., Gambello, M.J. und Iglewski, B.H., Pseudomonas aeruginosa LasA: a second elastase under the transcriptional control of lasR. Mol Microbiol, 1991. 5(8): S. 2003-10.

295. Touze, T., Hayward, R.D., Eswaran, J., Leong, J.M. und Koronakis, V., Selfassociation of EPEC intimin mediated by the $\beta$-barrel-containing anchor domain: a role in clustering of the Tir receptor. Mol Microbiol, 2004. 51(1): S. 73-87.

296. Tripet, B., Yu, L., Bautista, D.L., Wong, W.Y., Irvin, R.T. und Hodges, R.S., Engineering a de novo-designed coiled-coil heterodimerization domain off the rapid detection, purification and characterization of recombinantly expressed peptides and proteins. Protein Eng, 1996. 9(11): S. 1029-42.

297. Tsien, R.Y., The green fluorescent protein. Annu Rev Biochem, 1998. 67: S. 509-44.

298. Tümmler, B., Unusual mechanism of pathogenicity of Pseudomonas aeruginosa isolates from patients with cystic fibrosis. Infection, 1987. 15(4): S. 311-2.

299. Tümmler, B. und Kiewitz, C., Cystic fibrosis: an inherited susceptibility to bacterial respiratory infections. Mol Med Today, 1999. 5(8): S. 351-8.

300. Tümmler, B., Koopmann, U., Grothues, D., Weissbrodt, H., Steinkamp, G. und von der Hardt, H., Nosocomial acquisition of Pseudomonas aeruginosa by cystic fibrosis patients. JClin Microbiol, 1991. 29(6): S. 1265-7.

301. Ueda, T. und Coon, M.J., Enzymatic oxidation. VII. Reduced diphosphopyridine nucleotide- rubredoxin reductase: properties and function as an electron carrier in hydroxylation. J Biol Chem, 1972. 247(16): S. 5010-6.

302. Uetz, P., Giot, L., Cagney, G., Mansfield, T.A., Judson, R.S., Knight, J.R., Lockshon, D., Narayan, V., Srinivasan, M., Pochart, P., Qureshi-Emili, A., Li, Y., Godwin, B., Conover, D., Kalbfleisch, T., Vijayadamodar, G., Yang, M., Johnston, M., Fields, S. und Rothberg, J.M., A comprehensive analysis of protein-protein interactions in Saccharomyces cerevisiae. Nature, 2000. 403(6770): S. 623-7.

303. Vallance, B.A. und Finlay, B.B., Exploitation of host cells by enteropathogenic Escherichia coli. Proc Natl Acad Sci U S A, 2000. 97(16): S. 8799-806.

304. Veiga, E., de Lorenzo, V. und Fernandez, L.A., Probing secretion and translocation of a $\beta$-autotransporter using a reporter single-chain $\mathrm{Fv}$ as a cognate passenger domain. Mol Microbiol, 1999. 33(6): S. 1232-43.

305. Venter, J.C., et al., The sequence of the human genome. Science, 2001. 291(5507): S. 1304-51.

306. Victor, B.L., Vicente, J.B., Rodrigues, R., Oliveira, S., Rodrigues-Pousada, C., Frazao, C., Gomes, C.M., Teixeira, M. und Soares, C.M., Docking and electron 
transfer studies between rubredoxin and rubredoxin:oxygen oxidoreductase. J Biol Inorg Chem, 2003. 8(4): S. 475-88.

307. Vidal, M., Braun, P., Chen, E., Boeke, J.D. und Harlow, E., Genetic characterization of a mammalian protein-protein interaction domain by using a yeast reverse two-hybrid system. Proc Natl Acad Sci US A, 1996. 93(19): S. 10321-6.

308. Visick, K.L. und McFall-Ngai, M.J., An exclusive contract: specificity in the Vibrio fischeri-Euprymna scolopes partnership. J Bacteriol, 2000. 182(7): S. 1779-87.

309. Waley, S.G., A spectrophotometric assay of $\beta$-lactamase action on penicillins. Biochem J, 1974. 139(3): S. 789-90.

310. Wan, L.S.C., Heng, P.W.S. und Chan, L.W., Influence of hydrophile-lipophile balance on alginate microspheres. Int J Pharm, 1993. 95: S. 77-83.

311. Wan, L.S.C., Heng, P.W.S. und Chan, L.W., Surfactant effects on alginate microspheres. Int J Pharm, 1994. 103: S. 267-275.

312. Washida, M., Takahashi, S., Ueda, M. und Tanaka, A., Spacer-mediated display of active lipase on the yeast cell surface. Appl Microbiol Biotechnol, 2001. 56(5-6): S. 6816.

313. Wee, S. und Gombotz, W.R., Protein release from alginate matrices. Adv Drug Deliv Rev, 1998. 31(3): S. 267-285.

314. Wentzel, A., Exposition von Proteinen auf der Oberfläche von Escherichia coli Zellen: mechanistische Betrachtung und biotechnologische Anwendung, Dissertation zur Erlangung des Doktorgrads, 2003, Georg-August-Univeristät Göttingen

315. Wentzel, A., Christmann, A., Adams, T. und Kolmar, H., Display of Passenger Proteins on the Surface of Escherichia coli K-12 by the Enterohemorrhagic E. coli Intimin EaeA. J Bacteriol, 2001. 183(24): S. 7273-84.

316. Wentzel, A., Christmann, A., Krätzner, R. und Kolmar, H., Sequence requirements of the GPNG $\beta$-turn of the Ecballium elaterium trypsin inhibitor II explored by combinatorial library screening. J Biol Chem, 1999. 274(30): S. 21037-43.

317. Westerlund-Wikstrom, B., Peptide display on bacterial flagella: principles and applications. Int J Med Microbiol, 2000. 290(3): S. 223-30.

318. Westerlund-Wikstrom, B., Tanskanen, J., Virkola, R., Hacker, J., Lindberg, M., Skurnik, M. und Korhonen, T.K., Functional expression of adhesive peptides as fusions to Escherichia coli flagellin. Protein Eng, 1997. 10(11): S. 1319-26.

319. Whitehead, N.A., Barnard, A.M., Slater, H., Simpson, N.J. und Salmond, G.P., Quorum-sensing in Gram-negative bacteria. FEMS Microbiol Rev, 2001. 25(4): S. 365404.

320. Wiehlmann, L., Sequenzspezifizierte Transposonmutagenese (STM) in Pseudomonas aeruginosa, in Dissertation zur Erlangung des Doktorgrads. 2001, Medizinische Hochschule, Hannover.

321. Wiehlmann, L., P., S., Larbig, K.D., Ritzka, M. und Tümmler, B., Signature Tagged Mutagenesis of Pseudomonas aeruginosa. Genome Letters, 2002. 1(3): S. 123-131.

322. Wilfinger, W.W., Mackey, K. und Chomczynski, P., Effect of $\mathrm{pH}$ and ionic strength on the spectrophotometric assessment of nucleic acid purity. Biotechniques, 1997. 22(3): S. 474-6, 478-81. 
323. Winkler, U., Wingender, J. und Jager, K.E., Infektionen der Atemwege mit Pseudomonas aeruginosa bei der Cystischen Fibrose. Klin Wochenschr, 1985. 63(11): S. 490-8.

324. Winson, M.K., Camara, M., Latifi, A., Foglino, M., Chhabra, S.R., Daykin, M., Bally, M., Chapon, V., Salmond, G.P., Bycroft, B.W., Multiple N-acyl-Lhomoserine lactone signal molecules regulate production of virulence determinants and secondary metabolites in Pseudomonas aeruginosa. Proc Natl Acad Sci US A, 1995. 92(20): S. 9427-31.

325. Winter, G., Griffiths, A.D., Hawkins, R.E. und Hoogenboom, H.R., Making antibodies by phage display technology. Annu Rev Immunol, 1994. 12: S. 433-55.

326. Wittrup, K.D., Protein engineering by cell-surface display. Curr Opin Biotechnol, 2001. 12(4): S. 395-9.

327. Woodmansee, A.N. und Imlay, J.A., Reduced flavins promote oxidative DNA damage in non-respiring Escherichia coli by delivering electrons to intracellular free iron. J Biol Chem, 2002. 277(37): S. 34055-66.

328. Woods, D.E., Sokol, P.A., Bryan, L.E., Storey, D.G., Mattingly, S.J., Vogel, H.J. und Ceri, H., In vivo regulation of virulence in Pseudomonas aeruginosa associated with genetic rearrangement. JInfect Dis, 1991. 163(1): S. 143-9.

329. Wouters, F.S., Verveer, P.J. und Bastiaens, P.I., Imaging biochemistry inside cells. Trends Cell Biol, 2001. 11(5): S. 203-11.

330. Wu, T.H., Clarke, C.H. und Marinus, M.G., Specificity of Escherichia coli mutD and mutL mutator strains. Gene, 1990. 87(1): S. 1-5.

331. Yahr, T.L., Vallis, A.J., Hancock, M.K., Barbieri, J.T. und Frank, D.W., ExoY, an adenylate cyclase secreted by the Pseudomonas aeruginosa type III system. Proc NatI Acad Sci US A, 1998. 95(23): S. 13899-904.

332. Yates, E.A., Philipp, B., Buckley, C., Atkinson, S., Chhabra, S.R., Sockett, R.E., Goldner, M., Dessaux, Y., Camara, M., Smith, H. und Williams, P., Nacylhomoserine lactones undergo lactonolysis in a $\mathrm{pH}-$, temperature-, and acyl chain length-dependent manner during growth of Yersinia pseudotuberculosis and Pseudomonas aeruginosa. Infect Immun, 2002. 70(10): S. 5635-46.

333. Yates, E.A., Philipp, B., Buckley, C., Atkinson, S., Chhabra, S.R., Sockett, R.E., Goldner, M., Dessaux, Y., Camara, M., Smith, H. und Williams, P. Combined transcriptome and proteome analysis as a powerful approach to study genes under glucose repression in Bacillus subtilis. Nucleic Acids Res, 2001. 29(3): S. 683-92.

334. Yost, F.J., Jr. und Fridovich, I., An iron-containing superoxide dismutase from Escherichia coli. J Biol Chem, 1973. 248(14): S. 4905-8.

335. Zak, J.K., Butler, J.E. und Swain, G.M., Diamond optically transparent electrodes: demonstration of concept with ferri/ferrocyanide and methyl viologen. Anal Chem, 2001. 73(5): S. 908-14.

336. Zhang, H.B., Wang, L.H. und Zhang, L.H., Genetic control of quorum-sensing signal turnover in Agrobacterium tumefaciens. Proc Natl Acad Sci U S A, 2002. 99(7): S. $4638-43$.

337. Zhu, H., Bilgin, M., Bangham, R., Hall, D., Casamayor, A., Bertone, P., Lan, N., Jansen, R., Bidlingmaier, S., Houfek, T., Mitchell, T., Miller, P., Dean, R.A., 
Gerstein, M. und Snyder, M., Global analysis of protein activities using proteome chips. Science, 2001. 293(5537): S. 2101-5.

338. Ziegenhorn, J., Senn, M. und Bucher, T., Molar absorptivities of $\beta$-NADH and $\beta$ NADPH. Clin Chem, 1976. 22(2): S. 151-60.

339. Zielinski, N.A., Maharaj, R., Roychoudhury, S., Danganan, C.E., Hendrickson, W. und Chakrabarty, A.M., Alginate synthesis in Pseudomonas aeruginosa: environmental regulation of the algC promoter. J Bacteriol, 1992. 174(23): S. 7680-8. 


\section{Eigene Veröffentlichungen im Rahmen dieser Arbeit}

1. Wentzel, A., Christmann, A., Adams, T. und Kolmar, H., Display of Passenger Proteins on the Surface of Escherichia coli K-12 by the Enterohemorrhagic E. coli Intimin EaeA. J Bacteriol, 2001. 183(24): S. 7273-84.

2. Adams, T.M. und Kolmar, H., Enzyme Engineering by Microbial Cell Surface Display, in Enzyme Functionality: Design, Engineering and Screening, A. Svendsen, Editor. 2004, Marcel Dekker: New York. S. 599-616.

3. Adams, T.M., Schmoldt, H.U. und Kolmar, H., FACS Screening of Combinatorial Peptide and Protein Libraries Displayed on the Surface of Escherichia coli Cells, in Evolutionary Methods in Biotechnology: Clever Tricks for Directed Evolution, S. Brakmann and A. Schwienhorst, Editoren. 2004, Wiley VCH: Weinheim.

4. Becker, S., Schmoldt, H.U., Adams, T.M., Wilhelm, S. und Kolmar, H., Ultrahigh-throughput screening based on cell-surface display and fluorescence-activated cell sorting for the identification of novel biocatalysts. Curr Opin Biotechnol, 2004. 15(4): S. 323-9.

5. Adams, T.M., Wentzel, A. und Kolmar, H., Intimin-mediated export of passenger proteins requires maintenance of a translocation-competent conformation. J Bacteriol, 2005 (im Druck). 187(2). 


\section{Anhang}

\subsection{Danksagung}

An erster Stelle gilt mein Dank Harald Kolmar für die Betreuung dieser Doktorarbeit und die produktive und erfrischende Zusammenarbeit. Wilfried Kramer danke ich für die Übernahme des Korreferates und für die vielen guten Ideen, die er in diese Arbeit einbrachte.

Prof. Burkhard Tümmler von der Medizinischen Hochschule Hannover ermöglichte diese Arbeit, indem der die Pseudomonas aeruginosa Mutanten zur Verfügung stellte und in zahlreichen Diskussionen zum Erfolg dieser Arbeit beitrug. Lutz Wiehlmann, ebenfalls von der $\mathrm{MHH}$, gebührt mein Dank für die intensive und fruchtbare Zusammenarbeit bei der funktionellen Charakterisierung der potentiellen Pathogenitätsfaktoren. Birgit Huber von der TU München danke ich für die Zusammenarbeit bei der Untersuchung des Proteins Pa0740.

Meinen Kollegen Andreas Christmann und Alexander Wentzel danke ich für die hervorragende Zusammenarbeit und die nützlichen Hilfestellungen, die sie stets zu geben bereit waren. Meinem Laborkollegen Ulli Schmoldt danke ich für die zahl- und hilfreichen Diskussionen und dafür, daß er Teile der Arbeit Korrektur gelesen hat. Aus demselben Grund gilt Matin Daneschdar mein Dank, und Stefan Becker dafür, daß er zu jeder chemischen Fragestellung eine Antwort wußte. Susanne Behrends danke ich für viele nützliche Tips, die im zweiten Teil der Arbeit entscheidend zum Erfolg beitrugen. Christian Rudolph danke ich sehr für die Hilfestellung bei der Formatierung des Word-Dokuments, die er per Email aus Nottingham beisteuerte. Bettina Hucke gebührt großer Dank für die hervorragende technische und logistische Unterstützung. Marita Kalck war bei organisatorischen Fragen eine große Hilfe. Anke Schürer und Birgit Zeike etablierten dankenswerterweise die generalstabsmäßige Verteilung der Enzyme. Dennis Wegener und René Hempel danke ich für die aufopferungsvolle Wartung des Zelldisruptors. Rainer Merkl, Gerrit Hennecke und Jarek Sobkowiak halfen gerne und kompetent in Computerfragen, auch ihnen sei gedankt. Olaf Waase und Patrick Regin danke ich dafür, daß sie die technischen Geräte in einen verwendungsbereiten Zustand versetzten. Der General trug zwar nichts zum Gelingen dieser Arbeit bei, dennoch möchte ich ihm für die Verbreitung guter Laune danken, genau wie allen anderen, deren Namen ich zu erwähnen vergaß.

Nicht zuletzt danke ich Prof. Hans-Joachim Fritz für die Möglichkeit, diese Arbeit in seiner Abteilung anfertigen zu können und für das große Interesse, daß er im Rahmen der Arbeitsberichte und Seminare dieser Arbeit entgegen gebracht hat. 


\subsection{Lebenslauf}

Name: $\quad$ Thorsten Michael Adams

Geburtsdatum: $\quad$ 19. Februar 1975

Geburtsort: Göttingen

Staatsangehörigkeit: deutsch

Familienstand: $\quad$ ledig

Eltern: Hans-Otto und Helga Adams, geb. Krengel

Schulbildung: $\quad \underline{1981 \text { bis } 1985}$ Grundschule „Egelsbergschule“ in Göttingen

1985 bis 1987 Orientierungsstufe „Jahnschule“ in Göttingen

1987 bis 1994 Otto-Hahn-Gymnasium in Göttingen

1994 Abitur am Otto-Hahn-Gymnasium in Göttingen

Zivildienst: $\quad \underline{1994 \text { bis } 1995}$ beim Gemeinnützigen Fahrdienst, Göttingen

Studium der Biologie: 1995 bis 1998 an der Georg-August-Universität zu Göttingen

1998 bis 1999 an der University of California at Berkeley

(Molecular and Cell Biology) als Stipendiat des Education Abroad

Program

1999 bis 2001 an der Georg-August-Universität zu Göttingen

Diplomarbeit: $\quad 2000$ bis 2001 in der Abteilung für Molekulare Genetik und Präparative Molekularbiologie des Instituts für Mikrobiologie und Genetik der Georg-August-Universität zu Göttingen.

Titel: „Zur Analyse und Optimierung biomolekularer Wechselwirkungen durch adhäsinvermittelte Zell-Zell-Interaktion“, Gesamtnote: „Sehr gut“

Dissertation: $\quad$ seit September 2001 in der Abteilung für Molekulare Genetik und Präparative Molekularbiologie des Instituts für Mikrobiologie und Genetik der Georg-August-Universität zu Göttingen. Unterstützt durch das Bundesministerium für Bildung und Forschung sowie den Mukoviszidose e.V. 